HANDIIING, STORAGE, AND RETRIEVAL OF PETROLEUM DATA

IN CCOP COUNTRTES

(Revised)

By

Allen L. Clark, Jennifer L. Cook

and

Richard Sinding-Larsen

OPEN FILE REPORT $81-662$

This report is preliminary and has not been reviewed for conformity with U.S. Geological Survey editorial standards and stratigraphic nomenclature. Any use of trade names is for descriptive purposes only and does not imply endorsement by the USGS. 
EXECUTIVE SUMMARY $\ldots \ldots \ldots \ldots \ldots \ldots \ldots \ldots \ldots \ldots \ldots \ldots \ldots \ldots \ldots \ldots \ldots \ldots$

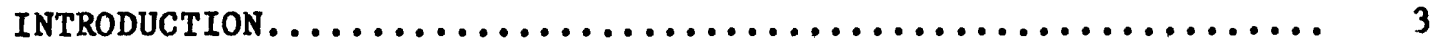

Project initiation............................ 3

Purpose...................................... 4

Scope...................................... 4

Implementation............................... 5

PROBLEM AREA OVERVIEW................................ 5

Evaluation procedure........................... 7

Problem areas............................... 8

DATA ARCHIVING ............................... 8

Data acquisition. .......................... 8

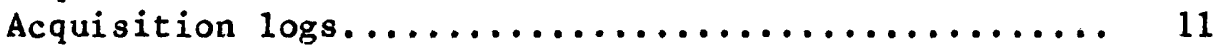

Classification indexing.................... 12

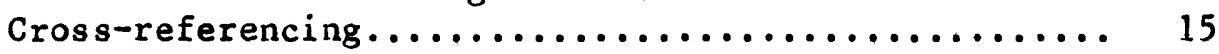

Card indexes.............................. 16

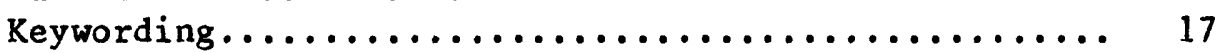

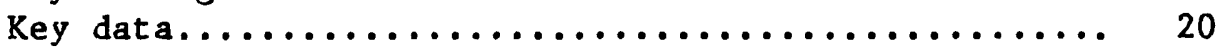

Abstracting.............................. 21

Filing of documents, reports, and magnetic tapes........ 21

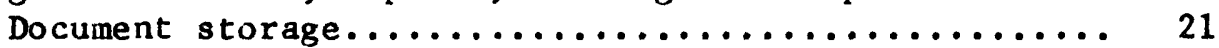

Map storage............................. 22

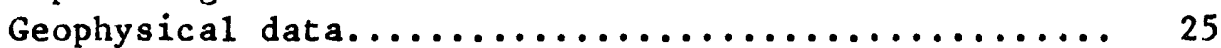

Active, inactive, and dormant data storage............ 30

Data contro1............................. 32

Microfilming................................ 32

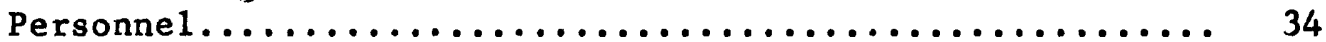

Computer data archival information systems............ 35

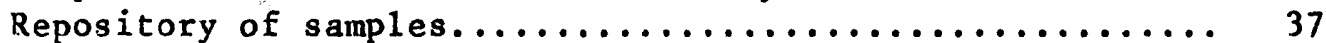

Core and chip sample acquisitions.............. 38

Storage facilities........................ 38

Analytical samples.......................... 39

Existing sample storage facilities.............. 40

Potential uses for sample storage............... 40

COMPUTER APPLICATIONS RELATED TO PETROLEUM DATA HANDLING...... 41

Analysis of computer-based systems and programs in the earth sciences ............................ 41

0 il and gas data files......................... 44

DATA FILE CONSTRUCTION...............................46

Data file structure........................... 46

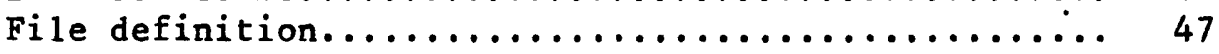

Format definition..................... 48

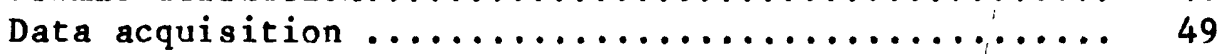

Data file updating ..................... 51

SPECIFIC DATA FILES ............................. 52 


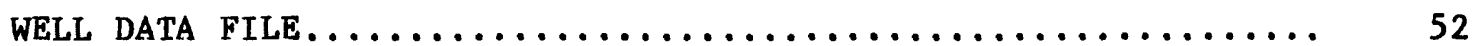

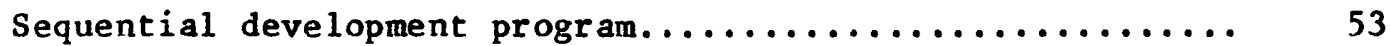

Applications of well data file.................. 55

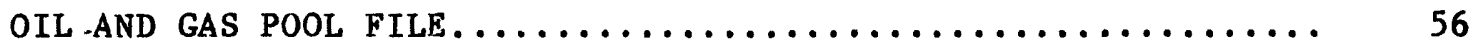

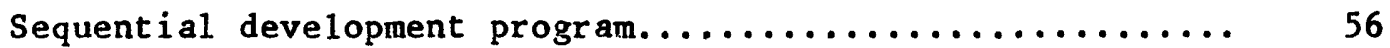

Applications of the oil and gas pool file............. 58

ANCILLARY FILES.............................. 59

DATA BASE CONSTRUCTION......................... 59

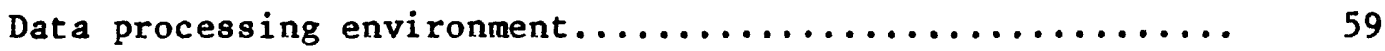

Present capabilities........................ 59

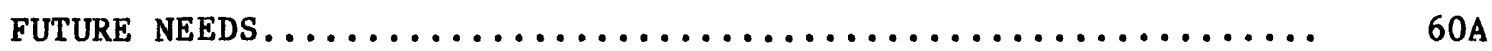

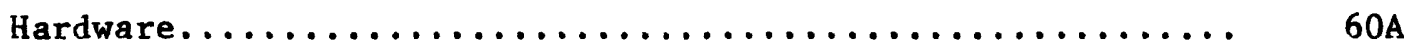

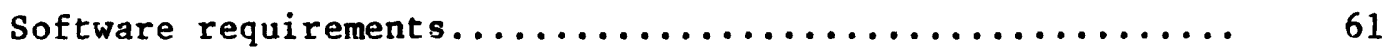

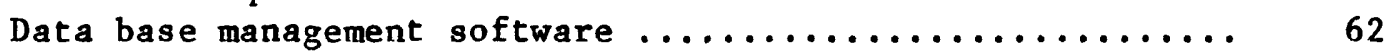

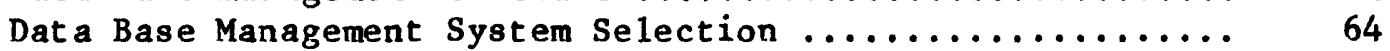

Evaluation scheme for Data Base Management Systems ........ 66

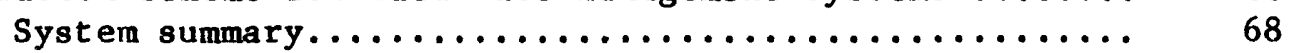

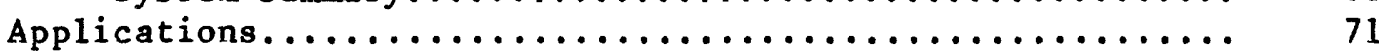

Batch vs. interactive computing environment.......... 72

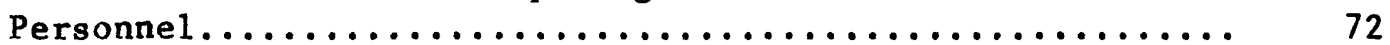

Computer resource administration................... 73

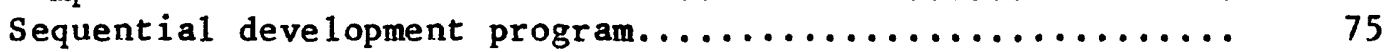

Program development.......................... 76

WORKING GROUP ON PETROLEUM DATA................... 78

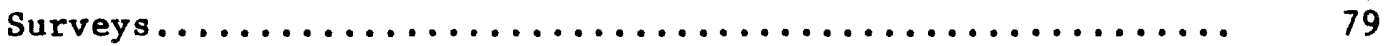

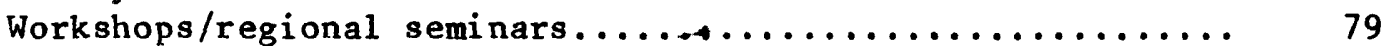

Petroleum data literature........................ 79

Software development/distribution................. 80

Institutional development..................... 80

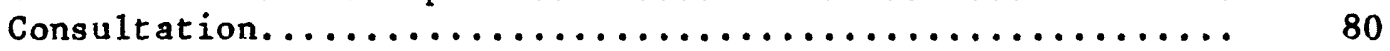

Permanent full-time information specialists........ 81

Software and hardware specifications................ 82

CONCLUSIONS............................... 83

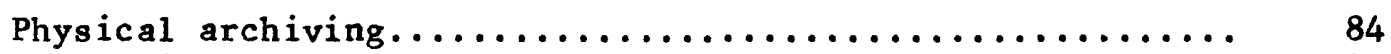

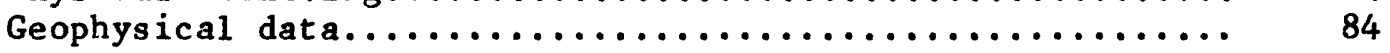

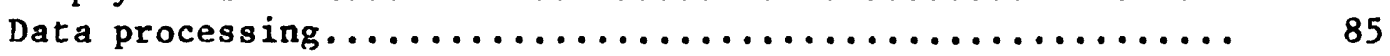

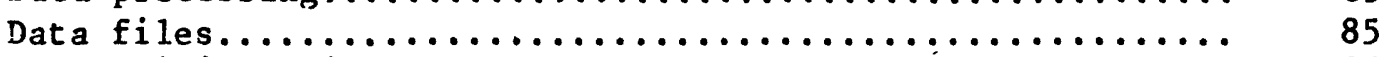

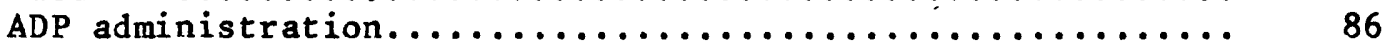

REFERENCES .................................. 88 


\section{ILLUSTRATIONS}

Page

Figure 1. Data archival flow diagram.................. 10

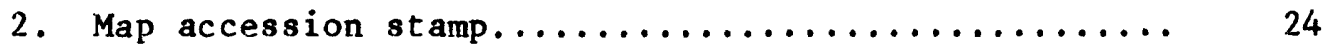

3. Petroleum data storage and information system....... 77

Appendix 1. Data collection format................. 89

2. Secondary bibliographic services.............. 99

3. Reference manual for machine-readable bibliographic descriptions............................. 145

4. We 11 and pool file formats................ 181 


\title{
HANDLING, STORAGE, AND RETRIEVAL OF PETROLEUM DATA IN CCOP COUNTRIES
}

By

\author{
Allen L. Clark, Jennifer L. Cook \\ and
}

Richard Sinding-Larsen $\underline{1}$

\section{EXECUTIVE SUMMARY}

An analysis of petroleum data storage and retrieval programs within the nember countries of the Committee for Coordination of Joint Prospecting for Mineral Resources in Asian Offshore Areas (CCOP) demonstrated that this is an area of both great interest and great problems. Specifically the major problem areas are (5):

1. Data archives.

2. Data files.

3. Data processing hardware and software.

4. Geophysical data.

5. Automatic Data Processing (ADP) management.

The resolution of many of the existing problems lies in their recognition and the implementation of a sequential development program to meet the need for data storage and retrieval. This begins with a systematic procedure for data acquisition and archiving and proceeds to an integrated system for the storage, retrieval, and analysis of

If Norwegian Geological Institute. 
petroleum data. Corresponding to the sequential development of the system is the transition from manual handling of data to the development of main frame and mini-micro computer process activities.

To effectively address the petroleum data storage and retrieval problems of the CCOP member countries and implement a sequential development program, three major areas require immediate consideration:

1. Authorization by senior-level management to expand data storage and retrieval programs with both monies and personnel.

2. Development of an agency-specific sequential development program.

3. Availability of technical consultants in the areas of data archiving, data base development, and hardware and software systems.

No manual or machine shortcuts exist or should be attempted for the development of an adequate storage and retrieval program. Only through time and effort will truly integrated multipurpose systems be developed. 
INTRODUCTION

Project initiation

The annual sessions of the Committee for Coordination of Joint Prospecting for Mineral Resources in Asian Offshore Areas (CCOP) of 1973, 1974, and 1975, repeatedly stressed the importance of establishing national centers in each of the member countries for the storage and retrieval of the proprietary petroleum data and the geological samples that each country has received following the increased regulation and operations of petroleum activity. To this end, the Committee arranged a seminar in Bundung, Indonesia, in April 1976 on "Data collection, storage and retrieval," with particular reference to hydrocarbon exploration and development.

The 15th session of CCOP in 1978, held in singapore, acted on the recommendation of its Technical Advisory Group and in early 1979 established an Ad Hoc working group on petroleum data collection, storage, and retrieval. The working group consisted of Dr. Richard Sinding-Larsen (Chairman of COGEODATA, the Committee on Storage, Automatic Processing and Retrieval of Geological Data, of the International Union of Geological Sciences (IUGS)), Dr. Allen L. Clark (Chairman of the COGEODATA Working Group on Data Capture), and one member from each of the CCOP countries. In January 1979, the CCOP project office was delegated the support monies given by the Government of Norway to finance the travel expenses of the working group. Two contracts between IUGS and the Economic and Social Economic Commission for Asia and Pacific (ESCAP) were then set up covering the time period January 1 to October 15, 1979. This report was prepared for the CCOP member countries under the auspices of COGEODATA, of IUGS, under Contract CAP/79/01/061/Con/79-01/ESCAP/CCOP. 


\section{Purpose}

According to the contracts, COGEODATA should perform:

a) An appraisal and evaluation of the national needs of the CCOP countries concerning petroleum data collection, storage, and retrleval.

This should be understood as involving the whole aspect of identification, indexing, storage, retrieval, dissemination, and utilization either in a wholly manual mode, partly by the use of computer technology, or by means of comprehensive incorporated data systems.

b) Evaluate existing governmental and commercial data systems in North America and Europe suitable for petroleum data collection, storage, and retrieval.

c) In light of the individual needs of the CCOP countries, discuss the usefulness of available data systems for the petroleum-data activities of the member countries.

d) Prior to the loth annual session of CCOP, arrange a meeting with the designated CCOP representatives and recommend a plan of action for subsequent discussion at the 16 th annual session of CCOP.

\section{$\underline{\text { Scope }}$}

The 11 CCOP countries (Japan, Korea, Philippines, the Trust Territory of the Pacific Islands, Japan, Papua New Guinea, Indonesia, Singapore, Malaysia, Thailand, Kampuchea, and Vietnam) have each reached

different levels of petroleum development and accordingly have a variety of problems and corresponding needs. The present study attempts to address the full spectrum of the more important problems and provide recomendations for dealing with the overall range of problems. 


\section{Implementation}

Jan. 12-Jan. 28: Reconnaissance visit to Malaysia, Indonesia, Philippines, and Thailand by R. Sinding-Larsen, Norway, and O. Kvig, Norway.

March 30-April 4: Meeting at the Norwegian Petroleum Directorate by-R. Sinding-Larsen, O. Kvig, A. L. Clark (USA) and J. Cook (USA). April 5-April 23: Reconnaissance visit to Korea, Japan, and follow-up visit to Philippines by A. L. Clark.

June 6-July 8: Follow-up visit to Indonesia, Malaysia, and Thailand by A. L. Clark and J. Cook, with subsequent reporting of results in cooperation with R. Sinding-Larsen.

June/July: Review of North American data systems by G. Gabert (Germany) and S. Bie (Norway).

August: Final visit to the CCOP countries by A. L. Clark and R. Sinding-Larsen to make recommendations on how to meet national needs for petroleum data storage and retrieval.

September: Meeting of the Ad Hoc working group September 5-8 to formulate recommendations to the 16 th session in Bandung, Indonesia. PROBLEM AREA OVERVIEW

The majority of oil and gas agencies receiving data in Southeast Asia are performing mandated archiving activities in support of national oil and gas programs. However, in most of the organizations, this activity has not held a very high priority for many reasons, among the most significant of which are:

1. The oil and gas agencies are only recently established and emphasis 
has been placed on priorities other than data management.

2. There was an initial lack of need for data management because the volume of data was very small.

3. Recent activities in exploration and development, coupled with increased analyses and national mandates for data submittals has resulted in a rapid increase in data.

4. There has been a general lack of trained personnel, particularly information specialists, to develop data management procedures.

5. Upper level management has failed to recognize the need to improve data management procedures, and as a result, programs have not been developed in this area.

These information sources in the oil and gas agencies represent a variety of forms ranging from core samples, tapes, reports, maps, telex, and microfilm, all of which must be identified, catalogued, and indexed in a standardized procedure. Indeed, in Southeast Asia as more and more data are generated and information developed and collected, there is an ever increasing need for adequate bibliographic control and archiving. It is essential that the general problems of data management defined and described in this respect be addressed and that all oil and gas data that are worth preserving be placed under some form of bibliographic control.

It is rapidly becoming recognized that there is a very critical need to better organize and handle oil and gas data to support better decision making throughout an organization. This activity is leading to the need for a new type of specialist, the "information" or "data base" administrator. 
This individual is charged with knowing, or being able to find out, exactly what is in his or her file, where each item of information is stored, how frequently it has been updated and the implications of changing the present routines for bibliographic control and archiving of the data. As a part of this pattern it is also being recognized that information is not static, but is normally in a transition phase between its use in a dynamic process (exploration) and its longer-term storage as part of a national oil and gas archive.

\section{Evaluation procedure}

In order to conduct the proposed program in a systematic manner, a standardized procedure was adopted and applied to each country. Although the procedure was as inclusive as possible, it was not always possible to apply the procedure entirely because of the varying levels of data management in the respective countries. Nevertheless, the "petroleum data problems" of each country were assessed utilizing the following procedure:

1. Initial definition of present data problems such as data volumes, user environment, organizational environment, physical environment, and national and agency needs for data management.

2. Definition and assessment of existing practices in the handing, storage and retrieval of petroleum data.

3. Detailed definition of present data types, data volumes, reporting and acquisition procedures, data completeness, and data integrity. 
4. Development of a short to intermediate analysis of data problems and an assessment of short to long range plans for data handing, storage, retrieval, and analysis.

5. Development of alternate solutions to effectively and efficiently manage petroleum data to meet present and anticipated needs.

A standard form was utilized for each country to acquire and evaluate the above data and alternatives and is presented in Appendix 1.

\section{Problem areas}

In addition to the general problems 1 isted at the beginning of this section, the detailed evaluation procedure also identified several specific problem areas which are common, to varying extents, in all the oil and gas agencies. The extent of the problems is primarily a function of the stage of oil and gas development, the volumes of data, existing and past data administration practices, and new needs for data and analyses.

The major problem areas, which are dealt with in detail in the following sections of this report, can be summarized in five main areas: 1) physical archiving, 2) data files, 3) geophysical data, 4) data processing, and 5) ADP administration, where specific needs are identified and action is called for to improve existing and future systems.

\section{DATA ARCHIVING}

Data acquisition

The physical storage and retrieval of oil and gas data in national archives and the internal systems of indexing and classification are 
critical to the efficient use of data by the petroleum professional. The need for management to be able to monitor data flow and know archive content cannot be overstressed for the following reasons:

1. Data loss from an il1-managed or unmanaged system is generally unrecoverable (indeed, if even realized).

2. Professional time spent in data search and retrieval must be optimized. Most large oil companies have instituted data management systems for this reason.

3. Data duplication/preservation techniques (e.g•, micro-filming) require an organized archiving system before being undertaken (insuring the organization of the resultant microfilm file).

4. The task of creating specialized data files (computer or manual) requiring large amounts of integrated data from varied sources is eased with a systemized, cross-referenced archive.

5. Each country organization has been trusted with the national oil and gas data repository where sufficient steps must be taken to insure data integrity, credibility, and security.

Standard procedures exist that can be implemented to acquire, classify, index, key word/abstract, and store documents, maps, and other data. These procedures can be implemenied manually or with computers, depending on number of skilled personnel and present or future access to computer facilities.

The general procedures in data archiving, which are discussed in the following sections, are shown in figure 1. 


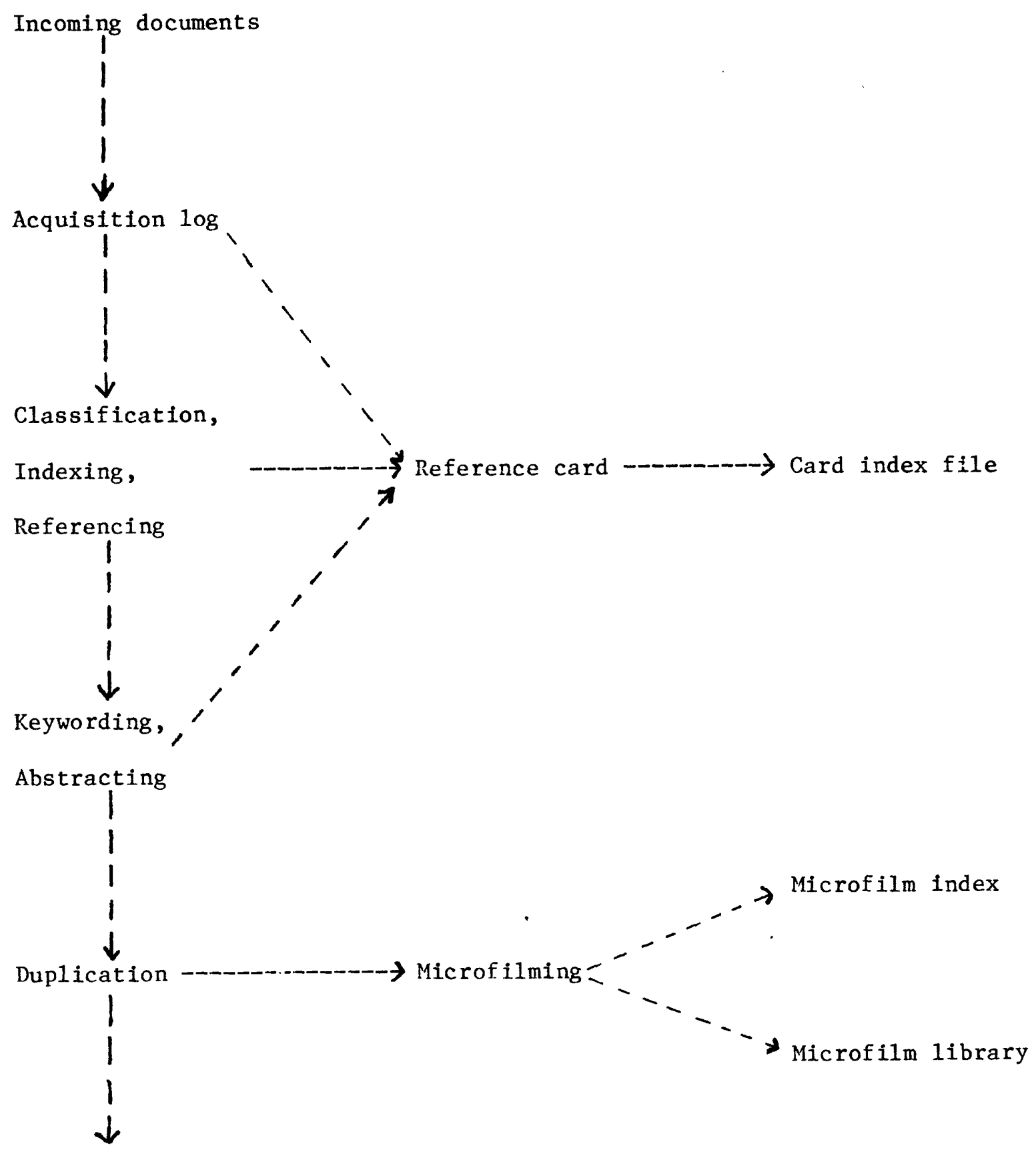

Physical storage

Figure 1. Data archival flow diagram. 


\section{Acquisition logs}

The initial step in the development and maintenance of a national archive is to institute a master acquisition log. It is absolutely essential that the receiving organization record each and every document as it is received. The responsibility lies with the archive management to ensure that all data required of petroleum companies is recorded before storage in the archive. The archive management should also assume responsibility for any duplication and distribution of incoming material to professional personnel after official acquisition.

The primary use of an acquisition log is simply to provide an official record of recelpt of a document, but it can and should serve other important purposes. Among the most significant are:

a) to record time and date of acquisition

b) to classify a document as to type (e.g., map, report, log)

c) to classify a document as to general subject matter and/or area

d) to assign a unique number to the document for later retrieval purposes or until assignment of an archive number

e) to serve as a primary bibliographic citation for entry into a data base.

It is therefore recommended that a master data acquisition catalog be instituted and a sincere effort made to list all present and future acquisitions. For each item recelved, the minimum data items should be:

Date of Acquisition:

Unique Identifier:
Submitted by (Author/Composer): Title: 
Other Identifier:

Data type:

Enclosures:

The acquisition log should be maintained daily, documents being recorded immediately upon receipt. The time necessary to maintain the acquisition $\log$ depends on the volume of incoming documents, but appropriate personnel should be assigned so all data can be logged the day they are received.

The acquisition $\log$ should be a hard-bound book with a strong binding so that pages do not tear loose with wear.

There are several ways to organize the acquisition catalog, each depending on the future indexing/classification schemes to be utilized.

a) If 11ttle or no classification and indexing will take place after acquisition, then the acquisition $10 \mathrm{~g}$ should be organized to derive maximum benefits. A chronological sequence of entries is not as desirable as receipt acknowledged by document type, subject, or area.

b) If good indexing, classification, and keywording are undertaken the items can be easily cross referenced after acquisition, and if accession lists reflect the acquisition by type, it is less necessary to organize the acquisition log by criteria other than date of receipt.

\section{Classification indexing}

classifying and indexing documents in a structured approach is the key to the efficient storage and retrieval of documents in an archive. 
Many efficient archival systems are in operation currently and most concerning ofl and gas data are variations based on a hierarchial, structured subject breakdown. Within the current operating petroleum data systems the major breakdown commonly is:

1. Exploration data

2. Development data

3. Drilling and production data

This breakdown gives the logical division points according to time sequences and the differing types and applications of data gathered within each phase. Within these three classes, further structural breakdowns are necessary by subject:

1. Exploration data

1.1 Exploration geology

1.2 Exploration geophysics

1.3 Exploration geochemistry

1.4 Exploration drilling

1.5 Well logging

1.6 Other

Each of the above subfields can be treated in the same manner and should be designed to collectively exhaust the subfield. For example:

1. Exploration data

1.2 Exploration geophysics

1.21 Gravimetry

1.22 Magnetometry 


\subsection{Seismology}

1.24 Down hole geophysics

\subsubsection{Electric logs}

1.24.2 Radioactivity logs

1.24.3 Lateral logs

1.24 .4 Other

The overall classification system should be standard within the organization and able to handle all types of incoming data. Each organization, however, functions differently, and receives different types and forms of data, so each should be designed to suit the specific need. Examples of current classification schemes are provided in the appendices (under specific secondary services, i.e., those commercial bibliographic systems that deal exclusively with geological or petroleum data).

Once the classification scheme is set up and the decision is made to index the archive accordingly, each document can be analyzed for position within the classification, and assigned a classification number.

After the document is logged properly in the acquisition catalog and assigned its relative place in the classification scheme, it is necessary to record the reference in a standard format for use in the archive's master index file (manual or computer). For each document the minimum data items are:

Unique number: (assigned in acquisition catalog)

Classification number: 
Cross-reference numbers: (to be discussed)

Other identification number: (any internal numbers of submitting agency)

Date: (from publication/document)

Author: (from acquisition $10 \mathrm{~g}$ )

Company: (from acquisition $1 \mathrm{og}$ )

Title: (from acquisition $10 \mathrm{~g}$ )

Enclosures: (any separate maps, logs, or tables enclosed with a report are to be listed completely)

Location: (physical location/address within archive)

Cross-referencing

An important function of the indexing and classification system is the ability to accomodate cross'referencing and the creation of ancillary files to help the professional search for information.

Each document is placed in one position within the classification hierarchy and given the respective classification code. The keywords are then selected reflecting the content of the report. These keywords, however, often refer to subjects covered in other parts of the classification. Those that are significant should be cross-referenced. A record should be placed in the card index that is a standard, cross-reference card containing the 'header' information (bibliographic elements), location, and the original classification code. The professional searching for a topic will then be assured of finding not only major sources but also important secondary sources. 


\section{Card indexes}

The internal organization of the card index file should follow the logic of a normal search. It appears that in the CCOP oil and gas agencies, the bulk of research work is performed on the basis of area, most of ten on the basis of contract area. The card index should reflect this by having the basic organization by area; $1 . e .$, basin or structure. Contract area should not be used as a breakdown as the boundaries are of ten an arbitrary grid and not static entities. If the boundaries change in the future the card index system would collapse. It is therefore important to choose an area breakdown that sufficiently divides the offshore into convenient, logical subareas, which should be able to accomodate the contract areas also.

Within each area breakdown the classification hierarchy is used.

For example:

Area A:

1. Exploration

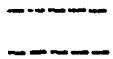

2. Development

- -

3. Drilling and production

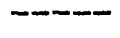

Area B :

1. Exploration

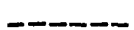

2. Development

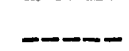




\section{Drilling and production}

\section{Keywording}

The present reference systems operating in CCOP rely on title searches for specific data within a data type, e.g., geologic reports. Such a system will be inadequate for larger amounts of data when for a single project the professional must peruse all kinds of reports for data content. Therefore, a keywording or annotated-bibliography system should be implemented for all geologic and engineering reports by subject specialists in the data management staff.

Keywording is simply the process of extracting the pertinent subjects, geographical areas, analytical techniques, equipment, or other items that describe the content of the document. Therefore, upon review of the reference and keywords, the professional can make a better decision of whether or not the specific report is of interest to his field of research.

Keywording can be undertaken by natural language or a controlled vocabulary. It is recommended that a controlled vocabulary be used for the following reasons (Lea, 1978):

1. Retrieval success depends on the class size and composition of the document classes in the system: class size and composition depend on the vocabulary used to index the documents.

2. A controlled vocabulary is essential to avoid synonym duplication.

3. A controlled vocabulary can eliminate homonym problems, i.e., the same word having different meanings in different contexts. 
Furthermore, a structured vocabulary can allow homonyms since

a particular use of a homonym can be specified.

4. Semantically related terms can be linked by means of a controlled vocabulary.

5. A hierarchical structure in a controlled vocabulary allows generic searches to be undertaken.

6. Retrieval precision depends on the specificity of the controlled vocabulary.

7. A greater intellectual burden is placed on the searcher in natural language systems.

8. False coordinations and incorrect term relationships are likely to be more prevalent than they are in controlled vocabulary systems.

9. Searching stems by natural language techniques may often yield surprising results, e.g. with ANALYSIS.

10. It is true that a thesaurus can be used as an aid to natural language searching, but because there is no structure it is less successful.

11. Natural language techniques can be used in addition to controlled language techniques, but the reverse is not possible.

12. A study of retrieval success has shown that controlled language is superior in performance to all other systems.

13. Services that started without a controlled vocabulary are mostly changing to a controlled vocabulary system as their database becomes too large for good retrieval. 
14. There are problems with singulars and plurals.

15. When terms are inverted there are precedence problems.

16. Variations in spelling can cause difficulty.

17. Different hyphenation practice can cause different collation after machine sorting.

18. Abbreviation practice is not standard in uncontrolled vocabularies.

19. Compound terms can cause problems in uncontrolled vocabularies.

A controlled vocabulary can be grouped in several ways in a thesaurus for use by the Data Management staff (Lea, 1978).

1. Lexicon of grouped controlled terms

2. Alphabetical thesaurus

3. Classification hierarchy

4. Thesauro-classification.

A thesauro-classification is the best way for keywording to be done because synonyms are then controllable, the subject is structurally grouped, and the classification numbers reduce spelling and language difficulties in indexing.

Initially, a commercial thesaurus is recommended for use. There are several which deal with geology and one exclusively with exploration and production of oil and gas, by Petroleum Abstracts. See Appendix 2 . It is advisable to use the Petroleum Abstracts as a source of keywords as they have addressed and solved many of the problems inherent in building a thesaurus. Several topics will have to be amended by each respective 
country in that areas, lithologies, and other similar topics must be listed that refer to country-specific locations.

For example, a geographic thesaurus will have to be instituted using the indigenous area names which have been agreed upon as standard and unique. The thesaurus can be built structurally in the same manner as the overall classification system, in which the largest overall area is broken into its respective sub-areas and named structures. From the hierarchial classification it is important to make an alphabetical index which involves:

1. The terms used in the classification sequence

2. Inversion of terms used in the classified sequence

3. Synonyms of terms used in the classified sequence (e.g., Siam, Thail and)

4. More definitive terms than those used in the classified sequence. Key data

An annotated-keyword/key data bibliography follows the same general scheme as keywording--choosing controlled vocabulary from a structured hierarchy--but makes a distinction between keywords and actual data. This scheme would be ultimately of more use as a professional would find tabulations of data more important than mere subject descriptions. Indexing and keywording would be carried out in the fundamental manner described previously using a thesaurus, but specific data would be included. Included in Appendix 2 is an article discussing the GEOSYSTEM key data activity. Unfortunately, the process involved is 
very exacting for the inclusion of data and would require a professional staff that is probably not feasible until data volumes become very much larger than the expected volumes of the respective CCOP member countries. Abstracting

Abstracting of reports and other documents containing textual material is also a very effective manner to initially provide information regarding data sources. The same indexing and keywording process is carried out as described previously, but in addition, two to three paragraphs are written to describe the content of the report. The staff that actually abstracts the text must be subject specialists, geologists, geophysicists, or petroleum engineers to ensure that the information is abstracted from the text.

Filing of documents, reports, and magnetic tapes

\section{Document storage}

The physical storage of the data after acquisition is recognized as a major problem. Each country visited has a slightly different archiving system, none of which will be able to successfully handle, store, and retrieve their data in the future if the data volume increases as expected.

The primary storage criteria should be by area, as general divisions of the offshore by basins, structures or pools. The major consideration is that most searches for data are on the basis of an area so the structure of the archive should reflect this. Within each area designation all document types should be stored by subject, i.e., exploration, development, or production, then follow the index classification within each. 
Certain document types should not be stored with the others, specifically maps, core and chip samples, and magnetic tapes should each be logged separately, and a separate index should be maintained.

Map storage

The variable physical nature of maps and explanatory texts makes it desirable to keep the collection in more than one sequence (Lea, 1978). Most explanatory texts accompanying maps are more conveniently shelvable; certain maps also arrive folded into a shelvable container. Many of these are shelved with the main serial collection, which is arranged geographically by continent, then by country, then alphabetically by the title of the serial. Certain folded maps and explanations that are not part of a series should be shelved with the reports. The majority of maps, however, are unfolded and are kept in horizontal or vertical map presses. Access to horizontal presses is more difficult because of the need to lift or remove maps to reach one in the middle of a sequence; for this reason the lesser used regional and non-series maps are stored horizontally. Vertical arrangement is used for the major national map series; although access and refiling is easier, the guards used to hold the maps in the cabinets are not wholly satisfactory and require maintenance. 
In the case of shelved maps and explanations, these use a normal shelf-location mark system. This consists of a one- or two-letter physical location code, followed by a numerical sequence which achieves country arrangement. The location mark for flat maps has seven elements:

1. A prefix such as ' $H$ ' for horizontal plan presses, ' $V$ ' for vertical presses, and ' $C$ ' for vertical cupboard filing.

2. Thesaurus geographical code for the area covered by the whole series (rather than the individual map sheet).

3. The series code.

4. The issue (normally the sheet number).

5. The date of the map.

6. The variant indicator (a sequence number to distinguish between minor variations, particularly in the case of manuscript maps).

7. The copy (a letter code, from A onward, to distinguish identical maps).

This location mark serves a number of purposes:

1. All parts of the mark have meaning, other than being merely a filing location.

2. Each mark must be unique.

3. The mark can be treated in parts, so that only a few characters need be used at a time to find or file a map.

4. The system is infinitely expandable.

5. The system is as efficient as possible, in that another artificial location mark does not have to be used. 
6. The accession number can be used as a check in map retrieval, as the number is always included in printed indexes and computer retrievals; this gives an independent check.

7. The collection is most frequently consulted geographically, and the location mark reflects this.

An accession stamp can be designed to incorporate all elements of the location mark, with the addition of:

1. Country or organization name.

2. The acquisition number, from the acquisition catalog.

3. The date the accession stamp was applied.

The design is shown in figure 2.

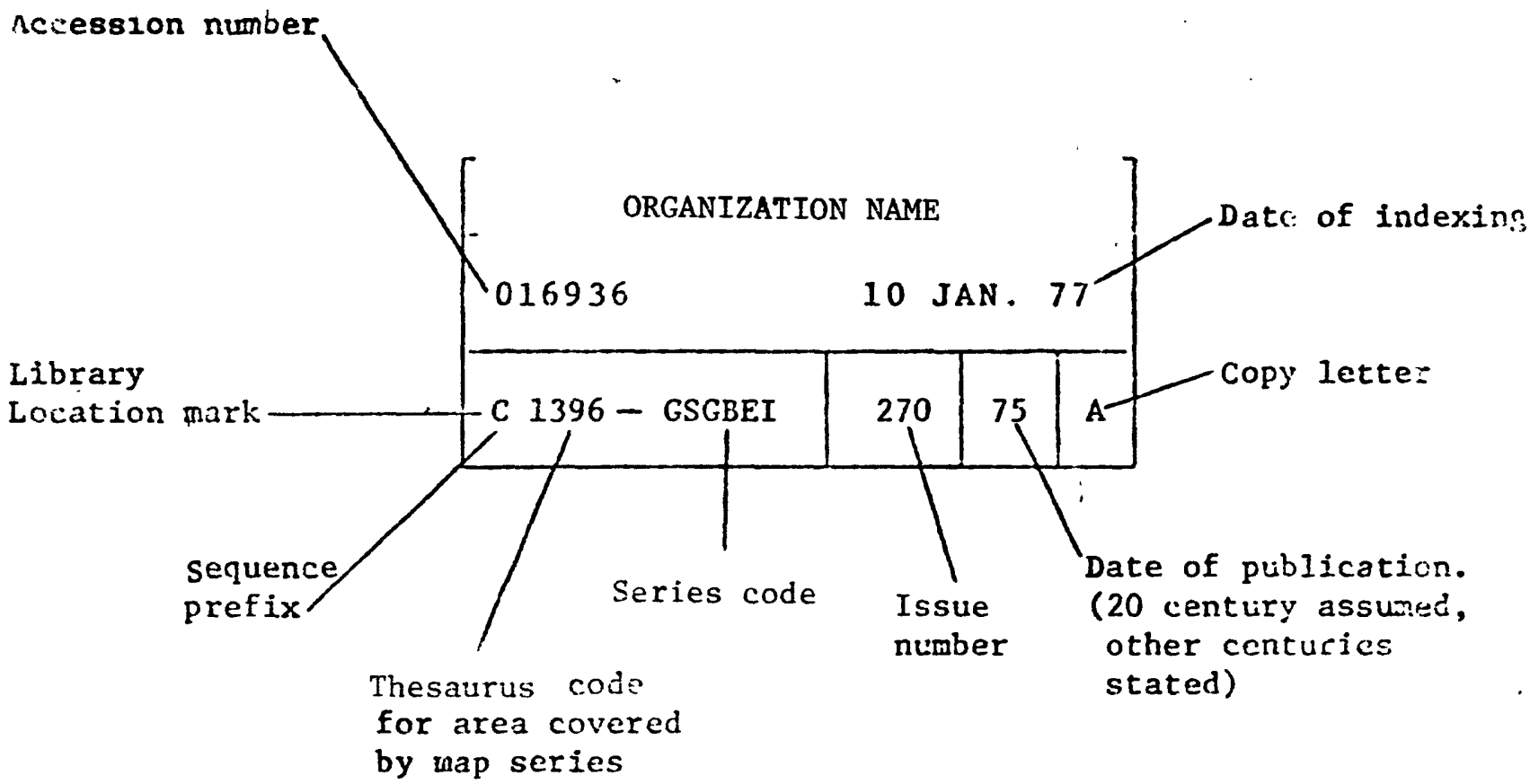

Figure 2. Map accession stamp. (from: Lea, 1978). 


\section{Geophysical data}

The storage, retrieval, and analysis of geophysical data is perhaps the largest single area of data handling within the oil and gas agencies of the CCOP countries. Most geophysical data processing is related to seismic data, and is almost always done either by the contractor or in-house by the agencies, utilizing software packages purchased or leased from the major geophysical companies. As a result of this procedure, the greatest problem faced in the storage of geophysical data is in fact a problem in map storage and archiving. There is also the additional problem of tape storage of seismic data. Because the major oil and gas agencies require the contractor to maintain all geophysical raw data, the agencies face a large storage problem when seismic data are turned over to them for handling.

We11-log data represent the second large volume of geophysical data that is available to the ofl and gas agencies and produces almost identical problems to that of the seismic data, i.e., submittal in paper format and a large number of digital tapes containing basic data. The problem associated with tape storage of well log data is not nearly as severe as that for seismic data, simply because there are fewer digital logs. There is, however, a growing tendency within both the major companies and the CCOP oil and gas agencies to digitize a larger number of $\operatorname{logs}$.

Because the majority of all geophysical data collected that relate to oil and gas activities of the CCOP countries are normally processed 
by either private contractors or in-house computer centers by means of commercial data packages, this report does not deal with these activities. There is, however, a need to discuss national collection and storage procedures with respect to magnetic tapes of geophysical data. National collection and storage procedures for geophysical data.-At present most CCOP countries require, or would like to require, that contractors provide magnetic tapes of all seismic data collected within the nation's jurisdiction. Although the requirements are al1-inclusive, they rarely specify the following:

a) Precisely when data are to be transmitted to the oil and gas agency.

b) The physical description of computer tapes that are provided with the basic data.

c) Standards for data format for geophysical data provided.

The lack of specific standards related to the areas listed above has resulted in numerous problems, the end result of which is that adherence to the requirement to provide basic geophysical data is incomplete at best. Some of the more significant problems are:

1. Virtually no nation has an immediate need to acquire all the historic data related to seismic surveys. Therefore, there is not a concentrated effort to acquire the data and as a result data organization is spotty.

2. Virtually no nation is in a position to receive the thousands, in some cases hundreds of thousands, of magnetic tapes of geophysical data. 
3. The lack of clear-cut standards for even the size of magnetic tapes creates a serious storage problem.

4. The lack of data formats for the submitted data means that most of the information would need to be converted to a standard format before it could be used. This represents a major task both in terms of computer time and personnel.

5. The widespread dispersion of seismic data outside the CCOP countries, both regionally and by company, makes the maintenance of an index or archive almost impossible.

Given the desire of all nations to acquire and archive magnetic tapes of their data and the present problems associated with meeting this objective, there is a clear need within the CCOP countries to initiate the following actions:

1. To effectively store, retrieve, and utilize geophysical data, each country should establish, either nationally or by adopting an international standard, a procedure for the submittal of magnetic tapes that includes:

a) standardized label of tape characteristics;

b) standard size of reel and method of sealing;

c) grouping of data by survey, area, and scale at the time of submittal.

2. If detailed standards on a national or international basis are not feasible or not available within a reasonable time period, then each nation should develop an internal standard, and upon receipt, 
all tapes that do not conform to the standard should be duplicated in-house to meet standards.

3. For the physical storage and retrieval of magnetic tapes it is recommended that all standard size reels be color-coded, normally by multi-colored sealing strips where the color designates:
a) Type of data
b) Area covered
c) Geophysical company
d) Year of data acquisition.

4. All geophysical data should be stored together in a common facility which provides the required physical environment, security, and access to tapes for utilization.

These recommendations represent the minimum standards that would be acceptable for the submittal, storage, and retrieval of magnetic tapes of geophysical data.

Anticipated programs in computer processing of geophysical data.-As the need for expanded analyses of data related to exploration, reserve estimation, basin analysis, and regional correlations becomes apparent, and the applications are recognized, there will be a major effort within the oil and gas agencies to better utilize their geophysical data. Indeed, there is at present a growing interest in the following areas that will mandate an expanded data processing activity with respect to geophysics: 


\section{Reservoir engineering studies}

\section{Seismic reprocessing}

3. Modelling

4. Velocity analyzers.

5. Depth conversions.

6. Density analysis.

7. Graphics.

8. Resistivity profiles.

These needs and associated areas of activity are rapidly expanding and recuire an expanded effort in at least two major areas: geophysical data files, and in-house mini-micro processing. Both these subjects are covered in following chapters of this report. In general, however, it is anticipated that the iaitial development of geophysical data files will normally proces by the development of individual special-purpose files that will be used in a limited number of applications. Because of this fact, considerable attention must be given to the use of mini and microprocessers which lould, at present, seen to offer the greatest potential for cheap, efficient, and rapid processing and handing of Seophysical data files.

The very nature of the development, handling, and processing of individual geophysical data files mandates that there be some overall data manasemert to insure that the activities are coordinated. Specifically, there is a need to set rininu- standards for data content and definition to insure that at scme later date the various files can be integrated into 
a comprehensive well data base or geophysical data base. With respect to these considerations, three major areas need to be monitored:

1. The basic input to geophysical data files will be digital data, much of which will be produced by hand digitizing. Therefore, it is necessary to insure that the same digitizing standards are employed to insure data compatibility.

2. Careful attention should be paid to insuring that digital data are compatible from file to file with respect to intervals and specific contacts, units, or zones.

3. All digitized geophysical data should carry specific identifiers with respect to company, time, method, etc., to insure that data to be compared are compatible.

Careful attention to detail and monitoring of activities will produce a series of files which can later be merged into a geophysical data base. Failure to provide the proper administration will lead to costly redevelopment of the data and sizeable delays in development of application.

\section{Active, inactive, and dormant data storage}

During the visit of the $\mathrm{CCOP}$ consultants to the oil and gas agencies, it was observed that an undetermined but sizeable amount of data is maintained in the files that is either duplicates or is not used at present. Removal of these data from the library would reduce both the volume of the library and the necessity to maintain a record of the data.

Duplicate data are best represented by the daily, weekly, and monthly progress reports that are superseded either by annual reports or completion 
reports which are a compendium of the dally, weekly, and monthly reports. To alleviate this problem it is suggested that preliminary reports be maintained in a separate file; and, on receipt of annual or completion reports, that the preliminary reports be placed in storage or destroyed. Data that are presently not used, 1.e., very old, or on areas or subjects that are no longer under study should be removed from the library and placed in suitable storage. In addition, data presently used for study but which are of little value for subsequent studies, or for which summaries are available, should also be placed in storage.

It is appropriate to mention that three levels of data are normally designated :

a) Active--data that are of present and ongoing use, or have a recognized use in the future, should be maintained in the master library;

b) Inactive--data that have been superseded, are of no forseeable use in analyses or studies or for which other data sources are avallable (such as summaries). Such data are stored external to the master 1 ibrary but in an area and state such that they are readily retrieved if needed;

c) Dormant--data of only historical value, that are not required for any future studies, or are totally superseded. Such data are normally boxed, indexed, and sent to a permanent storage area and are normally retrievable only with sufficlent lead time. 
Development and implementation of a three-stage physical storage plan will substantially reduce the space requirements of the present and future library and will result in a much more efficient and useful library facility.

\section{Data control}

- The present system of data control within the CCOP countries is inadequate to:

1. Insure the security of data.

2. Insure the proper filing of data.

3. Provide accountability for specific data items.

4. Accomodate an expanded study, analysis, and data base development program.

The major problems with the present system, recording the data user and the data borrowed on individual cards, is that the system is not used consistently and no one single individual serves to monitor data use and distribution.

It is recommended that the present Ad Hoc system become mandatory and that some one individual be placed in charge of monitoring the use and distribution of the library materials. The ideal situation would be that one of the staff to the Data Manager be assigned this task.

$$
\text { Microfilming }
$$

Microfilming is an efficient way to handle the preservation and duplication of archival materials for the following reasons:

1. Amount of physical storage is reduced.

2. Information is readily available in one spot. 
3. Material is easily reproduced.

4. Method is exceedingly efficient for storing and retrieving map information,

5. Reduces wear on original material.

6. Acts as a backup library to insure against loss through fire, etc., of original documents.

7. Allows cheap and easy dissemination of data to regional offices.

8. Stable and easy to store, deteriorating less quickly than paper.

9. Microfilm is cheap to mail.

10. Color can be reproduced cheaply, as positives.

11. COM (computer output on microfilm) can be cheaper than a line printer, especially if several copies are required.

12. Storage costs are minimal.

A few disadvantages are encountered in that (Lea, 1978):

1. A microfilm reader is required.

2. There are many 'standards' and sizes: $16 \mathrm{~mm}$ and $35 \mathrm{~mm}$ roll microfilm; microfiche in $3^{\prime \prime} \times 5^{\prime \prime}, 5^{\prime \prime} \times 8^{\prime \prime}$, but most commonly $4^{\prime \prime} \times 6^{\prime \prime}(104 \times 148.75 \mathrm{~mm})$.

3. Some users do not like the medium.

4. Some data and papers on microforms are poorly edited.

5. Browsing is difficult or impossible.

6. Archive must be in order before microfilming, as an unorganized microfilm file is unusable. 
It is recommended that provisions be made in the CCOP countries to buy microfilm equipment and proceed in duplicating their archival data, or that they contact microfilm contractors to provide the service, allowing for future updates to the file.

\section{Personnel}

The acquisition, referencing, keywording, storage, and retrieval procedures in archiving materials requires a Data Management staff. The importance of data availability in an organization of these types spans all levels of activity. Data are needed for all operations (exploration, production, and regulatory) that need to be coordinated at the department level. Top administration also requires the submittal of reports data status justifying a position in line with other department heads. The staff under the Data Management specialist should include a senior information specialist, preferably a librarian, two technical personnel, ideally a geologist and a geophysicist or a petroleum engineer, and three to five clerks and authorities, depending on the activity level with respect to data in the archive. Obviously this number will vary depending on the size of the installation; however, a minimum skill mix that includes the above areas of expertise should be maintained.

In most of the installations visited, junior geologists were put in charge of data activities in addition to their other duties. Geologists basically do not have the background to deal with the problems of physically storing and retrieving data, indexing, classification, etc. 
Information specialists and librarians, however, have no geologic expertise, therefore lacking professional judgement in the actual indexing classification, and keywording. Therefore, a mix of information specialists to outline general procedure, organize data flow patterins and handle the physical storage problems is necessary with a complement of professional/technical people to provide the geologic background necessary to deal with the specific types of incoming data.

\section{Computer data archival information systems}

Once the archival procedures recommended are implemented: physical storage is arranged, indexes are complete with standard reference and keyword formats and the flow of incoming documents from acquisition procedures to storage is standardized, the conversion of the manual files to computer files is relatively easy. The majority of large oil companies and many other organizations dealing with petroleum data have converted their bibliographic files to computerized methods for the following reasons:

1. Organizations cannot acquire and manually process the majority of literature pertinent to their interests.

2. Traditional library methods are inadequate to cope with the detailed information requirements of users and potential users.

3. The retrieval system, the card catalog, is difficult and alien to many users.

4. Card catalogs become very large and inefficient to use. Several existing systems successfully deal with bibliographic data. The American Geological Institute (AGI) publishes GEOREF which deals with 
referenced keyword formats. Geosystem's database GEOARCHIVE uses a keyword/annotated bibliography format. Petroleum Abstracts publishes abstracts of all published exploration and production information in the United States. An overview is provided of each in Appendix 2 describing their indexing and classification procedures, record formats for references keywords and data, their computer facilities and published products.

A computerized system for bibliographic data provides the following advantages:

1. The search for pertinent information sources uses keywords which are fast and comprehensive.

2. The hierarchial structure of the classification allows for generic searches.

3. The ability of the computer to autopost the larger (broader) divisions of the classification of a reference is extremely useful and time-saving.

4. The capabilities of cross-referencing are extensive and easy.

5. Search parameters of two or more criteria can be accomplished with one step.

6. Master listings of accessions can be produced easily.

The computer hardware and software required to support a machineprocessable bibliographic data system is dependent on the required applications. Normally, however, the bibliographic data base can be run on most existing systems with simple applications software. If no machines are accessible, bibliographic systems can be most easily run on minicom- 
puters with simple software designed to manipulate datafiles.

For more detalled discussion on the computer applications of bibliographic data regarding international standards for machine-readable formats, the Reference Manual prepared by the UNISIST/ICSU-AB Working Group on Bibliographic Descriptions is included in Appendix 3. The purpose of the UNESCO working group has been to define, for scientific and technical literature commonly covered by secondary information services, a set of data elements which will constitute an adequate bibliographic citation. For each type of 1 iterature the minimum number of data items per record is identified with any supplementary elements that may be deemed necessary.

Elsewhere in this paper the computer hardware and software necessary to implement a bibliographic file.are discussed. Repository of samples

One of the major areas of data storage and retrieval that should be addressed in detail, within the CCOP countries, is the acquisition, storage, and retrieval of physical samples, i.e., drill core, chip samples, and analytical samples. The extent of this problem is actually difficult to ascertain in detail, a problem in itself, because of the present lack of acquisition logs, poor storage facilities, and no overal1 emphasis on the data. In some instances, however, the problem is simply inadequate space for storage, which itself poses difficulties. The following general comments apply to virtually all the CCOP countries and represent problem areas which should be addressed. Although 
the solutions will be unique to each country, there is a general approach that might resolve many of the problems which is discussed at the end of this section.

Core and chip sample acquisitions

In general, it is surprising how few physical samples are acquired by the ofl and gas agencies of the CCOP countries. Although most countries have mandatory sampling requirements, there are very few concerted efforts to acquire these samples. It is believed that the majority of samples still remain with the drilling contractors; however, very few agencies know how much core or how many chip samples are held, nor do most have any knowledge of where such samples are stored. These factors pose a serious problem with respect to each nation's knowledge of its physical samples.

Given the above conditions, it would seem advisable that each country begin a program for the acquisition of core and chip samples and that this program proceed as rapidly as the samples can be handled.

\section{Storage facilities}

The very nature of core and chip samples dictates that they be physically archived separately from other types of data. This fact, however, does not negate the need for the development and maintenance of an acquisition $10 \mathrm{~g}$, similar to that used for text information, and an indexing system to catagorize the type of sample and other identification.

Physical storage facilities for core, chip, and analytical samples presents several problems, among the most significant of which can be mentioned: 
a) Normally, the need for a special housing for the samples.

b) The need for staff to maintain and work with the preparation, retrieval, and utilization of the samples.

c) The need for large expansion potential which normally results in large front-end expenditure.

d) Physical handing and archiving are difficult.

Given all of these problems, however, it is still essential that physical samples be preserved and physically archived.

Analytical samples

Unlike their "big brothers," core and chip samples, most samples taken for laboratory analysis require considerably less space but do require unique storage accomodations. Additionally, most analytical samples are derived from chip or core samples and as a result are rarely included in normal acquisition logs and lack cross-referencing to data files on well information. This is a particularly acute problem when files of analytical data and samples are created, as they are rarely directly correlated with the well files on geology, geophysics, etc. Analytical samples pose a peculiar problem in that because they are analyzed they are normally given privileged storage space. Indeed, in some organizations, samples occupy rooms while professionals are forced to share offices and find alternate work areas. Attention should therefore be paid to moving analytical samples back to the storage areas as soon as work is completed and they are no longer needed for analytical purposes. 


\section{Existing sample storage facilities}

Because of the unique nature of core, chip, and analytical samples, their physical archiving and handling is a separate study and not specifically a part of the present study. It is, however, a major problem which can best be addressed by having the individual country representatives visit the physical storage facilities of the Norwegian Petroleum Directorate, Stavanger, Norway, or the Alberta Core Storage Facility in Calgary, Alberta, Canada. Specifically, the Calgary repository is one of the world's largest and most efficient; it should be visited prior to the development of any sample-storage facility so that planning officials may gain the required insight into both the physical plant requirements and the procedures for sample storage.

Potential uses for sample storage

As stated earlier, the acquisition and storage of physical samples have not been given a high priority in the CCOP countries. Although there are many reasons for this fact, perhaps the most important is that the value of such samples is not truly recognized. It should therefore be stressed that the development of a physical sample repository is of great value in modern exploration and exploitation technology which now employs physical and chemical properties of rocks for analyses utilizing new concepts of geology and petrophysics. Today, geologists and engineers can learn as much or more using samples from unsuccessful holes as samples from successful ones. Modern exploration is directed toward the search for stratigraphically trapped hydrocarbons. These accumulations 
are already becoming harder to find in the offshore areas of most CCOP countries, and successful exploration requires rock cores and cuttings to determine the lateral and vertical distribution of porous reservoirs, impermeable seals, and traps. Obviously, fossils found in cores and chips are invaluable for correlation of subsurface rocks and in the predicting of reservoir rocks. Perhaps more important in the future will be the value of cores and chips to provide critical information for secondary recovery processes.

The present and potential value of core and chip samples is enormous and a concerted effort should be made to acquire and maintain this valuable information source.

COMPUTER APPLICATIONS RELATED
TO
PETROLEUM DATA HANDLING
$\frac{\text { Analysis of computer-based systems }}{\text { and programs in the earth sciences }}$

Dr. Stein Bie, of the Norwegian Computer Center, recently completed a review of computer-based systems and programs in the earth sciences as a part of the present IUGS/CCOP study. The report details that the earth sciences are in an early stage of development of computer-based systems. Nearly all systems are first or second generation, many not yet in routine production.

Geophysics forns the major exception, with highly developed and stable systems in extensive use, and with a well-informed and numerically minded user community. Standard software packages, often commercial, are in use with both government and private industry. Major activities are confined to private industry, with less evidence of active government research participation for systems development. 
Outside geophysics, there is no distinct difference in level of attainment between government and industry, with government actively involved in systems research and development. Development is frequently initiated and maintained by a few devoted individuals, but there are some examples of firm organizational commitment to computerized information systems.

Input now creates a major bottleneck in many organizations. Data capture from field records and archival material remains problematic, particularly for alphanumeric data sets. Input efforts are frequently underestimated and sometimes allocated to staff with incomplete understanding of original data quality and context. Examples of large-scale data capture being successfully accomplished are found with commercial oil well records and government minerals files. Record costs of $\$ 10$ (U.S. dollars) or more are frequently quoted. Also, in cartography digitizing is a major problem. Automated digitizing of earth science manuscript maps has been largely unsuccessful; hopes are pinned on recent developments. Lack of large cartographic data files also prevents development of efficient cartographic systems. Data input seems to be an important field for active research and development.

For data storage and retrieval, simple sequential or index-sequential file systems have achieved most success. Earth scientists frequently have insufficient computing experience to operate large data base management systems. Supporting computer centers sometimes lack interest in applying the potentials of large systems to geological problems. There are, however, successes with system 2000 ADABASE, TOTAL, STAIRS and IMS in selected organizations with high computing ability. Beginners are well advised to start with simple systems (standard file routines, GRASP, GIPSY). 
Many different processing programs are in use and it is difficult to generalize about them. Geological users strongly wish to have inter active systems replacing batch oriented processing, and a willingness to bear the higher costs. Many find use of the computer as a preprocessing tool important, easing the geological interpretation of data rather than automatically generating conclusions.

Although graphical display is currently poorly developed, some fine analytical work is done in environmental geology, geochemistry, sedimentary petrology, and regional planning using raster (cel1)-based cartography. Colors seem important for user communication. Computer-aided cartography has yet to make a major impact in the earth sciences, apart from in contouring. Grid methods are here near-universal, with experimental work with regionalized geostatistics. A few commercial packages dominate the digital terrain model field.

Relating to organizational structures we note mixed management support for computer systems for geology, which also reflects mixed feelings among their geologic staff. Long-term funding seems essential for useful developments, especially as data capture can be slow. Stop-go policies have widely interfered with systems development.

Traditions with working environments differ significantly between, for example, U.S.A. and western Europe. Small and crowded rooms for both equipment and scientists were common, and support staff (for example, data entry and digitizer operators) give simplistic and repetitive tasks which would enfringe on labor agreements in some other countries. We noted high turnover rates among personnel. Carefully designed entry systems and good job 
organization in some institutions in the U.S.A. and Canada were often associated with successful systems.

Geologically, the new techniques have yet to make a fundamental impact, but younger geoscientists are clearly more quantitatively inclined than their older colleagues. Multivariate data analysis seems useful for such subjects as geochemistry. Remote sensing has yet to show consistency in production environments. Educational aspects are important to future progress and to the system user; friendliness is a valuable attribute of a system. Training tools (for example, prospector) offer some promise.

We expect the next decade to bring major changes to data handling in the geosciences, with computer-aided processing playing an increasingly important role. Most constructive developments so far have centered on creating archival files, simple processing, and preparation for manual interpretation. Dataabout-data systems are particularly successful and should be more widely encouraged.

This analysis of international activities provides an overview of problems and activities that are in large part similar, if not identical, to those within the CCOP member countries as evidenced in the following discussions.

$$
\text { Oil and gas data files }
$$

Within all the oil and gas agencies visited by the consultants during the information collection phase of the program, there was both a clear need and desire to develop both manual and computer-processable data files. Many data files have already been developed for use in specific programs and projects. Although the present emphasis is on the creation of specific data files, there is an intermediate- to long-term 
need to integrate the existing or planned data files into a data base (a comprehensive file or set of files, normally in a machine processable format, for use by several users). However, to accomplish the present intermediate- and long-range goals of data base development, several key factors must be considered in terms of the design, construction, updating, and uses of the data base as its constituent files. The purpose of this section is to review the more critical aspects of these areas, and to discuss these specific types of oil and gas data bases. The three major data base activities common to the majority of the CCOP countries are the formation of a well file, an oil and gas data file, and a basin file. When use together in a data base system, these three files can be used to answer the majority of questions addressed by the exploration and production departments of the oil and gas agencies.

It should be emphasized that throughout the following discussion reference is made to the construction and development of computer based files applicable to the development of manual files both because of increasing the integrity and usefulness of the manual file but also because experience has shown that with increased application and data volumes the majority of manual files will be converted to machine processable files. It is therefore imperative that they be originally designed and constructed with the same guidelines as machine processable files to expedite their later conversion. 
the definition of the file structure.

The interrelationship or organization of indvidual items of data in a file define what is termed the data structure. In order for fils:builders to capture, store and communicate the intended meaning of their data it is essential that the structure of the data be ana lyzed and defined. However, there are seieral levels that require definition (Table 1). First, file-builders should acknowledge existence of the natural structure of tt:e entity being described, which is real but unknowable. The ways in which a scientist then logically arranges or "structures" data about natural phenomena reflect his or her current perception of them and form the basis for the conceptual structure.

A third level for definition is introduced when one considers the limited number of ways in which data can be recorded and stored. Each recording and storage medium (e.g. data forms. diagrams) constrains in some w:y the physical structuring of the data. which may not correspond exactly to the conceptual structure of the object being studied and still less to the natural structure. This limitation is inherent in all data storage devices. from the simplest field notebook to

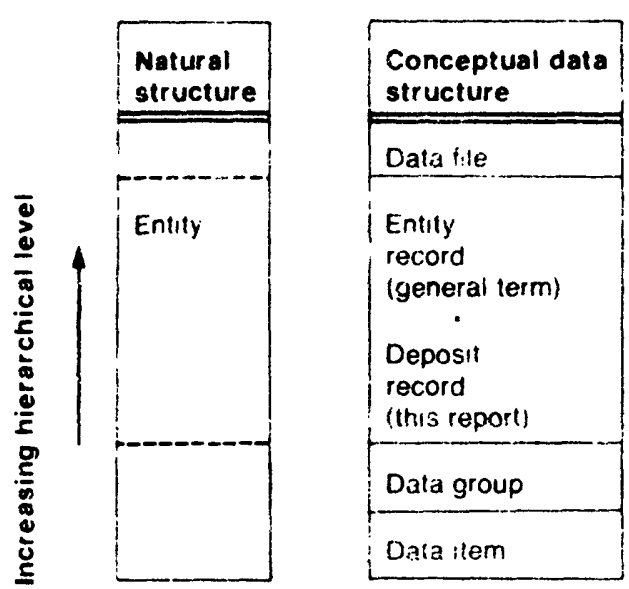

Schematic retationship between natural, conceptual, physical and electronic others, 1978). the most complex electronic equipment. Thus we must distinguish conceptual structures from physical and, at a fourth level, electronic structures. In most cases, the structures at each level are similar, but fait ure to appreciate and recognize some real differences can lead to confusion.

Except where stated otherwise, the recommendations in this report are confined to conceptual data structures. We have considered only how the data must be logically associated and "linked" in order to preserve a given meaning.

Data structures may be portrayed or "mapped" in terms of one or more models, the most common being the hierarchical. network and relational models (Bie et al. 1977). The Working Committee : as employed the familiar hierarchical (inverted tree) model throughout, but recognizes that in certain circumstances others may be superior in view if file objectives and/or available database management systems. We have not pursued this important aspect of data management.

\begin{tabular}{|l|}
\hline $\begin{array}{l}\text { Physical data } \\
\text { structure }\end{array}$ \\
\hline Data file \\
\hline $\begin{array}{l}\text { Entıty } \\
\text { record }\end{array}$ \\
\hline Data group \\
\hline Data item \\
\hline
\end{tabular}

data structures. This report focuses on conceptual cata structures. (After Longe and 


\section{File definition}

Too often, in the majority of organizations, the initial definitions of a data file, in terms of its content and applications is left to a single individual or a small group of people with a common problem or philosophy. This situation almost invariably leads to the development of a data file which has 1imited applicability and supports only a very small user community. Unfortunately, the opposite is also true and that is that a large group defines the file content and application with the result that the file is too complex to be effectively constructed and will rarely be able to meet the diverse users needs.

To avoid the problems described above the following procedure is recommended for defining the content and scope of a data file.

1. A users' committee should be defined, which includes a data base specialist, several of the larger potential users and several data specialists who are either responsible for the development or acquisition of the basic data.

2. The users' committee should address in detail the following three factors with respect to the entire agency:

(a) How many people will use the data file."

(b) How often will the data file be used.

(c) Specific purposes of the data file.

3. Given the information from the questions in No. 2 , the users' committee should develop a check 1 ist of data items required to meet the intended uses. 
Upon completion of the above three steps the next element in the data file development is the format definition.

Format definition

Central to the development of any data file is the definition of the format to be used in data collection. Although simple in concept, one only needs list the data required. The actual development of the format is considerably more difficult if it is to be done correctly. The following are critical considerations:

(1) There is the basic need to insure that all the relevant data items, these that will be used singly or together, are included in the format.

(2) Normally only disaggregated data, usually referred to as the basic data element in its simplest form, should be stored in the file. It must always be remembered that basic data can always be aggregated; however, aggregated data cannot be reduced to basic data.

(3) A standardized set of terms and a corresponding thesaurus must be developed for each data field within the file.

(4) Standard units of measure must be utilized throughout the format so that data can be aggregated without the necessity of conversion of units.

(5) Every format must contain sufficient ancillary data, much of which will not be of direct use in the files application, to allow linkage with other files in the data base, the most 
common links being by longitude-1atitude, national grid, or map area.

(6) As no data file is static, the basic format must allow for the addition of more basic data than originally planned, and for the addition of other data items.

Once a preliminary data file format has been developed, a form should be sent to a group of users, or circulated through the user community, who are asked to $f 111$ in the form with available data. During this exercise, careful records should be kept of time requirements, problems in data acquisition, and other problems in completion of the format. Following such an evaluation, the format should be revised to eliminate problem areas and to make it more efficient with respect to data acquisition.

Data acquisition

Data acquisitions are normally the most expensive, time consuming, and personnel intensive activity in the development and application of a data file on a data base. At the same time, it is an area where perhaps the least effort is expended to make the job efficient and comprehensive. For data acquisition activities within the CCOP countries, the following problems are critical.

First is the problem of the sequence of data acquisition with respect to the basic data. There are three fundamental types of data: PAST, PRESENT, and FUTURE, which must be accomodated in data acquisition. Although past data are obviously the bulk of most archives, they should be treated last in any data acquisition program. Initial effort should 
always be placed on the efficient capture of future data. The emphasis on future data insures that all of the most recent data and that to be acquired, which normally has the highest information value, will be available in the data file. Once the procedures have been developed for the acquisition of present and future data, then and only then can attention be placed on recovering the past data.

Although the above is a simple concept, it is too of ten overlooked in many agencies where only the supposedly overwhelming problem of handling past data is recognized.

Second is the problem of who collects the basic data for input into the data file. In most agencies it is assumed that this task can be handled by clerical personnel but experience has shown that this is not workable. Although the data acquisition task is long and tedious, it must in large part be done by professional personnel. Even those parts done by the clerical staff must be done under the close supervision of a professional and all data acquisitions must be checked by a professional.

The need for professional data acquisition can be substantiated by the facts that:

1. Most technical data require some subjective evaluation as to its merits before it is entered into a data file.

2. Professional data acquisition insures the technical integrity of the file and reduces the time required for cross-checking and verification. 
3. Only technically trained people recognize the need for additional data and where such data may be acquired.

The level of professional expertise need not be overly high for data acquisition activities but must be sufficient to insure data integrity within the file and be capable of data file updating.

\section{Data file updating}

There are two major philosophies with respect to updating data files.

1. Updating can and should be done by the users of the data base.

2. Updating can and should only be done by a special staff charged with this responsibility.

The procedure selected, however, is totally dependent on the type of users and applications of the data file; indeed, in some international oil and gas agencies, both systems are utilized.

The procedure of user updating is most often employed when the data file is small, has only limited applications, and the user community is composed only of highly skilled technical personnel. The user update system is particularly effective in an environment where data are often updated, but at irregular intervals, and results based on new data are needed quickly.

The system where a specific group is charged with updating is normally employed in conjunction with large data files that have a large number of applications and users. Normally the user community is professional in nature but from diverse backgrounds and the input data needs additional review. The group-updating procedure is most effective where many entries 
in a large number of files are regularly updated. The system is also employed where there is a geographically dispersed reporting community.

As stated previously each procedure has its benefits depending on application and uses, and an agency must decide which system it will employ very early in data file creation. It must, however, be cautioned that if one adopts the user-update procedure, there is no actual accountability for file and data credibility. It is this single fact that has dissuaded most companies from adopting the system. It is required that the update procedure be decided initially because it will in large part dictate the data base management system and will have a major impact on whether updating needs to be done in a batch or interactive mode.

\section{SPECIFIC DATA FILES}

Although a large number of data files can and will be developed for use within the oil and gas agencies of the CCOP countries, perhaps 2 files, well data file, and the oil and gas pool file, are a common requirement within all petroleum-producing countries. In the following sections a generalized outline of the content and sequential development of such files is given as a potential model for the development of such files, with appropriate modifications for the CCOP countries.

\section{WELL DATA FILE}

Well data represents perhaps the greatest single volume of information available in all the oil and gas agencies within the CCOP countries. In addition, it is also the most used information and therefore has a very high priority for being placed in a machine-processable data base. 
It is recommended that a well data file be used as the pilot program for data file creation in most of the CCOP countries, both because of its extreme utility and the fact that it can be developed in a modular fashion. The modular development allows for the rapid development and application of the data file for specific uses and also provides for a wide variety of applications as additional data are required.

Sequential development program

Each well record must contain a minimum of heading information which serves to locate and uniquely identify the well. The amount and type of information will depend on the use of the data but at a minimum should include:

(a) Geographic coordinates (longitude and latitude or national grid).

(b) Operator name, well number, contract number.

(c) Spud and completion dates.

(d) Depth data.

(e) Projected geologic formation or formations. Given the above information unique to each well, then the sequential developinent of a well file could proceed as follows:

Step I. To build a data file, utilizing well data, for the computation of porosity and permeability, the data base would have a matrix for construction and data capture as follows:

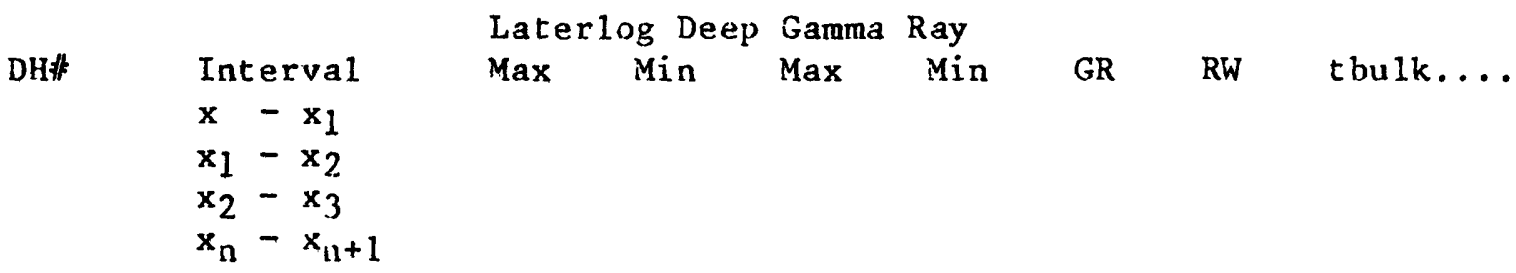


Step II. Utilizing the matrix above, all that is required to expand the file, assuming constant well intervals, is simply add columns for the added data and the expanded version becomes:

DH\# Interval (Present Data Items) Lithology Paleontology Age

$$
\begin{aligned}
& x-x_{1} \\
& x_{1}-x_{2} \\
& x_{2}-x_{3} \\
& x_{n}-x_{n+1}
\end{aligned}
$$

Step III. If for data processing reasons it is considered advisable to not carry all of the data in one file, the data could very easily be broken into 2 or more files. The primary consideration, however, is to maintain the unique descriptors in both files. This will be particularly true within PETRONAS with respect to production and reserve data. In the case of the well data file there would be two files:

File I

Well log File Production

DH\# Interval $t$ bulk Matrix

$\begin{array}{lll}x_{1}-x_{2} & " & " \\ x_{2}-x_{3} & " & " \\ x_{3}-x_{4} & " & " \\ x_{n}-x_{n+1} & & \end{array}$

File II

We11 log File (Porosity-Permeability)

DDHF Interval Lithology Age

$\begin{array}{lll}x_{1}-x_{2} & " & " \\ x_{2}-x_{3} & " & " \\ x_{3}-x_{4} & " & " \\ x_{n}-x_{n+1} & & \end{array}$

The eventual expansion of data base activities to accomplish a wide variety of analyses will obviously require the addition of a large number of variables to the file. This expansion, however, will result in a more useful data file which will have a wide range of applications. 
Petroleum Information has developed an excellent and widely-used well

file record format (see Appendix 4).

Applications of well data file

Obviously a complete well data file would contain a greater variety and number of entries described in the proceeding sections, specifically with respect to data relating to:

(a) Tops and bottoms of formations.

(b) Initial potential and production tests.

(c) Core data.

(d) Drillstem and wireline test data.

(e) Production data.

(f) Analytical data.

Given the above data, the normal applications of such a file would include the following:

(a) Structure and show maps.

(b) Producing and non-producing show maps.

(c) Initial potential maps.

(d) Penetration maps.

(e) Well data ístings.

(f) Audit reports.

(g) Production decline curves.

Once a well data file has been created and is operational, or in some instances while it is being created, there is normally a need to cy ind data file activities to begin development of an oil and gas pool file. 
OIL AND GAS POOL FILE

With the development of mature producing fields, the transition from exploration to production, and an expanding role in reserve and resource estimation, many of the $\operatorname{CCOP}$ countries are finding that the data contained in the well data file is not adequate to support their activities. There is a need therefore to begin the development of an oil and gas pool file which will provide the basic data required to support such analyses. The same procedures should be used in defining the data file and undertaking its sequential development as have been described before.

\section{Sequential development program}

The oil and gas pool data file is potentially a very large and complex file which covers a wide spectrum of activities, all, however, related to a specific oil and gas pool. To begin the development of such a file, it is necessary to once again define those attributes that constitute the heading information for each record for an oil and gas pool. Such information would include:

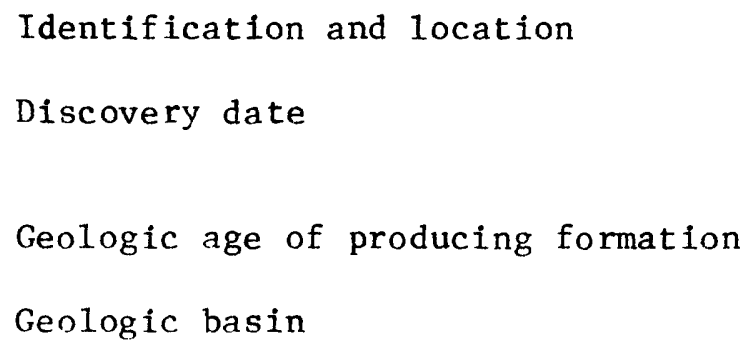

Step I. The primary data requirements of an oil and gas pool file are concerned primarily with discovery and development data including the following: 
Information source document

Producing formation name

Field discovery method

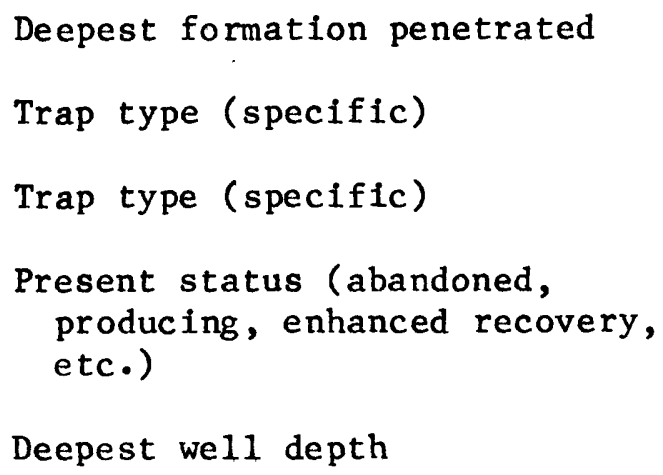

Deepest well depth

Step II. Having acquired the discovery and development data the next step is to acquire the basic engineering reserves data which include:

$\begin{array}{ll}\text { Status and types of wells } & \text { Reservoir lithology } \\ \text { Proved acreage } & \text { Primary drive type } \\ \text { Spacing (acre/we11) } & \text { Porosity } \\ \text { Producing Interval } & \text { Permeability } \\ \text { Average thickness } & \text { Formation volume factor } \\ \text { Depth to top } & \text { Recovery factor } \\ \text { Depth range } & \text { Average oil and water } \\ & \text { saturation } \\ \text { Bulk volume } & \text { Temperature } \\ \text { Pressure decline } & \text { Shut in bottom-hole } \\ \text { Gas/oil ratio } & \text { pressure }\end{array}$

Step III. Following the acquisition of the engineering and reservoir data acquisition, which is of critical importance in monitoring the pool development, there is a need to acquire production, reserve and recovery data as follows:

Annual production

0i1

Natural gas

Condensate
Cumulate production

Oil

Natural gas

Condensate 
Primary

Step IV. The final step in the sequential acquisition and construction of the oil and gas pool file is the acquisition of analytical data including the following:

Crude oil analyses
API gravity
Viscosity
Sulfur

Crude oil analyses (fractions)

Water analyses

Natural gas analyses

Having completed the development and construction of a oil and gas pool data file there are a wide range of potential applications for the data. A good example of a pool file record format has been created by the Petroleum Data System (PDS) (see Appendix 4).

\section{Applications of the oil and gas pool file}

There are many uses for the oil and gas pool file; however, perhaps the most important is that for each nation it serves as the permanent archive of its oil and gas endowment; a factor that is often unfortunately overlooked in considering the development of such a file. In addition, however, there are the following applications:

1. Scientific research.

2. Evaluation of reserves.

3. Resource distribution studies.

4. Analysis of quality of oil and gas.

5. Development of national policy with respect to:

exploration

production

secondary recovery projects 
6. Resource assessments

7. Production decline analyses

A11 of these are areas where there is either already a need or will be a need in the near future.

\section{ANCILLARY FILES}

There is at present, and will continue to be in the future, a broad spectrum of data file development for individual projects and for special purposes. Some of the more obvious being specialized geological (paleontology, stratigraphy), geophysical (seismic, gravity, magnetics), and geochemical (brine analyses, hydrocarbon analyses). Regardless of the content of the data file being created, it is recommended that the basic concepts discussed in this section be applied to all data bases.

DATA BASE CONSTRUCTION

Data processing environment

Present capabilities

A11 the organizations in Southeast Asia responsible for the petroleum data collection have either in-house or in their geographical vicinity large computers of the type IBM $370 / 145$, or UNIVAC 1100 , or smaller minicomputers like PDP 70. These computers are currently used mostly for business management (financial planning and analysis or production monitoring) and to a lesser degree to applications in petroleum exploration or to the bibliographic control of existing petroleum data.

Therefore, in general, it can be stated that computer hardware is available to support the majority of processing needs within the CCOP member countries. More critical to the problem, however, is the availability of computer software, particularly Data Base Management Systems (DBMS) and Data Management Systems (DMS). 
A DBMS, on the other hand, is a software system intended to manage and maintain data in a nonredundant structure for the purpose of being processed by multiple applications. A DBMS organizes data elements in some predefined structure, and retains relationships between different data elements within the data base.

A DMS can perhaps best be defined as a software system intended primarily to permit access to, and retrieval from, already existing files, usually for a single application. Although a DMS may provide the capability to minimize data redundancy and centralize the storage of data, the principal intent of the system is to perform such functions as information retrieval, report generation, and inquiry for a single application.

Most of the existing installations are supported by either a DBMS or DMS system which can run concurrent in both mode or on-line and which are either machine dependent like IMS (IBM system 360, 370, 303X), DMS-1100 (Univac 1100 series) or a system like Total which is running on most major minicomputers, medium-and large-scale computers.

The effort involved in installing a minicomputer DBMS can be as large as for a ful1-blown DBMS on a giant mainframe; the degree of preparation is not necessarily proportionate to the size of the mainframe. The extent of implementation of application programs may or may not be smaller, but the planning efforts are much the same.

\section{FUTURE NEEDS}

The field of both present and anticipated needs for data processing are expanding rapidly within the petroleum agencies of the Ccop countries and can only increase as demands for data analysis increase. The major areas of anticipated increase are discussed in the following sections. 
The rapid evolution of the minicomputer industry (Digital Corp., Hewlett Packard, Nova etc.) and the introduction of small computers by the big computer firms, sisch as IBM's system 38 ( $512 k$ bytes of main storage, 193-5 megabytes of auxiliary storage, a 650-1ine-per-minute printer, seven display stations, a remote printer and all necessary system software can be purchased for less than $\$ 140,000$ (U.S.) offers the necessary hardware to implement all three phases described in the previous section without having to use a large mainframe like IBM $370 / 175$ or UNIVAC 1100 . If, however, these machines are available and are not reserved for other applications all three phases could be implemented on them. It should be pointed out there seems to be a trend toward the use of smaller computers for interactive graphical type work involved in parts of the applications of phase III.

\section{Software requirements}

Each of the individual phases of the sequential development program requires specialized software to process the data and produce the reports and analyses required. In many instances the software programs will actually be written at the installation to do a specific task (utility programs). Alternatively, programs will be developed which allow the user to utilize portions of existing software programs extant on available machines. In both cases the software should be written in compatible or single programming languages and be well documented.

With an increase in data processing activities the normal computer center will begin to rely less on utility programs, although they will always be of value for specific applications, and more on comnercially available data base nanagement systems (DBMS) as well as graphical subroutine packages. 
It is important to emphasize that the acquisition of computer software is a complex and time consuming task if the software acquired is to be compatible with any anticipated integrated system. Very large sums of money can be expended on software packages which will become obsolete or inadequate with the expansion of data processing activities. Therefore in the evaluation and acquisition of all software packages the following general guidelines should be considered:

1. Applicability to present and anticipated program needs

2. Adequacy of documentation and seller support for package

3. Machine and peripheral dependencies which limit use of package

5. Ease in modification and linkage of software package with other software

6. User friendliness and technical support requirements.

Software activities are perhaps the most volatile aspect of computer processing with an enormous number of packages available for almost every application. It is therefore critical that the exact software specifications be developed for each application and that all acquisitions made support not only the user but the longer term need of the individual computer centers.

\section{Data base management software}

Data Base Management Systems (DBMS) have been available for more than a decade, yet have had a profound effect on the market only in the last 3-4 years. Of particular interest to the CCOP countries is the fact that the most recent trends have been in the application of the DBMS technology and applications to minicomputers and even microcomputers. 
Many systems have started out as DMS and through time and expanded capabilities have become excellent DBMSs and well as DMSs. It should be emphasized that many of the initial applications for data files could be, and most probably will be in most installations, handled by application programs. Ultimately, however, almost all installations will require a true DBMS in order to reduce redundancy in data files and permit greater efficiency in the storage and utilization of information.

This sequential development within the oil and gas agencies is also reflected in the development trends of DBMS systems toward total systems. In particular, this trend is characterized by a modular set of programs that is combined to handle not only the users' data base management requirements, but also to supply the associated inquiry/response, data retrieval, accounting and billing, report writing, and other functions in a single integrated system. Originally, interfaces were built to independently supplied application programs; however, it soon became clear that it was more beneficial to develop a series of related programs and market the resulting "total system" to the end users.

There is a constant changing, compacting, subsetting, and modifying activity within the DBMS industry. The introduction of new and more powerful hardware systems and new DBMS technologies, such as relational and distributed data base concepts, have necessitated a reevaluation and improvement of packages.

It is important to keep in mind that the DBMS systems that are presently being marketed are actually packages, and although this may be an approach that is just right for some users, it may be excessive for others. It is important to realize that once an agency has committed itself to a DBMS 
environment, it becomes progressively more difficult to change systems as the implementation and application become basic to the agency's operation. The DBMS field, however, is rapidly changing to accommodate an equally rapid changing environment in data processing within the geological sciences and the oil and gas activity, specifically.

The general conclusion from the overall analysis is that the field of computer applications is changing rapidly and that organizations are best prepared to cope with the growth if they have a capacity to respond to these diverse changes. This fact is further demonstrated within the oil and gas agencies of the ccop whose role has changed rapidly in the last 5 years. Therefore, because a DBMS allows for maxinum efficiency and supports multiple applications, considerable effort should be directed toward the selection of a DBMS or a DMS that can be expanded. However, the acquisition of a DBMS is a major Jecision and should be carefully planned, and available DBMS or DMS should be eraluated carefilly.

\section{Data Base Management System selection}

Perians the single most important decision, with respect to computer softwate. is the selection of a DBMS. This problem is particularly critical in the ccop countries, as they are either now in the process, or will shortly find it necessary to consiser, the acquisition of a DBMS to hand le their computing need. Given this need, the consultants would suggest that each sounty utilize a standardized procedure, peculiar to each country's needs, so: evaluating DBMSs. The following procedure is modified from that used by the $\because$. . Geosogical Survey in evaluating DBMS procurenents. The system utilizes 
a series of critical factors which are given weights depending on their potential importance to anticipated applications. The numerical weights can be modified to suit the specific needs of each country. 


\section{Evaluation scheme for Data Base Management Systems}

DBMS Characteristics

Weights

1. Hardware independence

A separate device media control language exists

The placement of data is completely automatic, or

A "place near" type of command exists

Interface of DMS with operating system

2. Language fac1lities

Application programs in COBOL, FORTRAN, assembler, ALGOL, PL/I: all five

four

three

*An interactive enquiry language exists (IEL)

A data management language exists (DL)

Reportwriters in both IEL and DL

IEL and D1 are "the same language"

User extensions to IEL

User functions in IEL and DL

*Terminal networks language or equivalent

Data dictionary and data directory

3. Data independence and system/subsystem considerations

System description is separate from subsystem descriptions Security locks at system and subsystem level Validation rules in system Location modes: standard (set-subset), direct, calculated (random) ordered (next, prior, owner)

User-defined functions in subsystem, e.g., scramblin

Data manipulation language interface for macro READ, WRITE, CALL

Add or delete a domain - must be transparent to application programs not using domain

* System must not store blanks, zeros, or polnters if domain absent

4. Other utilities

Data base recovery: back-up tapes 
$\begin{array}{ll}\text { Security: lockout from certain operations } & {[1]} \\ \text { terminal type } & {[2]} \\ \text { * user's password for access to "his" data } & {[2]} \\ \text { Structure simulation } & {[2]} \\ \text { Monitoring routines } & {[1]}\end{array}$

5. Usage and users

Datamation Dec. 77 users opinions: placed first [5]

second [3]

third [1]

Opinions of local users

[3]

General impression when using terminal [4]

Ease of diagnostic messages [1]

Ease of recovery procedures [1]

6. Cost

$\begin{array}{ll}\text { Hardware cost p.a. lowest } & \text { [4] } \\ \text { second lowest [3], etc. } & \text { [4] } \\ \text { Software cost p.a. lowest } & \text { [2] } \\ \text { Cost of educational support/documentation } & \text { [2] } \\ \text { Cost of technical/speclalized support } & \end{array}$

7. Other considerations

Multi or single thread: only one copy of DMS in memory Only missing parts of subsystem added to transaction file

Overheads on DB size due to pointers, tables, indices: $<10 \%$

$<50 \%$

What percent of firm's turnover is in S.A.: highest

*DBMS must handle networks, 1.e., many-many relationships

Re-entrancy (more than one set of complete registers)

Certain of the evaluation criteria will be mandatory, i.e., must be present before the system can be considered, depending on the specific needs of the user and the installation. As an example, the * in the above format would identify mandatory aspects of a DBMS that was speciflcally to be used for interactive data processing. 
In order to effectively evaluate a DBMS, using the proposed evaluation scheme, the minimum information concerning the DBMS, which should be provided by the vendor, would include the following sections:

\section{System summary}

This section should provide a general description of system requirements and capabilities. The information should be provided at a level of detail such that the evaluator can very quickly determine whether a given system satisfies the minimum requirements.

Current applications.--A list of general applications for which the system has proven useful should be given. The list need not be exhaustive, or imply that the system is limited to the particular applications cited.

Hardware/software requirements. --The Hardware/Software Requirements section provides a list of the computers on which the system has been implemented, the operating systems required, minimum main storage necessary, and auxiliary storage requirements. Any special hardware or software requirements, such as teleprocessing support, should also be indicated.

Capabilities.--Topics discussed in this section should be descriptive entries and provide the reader with a general idea of system strengths.

Mode of operation.--The system's operating environment is indicated: remote terminal, batch, remote batch, or time-sharing, and general system class and operations supported should also be indicated.

Data files.--Information should be given on the file structures supported by the system. The information provided would depend upon the class of system being described. For self-contained and host language data management systems, the information indicates the type of file structured during the creation. For 
retrieval and report formatting systems, the type of file structure acceptable to the system should be given.

System output.--Descriptions should be given of the types of output provided by the system:

- User or system formatted reports. Simple reports requiring few computational steps, or complex reports with numerous computational steps to include sums, tallies, and averages.

- Selected subsets of master files. Subfiles selected from master files based upon user-defined logical selection criteria.

- Transaction journaling. Records kepi of dates added to, changed, or deleted from the master file.

User Interface.--This section should include a discussion of the manner In which system functions are invoked by the user. Indicated should be the general steps required of a user to perform the following:

- File creation and restructuring.

- File maintenance.

- Data retrieval.

- Report formulation.

This section should also discuss how a user communicates with the system, whether through punched cards, pre-printed control forms, or on-line interactive remote terminals.

System characteristics.--This section would provide a more detalled description of the system's operations than presented in the System Summary section.

File structure.--This section should provide an explanation of the physical and logical file structures supported by the system. The type of information 
presented would depend on the class of system being described. For selfcontained and host language data management systems, a description of the physical and logical files created by the system for storing the data and data indexes should be presented. For retrieval and report formatting systems, an explanation of the acceptable physical and logical file structures should be provided. The information is an expansion of the material contained in the Data Files section under System Capabilities.

File creation.--A description should be given of the steps a user must follow to create a file:

- Prepare the file definition.

- Prepare the input

- Generate the file

The manner in which the file is created should be discussed, as well as methods of file restructuring, and the user-environment (remote terminal, batch, remote-batch, time-sharing) supported during the file creation process.

The File Creation section will be present only for self-contained and host language data management system descriptions. Retrieval and report formatting systems process files created by other systems or programs, and do not support a file creation capability.

\section{File maintenance}

This section would describe the system functions available to the user to add, change, or delete data in the file and the manner (on-line or batch) in which these updates are performed.

\section{Retrieval and output}

The methods available to the user to retrieve data from the file and format reports should be given. Described in general terms are: 
- The query language.

- The query formulation method (batch or interactive).

- The types of simple and compound logical selection criteria provided.

- The types of output supported.

- The report formulation method.

- Other system-unique features.

This section should provide the reader with a general idea of a system's ability to respond to his information and reporting needs.

External programing interfaces.--Many systems provide exit points where the user, to improve flexibility, can enter his own routines to perform processing not inherently supported by the system. The purpose of this section should be to provide the user with a general idea of the types of user-exits provided by the system.

Users of host language data management systems have all the capabilities of the host language at their disposal to perform processing not supported by the system, therefore this section would not be presented for host language data management systems.

\section{Applications}

For minor applications, programs should be developed according to the specific needs of the individual organization. For the major petroleum oriented applications a collection of computer programs should be assembled by purchasing or leasing some of the available packages. The technical programs : available in such packages cover fields like: the calculation of subsurface $\therefore$ safety valve sizing, core data processing, optimum casing design, calculation of reservoir and aquifer volumes by material balance, fluid analysis by correlation technique and simulation technique, multi-purpose flash, 
recombination and plant recovery, flow string gradients in gas we11s, grid-type reservoir analysis and simulated performance, general reserve estimating and appraising and tabulating, quantitative interpretation of electric logs, flow string gradients in ol1 wells, pressure analyses for reservoir definition.

Production and reserve information management and evaluation, pumping unit and rod string design, oil-gas and water PVT data, risk analysis for drilling prospects, stratifled waterflood element performance, theoretical recovery analysis and productivity, decline and volume of gas in place. Batch vs, interactive computing environment

Most of the modern systems can operate concurrent in batch or in interactive mode, and this is a necessary requirement for the activities described as phase II and phase III. The use of interactive timesharing to either process data directly or to submit a job as a batch session gives flexibility and will very soon make the use of punched cards and card readers superfluous.

\section{Personne1}

The need for personnel to run a computer center are a function of the type of hardware (mini machine/big machine) and the amount and complexity of the software which should be maintained and developed.

There is a need for manpower to support the following automatic processing functions:

ADP Management

ADP Technical support

Systems Analysis Programming 


\section{Computer Operations}

Computer Aides and Technicians

Key-Punch Operators

In addition to these people who work closely in connection with the computer, there is a need for manpower to register and manage the incoming petroleum data.

\section{Computer resource administration}

The CCOP member countries are presently entering a period of growth both with respect to computer acquisition and with respect to computer applications to support a wide range of users, many of whom have specific computing requirements that are both hardware- and software-dependent. As a result, it is absolutely essential that all computer activities adequately reflect the diversity of needs within each country and provide not only for immediate computer support, but also anticipate and accommodate future computer requirements. There is serious doubt that the present system of a single management level committee, found in most organizations, is adequate to meet the above stated needs. A committee composed of only management level presents the following problems:

a) The user needs are not adequately reflected because of the composition of the committee.

b) Management should deal primarily with policy and funding problems and not with individual technical problems.

c) Systems needs and developments are generally foreseen first by the user who has the responsibility for a specific task. 
d) Technical aspects of the hardware and software are usually more familiar to the user than to management.

Experience has shown in the majority of private and public organizations that the most efficient means of managing computer development and resources is to establish the following procedure.

First, designate an executive level committee which is responsible for establishing interdepartmental policy with respect to the computer resources, and evaluates and approves systems expansion or sof tware acquisition and oversees computer applications.

Second, the establishment of a users committee, composed of representative users from each of the operating departments, which has the responsibility for:

a) Liason between departmental users with respect to computer hardware and software needs.

b) Providing recommendations to the executive committee with respect to hardware and software acquisitions, computer resource utilization, and problems related to present computing operations.

c) Prepares a quarterly, semi-annual or yearly report, whichever is deemed necessary, with specific recommendations for systems development of expansion to meet specific user needs.

d) Serves as a task force to the Executive Committee for analyses or specific studies required to support Executive Committee decisions. Third, as deemed necessary and when the scope of the study is beyond the capability of the expertise of the user committee, the Executive Committee should establish specific task forces of interdepartmental specialists to 
evaluate major hardware or software acquisitions on the impact of major programs on the existing system.

The primary benefits of the proposed system of an Executive Committee, a user committee ans task forces are:

a) Frees Management from dealing with problems other than policy, planning, and budget.

b) Provides user inputs which anticipate needs rather than having the Executive Committee in a "react mode" when the need suddenly appears .

c) Insures that all user needs are considered in the acquisition of hardware and software.

d) Provides the Executive Committee with an established accountable group to provide required inputs.

e) Insures communication on an interdepartmental level and between the Executive Committee and user level.

It should be stressed that representation from the computer center is essential to all of the proposed committees and task forces. It is also essential that the proposed system be initiated as soon as possible so that all inputs are considered during the initial phases of hardware and software acquisition. It is a long-established and sometimes painful fact that decisions with respect to hardware and software can only be influenced prior to acquisition. From then on you must make do with the system, as changes are too expensive. Sequential development program

In order to reach the objectives CCOP member countries have been entrusted to achieve, in the regulation and/or operations of petroleum exploration, development, and production, it is necessary to utilize 
the complete spectrum of data provided by contractors or national companies. In order to utilize the data effectively, it must be received in a logical form, the flow of data through the organization must be regulated, and the aggregation or use of the data should be facilitated by specialists in petroleum information and automatic data processing.

The development of the capacity to store, retrieve, and analyze petroleum data can only be accomplished by a sequential development program which provides for the basic information being made available for each phase of the program. The developmental sequence begins with the physical acquisition and archiving of the data, proceeds through data base, hardware and software developinent, and ends with the development of a truly integrated petroleum data system (see figure 3 ).

Each CCOP country is, of course, at a slightly different level of development within the sequence, and therefore has differing needs with respect to consultants, hardware, software, training, organization, and data. In order to accommodate these diverse needs, a broad range of activities should be undertaken, at the CCOP, national, and organizational level, the most significant of which are discussed in the following sections.

\section{Program development}

The elements of a program to resolve the Petroleum Data Storage and Retrieval problem for the CCOP countries are as follows:

1. Establish standing working group on Petroleum Data.

2. Surveys workshops/regional seminars. 
Figure 3. PETROLEUM DATA STORAGE AND

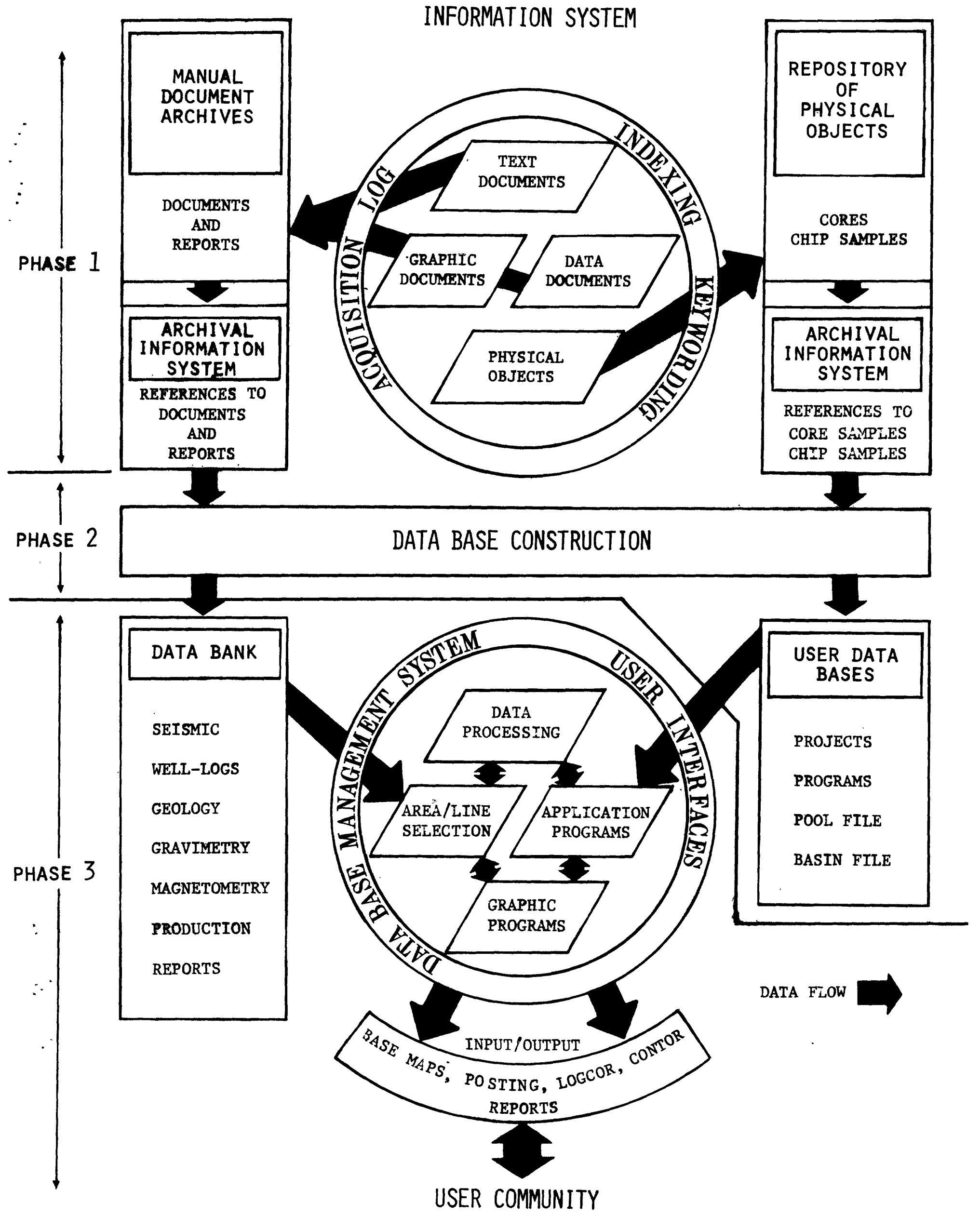


3. Petroleum data literature.

4. Software development/distribution

5. Institutional development

6. Consultation

7. Software and hardware specification

WORKING GROUP ON PETROLEUM DATA

It is recalled that the Committee, at its 13th session, had endorsed the proposal of the Seminar on Data Collection, Storage and Retrieval, held in Bandung, Indonesia, in April 1976, that a Standing Working Group of Experts be organized to undertake, upon request of the member countries, the following phase of work:

1. Assist countries in assessing the existing status of their data collection, storage and retrieval activities, and in formulating their long-range national objectives and requirements in petroleum exploration and development data, including governmental data management and expanded uses of the data in future programs;

2. Develop uniform formats and terminology as guidelines for the governments' collection of exploration and production data and geological samples to ensure that complete data are reliably acquired;

3. Conduct training and pilot studies in computer applications to specify exploration and production problems;

4. Advise and assist the countries in feasibility studies, systems design, and implementation of the required systems which would 
constitute their national petroleum data centers and sample repositories.

It was considered during that session that three or four international experts having extensive practical experience should be first selected and appointed as core nembers of the Standing Working Group to cover a range of specialized fields, including down-hole data systems (i.e. well data systems) geophysical data systems, reservoir and production/ data systems, and sample repositories. Because of the confidential nature of some of the national petroleum data acquired, it was felt that the core members of the Group should preferably be obtained from governmental agencies and academic institutions.

\section{Surveys}

A study mission should be undertaken for selected technical staff from the CCOP countries pursuing work on petroleum data collection, storage and retrieval, to visit governmental agencies and petroleum companies that have systems ranging from efficiently operating manual to sophisticated computer processing. They would themselves see how other people have solved problems similar to their own.

$$
\text { Workshops/regional seminars }
$$

Workshops or regional seminars of about one week duration should be arranged at which specific problems could be discussed and solutions proposed. Petroleum data literature

Another important element of the program should be the distribution of literature on petroleum data storage and retrieval for the Ccop countries. 


\section{Software development/distribution}

The software needs of the CCOP countries should either be accommodated by the distribution of available software packages or through development contracts benefiting one or more of the countries. A substantial reduction in development costs can be expected if several of the countries pool their efforts.

Institutional development

Contact between the petroleum organization in the CCOP countries and similar organizations in Europe or North America should be developed on a long-term basis. The European or North American organizations should provide opportunities for the staff of the CCOP petroleum organizations to come and learn about their special capabilities, and to develop the capacity of the CCOP countries to conduct the same type of work. Such organizational contact should also include consultation on such matters as general program direction for the petroleum data activities, e.g., building facilities and hardware procurement.

\section{Consultation}

The presence of a major data acquisition, storage, retrieval, and applications problem within the CCOP countries, especially those within the Asian Commission of Petroleum Exporters (ASCOPE) has been recognized for several years. Because of this recognized need, the current program was undertaken to specifically define many of the problems and to make appropriate recommendations for their resolution. However, the recognition of a problem and recommending a solution is rarely adequate to insure a satisfactory resolution. This has been and will continue to be 
true unless the CCOP itself, or in conjunction with other groups within the CCOP community and the international community (such as COGEODATA), makes adequate provisions to provide high-level consultation, on a continuing basis to the interested oil and gas agencies. The need for continuity and expertise with respect to consultation cannot be stressed too strongly-it is absolutely critical to the success of the program!

Given the need for consultation assistance, in virtually all the CCOP countries, it is suggested that this need would be most effectively provided, given the requirements above, by the following consultation services.

\section{Permanent full-time Information specialists}

The level of activity and scope of data management problems within the CCOP countries could best be met by the appointment of a permanent full-time staff information specialist. In general, the individual should have a background in the archiving of petroleum data and experience In the development of 011 and gas data bases. Ideally, such an individual should also have a broad general knowledge in data processing. However, because of the tremendous range of hardware and software avallable, it is not feasible to assume that the Individual could provide more than general information. Such an individual should be hired for a minimum of 1 year and preferably 2 , and then the position reevaluated after the 2-year period.

It should be emphasised that this individual will be completely occupled with simple program oversight and consultation activities

$\therefore$ because of the magnitude of the task and should not be expected to -actually work on the implementation of specific programs with the oil and gas agencies. 
There is a need to secure the services of at least 3 additional consultants, probably for approximately 8-10 person months, to assist in the actual program implementation and training phases within individual oil and gas agencies. The recommended areas of expertise for these individuals are:

Physical data archiving.--An expert in the area of indexing, archiving, referencing, keywording, and archival information systems. This would Include text, graphic and physical sample archiving. This individual should preferably be from industry or a major geological survey.

Data base construction.--An expert in the development and definition of ofl- and gas-related data bases, who should have broad experience in file definition, data formats, data input procedures and equipment, data file structures, and data base management systems. Experience with the construction of data bases and work with large integrated systems is essential.

Hardware and software.--An expert in the definition of hardware and software specifications to meet multiple user needs is required. Emphasis should be placed on expertise in mini and microprocessors and peripheral equipment. Experience in systems design, contract writing, and benchmarking of systems is required. Preferably, this expert should come from a research-oriented environment where knowledge of hardware and sof tware development is required.

The following tabulation shows the present areas of need for expert consultation within the CCOP countries visited and the CCOP office itself. Software and hardware specifications

An important task is the procurement of software and hardware. Basic 
training in how to write specifications for computer software and hardware contracts should be given. Owing to the tremendous development in computer science, it is recommended that, if possible, the latest hardware and software products available be used.

The area of consultation is one that must be addressed quickly and effectively and the above recommendations are regarded as minimal if the major tasks and problems areas are to be addressed.

\section{CONCLUSIONS}

The present study has shown that the CCOP countries can be divided into three major groups: those having a small amount of data and data management problems which can be addressed manually, those that have modest amounts of data which are expanding rapidly and require a combination of manual and machine procedures, and finally, those that have very large amounts of data which are expanding rapidly and whose data handing problems would be best addressed by machine processing. In all the countries there are data-handling problems and many countries are on the verge of major decisions and actions with respect to data storage, retrieval analysis; others are moving less rapidly, but are rapidly approaching the time when major decisions and actions are required.

Fortunately, the needs and approaches with respect to the storage, retrieval, and analysis are similar within oil and gas agencies worldwide and variations occur primarily in the areas of responsibility. As a result, 
the activities of European and North American organizations are relevant and applicable to the problems within the oil and gas agencies of the CCOP countries. As a result, the experience of the COGEODATA consultants could be adapted for the individual agencies and appropriate recommendations made within the following major areas:

Physical archiving

The physical control and handiing of petroleum data represents the single greatest problem in the majority of oil and gas agencies. To resolve this problem there is a need to consider the following activities:

(a) Develop and maintain an acquisition and catalogue system for data control.

(b) Develop and implement a data classification scheme which can be utilized by both the exploration, development, and production departments.

(c) Develop a keyword and thesaurus program, which might include an annotated bibliography, for retrieving data.

Geophysical data

The largest volume of data within all of the oil and gas agencies, with respect to a single data group, is geophysical data, and it is the sheer volume of data which poses the major problems. In particular, the following problems are common to most oil and gas agencies:

(a) Need to develop standards of format, size and type, to be followed by industry, for magnetic tapes.

(b) Physical storage presents a major problem because of the shear number of tapes to be stored. 
(c) Standardized procedures should be adapted for duplicating and dissemination of archival geophysical data.

(d) Geophysical data files, developed for specific purposes and operated on main frame, mini and microcomputers, should have a coordinated development to insure compatibility.

Data processing

Data processing is a rapidly expanding activity within the majority of oil and gas agencles and its development poses numerous problems among which the most significant are:

1. Definition and selection of an appropriate Data Base Management System (DBMS).

2. Lack of coordination with respect to main frame, mini or micro computing activities and the resultant piecemeal systems development.

3. Dominance of batch computing in an environment which would be more efficiently supported by time-sharing.

4. Develop and implement a micro-filming program for development of a micro-film library.

5. Develop a data control and distribution procedure to monitor data.

6. Appoint a high-level data administrator, with sufficient staff, to oversee the data management activities of the organization.

\section{Data files}

Data file development is at present one of the major considerations $\therefore \quad$ of the majority of the oil and gas agencies. The development of such files is totally dependent on the availability of a good physical archive, but there is also a need to address the following areas: 
1. Need to develop a clear statement with respect to (a) how many users are there for the file, (b) how often will the file be addressed, and (c) for what purpose will the file be used.

2. Comprehensive data formats and input procedures need to be developed for each data file to insure that separate and distinct files are compatable.

3. Need to develop a program of sequential development of data files to insure continued development, updating, and application.

4. Appointment of a data-base administrator, at a high level organizationally, to oversee and coordinate the data file and computer support development.

5. Lack of skilled computer personnel, working in coordination with geologists and geophysists, to develop overall programs and systems.

\section{ADP Administration}

The present distribution of computer resources, the development of computer files and applications, and the acquisition procedures for hardware and software are all major areas effected by ADP administration; and all are major problem areas in most organizations. The major problems with the present procedures are that:

1. The users needs are not adequately reflected because of the composition of the administrative committees.

2. Systems needs for upgrading, or additional application packages, are not forseen by present administration and action is often taken after the fact. 
3. Present committees are normally not familiar with hardware and software developments and trends and have inadequate procedures for advice.

4. Liason between the user and the computer centers is normally poor, with no clear channels for access.

The vast majority of the above problems have come about primarily through the Ad Hoc development of individual aspects of data handling, storage, retrieval, and application programs. There are numerous reasons why development has proceeded to produce the present problems, but perhaps the most significant have been the lack of understanding of the sequential development of data management and application within an organization, and the lack of a clearly defined and responsible information and data base coordination. A clear definition of the sequential development of data administration and application needs, from physical archiving, to data files, to DBM systems to a final integrated system, must be made a primary objective of the organization and given both the budget and personnel to insure its successful completion.

The impact of the recommendations upon the activities of the oil and gas agencies will in large part be dependent on the internal circumstances of the individual countries and agencies. In particular it is hoped that the recommendation will effectively encourage top management in the oil and gas agencies to place more emphasis on data storage, retrieval and applications. At present the majority of programs suffer most because of the lack of a clear mandate for action and there seems to be a general lack of top management awareness of the required infrastructure to insure that petroleum 
data are archived, retrieved and used in a efficient way.

There is also a clear need to make available to the individual countries and oil and gas agencies the services of consultants who have experience in the areas of archiving, data files and hardware and software systems. A common problem within all the countries is that there simply is not an adequate number of personnel who are trained in the above areas of activity. Without the services of experts in these fields to provide training and to actively work at the program level, it is doubtful if any overall program on the storage, retrieval, and application of oil and gas data can be effectively implemented and developed.

It should be stressed that there are very few short cuts, either by hardware or software, to the development of adequate storage, retrieval, and application programs. As a result, there must be a sequential development of the capability desired that begins with physical archiving and only through time and development will truly integrated multi-purpose systems be developed.

\section{REFERENCES}

Lea, G., 1978, GeoArchive: Geosystems indexing policy: Proc. Geoscience Information Society, v. 8, p. 43-56.

Lea, G., and others, 1978, Computerized indexing of the Institute of Geological Sciences (UK) Geological Map Collection: Special Libraries Association, Geography and Map Division, Bull. no. 112, p. 27-46.

Longe, R. V., and others, 1978, Computer-based files on mineral deposits: Guidelines and recommended standards for data content: Geol. Survey of Canada Paper 78-26, Energy, Mines, and Resources, p. 7. 
APPENDIX 1. Data collection format.

EVALUATION GF NATIONAL NEEDS (CCOP COUNTRIES)

$$
\text { for }
$$

PETROLEUM DATA STORAGE AND RETRIEVAL

I. NATIONAL REGULATIONS CONCERNING PETROLEUM DATA

A. CCOP or Other International Recommendations

B. Norwegian Recommendations

C. National Regulations (Petroleun Act. etc.)

D. Present Method of Acquiring Data

1. Personal basis

2. Legal basis

3. Cooperative (Joint Working Arrangement)

4. Need to know (special requests)

E. Responsible Agency

1. Geology

2. Exploration

3. Production

4. Leasing 
II. NATIONAL COLIECTION PROCEDURES

A. Data Types

1. Exploration

a. well logs

i. how acquired

ii. in what form is data transferred

iii. frequency of acquisitions

iv. data volume (no. of logs) logs

v. release procedures

time requirements

to whom

b. Geologic information

1. how acquired

ii. what form

iii. timing of acquisitions

iv. data volume

v. relaese procedures

time requirements 
II. NATIONAL COLLECTION PROCEDURES (cOn't)

A. Data Types (con't $t$ )

1. Exploration (con't $t$ )

c. Gravity - Magnetic data

i. how acquired

ii. what form

iii. timing of acquisitions

iv. data volume

v. release procedures

time requirements

to whom

d. Maps

i. how acquired

ii. what form

iii. timing of acquisitions

iv. data volume

v. release procedures

time requirements

to whom

91 
II. NATIONAL COLLECTION PROCEDURES (cOn' $t$ )

A. Data Types (con't)

2. Production data

a. Well data

i. how acquired

ii. what form

iii. timing of acquisitions

iv. data volume

v. release procedures

time requirements

to whom

b. Production data

i. how acquired

ii. what form

iii. timing of acquisitions

iv. data volume

v. release procedures

time requirements 
II. NATIONAI COLIECTION PROCEDURES (cOn't)

A. Data Types

3. Documents and Reports

i. how acquired

ii. what form

iii. timing of acquisitions

iv. data volume

v. release procedures

time requirements

to whom

4. Physical Data

i. drill cores

a. how many, etc.

b. what form stored

c. how controlled

ii. rock chips

a. how mariy, etc.

b. what form stored

c. how controlled 
II. NATIONAL COLLECTION PROCEDURES (cOn't)

A. Data Types

5. Maps (General)

i. how acquired

ii. what form

iii. timing of acquisitions

iv. data volume

v. release procedures

time requirements

to whom

6. Analytical Data

i. who performs analyses

ii. does it come back in a standard form

iii. data volume

iv. release procedures

to whom 
II. NATIONAI COLIECTION PROCEDURES (cOn't)

A. Data Types

7. Tract and Leasing area Data

i. how acquired

ii. what form

iii. timing of acquisitions

iv. data volume

v. release procedures

8. Inventory Data (Compiled to date)

That have they inventoried to date 
II. NATIONAL COLIECTION PROCEDURES (cOn't)

B. National fiandling and Storage of Data

1. Data Centers

a. central (Location, contact)

b. Local (Locations, contacts)

2. Acquisition Procedures

a. Acquisition Logs

b. Indexing

c. Keywords

3. Physical Archiving

a. cross referencing

b. card/computer files

c. duplication

d. microfilming

4. Distribution procedures and control

a. to whom

b. how

c. security 
II. NATIONAL COLIECTION PROCEDURES (cOn't)

C. Data Retrieval

1. Retrieval practices

a. retrieval questions

b. retrieval uses

c. retrieval volume

2. Adequacy of system

a. card files

i. problem areas

ii. Present/Future

b. Computer files

i. Problem areas

ii. Present/Future 
II. NATIONAL COLLECTION PROCEDURES (cOn't)

\section{System Configuration}

\section{Manual}

2. Machine 


\title{
PETROLEUM ABSTRACTS INFORMATION SYSTEM
}

\author{
by
}

Roy W. Graves (Exploration Editor. Information

Services Division. The University of Tulsa)

and

John A. Balley (Director, Information services

Division, The Universily of Tulsa)

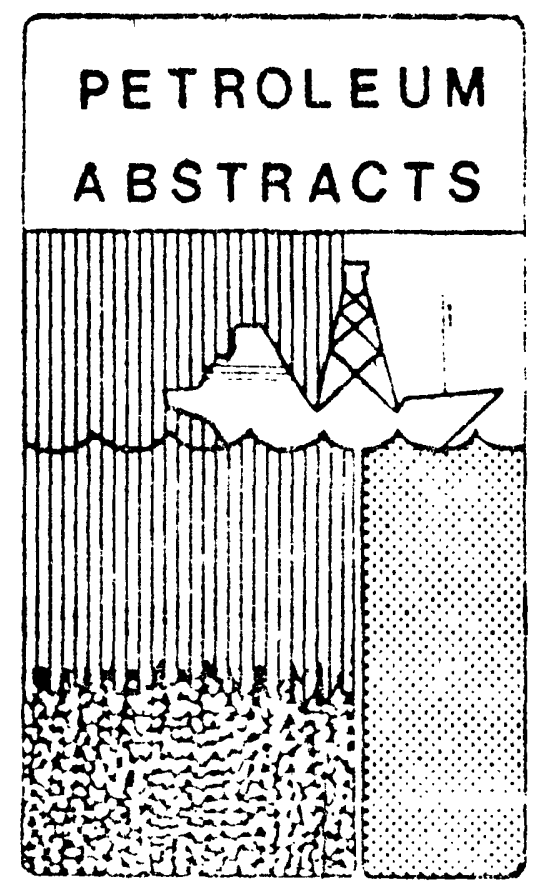

(Presented at the Geoscience Information Society Symposium on Geoscience Information, Denver, Colorado, November 8, 1976) 
$\begin{array}{ll}\text { ABSTRACT } & 1\end{array}$

INTRODUCTION

SYSTEM COMPONENTS 1

Petroleum Abstracts 2

Information Retrieval 2

Exploration and Production Thesaurus $\quad 2$

Geographic Thesaurus 4

Supplementary Descriptors 4

Key Word Out of Context Descriptor List 4

A?phabetic Subject Index 4

Dual Dictionary Coordinate Index 9

Master Record Tanes 9

Card Files $\quad 12$

Classification Retrieva? System $\quad 12$

Author File $\quad 12$

Accession Number File $\quad 12$

Datent File $\quad 12$

Reiated Patent index $\quad$ i2

Computer Hardware and Processing 14

PETROLEUM ABSTRACTS SEARCH SYSTEM $\cdot 14$

ORBIT III SEARCH SYSTEY

SYSTEM EXPANSION CARARILITIES

BIBLIOGRAPHY Nondiscrimination 20

The University of Tulsa employs. advances. admits and treats in its employment and educational programs. all persons without regard to their race, color, national or othnic origin, sex. age. religion. handicap. or status 


\section{PETROLEUM ABSTRACTS INFORMATION SYSTEM}

Now in its sixteenth year, The University of Tulsa's Petroleum Abstracts Information System for petroleum exploration, development, and production has increased its information retrieval capability. Presently in use for in-house information retrieval is the recentTy developed Petroleum Abstracts Search System (PASS). Through an arrangement with System Development Corporation, the Petroleum Abstracts information base now can be accessed internationally through the SDC ORBIT III search system. The Petroleum Abstracts Information System is based on the weekly abstract bulletin Petroleum Abstracts, which covers a selected range of worldwide scientific and technical serial literature. Printed bi-monthly and annual cumulative Alphabetic Subject Indexes are distributed to subscribers to the services. Dual Dictionary Coordinate Indexes have been changed from printed to microfilm format and are issued every six months. Back issues of Petroleum Abstracts also are available on microfilm. Master Record Tapes, for computer retrieval of information derived from articles used in preparing Petroleum Abstracts, are issued every four months. The Exploration and Production Thesaurus is being revised and expanded in its forthcoming Fifth Edition. A Geographic Thesaurus of area terms used in indexing in the System will be updated in a Third Edition. The Petroleum Abstracts Information System can be expanded into other segments of energy development.

\section{INTRODUCTION}

The Petroleum Abstracts Information System, initiated in January, 1961 , is operated by the Information Services Division of The University of Tulsa and is funded primarily by the Petroleum Industry through subscriptions to the services. Presently, 40 major subscribers (petroleum companies and petroleum service companies) and 137 minor subscribers (government agencies, institutions, universities) support the work of the Division. Approximately 700 serial publications provide the base from which this information system operates. Articles from journals, state and national periodicals, published symposia, patent disclosures, etc., are selected for inclusion in the System on the basis of pertinence to the oil and gas exploration, production, and development activities of the Petroleum Industry.

Selections of articles for inclusion in Petroleum Abstracts and indexing of information contained in those articles is done by experienced scientists and engineers. Most of the work is performed within the Division. Some, however, particularly for many articles in languages other than English, is performed on a contract basis.

\section{SYSTEM COMPONENTS}

The Petroleum Abstracts Information System has two basic parts: Petroleum Abstracts, a weekly current awareness bulletin; and (2) Information Re- 
trieval materials and services that include printed indexes and magnetic tape stored information files. Complete activities of the Information Services Division are concerned with the daily production and maintenance of the System.

\section{Petroleum Abstracts}

Each page-plate for the weekly bulletin is prepared "in-house" for direct offset reproduction. by a contract printer who al so produced the covers and mails designated numbers of final copies of Petroleum Abstracts to Subscribers, in this country and abroad. Page format for the bulletin has been changed from its original four abstracts per page to the present column format (Figure 1). Abstracts average about 150 words and are controlled for readability and for presenttation of maximum information. Back issues of Petroleum Abstracts bulletins now are available on microfilm.

Abstracts appear in the bulletin divided into the major categories of information provided by the Service:

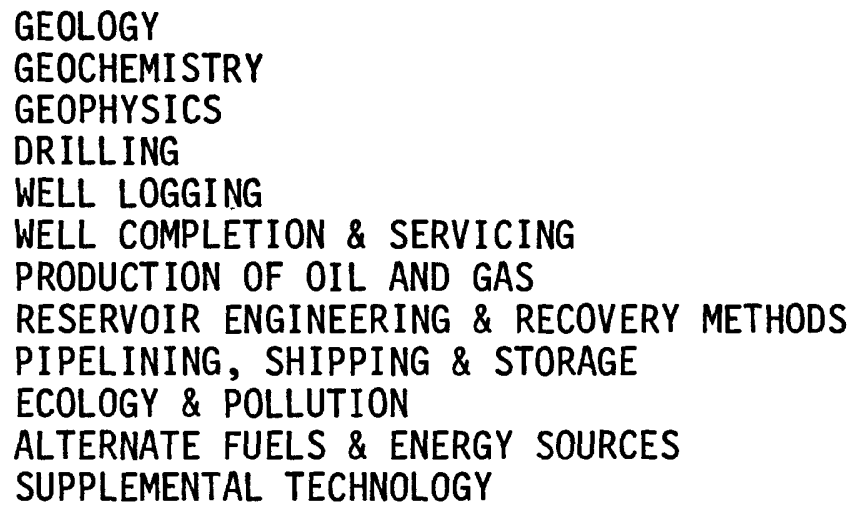

Petroleum Abstracts bulletins contain 200 to 300 abstracts each week. Through mid-year 1976, more than 200,000 abstracts have been publ ished.

\section{Information Retrieval}

Information contained in the articles for which abstracts are published in Petroleum Abstracts is indexed manually from the Exploration and Production (E \& P Thesaurus, the Geographic Thesaurus, and from the Tist of Supplementary Descriptors. This process produces from 10 to more than 100 descriptors for each article, depending on the amount of information contained therein. The manual indexing furnishes the basic input for production of all the information retrieval materials and services. A computer program provides autoposting of descriptors from the hierarchies of the $E \& P$ Thesaurus. Thus, only the most specific term for any concept is posted manualty. ATl broader terms are added automatically to the indexing.

Exploration and Production Thesaurus

The Exploration and Production (E \& P) Thesaurus was prepared as a cooperative effort between the Information Services Division and the major Subscribers. 
FORAMINIFERA

218,400

RECENT LITERATURE ON THE FORAMINIFERA--

R. Todd; J. FORAMINIFERAL RES. v. 6, No. 1, PP 78-85, Jan. 1976

This bibiography is the latest in a series by the same author. Some annotations are given for the articles which are recent publications concerning foraminifera. (90 refs.)

GLAUCONITE 218,401 FURTHER INFORMATION RELATED TO THE ORIGIN OF GLAUCONITE-- B.Velde and G.S. Odin (Paris Univ); CLAYS CLAY MINERALS v. 23, No. 5, PP 376-381, Nov. 1975

Glauconite-smectite and illite-smectite interlayered minerals are compared by various means in an attempt to establish the mineralogical relations between the 2 groups. Experiments at $2 \mathrm{~Kb}$ pressure and $200^{\circ}$ to $350^{\circ} \mathrm{C}$ are reported as well as microprobe scans of pelletal glauconites. This new information is used along with published chemical data in order to establish the following: (1) Illite and glauconite mixed layered phases appear to be crystallographically similar. Both series show the same relations between potassium (mica) content and the amount of smectite layers apparent in the interlayered structure. (2) Ulite and glauconite mica or mica-like phases can be separated on the basis of Fe and $\mathrm{K}$ contents. (3) Probable phase relations of the 2 mixed layered mineral series indicate that, when the starting materials contain mixed layered mica-smectites, increasing temperature produces an iron-rich mica in the case of glauconite and an aluminous mica in the case of illite. The mixed layered phases present at intermediate temperatures are not the same for illites and glauconites. (26 refs.)

GREAT BASIN 218,402

STRATIGRAPHY OF THE ORDOVICIAN ELY SPRINGS DOLOMITE IN THE SOUTHEASTERN GREAT BASIN, UTAH AND NEVADA -- T. L. Chamberlin; Illinois Univ. , Urbana-Champaign, Ph. D. Thesis, 209 Pp, 1975;

Abstr. No. 76-6717, DISS. ABSTR. INT. SECT. B v. 36, No. 9, P 4347-B, March 1976

The Ely Springs Dolomite of S. and E. Nevada and SW. Utah includes 13 informally defined members. These members are recognized on the basis of their chert content, color, detrital constituents, presence of algal balls, bedding properties, crystallinity, and weathering character. The formation is composed of 10 lithotopes. Depositional environments inferred from these lithotopes range from those of low to intermediate energy levels at depths of about $100 \mathrm{ft}$, as represented by the bioclastic dolomite, to shallow, low-energy environments represented by dolomicrite and shallow, high energy environments represented by lithoclastic dolomite and arenaceous dolomite. Offshore shoals are represented by oolitic dolomite and algal ball dolorudite. The Ely Springs Dolomite of the study area is almost entirely of Late Ordovician age. (Longer abstract available) (Abstract only-original article not available from T.U.)

GREENLAND 218,403 UPPER JURASSIC COAL-BEARING SHORELINE DEPOSITS, HOCHSTETTER FORLAND, EAST GREENLAND-L. B. Clemmensen and F. Surlvk: SEDIMENT. GEOL. v. 15, No. 3, pp 193-211, Apı

Upper Jurassic coal-bear at several localities on Hochs Greenland. The sandstones $h$ sedimentary facies, each faci assemblage of sedimentary st and, occasionally by the cont, The interpretations of the est high subtidal oyster banks ovi lagoonal and coastal swampd

facies occur in a vertical sequence where 2 slightly different facies associations could be discerned. It is suggested that both facies associations have been deposited in a barrier-lagoon coastal area characterized by minor shoreline oscillations. The paleogeographic setting of the investigated sequence in the fault-controlled basins along the E. Greenland continental margin is discussed. (27 refs.)

HYORODYNAMICS (GEOLOGY) 218,404 COMPARSION OF THE HYDR ODYNAMICS OF STEEP AND SHALLOW BEACHES.- D. A. Huntley and A. J. Bowen (Dalhousie Univ); NEARSHORE SEDIMENT DYNAMICS AND SEDIMENTATION [Book: ISB 047133946 6]

John Wiley \& Sons, New York; pp 69-109, 1975

This study describes times series for the 2 horizontal components of water velocity, measured at different distances from the shoreline on the 2 beaches, and discusses the probability distributions of the velocities, the mean current patterns close to the shore, and the frequency dependence of the wave energy. The hydrodynamics of the steep and shallow beaches differ widely. In particular, periodic longshore variations of the nearshore velocity field were observed on the steep beach, but not on the shallow beach. On the steep beach, edge waves with a period twice that of the incident waves and with a longshore wavelength of $32 \mathrm{~m}$ were observed and it is suggested that swash interaction in the narrow surf zone was responsible for generating these waves. The mear flow field on other occasions also revealed the existence of near shore circulation cells on the steep beach. (58 refs.)

\section{ILLINOIS}

218,405

MICROFACIES AND GEOCHEMISTRY OF THE BRERETON LIMESTONE (MIDDLE PENNSYLVANLAN) OF SOUTH WESTERN ILLINOIS- - M. R. Khawlie; Illinois Univ. Urbana-Champaign, Ph. D. Thesis, 110 pp, 1975;

Abstr. No. 76-6819, DISS. ABSTR. INT. SECT. B v. 36, No. 9, p $4351-B$, March 1976

The Brereton Limestone in SW. Illinois is a trans gressive carbonate unit over a delta system. It represents marine deposition in 3 interdeltaic troughs, and over an open shelf. The environment of deposition, entirely under relatively low energy conditions, consists of a general infratidal slope extending from a prodelta edge to a shelf and showing topographic irregularities such as depressions, corresponding to protected areas, and elevations represented by organic mounds and banks, and bioclastic bars. Detailed petrographic analy sis reveals 13 distinct microfacies divided in 3 series, characterized by the following benthonic associations: phylloid algae-bryozoans, crinoids-brachiopods-pelecypods, and fusulinids-arenaceous forminifers. The Brereton Limestone is a variety of the bank model of deposition typical of the Pennsylvanian of the Mid-Continent. (Longer abstract available) (Abstract only-original article not available from $T . U$. )

INDONESIA 218,406

SUBDUCTION IN THE INDONESIAN REGION-- W. Hamilton

(US Geological Survey); PROC. SOUTH EAST ASIA PETROL. EXPLOR. SOC. v. 2, PP 37-40, Oct. 1975

The Indonesian region has developed as the result of the Cretaceous and Cenozoic convergence of $3 \mathrm{great}$ lithosphere plate systems. Plates from the Indian Ocean region have been movine northward. and from the Pacific region Plate boundaries have subduction zones, spreading lave broken through, evolved scores of millions of years,

Example of page format from Petroleum Abstracts subject to much internal fashion. No boundaries tion: all have changed

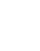

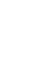


The presently available Fifth Edition is the product of extensive revision and updating. A typical page from the $E$ \& $P$ Thesaurus is shown in Figure 2.

Geographic Thesaurus

Terms (descriptors) included in the Geographic Thesaurus are 1 imited to sedimentary basins, geographic features, and selected geographic areas. In addition to the sedimentary basins, troughs, and embayments, this Thesaurus lists named areas (e.g. BIG BEND AREA) as well as named geographic features such as mountains and ranges, deserts, rivers, beaches, canyons, valleys, lakes, hills, national parks, deltas, islands, divisions of states (e.g., WEST TEXAS), oceans, seas, bays, gulfs, continents, countries, states, coasts, straits, ridges, lagoons, plains, peninsulas, submarine fans, and other comparable entries. Names of forma tions, groups, and series are omitted, as are $0 i 1$ fields, counties, and named geologic structures such as anticlines and faults. The geographic descriptors i isted are those assigned by the indexers; ultimate authority for location is the original article from which the term was derived. A revised and expanded fhird Edition of the Geographic Thesaurus will be available early in 1977. The Geographic Thesaurus is patterned after the $E$ \& $P$ Thesaurus. Figure 3 iliustrates type of entries.

\section{Supplementary Descriptors}

The addition to the descriptors contained in the $E$ \& $P$ Thesaurus and the Geographic Thesaurus, some specific terms such as chemicals, company names, geographic and geologic named features (excluded from the Geographic Thesaurus), and E \& P Thesaurus-type descriptors (seldom used terms - added as needed) are contained in a list of Supplementary Descriptors. As with all descriptors in the System, these are used for both indexing and retrieval. An example from the list is shown in Figure 4 .

Key Word Out of Context Descriptor List

The Key Word Out of Context (KWOC) Descriptor List is an aid in expediting searching and indexing. It is a list of descriptors from the $E$ \& $P$ Thesaurus and from the seldom used term list (of the Supplementary Descriptors List) organized in KWOC format so that descriptors related to a particular subject (or concept) are listed together. As an example, all of the descriptors in the system (excluding those in the list of Company names) that contain the word EXPLORATION appear in one place. Terms from the seldom used list are indicated by an asterisk. Some descriptors contain words in parentheses. In the KWOC listings these parentheses are not shown in the alphabetical listing column. Abbreviated words in a descriptor are listed in the alphabetical listing column in their full spelling. Connecting words such as AND, IN, OF are eliminated. A sample from a KWOC Descriptor List is shown in Figure 5.

\section{Alphabetic Subject Index}

The Alphabetic Subject Index (ASI) is a manual search index designed for rapid location of major articles and patents on a given subject, for review of 


\section{E \& P THESAURUS}

\section{MODC SPECIFICATION \\ $\therefore \quad$ NOOED JANUARY 3965. BT (76--) SPECIFICATION BT SPECIFICATION \\ : ABANDONMENT \\ UF ABANDONMENT PLUGGING \\ WTH WELL PLUGGING \\ UF WELL ABANDONMENT \\ SA DEPLETED RESERVOIR \\ SA DRY HOLE \\ SA LAND RECLAMATION \\ SA MARGINAL WELL \\ SA RESERVE ESTIMATE \\ SA SALVAGE VALUE \\ SA SALVAGING \\ SA WATERED OUT \\ SA WELL KHLING}

\section{ABANDONMENT PLUGGING}

USE ABANDONMENT

PLS WELL PLUGGING

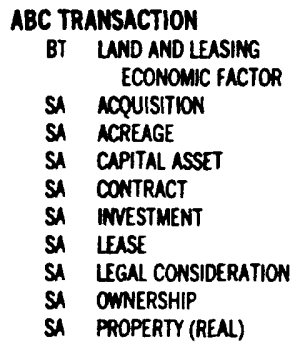

ABIOGENESIS

- PERTAINS TO MONBIOLOGIC ORIGIN OF PETROLEUM, ORGANIC COMPOUNDS, OR LIFE ADOED APRIL 1966. USED (65) INORGANIC PLUS ON AND GAS ORIGIN. BT (67--) ORIGIN

BT ORIGIN

SA OLL AND GAS ORIGIN

\section{ABNORMAL PRESSURE RESERV}

- ABMORMUL PRESSURE RESERVOIR

USE OVERPRESSURED RESERVOIR

ABOVEGROUND STOR FACILITY

- aBOVEGROUND STORAGE FACLITT

- aDOED January 1967. USED (65.66) STORAGE FACIITYIIES) PL US SURFACE.

UF STORAGE ABOVEGROUND

STORAGE FACILTT

SA SPHERICAL TANK

SA STORAGE PIT

SA SURFACE

SA UNDERGROUND STOR FACILITY

$$
\begin{aligned}
& \text { ABOVEWATER STOR FACILITY } \\
& \text { ABOVEWATER STORAGE FACIITT } \\
& \text { ADOED JANUARY I976. } \\
& \text { USED(65.75) STORAGE } \\
& \text { FACIITY(IES). } \\
& \text { UF STORAGE ABOVEWATER } \\
& \text { BT OFFSHORE STORAGE } \\
& \\
& \text { SA OFFSHORE STRUCTURE } \\
& \text { SA OFFSHORE TERMINAL } \\
& \text { SA UTORAGE FACILITY } \\
& \text { SA UNDERWTER STOR FACIITY }
\end{aligned}
$$

ABRASION

USE WEAR

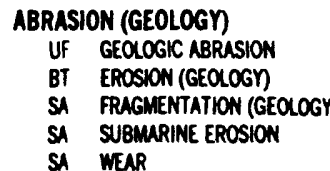

ABRASIVE

* NOOED FEBRUARY 1965

SA ABRASIVE JET

SA EROSION

SA FRICTION

SA SURFACE PREPARATION

SA WEAR RESISTANCE

ABRASIVE JET

UF ABRASNE JET PERFORATING

WTH SET PERFORATING

UF SAND JET

BT JET NOZZLE NOZZLE

SA ABRASIVE

SA HMDRAULLC PERFORATING

SA JET DRILLNG

SA JET PERFORATING

SA SANDBLASTING

SA SHOT PEENING

ABRASIVE JET DRILLING

USE JET DRILING

ABRASIVE JET PERFORATING

* USED (65-66) ABRASIVE JET PLUS PERFORATING.

USE NBRASIVE JET

PLS JET PERFORATING

ABSOLUTE AGE

USE RADHOACTNE AGE DETERMINAT

ABSOLUTE GEOCHRONOLOGY USE RADHOACTIVE AGE DETERMINAT

ABSOLUTE OIL RECOVERY

USE O\&L RECOYERY

ABSOLUTE OPEN FLOW TEST USE OPEN FLOW TEST

ABSOLUTE PERMEABILTTY USE PERMEABHLITY (ROCK)

ABSOLUTE POROSITY USE POROSITY (ROCK)

ABSOLUTE RECOVERY

USE OIL RECOVERY

ABSORBENT

NT ABSORPTION OIL

BT SORBENT

SA ABSORPTION

SA ABSORPTION PROCESS

SA GAS ABSORPTION

SA NATURAL GASOLINE PLANT

SA REGENERATION

ABSORBER

- NT (76..) STRIPPER

IIF ARSORRER SYSTFM

Page from the 5th Edition of the Exploration and Production ( $E \& P$ ) Thesaurus.

SA ABSORPTION SPECTROSCOPY

USE ABSORBER
Figure 2 .

ABSORBER SYSTEM

USE ABSORBER

ABSORPTION

- PHEMOMENON, MOT PROCESS

NT (76-.) GAS ABSORPTION

NT (67.-.) MMBIBITION

NT (76--) WAVE ABSORPTION

NT GASABSORPTION

NT IMBBBTTION

NT WAVE ABSORPTION

BT SORPTION

SA ABSORBENT

SA ABSORBER

SA ABSORPTION PROCESS

SA ADSORPTION

ABSORPTION COLUMN

ABSORPTION GASOLINE

USE MATURAL GASOLINE

ABSORPTION OIL

BT ABSORBENT

SORBENT

SA ABSORPTION PROCESS

\section{ABSORPTION PLANT}

- USED (65-66) GASOLINE PUANT(S)

USE MATURAL GASOLINE PLANT

ABSORPTION PROCESS

* NT (68.75) gaman raY ABSORPTION

NT (68.75) INFRARED ABSORPTION

NT IEAN OIL ABSORPTION

BT SORPTION PROCESS PHYSICAL SEPAPATION

SA ABSORBENT

SA ABSORBER

SA ABSORPTION

SA ABSORPTION OIL

SA GAS ABSORPTION

ABSORPTION SPECTROSCOPY

NT ATOMIC ABSORPTION SPECTROS

NT INFRARED SPECTROSCOPY

NT ULTRAVIOLET SPECTROSCOPY

BT SPECTRAL ANAL YSIS ANALYTICAL METHOD TESTING

SA ABSORPTION

SA EMISSION SPECTROSCOPY

SA INFRARED ABSORPTION

SA WAVE ABSORPTION

ABSTRACT

UF SUMMARY

SA INFORMATION RETRIEYAL SYST

\section{ABUNDANCE}

** ADOED JANUARY 1965.

SA AVALLABILITY

SA DISTRIBUTION

SA SHORTAGE

SA SURPLUS

ABYSSAL DFPOSIT

CATALYST

ICCELERATION

- BT (65.66) VELOCTTY

SA ACCELERATOR NT (76-) EDUCATION

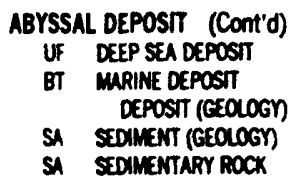

ABYSSAL ENVIRONMENT

- FOR LAKES, MDOX LAKE PLUS DEEP WATER

(70.75) WOEX NLSO AS DEPOSTIONUL EMMRONMENT,

(65-66) DEPOSTIONAL ENIRONMENT(S) BT (67.75) EMVIRONUENT

BT MARINE ENVIROAMENT DEPOSTIOAULL ENVIRONMENT ENIRONIENT

SA APHOTIC ZONE

SA BATHYAL ENYIRONMENT

SA COMPENSATION DEPTH

SA DEEP SEA

SA DEEP WATER

S4 NERTIC EMMIROMUENT

SA QUIET WATER ENVIRONMENT

SA SHALLW WATER ENVIRONMENT

ABYSSAL HILL

- NDOED SEPTEMBER 1970

USED (65-70) SUBMARINE

TOPOGRAPHY

BT (76--) SUBMURINE

TOPOGRAPHY

BT SUBMARINE TOPOGRAPHY UNDERWATER TOPOGRAPHY TOPOGRAPHY

SA ABYSSAL PUIN

SA SEAMOUNT

ABYSSAL PLAIN

- BT (65-66) SUBMURINE TOPOGRAPHY BT (67.75) PLAN

BT SUBMARINE TOPOGRAPHY UNDERWATER TOPOGRAPHY

SA ABYSSAL HILL

SA OCEAN BASIN

SA PUAIN

ABYSSAL SAMPLE

USE ABYSSAL DEPOST

CADEMIC

- ADOED MURCH 1967. USED (65-66) TRAINING PROGRAM(S).

UF UNIVERSIT

NT EDUCATION

SA THESIS

CADIAN OROGENY

"* BT (65.66) OROGENY

BT OROGENIC PERIOD OROGENY TECTONICS

SA ANTLER OROGENY

ICCELERATING AGENT

- USED (65-66) CATALYST(S) OR CEMENT ACCELERATOR(S) 


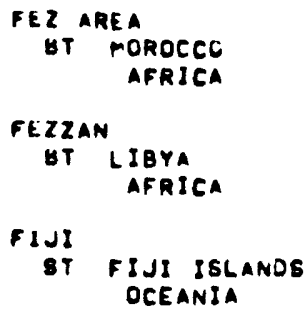

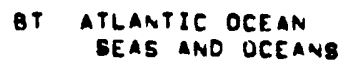

flatHeao valley

\section{Figure 3.}

Sample page from the 2nd Edition of the Geographic Thesaurus.
Bar

EXICO BULF

ATLANTIC OCEAN

SEAS AND OCEANS

UTTONMOOD SOUND

LORIDA KEYS

COAST

SE GULF COAST, FLORIOAD

MEXICO BULF, ATLANTIC COAST,

atLANTIC OCEAN. VAL:D 
CANSO STRAIT

CANTABRIA DDME

CANTAURE FM

CANTON OAS FIELO

CANTON TAOUOH

CANTUA CREEK OIL FIELO

cantua oIL FIELO

CANTWELL FM

CANYON EREEK FM

CANYON FM

CANYON BPRINO FM

CAP AL AIOLE FM

CAP AUX MEULE FM

CAP BLANE

CAP BRETON AREA

CAP DES ROSIEAR FM

CAP ENRABE FM

CAP LOPEZ FM

CAP MARTIN FM

CAPAKD FM

CAPE ARABO

CAPE BIOT FM

CAPE BOT

CAPE BOJADOR

CAPE CANAVERAL IREA

CAPE COVE FM

CAPE DISCOVERY FM

CAPE FLATTERY

CAPE FOLO BELY

CAPE GEORGE AREA

CAPE GR

TAPE MENLDPEN

CAPE MENAY AMEA

CAPE INGULATION LTO

CAPE LIMESTONE

cape LOOKOUT

CAPE MENODCINO

CADE DEREE ANTICLINE

CAPE PROVINCE

CAPE RISE

CAPE RODNEY FM

CAPE BAN MARTIN QUAORANOLE

CAPE BCHUCHERT FM

CAPE BTORM FAULT

CAPE BTORM FM

CAPE GUBMaRINE CANYDN

CAPE VERDE PLATEAU

CAPE YDOEL OA

CAPE YDRK PENINBULA

CAPEL CURIG FH

CAPETI ANTICLINE

CAPITOLA PARK OIL FIELO

CAPPANANA BEDE

CAPRICORN REEF COMPLEX

CAPRDATE

CAPROATE, OODECYLAMMONIUM-

CAPROLACTAM

USE HEXAHYORO=2H-AZEPIN=2DONE

CAPRYLATE

captaing Flat FM

CARABA FM

CAMADOCIAN EERIE

CaManda OIL FIELO

CARAPACHA FM

CARATAS FM

CARBAMATE, DIMETHYLOITHIO-

CARBAZIE ACID

canela oolite

CARBOL: AMEA

CAMBON LUBOXIOE

CARBONATE OIAOENEBIS

carbone lorraine oa

CAROONERA FM

CARBONIBATION CHARBONE ACT

CARDONISATION
CARBORUNDUM CO

CARBORUNDUA CO

CARBOXYLIC ACIO. AMINO=

CAREOXYLIC ACIO. HYOROXY

CAREDXYLIC ACIOD NIPAOE

- CARBoXYNaPHTHALENE。 DIHYOROXYE

CARDiFF GHALE

CAROINAL CHEMICAL INC

CAROINAL PEYROLEUM CD

CARENTON BABIN

CAREY DOLOMITE

CAREY MACHINE 8 SUPPLY CO

CARBo MUCHACHO MT

CARIACO OULF

CARIAOUITO FM

CARIBBEAN ORDBENY

CARIBOO OR

CARIBOO OR

CARLIN CANYON FM

CARLSBAO BOUTH BAB FIELD

CARLSBERO RIDOE

CARMEL SAY

CARMEL SUBMARINE CANYON

CAMMEN FM

CARMET CO
CARMILA DED

CARNEDD IAOO FM

CAANEGIE INET WAEHINOTON

CARNEGIE AIOBE

CARNIAN DERIE

CAROLINE AIOOE

CARONI LLAIN

CARONI OYNCLINE

GAROTENOIO

CAMPA OIL FIELO

CARPINTERIA OIL FIELO

CARAETO FM

CARRIACOU FM

CARAIACOU IOLANO

CARRIER CORP

CARRIOEEN FM

CARPIOHILL FM

Canter caves gaNDETDNE

canter (J e) Co

CARTERVILLE FM

CanTY oANOETONE

CARUPANO AREA

CARUPANO FM

CaRupano oEa Valley

eanvajal Fm

canvea L Co (ENO) LTO

CARWELL CAEEK DEOS

CARHOOLA DESE

CABA BLANCA OIL FIELD

CAEA OIABLO OEOTHERMAL FLO

CABA ORANDE FM

cABABE OIL FIELO

CABAL DA BOMBAROA ANTICLN

CABAL DO AMAMO gYNCLINE

CABAPALEA FM

CABCADE PACIFIC RIM CO INE

CABEIN

caser io fl co

CABHEW KABUEHIKI KatBHA

CASPER MT

CABgELLA FARBWERKE MAIN AO

CABO INABCD EM

CASTELLANIA FM

CABTILLETES FM

CABTLE CRABE FM

CABTLE HARBOR

CASTLE HILL OUTLIER

CABTLE HILL OUTL

CADTL MUIR PM

CABTLE REEF OOLOMITE

CaOrLe Riven ANTICLINE

cabtlegate Ganostone

CABTLEMAINIAN BERIEB

CABTLEPOINT FM

CABUPE FM

CAT I BLANO

cata SEP INE

catal tepe olequence

catal ana oas Electric sa

catalina islano

CATALONIA BAEIN

CATALONIDE MT

catamaran Fault

CATANZARD AREA

catatume FM

CaTERPILLAR TRACTOR co

CATHEDRAL ELIFFs FM

CATHEOAAL CRAOS ANYICLINE

cathode maY TUBE

CATLINS OA

catoche FM

catoche tonaue

CATRELEO GRANITE

CAUBERRY BAEIN

CAUCABUE MT AREA

caur FM

CAUBEY OAM OUADRANOLE

CAUETIC MATERFLOOOINO

CAUX AREa

Cavalient in el DITTa

CAVE MT ANTICLINE

cave canostone

CAY DAL DANK

CAYMAN IBLAYO

caro chico oE moA

CAYO COCD FM

CAZAUX OIL FIELO

CEAB DOMINIT AB

CEARA ABYBEAL PLAIN

CEARA DASIN

Figure 4.

Typical listings contained in the List of Supplemental Descriptors.
CELAOA FM

CELANEOE CORA

CELEBES

CELENOIN FM

CELL IETRUCTUAALI

celmae olaclito lto

CEMENT MARKETING CO LTO

CEMENT OIL FIELO

CENE FM

CENBURE OR

CENT PHILIPDINE RSN FAULT

CENTENNIAL RIOBE FAULT

CENTERFIELO FM

CENTINELA FM

CENTRAHOMA OIL FIELO

CENTRAL BAEIN AREA

CENTAAL GEOPHYBICS LTD

EENTRAL GRABEN

CENTAAL MISSISEIPA! UPLIFT

CENTRAL PACIFIC RASIN

CENTRAL Ranoe antICLINE

CENTRAL SICILY BISIN

CENTRAL SOMEREET BAEIN

CENTRAL SUMATRA AABIN

CENTAALIA OIL EIFLO

CENTRE OEOL MARINE CAEN

CENTRE NATL EXPLOIT DCEANA

CENTRE RECH ETUD OCEANOGR

CENTAE RECH MEC HYORO FROT

- centre stephanots de RECHERCHEB MECANIOUE HYDROMFCANIOUE 5 FROTTEMENT

CENTRE RECH GEDIMENTOL MAE

CENTRO OPERI MEYALL BPA

CEPHALONIA ISLAND

CEPHALOPOD SHALEB

CEREAL

CEREBAO OYNAMICS INC

CERITHIUM LIMETTONE

CERIUM BORIDE

CERMAT

CEARO ALTO LIMESTONE

CERRD BLANCO FM

CERRO BORORO

CERAO BORORO FM

CERAO BREA FM

CERRO CARNERERO FM

CERRO CARRIZALITO BR

CERRO COLORADO QR

EERRD DRABON OIL FIELO

CERRO FM

CERAD FORTIN FM

CEARO OORDO CO. IOWA

CERRO JHU BANDOTONE

CEARO LUPIN FM

CERRO MORADO EM

CERRO PENA NEVADA

CERRD POZO SERNA

CERAO ROSILLO FM

CERMOE AZULEB FM

CERVANTEB FM

CEAVAROLA OA

CEBCD BA

CEBIUM CARBONATE

CEOSOLE FM

CETYL PYRIOINIUM BROMIOE

CETYL PYRIOINIUM CHLORIDE

CEUTA OAS FIELD

CEVENNES GABTA

CEVENNE: FAULT

CEZE OAOIN

CHACAHOULA Bal T

chacar on

ehaco

CHACO DENIANA BABIN

CHACD D

CHAORON ARCH

CHADOE FRACTURE TONE

CHAOOS LACCAOIVE RIDOE

CHAORES SANDETONE

Chaidar basin

CHAIN EIT

CHAIN DIDEE

CHALCANA FM

CHALCOCITE

CHALOON HERAINO ANTICLINE

CHALEUR TROUBH

CHALK FM

CHALKY IOLAND FM

TEAV

ITEAL
IICE

TELO

:ONE

eERT LTD

- AULT 
EVENT

EVENT

EVENT

EVENT

EVENT

EVERDINGEN

EVOLUTION

EVDLUTION

EVOLUTION

EVOLUTION

EXAMINATION

EXAMPLE

EXCAVATING

EXEAVATION

EXCAVAIION

EXCHANGE

EXCHANGE

EXCHANGE

EXCHANGER

EXHAUS I

EXINE

EXPANDDED

EXPANDER

EXPANDING

EXPANSIBLE

EXPANS ION

EXPANSION

EXPANSION

EXPANSION

EXPANS ION

EXPEDI I NG

EXPENDABLE

EXPENDABLE

EXPER IMENT

EXPERIMENT

EXPERIMENTAL

EXPLODER

EXPLODER

EXPLORATION

EXPLDRATION

EXPLORATION

EXPLORATION

EXPLORATION

EXPLORATION

EXPLORATION

EXPLORATION

EXPLORATION

EXPLORATION

EXPLORATION

EXPLORATION

EXPLORATION

EXPLORATION

EXPLORATION

*SCHOONER EVENT

SEISYIC EVENT

* SHOAL EVENT

STEEP DIP EVENT

*STERLING EVENT

HURST VAN EVERDINGEN EQUAT

CONTINENTAL EVOLUIION

EVOLUTIOY

EVOLJTIOV (URGANIC)

EVOLJTIOY THEORY

EXAMINATION

EXAMPLE

EXCAVATINO

PI (EXEAVAIION)

SHAET (EXCAVATION)

FOREIGN EXCHANGE

ION EXCHANGE

ION EXCHANGE RESIN

HEAT EXCHANGER

EXHAUST GAS

EXINE

EXPANDED PERLITE

EXPANDER

EXPANDINO CEMENT

EXPANSIBLE

EXPAVSION

EXPAVSIOY JOINT

EXPAVSION RATE

POWER SER IES EXPANSION

THERMAL EXPANSION

EXPEDITIVO

EXPENDABLE

EXPENDABLE RERFORATOR

EXPERIMENT

STRUCTURAL EXPERIMENT

EXPERIMENIAL DATA

GAS EXPLODEK

WIRE EXPLODER

AEROMAGNEIIC EXPLURATION

PIBECT CURRENT EXPLORATION

ELECTRICAL EXPLORATION

ELECTRICAL EXPLORATION EO

ELECTROMAGNETIC EXPLORATN

ELECTROMAGNETIC EXPLR EO

EXPLORATION

EXPLORATION COST

EXPLORATION EVALUATION MAP

EXPLORATIUN RESEARCH

GEOBDTANICAL EXPLORATION

GEOCHEMI EAL EXPLDRATION

GEOLDGIC EXPLORATION

GEOPHYSICAL EXPLORATION

GEOTHERMAL EXPL EQUIPMENT

Figure 5.

Sample from the Key Word Out of Context (KWOC) Descriptor List. 
current technology, and for browsing. This Index brings together, under a single subject heading, titles of articles and patents whose abstracts have appeared in the weekly bulletin, Petroleum Abstracts. The ASI is photocomposed from processing tapes and is printed and distributed bi-monthly, with the first issue being a hard-bound, 12 months' cumulative index. Three appendices contain bibliographic information (arranged numerically by abstract number), an alphabetic listing of authors, and a patent index (arranged sequentially by patent or application number, under each individual country).

Basically, the Alphabetic Subject Index is a listing of the titles of documents (both articles and patents) under two to six pertinent descriptors. One of these considered as being most descriptive of the document involved (or the major geographic location of the report), is designated as the Primary Descriptor. Additional cross-reference listings under Secondary Descriptors aid in retrieving desired information.

The format for Primary and Secondary Descriptor listings differs. In addition to the title and abstract number, a list of selected descriptors is printed under the Primary entry, following the title. This list of descriptors shows the subject matter of the document and serves as a miniature abstract. Asterisks indicate secondary descriptors, which appear elsewhere in the Index as cross-referenced listings. Remaining descriptors in the list do not appear individually, but are cited for information only. Typical entries in the Alphabetic Subject Index are shown in Figure 6.

\section{Dual Dictionary Coordinate Index}

The original concept for the Dual Dictionary (DD) Coordinate Index was the issuance each year of two printed copies at 4-month intervals, cumulative at 8 and 12 months. Presently, the Dual Dictionary is distributed on 16-mm. microfilm in July and December, the year-end issue being cumulative for the year. The Index also is available on microfiche, at the Subscriber's choice.

Two copies of the DD constitute the Dual Dictionary concept. Each copy contains an alphabetical listing of all descriptors used in indexing the information contained in the articles for which abstracts are published in Petroleum Abstracts. The abstract numbers are arranged by terminal digit in order to facilitate coordination. Each abstract number is 1 isted under every descriptor that was assigned by the indexer or that was generated from the $E$ \& $P$ Thesaurus hierarchies by computer processing. With the present microfilm or microfiche format, work paper copies of the pertinent DD page entries may be made with a reader-printer, to facilitate coordination. A sample page from a printed copy of the DD is shown in Figure 7 .

Master Record Tapes

When complex, deep, and long time span searches are needed, computer searching becomes feasible and economic. For this purpose, computer search tapes, called Master Record Tapes, are issued every four months. These tapes are organized sequentially by abstract number and contain all descriptors assigned or generated (by autoposting from E \& P Thesaurus hierarchies) for each article concerned. 


\section{ALPHABETIC SUBJECT INDEX}

SAFETY VALVE

MEANS FOR PREVENTING DAMAGE TO JACKETED FLEXIBLE PUMPING STRAND

"CABLE

*SHEATHING

ACTIVATION

.EXTERNAL COATING

PROTECTION

*PRESSURE SURGE

DENSITY

LIQUID

PRESSURIZED TANK

RESSURE ACTUATED SAFETY VALVE

ACTVATION

PRODUCIMG SURGE

PRODUCING

SAFETY EQUIPMENT

MOUNTING* RETRACTABLE LANDING SHOULDER FOR DOWNHOLE DEVICES

SAPAN ISLAND

MARIANA ISLANDS* LARGER FORAMINIFERA FROM THE ISLANDS OF SAIPAN AND GUAM, MICRONESIA

SAKHALIN ISIAMD

JAPAN SEA*RESULTS OF GRAVIMETRIC INVESTIGATIONS IN THE SOUTH PART OF THE WEST SAKHALIN SHELF

SALT CAVERN

EXPERIENCES GAINED IN THE CREATION AND OPERATION OF CAVERNS IN SALT DOMES WITH A LARGE CONTENT OF IMPURITIES

- CRUDe oIl STORAGe

*UNDERGROUND STOR FACILITY ELUTION

* SALT DOME

CAVITY

GERMANY

IMPURITY

ROCK MECHANICS

IN SITU INVESTIGATIONS OF FRACTURING IN SALT CAVITIES FOR DETER MINING STRESS COMPONENTS

FRACTURING "ROCK FaILURE

*SALT DOME

FIELD TESTING

IN SITU

FRACTURING PRESSURE

.ROCK STRESS

DERGROUND STORAGE OF LIQUID AND GASEOUS

HYDROCARBONS WITH SPECIAL CONSIDERATION TO PUBLIC

SAFETY, REGIOI

*CRUDE OIL STORAGE

GAS STORAGE

UNDERGROUND STOR FACILITY

PLANNING

ENVIRON IMPACT STATEMENT

REGULATION

SAFETY

UNDERGRO

THE STOR FACILITY* ORIGINAL OBSER VATIONS ON

THE MECHANICAL BEHAVIOR OF LEACHED CAVITIES IN THE EARTH AND NEW PROCEDURE FOR REHEATING FUEL STORAGE CAVERNS

\section{Typical AUTHOR INDEX Entries}

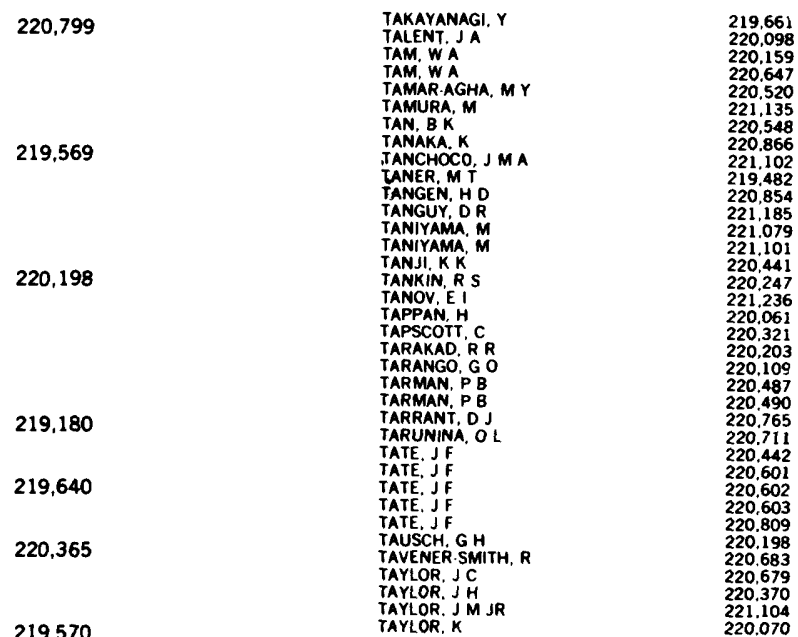

219,571

\section{Typical PATENT INDEX Entries}

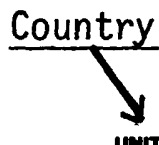

219,573

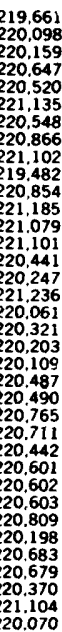

219,572

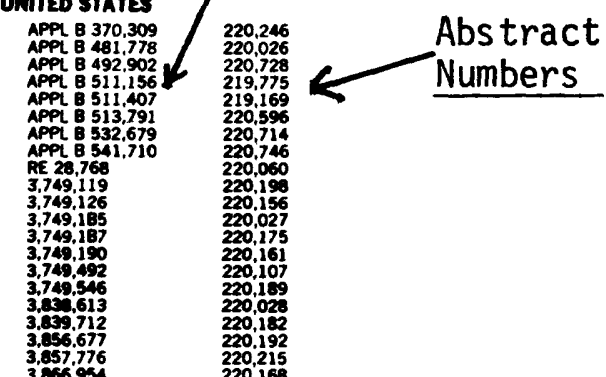

Bibliographic Information Listings

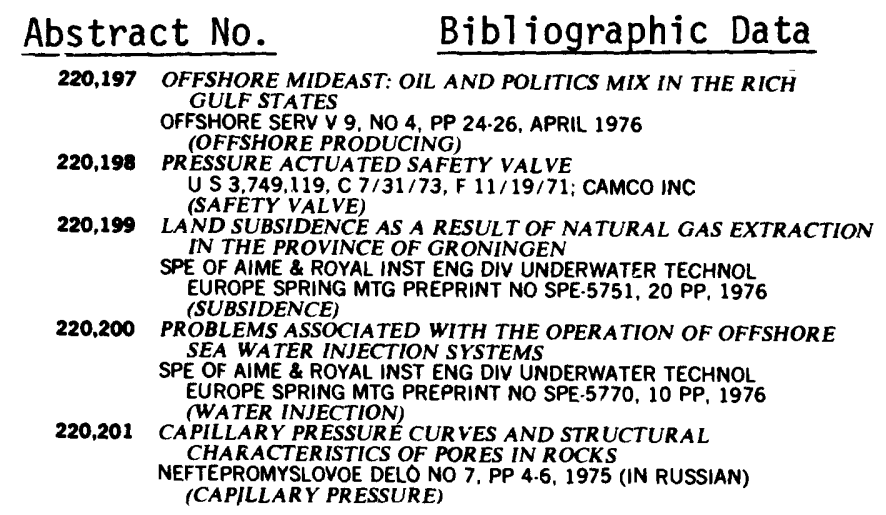

Figure 6.

Typical entries from the Alphabetic Subject Index (ASI). 
ABSORPTION OIL

ABSORPTION PROCESS (so)

ABSORPTION SPECTROSCOPY 1691

ABSTRACT

ABU DHABI

$(14)$

a UundaneE

(76)

MBYSSAL DEPOSIT

ABYSSAL ENVIRONMENT |s|

aerssal plain

1341

aCACUS SAMDSTONE

ACAOENIC

ACAOIAN DROGENY

(7)

ACCELERATION

(22)

ACCELERATOR

|4)

ACCELEROMETER

(16)

ACCIDENT

(53)

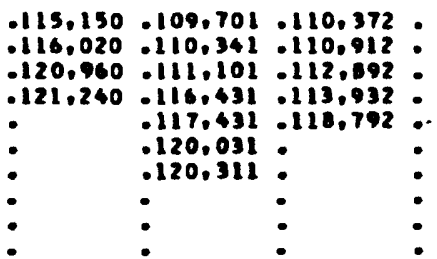
$.112 .300 .107 .631 .111 .102: 110,733: 117.234$ $.116,400.109,041 .-114,492.114,813$.

$.120,310-109.701-117.282$ 115.573 $\because \quad+110,241.120,562,119,703:$ 115.571 . 116.101. .116 .821 . .119 .181$. .119 .861

$\because 121.221:$

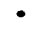

-

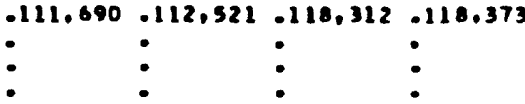

$.108,664 \cdot 117,775$

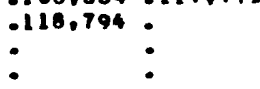

$.107 .590 \cdot 111.061 \cdot 106.422 \cdot 109,223.106,644.107 .605$

$.109,550.112,711.106,882,109,473.107,114.106,115$

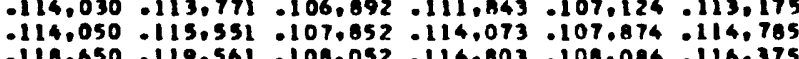

$.118,650.119,561.108,052,114,803.108,084.116,375$

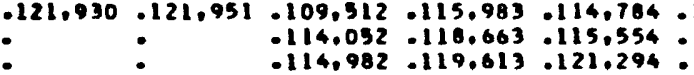

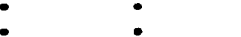

$\quad-115,812$

$\because \quad: 119,852:$

$.111 .840 .117,771 . \quad .117 .064$.

: $\quad:$

.119 .870

$\because \quad: 117,064:$

.120 .396$.

.121 .098

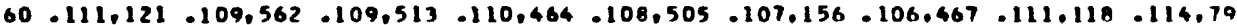

$.108,460.115,911.119,862.119,823.110,524.117,305.108,716.117,597.119,149.116,759$

$.111 .120 .117 .331 .121 .142 .120,003$

$116,130 \cdot 117,771$

117.350 .119 .581 .

.116 .450 .

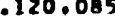

113.496

$.113,510 \cdot 110,601 \cdot 115,042$

.$\quad 110.821 .118 .532$

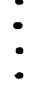

$.120,396$

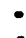

-

.

$.116,786$

.113 .696

.108 .954 .108 .985

.108 .964$.
.109 .014$.
.121 .098 .117 .339

:

.116 .769

.106 .389

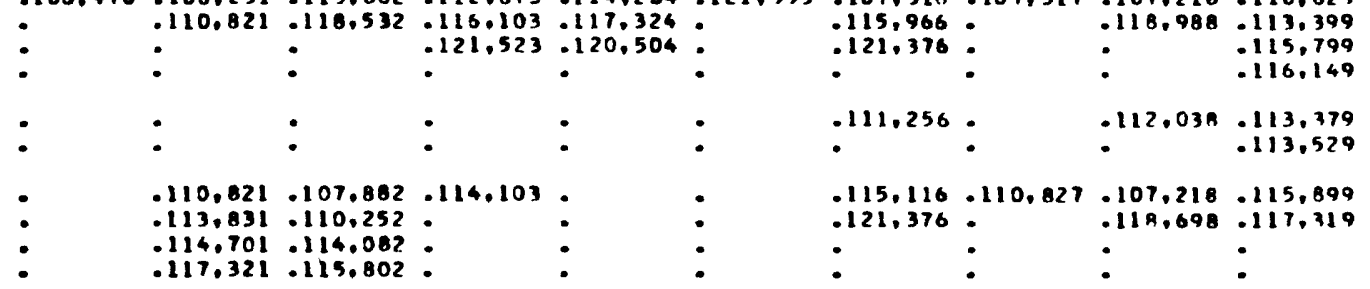

$108,040 \cdot 107,791 \cdot 107,772 \cdot 107,773 \cdot 107,024 \cdot 109,685 \cdot 111,996,112,607.0108,788,0107,039$

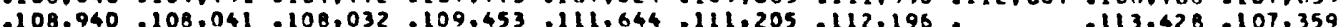

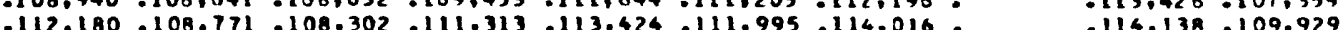

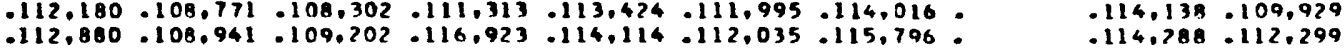
$.115,060.112,881.111,652.117,743.115,294.115,375.115,976: 0.113,399$

Figure 7.

ACCIOENT GAS FIELO

Example of format of the Dual Dictionary (DD) Coordinate Index. 
The tape can be searched sequentially with available computer programs. It is issued in several formats to match the requirements of the Subscriber's specific computer. Some search systems are available on local or national/international retrieval systems (to be described in a following section).

\section{Card Files}

At the outset of operation, the information retrieval aspect of the Petroleum Abstracts Information System was based on an abstract card file. Abstracts were printed on card stock for this purpose and contained Classification numbers. In addition to the classification file, cards were prepared for author files and for patent files. The classification card file no longer is active but the other two are current. At present, specially prepared abstract cards are used for this purpose. An accession number card file is maintained for quick access to abstracts.

Classification Retrieval System - During its first four years of operation, the Petroleum Abstracts Information System utilized an extensive classification coding system for information retrieval. Under that system, each abstract was assigned a series of code numbers based on 1200 classifications of information pertaining to petroleum exploration and production technology. From two to as many as seven such classification numbers were assigned to and printed on each abstract entry in the Petroleum Abstracts bulletin. At that time, the printing format was four abstracts per page and each page also was printed on card stock and the cards filed by classification number and by author name. An example of the Subject Classification System and an abstract card are shown in Figure 8.

Author File - For purposes of retrieving information based on author names and for checking against previously published articles or abstracts, a card file of authors is maintained. Abstract cards are used for this purpose.

Accession Number File - Since January, 1965 (beginning with abstract number 50,000) an abstract card accession number file has been maintained. This file provides quick access to any numbered abstract and facilitates easy reproduction of abstracts when needed.

Patent File - A patent file (of abstract cards) is maintained for retrieval purposes and for checking for related patents. The file is separated by country and contains both patent number and priority date listings.

\section{Related Patent Index}

An index of related patents is issued each six months and is cumulative from January 1, 1973. Prior to January 1, 1973, related patents were indicated by reissue of the original abstract card showing the related patent data. After January 1, 1973, no abstract cards have been distributed to subscribers, as had been done as part of the services since 1961.

The Related Patent Index is a list of each related patent processed since January 1, 1973. The index is ordered by the primary patent abstract number 

above rock types) stratigraphic unit)

$155.3,115,184.2,506.142,513.25,514.21,701$

THE UNDERGROUND STORAGE OF GAS - M. Perraud; 2ND U. N. DEVEL. PETR. RESOURCES, ASIA \& FAR EAST SYMP. (Tehran, Iran, 9/1-15/62) PROC. v.2, PP 66-73, 1963 (Recd. Dec. 1964)

The realization and utilization of underground storage at Lussagnet provided an underground storage in the vicinity of the Lacq $g$ as plant with an adequate reserve capacity. Underground storage had the advantage of greater reliability: a serious stoppage at the plant or field could result in a complete, if temporary, operational shutdown, whereas underground storage at a distance from Lacq would not run this risk. This Lussagnet structure is made up of a rather large anticline. The reservoir is a sandy horizon, ending in a relatively shallow depth and of good tightness due to a thick layer of impermeable marls. These characteristics seemed to meet with the requirements. Conceived and realized by a team of company engineer $s$ including specialists in geology, drilling, machinery and gas transport, this storage proved most useful in the exploitation of the Lacq deposits because of the following: (1) By its easy and secure functioning, and also by its great working flexibility, allowing a conveniently rapid change of flow; and (2) by guaranteeing supplies in any event, 80 as to play the part of regulator between the transport networks and the refining plant.

Figure 8 .

Illustrations of typical entries in the Subject Classification System and an abstract card showing use of the System. 
to which the patent is related and contains, as well, the related patent abstract number with its country of issue and patent number.

An abstract card with related patent information and a sample page from the Related Patent Index are shown in Figure 9.

\section{Computer Hardware and Processing}

The computer presently in use by the Information Services Division is a Xerox Sigma 6, which is housed at the University's Computer Center. All computer programs for processing and handling in the System are written in Fortran IV with a number of important assembly language subroutines. Thirty-plus programs are needed for all computer processing in the System.

\section{PETROLEUM ABSTRACTS SEARCH SYSTEM}

The Petroleum Abstracts Search System (PASS) is a coordinated set of computer routines that provides the user with a comprehensive literature search capability. Operating on-line from a remote terminal, a searcher can structure a search, review the results, and restructure as necessary to obtain whatever amount of generality or specificity is desired. Functions are available to allow display of results on the terminal and to print the final search results on the Computer Center line printer.

The search program is supported by two major information bases: (1) an inverted search file of descriptors that 1 ists all abstract numbers to which each descriptor has been assigned; and (2) the item files containing titles, bibliographic citations, and author names. Physical files in each class are stored on separate disc-packs for literature and for patents. These files are updated monthly.

PASS makes use of a Boolean search technique, based on logical combinations of logical operators. These operators are AND, OR, and NOT which may be combined with descriptors in three types of associations:

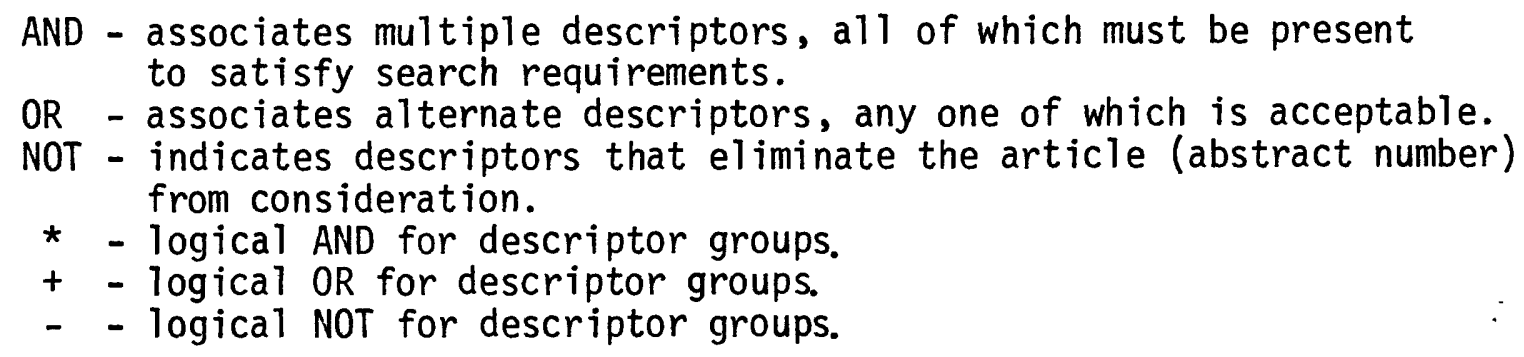
to satisfy search requirements.

$O R$ - associates alternate descriptors, any one of which is acceptable.

NOT - indicates descriptors that eliminate the article (abstract number) from consideration.

* - logical AND for descriptor groups.

+ - logical OR for descriptor groups.

- logical NOT for descriptor groups.

In tabular form, the above translates to:

\begin{tabular}{lll} 
Function & $\begin{array}{l}\text { Singly or } \\
\text { Within a Group }\end{array}$ & Between Groups \\
\cline { 2 - 3 } & & \\
Intersection & AND & $\star$ \\
Union & OR & + \\
Negative & NOT & -
\end{tabular}




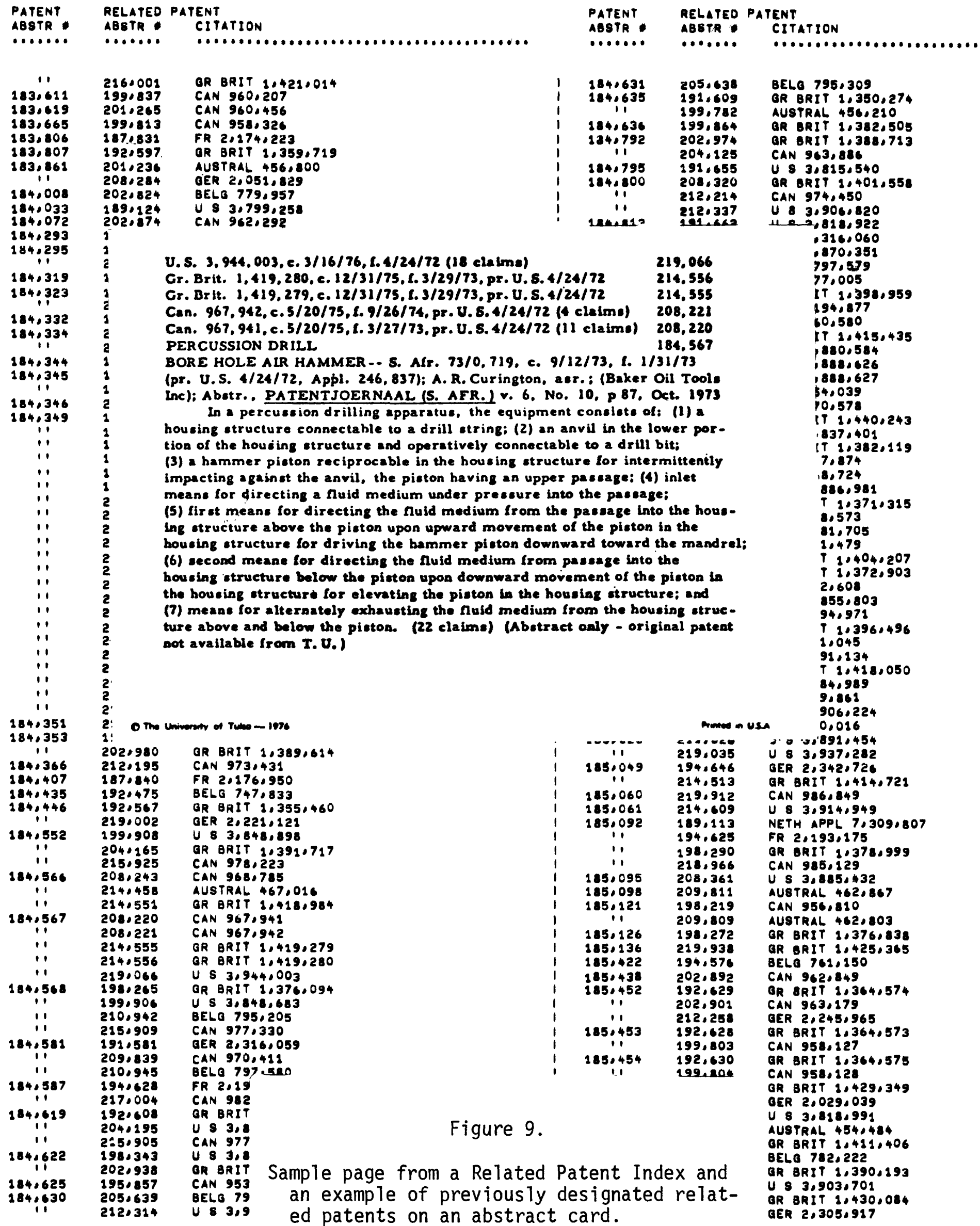


A PASS search structure can be as simple as a search on one descriptor, or as complex as is required. The number of descriptors that can be combined in one group is limited by the disc file space available. A maximum of 9 groups can be used in a given search.

Figure 10 illustrates a literature search for articles, in languages other than Russian, concerned with computer processing of paleontologic and stratigraphic data. The search strategy for this question is (COMPUTER or COMPUTER PROGRAMING) and (PALEONTOLOGY or STRATIGRAPHY and GEOLOGIC DATA PROCESSING not RUSSIAN).

\title{
ORBIT III SEARCH SYSTEM
}

Through an arrangement with System Development Corporation (SDC) the Orbit III Search System adds a new facet to the Petroleum Abstracts Information System. The information base of the Petroleum Abstracts System (1 iterature and patents) now can be accessed through SDC's Search Service Orbit III Search System (file TULSA).

The Orbit III Search System is an extensive and easily used information retrieval program that has been in operation daily since 1970. The program allows the searcher to specify his information needs by a logical combination of descriptors and of substantive keywords from the titles. Searches also can be made on specified author names. An interactive system, ORBIT III provides capability for progressively refining the statement of a search request to quickly and easily identify the item of primary interest. The TULSA file is updated quarterly.

Search results can be printed on the user's terminal or they can be directed to a high speed, off-line printer. Off-line reports are delivered by airmail from System Development Corporation's offices in Santa Monica, California.

ORBIT III is accessed through a worldwide communications network (Tymshare) that provides local telephone access to minicomputers in major U. S. population centers as well as selected cities in Canada and Europe. The System also may be used directly through WATS lines or by direct distance dialing.

The Orbit III Search System provides access to many other information files, some selected examples of which are as follows:

\author{
American Petroleum Institute (APILIT/APIPAT) \\ American Chemical Society (CHEMCON) \\ American Geological Institute (GEOREF) \\ Smithsonian Scientific Information Exchange (SSIE) \\ National Technical Information Service (NTIS)
}

The cost of searching the Petroleum Abstracts information base is structured upon an hourly charge for use of the file, an hourly charge for the communications network (optional), and a charge per reference for off-line printing. The actual rates vary; SDC search service customers and Petroleum Abstracts Information System subscribers are given preferential rates. No minimum charges or startup fees are imposed. Specific rates may be obtained from System Development Corporation or from the Information Services Division at The University of Tulsa.

Figure 11 illustrates a literature search (for the time period 1975) for articles concerned with the use of computers in geology excluding paleontology. 
! F'ASS

F. A $S$ S VEFSION 6 - -

FLEASE ENTER YOUR OFEFATOF IIIFIOYG

ENTEF FILE NAME: :TUL.IT

DPENING FILE

COMMANLIFR

ENTEF FIFST DESCRIFTOF

- COMFUTEF

SEARCHING

FNII- $\quad 3264$

ENTEF OFEF + + DIESCFIF .

:OF COMFUTEF FROGFAMING

SEAFICHING

$F N D=3463 \quad$ GFF $=5129 \quad 1$

ENTEF OFEF + + DESCFIF.

:*

ENTEF FIFST IIESCRIFTOF

- FALEONTOLOGY

SEAFICHING

FNII- $\quad 8172$

ENTER OFEF + IIESCFIF' :OF STFATIGFIAFHY

SEARCHING

$F N I=17650 \quad$ GRF $=19054 \quad 2$

ENTEF OFEF + + DESCFIF" .

:ANI GEOLOGIC IIATA FROCESSING

SEARCHING

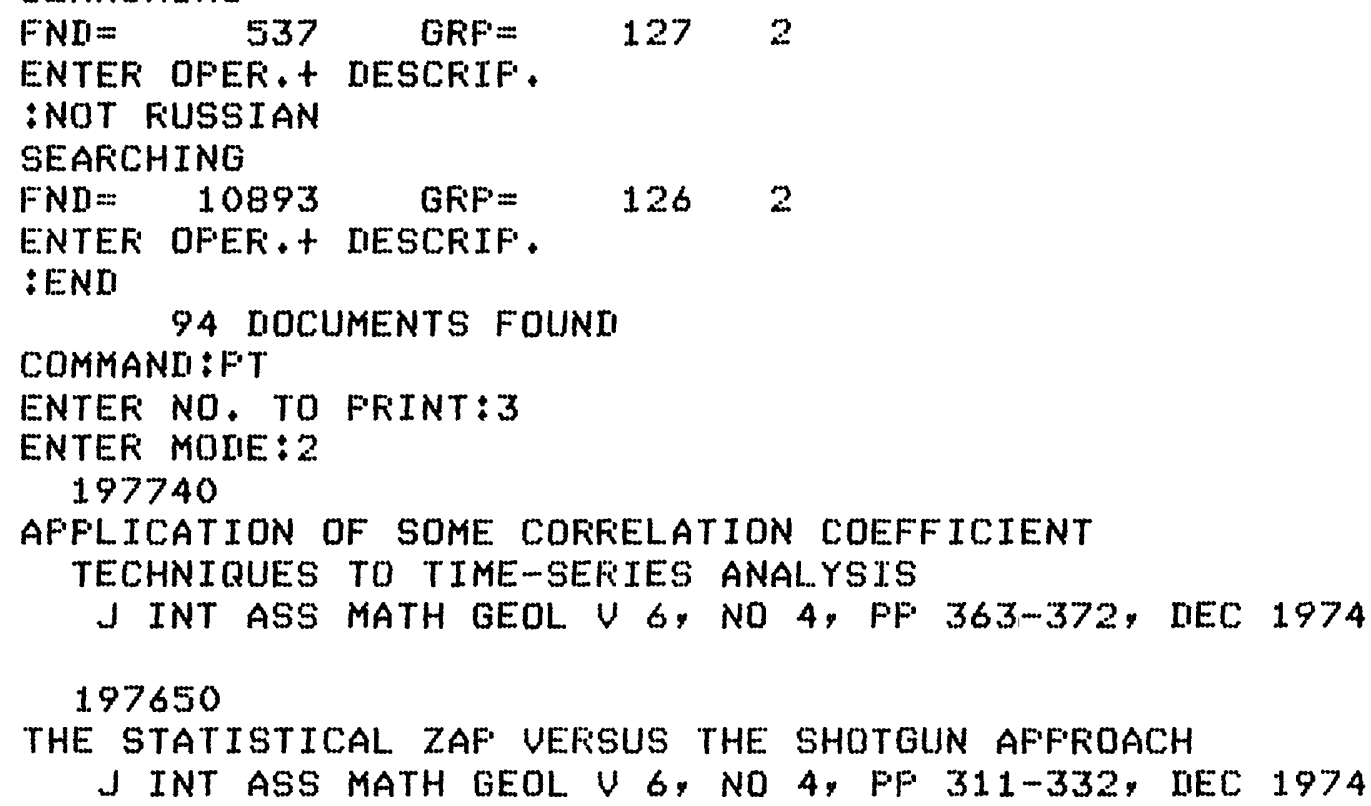

194279

A BIBLIOGFAFHY OF THE FAMILY FUSULINIUAE: AIIIENIUM 9

$J$ FALEONTOL $U$ 48, NO 4, FF 833-839, JULY 1974

COMMANI:TM

ENII OF SESSION

! OFF

Figure 10.

Example of Computer terminal printout from a Petroleum Abstracts Search System (PASS) search. 


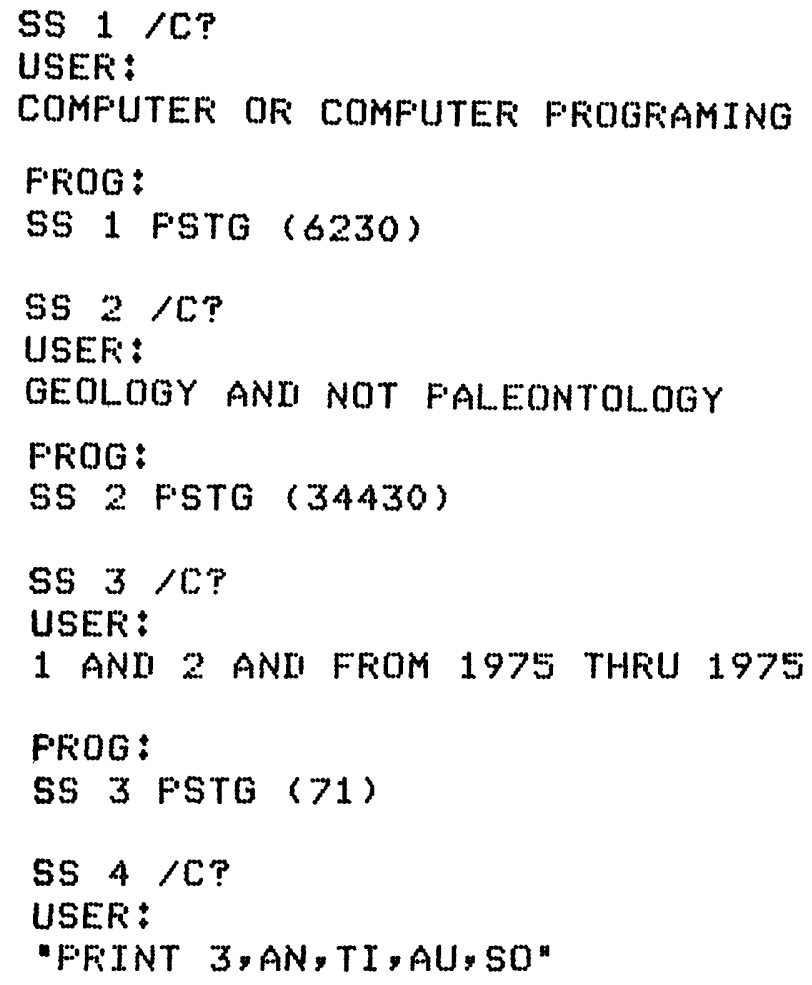

FROG:

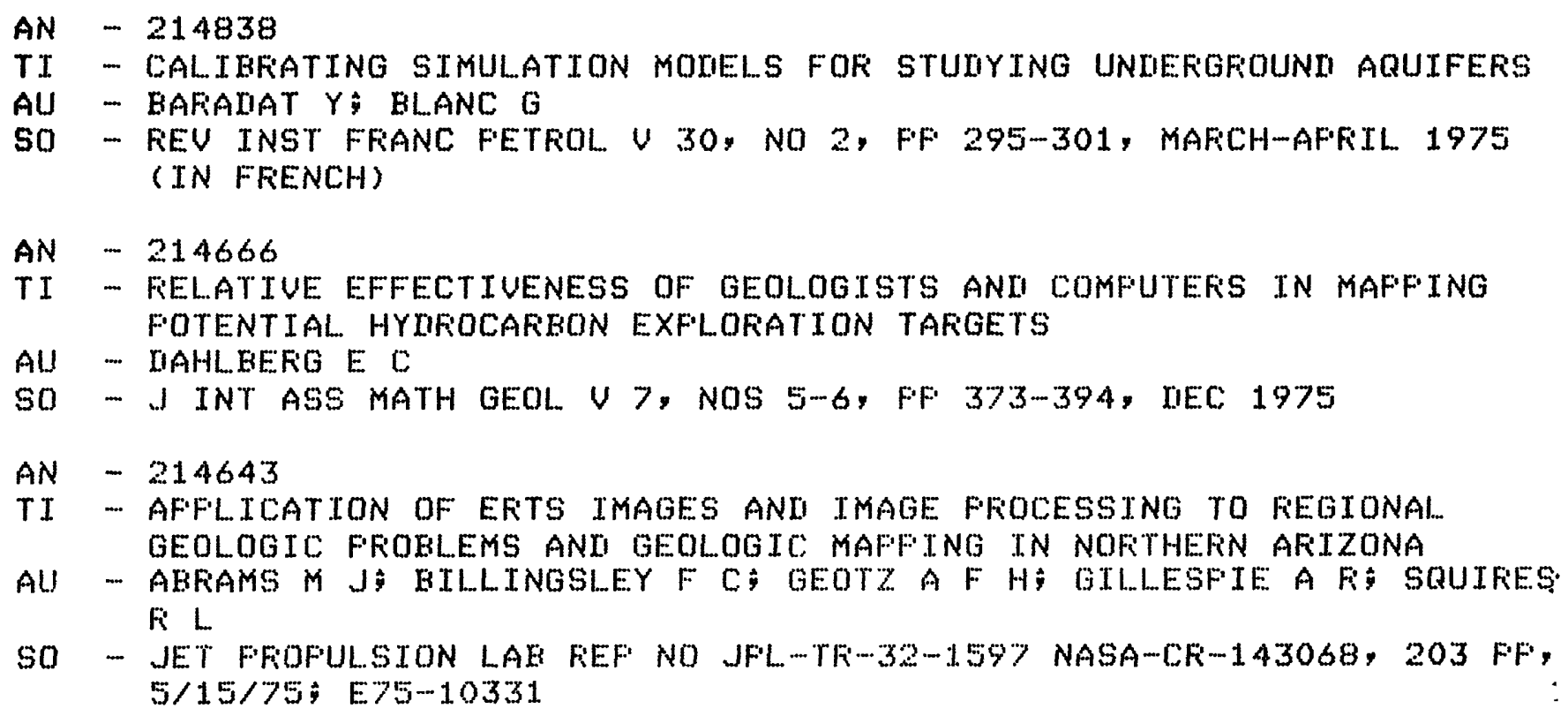

Figure 11.

Illustration of an Orbit III search. 
The search strategy for this operation is (COMPUTER or COMPUTER PROGRAMING) AND (GEOLOGY not PALEONTOLOGY) AND FOR 1975 THRU 1975.

SYSTEM EXPANSION CAPABILITIES

Because of the nature of the literature and patent base of the Petroleum Abstracts Information System, capability exists for rapid expansion into other mineral and/or energy fields. Proposals have been made over a period of the past few years to expand the services into specific areas of Economic Minerals and into limited areas of Nonconventional Energy Resources. The capabilities continue to exist even though the formal proposals met with negative results. Expert personnel and experience are available in these and other areas of interest. 


\section{Exploration and Production THESAURUS}

PETROLEUM ABSTRACTS

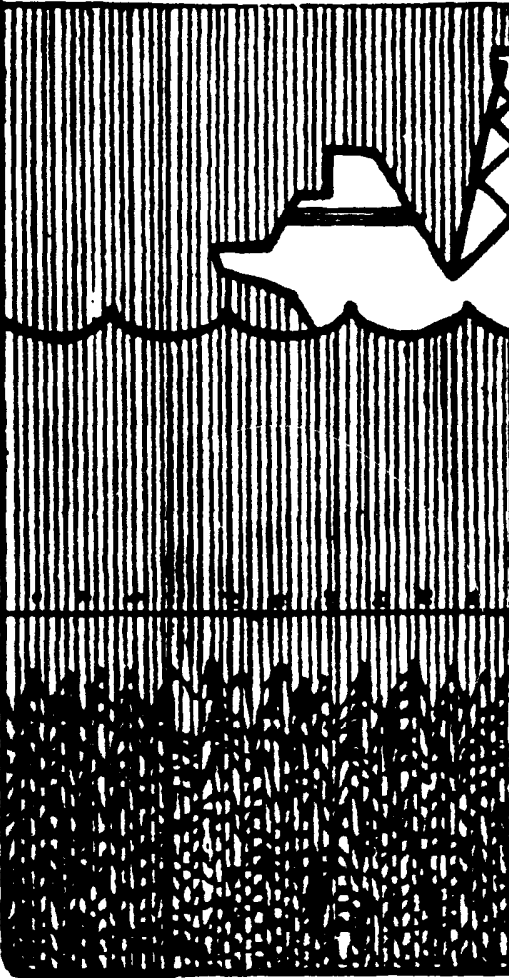

\section{5th EDITION JANUARY, 1976}

THE UNIVERSITY OF TULSA

Information Services Division

1133 Morth Lewis Avenwe

Tulsa, OkJahome 74110

Copyright $? 1976$ by The University of Tulsa 


\section{TABLE OF CONTENTS}

$E \& P$ Thesaurus Description ............ $V$

$E \&$ \&hesaurus .................. 1

Hierarchy . . . . . . . . . . . . . 286

Hierarchy Index ................ . . 306

Supplementary Descriptors . . . . . . . . . IA

Chemicals ............... 25A

Companies....................... 33A

Engineering Supplemental Descriptors. ....... 50A

\section{Nondiscrimination}

The University of Tulsa employs. advances, admits and treats in its employment and educational programs. all persons without regard to their race, color, national or ethnic origin, sex. age, religion, handicap. or status as a veteran. 


\section{E \& P THESAURUS DESCRIPTION}

\section{INTRODUCTION}

The Exploration and Production (E \& P) Thesaurus covers the subject aress of geology: geochemistry; geophysics; drilling; well logging; well completion \& servicing; production of oil \& gas; reservoir engineering \& recovery methods; pipelining, shipping \& storage; ecology \& pollution; attemate fuets \& energy sources; and supplemental technology (automation, economics, corrosion, instrumentation, etc.). The first edition of the E \& P Theseurus (1965) wes compiled in a format similar to that used by E.J.C. in its "Theasaurus of Engineering Terms." All subeequent editions of the Thesaurus, including this fifth edition, are similar in format to the first edition; howover, the philosophy used in building hierarchies is different. In developing the hiorarchical relationships of the first edition, discipline-oriented principles were used; wheress the later editions are based on concept-oriented (faceted) principles. A complete outline of the hierarchy, and an alphabetic index to the hierarchy are included at the end of the main Thesaurus.

\section{DEFINTION}

Thesaurus, by definition, is "a book containing a store of words, such as a dictionary or, especially, a book of classified synonyms and antonyms." The E \& P Thesaurs, then, a collection of words and phrases that are descriptive of the concepts and equipmemt pertaining to petroleum exploration, development and production. Further, it is a controlled vocabulary for these subjects, in which the various concepts have been linked by means of generic or hierarchical relationships. These relationships may be truly generic or may be associations by use, or even comvenience. An important factor of aspect of this, or any similer Thesaurus, is its treatment of synonyms. All terms or words of like meaning have been directed to one term or word, for use as a descriptor for thet perticular meaning or concept. This selection has been either arbitrary or, preferably, dicated by popular usage. The purposes for which this type of Thesaurus has been designed do not require the use of antoryms.

\section{Man BoOY}

The main body of the E \& P Thesaurus consist of descriptors arranged in alphabetical order. Under each descriptor, one or more of the following entries may be found:

- Entire spelling of Abbreviated Descriptor

- Scope Note or Explanatory Note, including history of usage and previous relationships, where applicable.

USE - Use. . . (preferred synonym)

UF. Used For

NT - Narrower Term

BT - Broader Term

SA. Seo Also

The $E \& P$ Theseurus preparation procedures allow a maximum of 26 characters (letters and/or spaces) for each descriptor. A fow descriotors require more characters than this; hence, abbreviations are necessary. The single asterisk entry, designates the entire spelling o such descriptors.

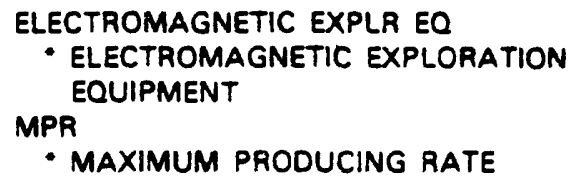

"Scope Note" entries (double asterisk) are used to restrict the scope of a descriptor or define its meaning, to indicate previous (now invalid scope notes, to tell when the term was first available for indexing, tc show what terms were previousty used to describe this concept, and tc indicate changes in hierarchical relationships. Numbers in parentheses (65-75) show applicable year ranges.

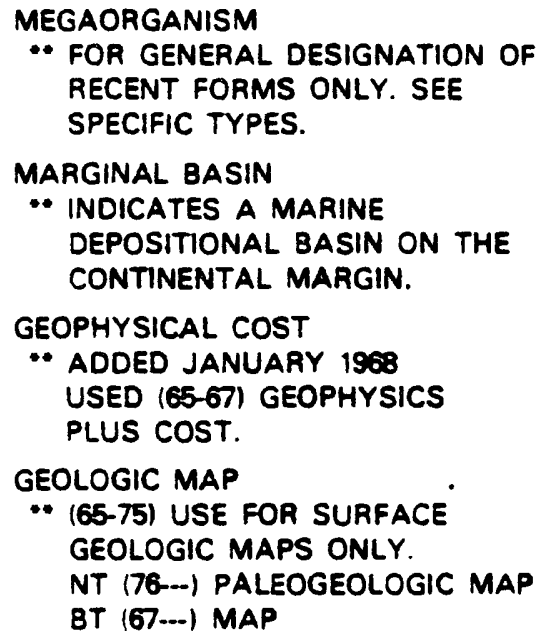

The entry "USE" indicates the preferred term designated tc describe a single concept, when two or more synonyms exist.

DOWNHOLE PUMP

FLUIOITY

USE VISCOSITY

"Used For" (UF) indicates an unacceptable synonym, for which a given descriptor serves as a substitute.

WELL PUMP

UF DOWNHOLE PUMP

VISCOSITY

UF FLUIDITY

"Narrower Term" (NT) designates a term which is a more specific subdivision of the descriptor.

LIMESTONE

NT CHERTY LIMESTONE

LINER (WELL)

NT PERFORATED LINER

"Broader Term" (BT) designates one or more hierarchically related terms, of which the concept is a logical subdivision. 
followed by (P). is asaigned for searching. A complete liat of such caccriptors is shown in Figure 3.

\section{MERARCWY}

A hierarchical listing of all acceptable descriptors, followed by an index to the hierarchy, will be found following the main body of the Thesaurus.

The hierarchy provides a compact listing of the descriptors in their structured form. Since the Theasurus terms hov been interrelated on the concept-oriented (faceted) principle, all descriptors are narrower

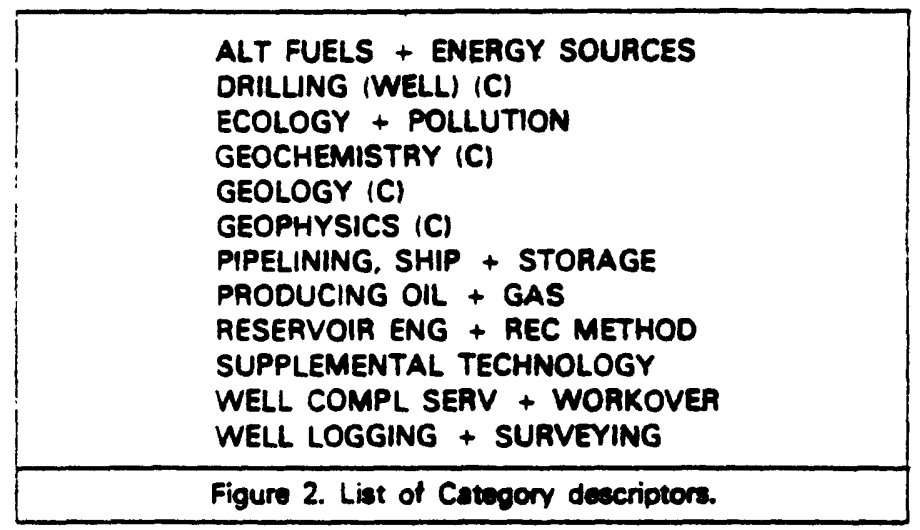
(P) ARGENTINA
(P) AUSTRALIA
(P) BELGIUM
(P) BOLIVIA
(P) BRAZIL
(P) CANADA
(P) COLOMBIA
(P) CUBA
(P) EAST GERMANY
(P) FRANCE
(P) GERMANY
(P) GREAT BRITAIN
(P) INDIA
(P) ITALY
(P) IRELAND
(P) JAPAN
(P) MEXICO
(P) NETHERLANDS
(P) PORTUGAL
(P) SOUTH AFRICA
(P) SWITERLAND
(P) USA
(P) USSR
(P) VENEZUELA
(P) YUGOSLAVIA

Figure 3. List of patemt country deseriptors.

terme of one of ten fecet heading. These ten facests, which apoeser iphabetically, are as follows:

COMMON ATTRIBUTE

ECONOMIC FACTOR

MATERIAL

ORGANISM

PROCESS

\section{EARTH AND SPACE CONCEPTS EQUIPMENT OPERATING CONOITION PHENOMENON PROPERTY}

In the hierarchical listings, the words apoenring in breckcts are included to show the scope of the hiererety. but do not epoeser in the main theseurus body as usable decriptors Words appearing in peremtheses ase usable descriptors but are not sutoposud.

The Indax to the Hierarcmy provides a comvenient mans for locating any word in. the Hiererchy. Since esch column of the Hierarchy is numbered, tha Index indicates the Hieraretoy cokumn in which the descriptor mey be found.

-

\section{MACHNE ALPMABETLATION RULBS}

Knowledge of the thesaurus formet important to both the indexer and the searcher. The E \& P Theacurus is an alphabetic listing of single words and descriptive phrase terme that are known a decriptore. The alphabetic order of thase descriptors does not follo the format of a conventional dictionary, wherein single, double, $c$ compound words are treated alike, in strict alphabetical order. Rathen singi-word and double-word descriptors appear before the plurals and before compound (joined) words; e.g., SLIP VELOCITY appear before SLIPS (PIPE); WAVE VELOCITY occurs before WAVEFORN

Letter abbreviations occur in regular aphabetic succession (e.. API CODE follows APHOTIC ZONE; BSEW follows BRYOZOA). O the other hand, it will be noted that descriptors containing numeral are entered in alphabetic sequence following the last normal entry 0 the word 10.g. CARBON 14 DATING occurs after CARBO NITROGEN RATIO, but precedes CARBONACEOUS DEPOSIT).

\section{AB8RJVATION PAOCEDUAES}

Descriptors, including spaces between words, are limited to maximum length of 26 characters. For longer descriptors abbreviations are required. In addition, certain commonty occurrin words in proper names may be abbreviated.

(1) The following are typical abbreviations of proper names:

$\begin{array}{ll}\text { Mount } & \text { Mt } \\ \text { Saint } & \text { St } \\ \text { Company } & \text { Co } \\ \text { Limited } & \text { Ltd } \\ \text { Incorporated } & \text { Inc }\end{array}$

12) Publication names are abbreviated as shown in the annua Publications List for PETROLEUM ABSTRACTS.

(3) When abbreviations are used because of space limitation:

(a) The first word of a concept is not abbreviated, except in rare cases where such is common usage.

API STANDARO NMR SPECTROSCOPY

(b) When necessary, individual letters (usually vowels) arendeleted trom individual words, near the end of a concept poscible.
AIRBORNE GRAVITY EXPLORATN
- airborne gravity exploration

(c) Speces are not loft between initisls, and they are not punctuated.

API STANDARD

(4) Other abbreviations are swected from the following references:

(a) Abbreviation compilation used for PETROLEUM
ABSTRACTS

(b) Suggestions to Authors, U.S. Geological Survey

(c) Wobster's Third. International Dictionary

\section{REOUHAZMNTS FOA NEW DESCRIPTORS}

Rules for the selection of cecriptors for inclusion in the Supplementary Descriptors liat are as follows:

(11) When a concept cannot be found in the $E \& P$ Thessurus, synonyms of thia descriptor should be sought in the Thesaurus.

(2) The API Thesaurus is then checked to see if the descriptor, one similer to $\mathrm{it}$, or a synonym exists. If so, consideration is given to 


\section{E \& P THESAURUS}

ACCELERATING AGEA

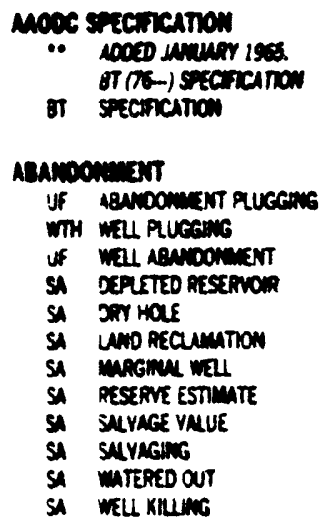

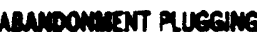

us a numboniment

pus wal puecing

Ac trunsuction

\section{T UNO NOL LSASEG}

Ecomanc FActo:

sa copusistion

SA Nonestes

5A LATR NSTR

54 contruct

sa mestivin

sa lese

5 LeGN consocerution

sA Onncrasu

SA RORERTY (REN)

\section{Nulocinesis}

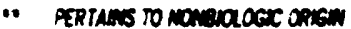
of Petrolevir anguic Sompouras of LA 10050 Nan 1966 LS50 (65) mancinc a qus xh no cas ancin. गT (67-) andin

at Danen

SA ON NOGS ORen

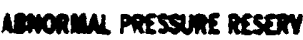

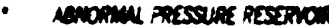

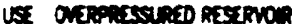

\section{Norfecound sto flcm \\ - noverano starice platr \\ - NDOCD ununt :907 CED (\$S6) STORACE icermines puls sefice \\ * STORne neOregrouno \\ IT STOLAS FNOIT \\ is SPERECN 'N \\ SA STORAE PT \\ sA supfice

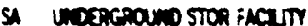

MOVIWATE STOA FMCUT

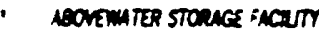

- LOCDD nuner 1976. SSED (65-75) STORACE ENCETmES?

* storuge neovemater

31 stanke incuitr

SA THFHORE STORAGE

SA PFYORE TERAMUL

a Unoermater stor sacrut

mension

UE TR

\begin{tabular}{|c|c|}
\hline 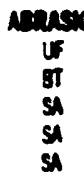 & 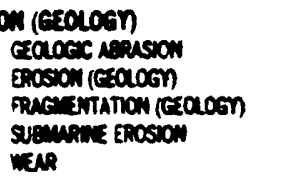 \\
\hline $\begin{array}{c}\min \\
\ddot{s i} \\
\dot{s i} \\
\dot{s i} \\
\dot{s i}\end{array}$ & 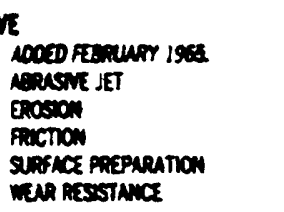 \\
\hline 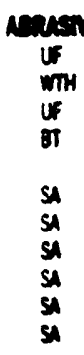 & 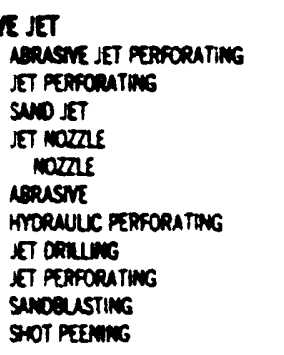 \\
\hline $\min _{\text {Lex }}$ & 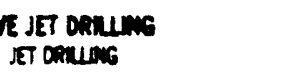 \\
\hline $\begin{array}{l}\text { Manen } \\
\text { use } \\
\text { as }\end{array}$ & 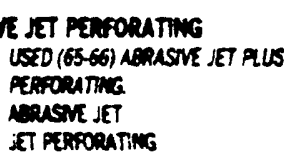 \\
\hline $\operatorname{sisen}$ & 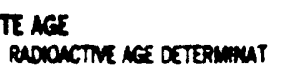 \\
\hline $\operatorname{soc}_{\text {use }}$ & 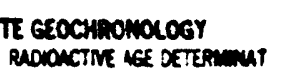 \\
\hline $\begin{array}{l}\text { Acosu } \\
\text { LES }\end{array}$ & $\begin{array}{l}\text { Te OL AECONIRY } \\
\text { OU RECOKEAY }\end{array}$ \\
\hline Nose & $\begin{array}{l}\text { TE OPEX FLOW TEST } \\
\text { OFEN FLW TEST }\end{array}$ \\
\hline $\begin{array}{l}\text { Assour } \\
\text { ist }\end{array}$ & 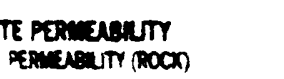 \\
\hline $\begin{array}{l}\text { Neour } \\
\text { Lex }\end{array}$ & 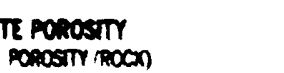 \\
\hline $\begin{array}{c}\text { Asour } \\
\text { use }\end{array}$ & $\begin{array}{l}\text { TE XECONERY } \\
\text { OA RECONERY }\end{array}$ \\
\hline 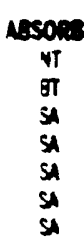 & 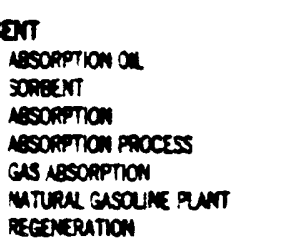 \\
\hline $\begin{array}{l}\text { and } \\
\text { if } \\
\text { if } \\
\text { if } \\
4 \pi \\
3 \pi \\
\text { sA } \\
\text { id } \\
\text { sA } \\
\text { is }\end{array}$ & 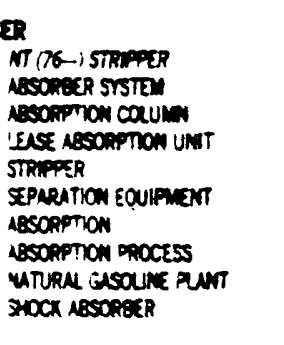 \\
\hline
\end{tabular}

\author{
NSORaER SYSTEM \\ LSE ABSORBCR \\ Necontron \\ - anemonizion not processs \\ VT (76-) Gas a \\ NT (67--) insisinow \\ NT 76. ) WAVE resopponon \\ MT GAS ABSCRPTION \\ NT Imeremon \\ vT mave ABSORPtion \\ 8T SORPTION \\ SA NOSORECNT \\ SA NBSOPBeER \\ SA nescoption process \\ SA nesomption spectroscopi \\ SA nosomption
}

NSOBPTION COLUMN

USE NESORBER

NSOMPTON GASOUNE

SE MUTURAL GASOLINE

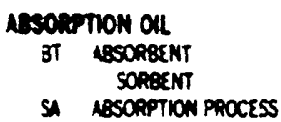

Asonption PLANT

-1 USED (65-66) GLSOUNe PUNT(S)

LE MUTURA GLSOUME QUNT
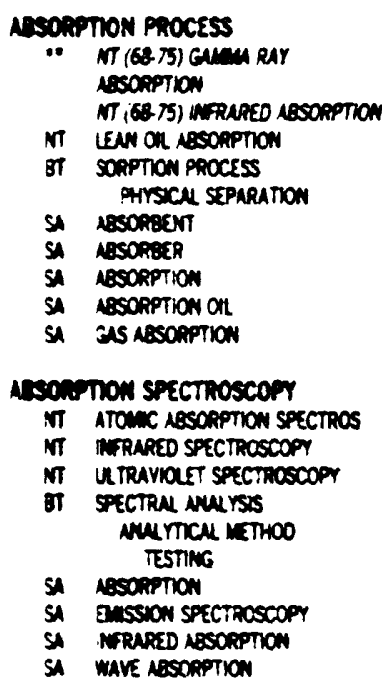

Aestruct

Jf sumuer

SA NFORMATION RETRIEYM STST

Neumances

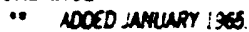

NT (76-) SHORTAGE

NT (76-) SURPLLS

$1 T$ SHORTAGE

NT supprus

is ivalubertr

si estribution

si sepply

Merssul ocposs

- OR LAKES. MOCX LAKE TEPDSIT

Q US OEEP WATER

65-66) MOEX 450 is

SEOMENTARY ROCKYST
Arrssul deposn (Cont'd) SEOMENTSI (GEOLOON is appicuere.

BT (67.75) DEPOST (GEOCOW

Uf Marssu sumple

isf DEEP SEl DCPOST

BT MARAK DCPOST oeposit (Ezalon

SA SEOMEMT (GEOLOCN)

SA SEDIMENTAPY ROCX

ABTSSAL ENVIRONMENT

- for laxes. moex uKe RLUS OEEP WATER. 70.75) INOCX N NSO AS XPOSITONUL ENVIROMUENT if Apquciere. BT (65-66) OEPOSTtomul

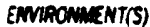
BT (67.75) ENIPOMUENT

BT MURINE EMTRONGENT DEPOSTIONUL EMTROMMENT EMTRONIMENT

5A Aptotic zOWE

SA BATHYAL EMMPONAMENT

SA COMPESASATION DEPTH

SA XEP SEA

SA XEP WATER

SA KERITTC ENVIRONIENT

SA PUIET WATER EMMROONMENT

SA SHLLOW WATER EMRROMUENT

MYYSSAL HILL

- NOOED SEPTEMBER :970 USED (65.70) SUBMARINE ropocrapar. 8T (76-) SUbmanave TOPOGRAPAY

3T SUEMURINE TOPOCRNPAY UNOERWATER TOPOCRAPHY tOPDGRAPYY

SA norssel PLAB

SA SEMOUNT

corssul pun

- $8 T$ (65-66) Sugumane topocenpar BT (67.75) PUAN

5T SUEMURIME TOPOCRAPUY UNOERWATER TOPOGRAPWY TOPOCRUPAY

SA CESSAL HILL

SA sosm BUSiN

in purm

Arrssel SAMPLE

ISE ABYSSAL OEPOSIT

\section{scadennc}

-* WOOED MMRCH !96; SSED (65-66) TRAINANC Procramist vi (76-) cacanow

u MUERSTIT

$v$ iovarion

SA THESS

ACAOUAN OROGENY

1. $3 T$ (65-65) OROCENT

3T JROGEMCC PERIOD SROGENY TECTONICS

SA WTER DROCEMY

ACCELERATING AGENT

- 'SEO (65.-66) CATALYST(S) OR IEMENT ACCELERATORIST

JSE ATALYST 
newT

- vadosenter

- use racom/lusecrm

centr/ensicstr

10000 samentir isos. 4520 (656) $\mathrm{Fh}$.

NT (T6-) REUTRN

uf MGOTI

ur neruintr

iT MeUTRa

NT

BT PAmscul paorertr

SA SUFFER (CAimcal)

sa cherucal mocató

\section{Actorenive}

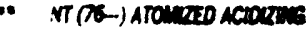

Uf ACTo Treations (well)

LF Nall Acroris:

NT ATOURED NCDORW

NT HOT NCD TREATIEST

NT jeT Aclozive

iT SUPFACTAT NCOOZWS

SA NCID

SA NCD NOOTME

SA NAD CLEAmis (NrTi)

SA ACIO Comerosion

A ACIO Floodins

ACID Iniverto

acio soverirtr

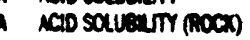

ACIO SPILL

a Acizing equmicar

sA chermar nuection

SA ETCHDE

ARACTURmo

NDOACDO

ACXunG

RETAROSD NCD

A SCUE REIOVM

5A SPEARHEAO

sa SPEIT ACD

SA val comintion

SA vall stimeution

SA Wall womover

Aciouring Equirear

- nooso Neni issa

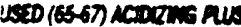
Equinignt.

SA nctoring

ncoustic nimmes

- LEDD (5.75)

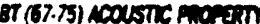

LeE wave nirutuos

fis sovio wave

Acoustc ATtenution

- 1500 (65.75)

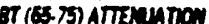

Ue wave ATtenuthor

ins sownoware

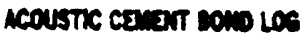

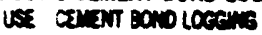

couste contrest

- noced sumurir Ises

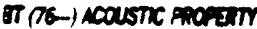

BT NCoustr moverm

arrsca pmoperers

ncoustc Dumpins

L50D (65,3)

$3 T(65.75)$ oumons

use mave oumpurs

-as sonio wave

Neustic oecoupune

- souno wave sescaption ar

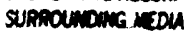

Acoustic ozcolntais (Conted

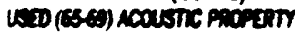
$4520(6975)$

Lex make nescopion

fis sowomave

\section{coust odsin Loceing \\ - Lend (65)

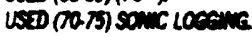

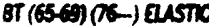 mus ineams \\ BT EUSTC wave Locens wall loseins}

neoustic DETOUATOR

BT Detowito

recustic Dinums

use sonc dortuns

coustr holoesart

- $\quad$ COCDO MAlich 1974.

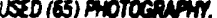
USED (\$5.73) Ho OSE

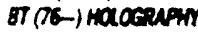

BT Hoccenar

data processing portical outa processing

sa OATA PoEsotatio

a PHotocenar

SA strimc outa processiono

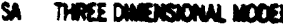

MCOUSTIC HORROM

USE RERECTIW 8ED

Acousnic umeseame

- 87 (656) vustart

vcoustr morem parices parram

sa ockstr

a Eumarr

sa make properm

SA mave roocm

nooustc miranuce locenns

us sustic wave loeens

CCOUSTK LOS EQUWmint

-* LSDD (SES) EUTTC mare loeens fuls wall Loefins EQMaris?.

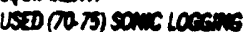

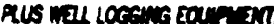

wo Bustc wave Loeen

pes wal soems equinast

ncoushis locerm

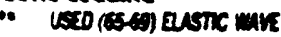
Loesive.

ves som loeens

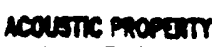

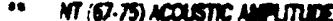

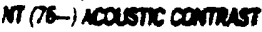

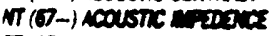

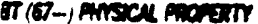

vi coustic cowmest

NT coustic inerpunce

BT arsich paperstr

SA noworias

SA cavtarion

Sa strimc wave

SA souvi kecom

sa sovio wave

sa wave Properert

NCOLIIC RECENER

- BT (76-) PECENER ELECTROWC

BT PECEMER IEIECTROMO EIECTRONIC EQUPNIST ELECTRCN EQU ONYTT
MCOUSTC RECENER (COAt'ol

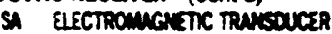

SA Electrouschuncer trussouc

SA Geophome

SA HYOROPHoir

sa merietic mansoucs

SA meroption

sa muspuces?

ncoustics

uf sonics

iT UTRAsonics

SA CCOUSTIC PROPERT

SA CENENT BOWO LOGGNO

SA REFLCTION (SOCVIN)

Sa utresconic wave

\section{scpusinom}

uf oata acouistion

WTH OATh

uf procuremem

If PURCHesing

BT naminstration gusiness OfERATION

SA AEC TRUASACTION

SA NCPEAGE

SA AUCTION

SA BID

SA WNO NOL LESTME

SA IEASE Bomus

Merenge

If ProOUCtion HCRestes

WTH ProOucling

if ProOUCTVE ACReACE

WTH ProOucine

gT LNO NOL LESTSE

ECONOANC FACTOR

SH ABC TRensiction

SA nocustion

sa

SA Gas LeSE

SA ImierN RIETT

SA ON LelsE

SA PROPERT (RELL)

SA PROVED AREA

SA RESERE

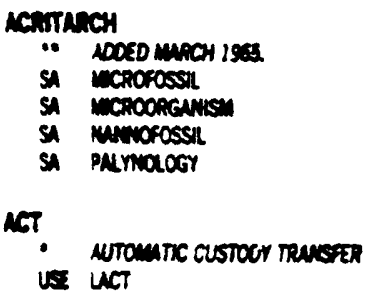

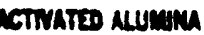

- noced Mucust 1974. LSED (55.74) N inmmim aroe: or 76-; Munary

gT summa

SA catarst

MCTwATE CAReON

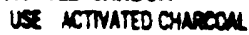

netwated charcons

- $5 T$ (65-60) (7a ) cancocal

(1) ACTVATED CAREOT

81 arrical

sa nosoriesw

sa carson sucx

SA SOUD 40SOBBEST

netvated sula

* c00Eo NPAL : 965 LSED (65) SLCa 87 (76... suca

gT such

ACTMATIOM

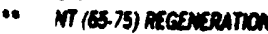

is actuation

SA NCTMTI

SA GOO2M

SA Roution nurses

SA RECEMERATION

SA STARTUP

AพTIII

$N T(67 \ldots)$ coninosm

$M$ (67-.) IImSMT

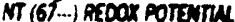

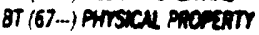

NT CORPOSNm

NT INERT

MT REDOX POTENTWL

ot PATSxal property

SA ACTNATIOA

SA OPTICN NCTIVIT

ACTIMT COEFTCIET

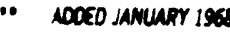
USED (65-57) ACTMTI FIUS COEfFICIENT(S)

uF DEVE HUCXEL EQuATION

GT THERIDONUMIC PEOFERTY

s Knetice ArsceN Propenty

MCTUATION

use netwation

NoOTIVE

- MOCX MSO BO SPECITC arincel Mirs. if postries

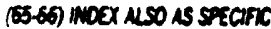
ateinculs

NT (67...) ACO AOOTTM

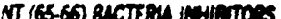
NT (67...) QUCTERIOSTAT

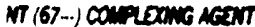

MT (67...: ococonant

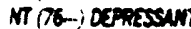

MT (67-) 0osis:ant

NT (57...) EXPANOED PERUTI

MT (67-..) Foumins neENT

NT (67...) FRACTURing FuD

Aooitme

NT (67.-) FRicton Las

Noorm

जT (67..) CES BEAKE

iT (67...) Gelluin kesn

NT (67...) inwerta?

NT (67..) ve cootws

NT (67.75) Mo PeEsrivatne

vT (67.-) NEUTRULER

NT (67..) coocent

NT (67-) RETAMDS.

NT (76..) senestrezR

NT 167-, SUPFIC ACTME

cest

vT $\pi$ - we corsts

DOAFER

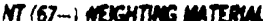

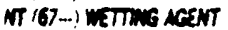

iI $\mathrm{ACO}$ A00Tm

MT ATtranims neET

IT NTIFouUn ACEMT

it NTLXIOWT ADOTIVE

iT NUTSTATIC AEENT

iT BCTEFOSTAT

NT CINENT ADOTINE

iT Comprexang AEST

iT DEMUSIFER

vT xocoinur

it aspessurt

$\pi$ OSPERSANT

$\pi$ EXPNOSD REMUTE

it rocculum 
$K_{\text {ey }}$
Word
Out of $_{\text {ontext }}$

KWOC LIST

OF PETROLEUM ABSTRACTS'

EXPLORATION \& PRODUCTION THESAURUS

AND SELDOM-USED DESCRIPTORS FROM

THE SUPPLEMENTARY WORD LIST

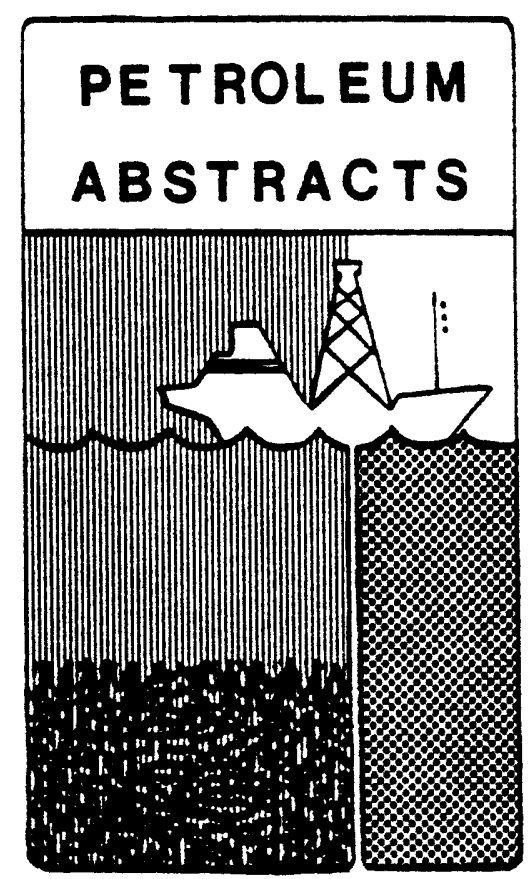

THE UNIVERSITY OF TULSA

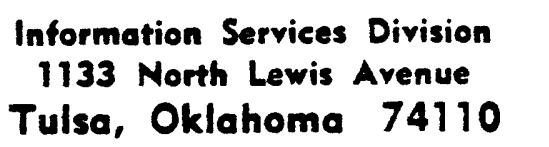

Copyright $\odot$ by The University of Tulsa -1978 
This KWOC (Key Word Out of Context) list is a quick reference guide to valid multi-word descriptors that contain the same word in common. For example, "Acid Additive" and "Organic Acid" both contain the word "Acid", but these descriptors would not appear together in a listing sorted alphabetically by the primary word. The KWOC list consists of two columns, the right hand column containing the complete valid descriptors, the left hand column listing the individual word components, arranged alphabetically. Thus, a descriptor consisting of three words would appear three times in the KWOC list, cross-referenced alphabetically by each of its component words. For example, "Fluid Flow Equation" appears in the alphabetically sorted list, opposite the words "Equation", "Flow", and "Fluid".

Each page consists of two double columns of words and complete descriptors, or a total of four columns. This list contains only valid descriptors from the $E$ \& $P$ Thesaurus and the Engineering Supplemental list. The Supplemental descriptors are specially marked with an asterisk.

Some words within a descriptor have been truncated due to space limitations. Such words are expanded to full length and appear in normal alphabetical order, in the single-word listing. Words within a descriptor which are parenthesized also appear in this listing. Descriptors containing words such as: of, the, to, etc., are not cross-referenced under these words, due to the lack of useful information these words convey. This KWOC list may be used by indexers or searchers to find out what valid descriptors are available, containing a particular word. It does not include words from the Geographic Thesaurus, or the Chemicals, Companies or Geologic Supplemental lists.

\section{Nondiscrimination}

The University of Tulsa employs, advances, admits and treats in its employment and educational programs, all persons without regard to their race, color, national or ethnic origin, sex, age, religion. handicap, or status as a veteran. 


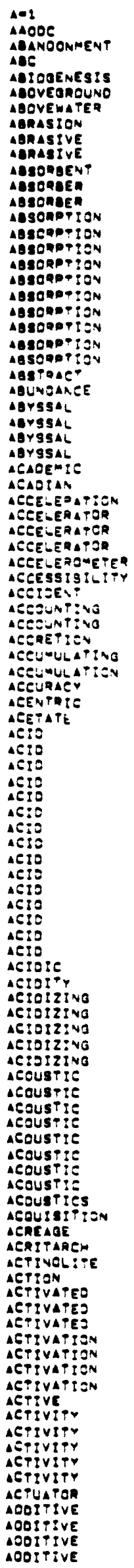

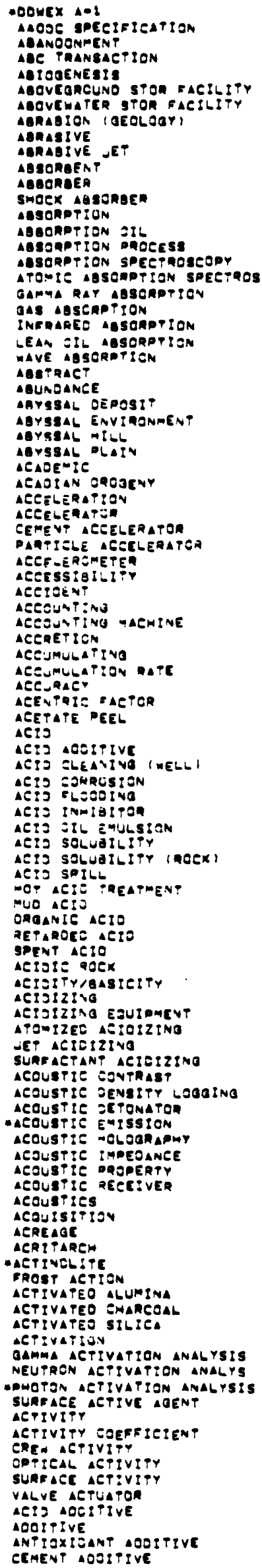

- LuJo loss noottive

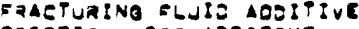
SRIETISN LOSS ACOTIIVE -OST EIRCULATION MOSITive mo anofitue SROANIE MUO AOOITIVE
STABILIZER (AOOTTIVE) DOMESION

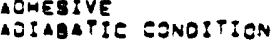

AOJuSTABILITY

AJUSTABLE ANEMOR

GRUSTAL AOJUSTMENT

AJMINISTRATION

ADMIX CEMENT

ANOATE

ASSORACN?

SOL:O ADSORBENT

ACSORBE?

AOSORPTION

AJSEROTIEN SADAC:TY

acscaptisn joluen

ins acscontisn

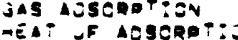

iogutal auvance equation

aivisatisinz

LERATEO WATER

aEvation

AERATOR

AERTAL

ERTIL MAP

ERTAL MAPDTVG

ERIAL PMCPCGRAPM

AERTAL ONCTEGRADHV

AETIAL SUPVEY

AERIAL TRANGRCATATISON

AERTBIC BACEERIA

AERUAT EERIST

a Erja:C Envinovment

aERzornamies

AERJMAGVETL EXPLERATIEV

AERJMAGNETIS SURVEY

AERSRAOLOMETRY

AEROSPACE IVOUSTRY

AFMA METHOO

AFTERELEW

aza soectitication

ABAR ABAR

ase

EARPM $\triangle G E$

JEULOUIS AOE SE ERMTVATIS4 i=E $A$ उE

RADIJACTIVE AOE EETERMIVAT

PEJULATERY ABENCY

antjezulina agent

avistaris aov

zonectiva a aeV

IMPLEXINO ABEV

JAYING AOEVT

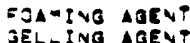

IXIOIZIVO AGENT

oluasing aGeV.

REOUEING

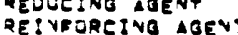

SUGFACE AEtive abet

METTINO AGENT

aOSLIERATE

ajiva

ajitateo mater eVViRonment

astativa

igitapos

agRicul ture

VISUAL A IO

II

itr conoittonine

itr coupleo mave

itr jRILLINa

AR FLOW

IT FUEL MATIO

itr bun

itr maMMER jRILLINO

AIR INJESTION

itr polluiton

air puratne

AIa mave

ATE ATR ANOMALY

TREE AIR CORRECTION

aperafo

a gRY HAVE

ALARM

ALSERTITE

aleOMOL

ALEOMOL SLUa anOEESS

L6A

cabiareous aloa 
abaab

ALOAL

alogara

ataresog

LLasNIPE

aloal

aloOR? THM

abJeYelte

AL SONMENT

AL IPHAT?C

ALITE

ALKENYLATION

ALKYLATION

ALLIEO

allocarton

alloCMPMON

ALLOPMANE

ALLOWABLE

ALLOWAOLE

ALLOHABE

aLLOWANEE

allowaneE

ALLOWANEE

ALLOY

ALLOY

aleuVial

aleuvial

alouvial

ALLUVIAL

ALLUVIUM

ALMMA

ALPMA

aLP I ve

altegation

aLterat:on

aLTERATION

altenation

alternating

aLTERNATINO

ALTIMETE

ALTITUOE

ALUMINA

ALUMBNA

aluminous

ALUMINUM

ALUminum

ALUMINUM

ALLMINUM

ALUNITE

AMINE

AMMETER

AMORPMCUS

AMPHIS IAN

AMPMIBIOLS

AMPMIBOLITE

AMPMINEURAN

AMPHIPATH!

AMPLIFIER

AMPLIFIER

AMPL IFIEA

AMPLIFIER

AMPLIFIEA

AMOLIFIER

AMPLIFIER

Amplifie

AMPLituor

AMPL: TUOE

AMPL I TUOE

AMPL I TUOE

AMPL I TLOE

AMPL: PLOE

ANAEROSTE

ANALESME

ANALOS

ANALOE

ANALSO

ANALOO

ANALSO

ANALOS

ANALOGY

ALYSIS

ANALYSIS

ANALYSIS

ANALYSIS

ANALYSIS

ANALYSIS

ANALYSIE

ANALYSTS

MALYELB

NALYSIS

ANALPS

ANALYSIS

ANAL'SI8

ANALTSIS
MaAb Hactes

maprix aloent

trngon alocena

alosejoE

ALarntre

Alaal

algoRstaM

ALICYCLIS HYOACEARLON

ALIONAEN

AL ZPMAPIS MYOROCARBON

ALITE

ALKALS VAPOR MAONETOMETER

ALKENYLATZON

- alerlation

URANIUM S ALGIEO miNERALS

altoea

ALGOCHTHON

ALLOPHANE

ALLOWABLE FORMULA

ALLOMARL PROOUCTION

FIELO ALLOWALE

WELL ALLOWABLE

ogPlePiOn ALtOWANCE

oeprectation allowance

FEROUS ALLOY

NONFERROUS ALLOY

ALLUVIAL FAN

ALLUVIAL FAN OEAOEST

ALLUVIAL OLAIN

aLLUVIAL LASN DEROSIT

OOULOERY ALLUVIUM

ALPMA PARTIELE

LEAO ALPMA DATINO

AL IVE JROQENY

ALTERATION

ORAIN ALTERATION

mYOROTMERMAL ALTERATION

TMERmal al PERATION

alternating rLow

ALTERNATINO

MIGM aLTITUOE

activateo alumina

alumiva

ALUMINOUS SEMENT

ALUMENUM DEPOEIT

ALUMINUM MINERAL

ALUMiNU DELLE

ALUMINUM o gee

GYOROXY ALUMINUM DAOCEs

ALUNTTE

AMINE

AMMETER

LIOUIO AMMONIA

AMORPMOUS

ATEAIBTAN

AMPNISTOUS TR

AMPIIVEURAN

AMPWIPATMIE SOLVENT

MMPLIFIER

FEFOBACK AMPLIFIEA

FIELJ AMPLIFIER

LuYex

Deconorms ampl

RECONOINO AMPLiFiER

DE ISMIE AMPLIFIER

- IDE BANO

AMPL: TUOE CMARACTERISTIC

AMPLITUDE SuRVE

AMPLITUDE MOOULATZON

AMPL IPUDE RESPONEE

LOW AMPL I TUDE WIVE

maVe AMPLITUDE

anAERDUIE maCtERIa

ANALEIME

MALOB

ANALOS computen

ANALOO RECOROSNE

ANALOO BTSNAL

ANALOO TELEMETERING

olastal to analoo converto

ANALSOY

ANALYSIS OF YARIANCE

BUEXLINO ANALYBIS

CAGM rLOW AMALYis

CLuETER ANALYBS

COA ANALYSIS

SONFORMATSONAL ANALYOJS

CORE ANALYETS

CORE ANALYSIS JATA

COQP ANALYSIS

CUTPINOS ANALYSIS

OATA ANALYBIE

DIFEERENTIAL PHERMAL ANAL

OIFTRACTION ANALYSIS

DimENSIONAL ANALYBIS

ANAGYSIS

ANAGYS?

MNALYE?

ANALYET:

ANALYERS

ANABYEIS

ANABrets

ANALYIS

NALYe?8

ANALYS?

ANabYs?

avabYese

Nabre?

Natreis

avabreis

ivabreis

vabrets

NALYSIS

AVALYSIS

NAbrste

yulyers

MALY

AYAYSIS

AYALYSIS

AYATYBIS

AVASYSIS

AVA-YSis

ANALYSIS

AYATBIS

ANATYSTS

MALYSIS

AYATSIS

AYALYSIS

ANAGYSIS

AYALYSIS

AYATYIS

AVALYSTS

MAOYSIS

AVAGYSIS

avalyeIs

avabyets

avabYeis

AYALYSIS

aAbYsis

avaLYZER

AYAGYER

AYABYZER

avabrzea

a vatase

avatomy

avevon

ivegor

AVE IOR

A VEMOR

ivenoR

AveroR

Ave

A VEMOR

ivenaR

a venOR

A YEMOR

AVEMAR

iveMOR

Avevon

A NEMORING

- VEMOR INe

ANCAORING
A VEIENT

AVDEAN

AVSESTTE

AVOESITIS

AVEMOMETER

- vat osperm

NOLE

ANOLE

avale

A YaLE

$\triangle$ YOLE

AYOJLARITY

ANHYORITE

A viYoR? TE

AYMYOROUE

AvIMAL

avisotropis

a visotaopic

AVIBOTROPY

ANIsotroer

ANKER ITE

ANUUAL

AYNULAR

4Nulis

veor

4 VED

AYOOE 


\section{GEOREF Thesaurus and Guide to Indexing Second Edition}

Edited by

Carol Heckman and others

Published by the

AMERICAN GEOLOGICAL INSTITUTE

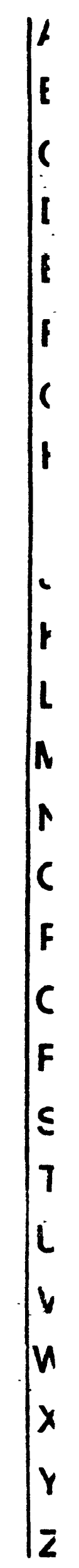


Earlier Edition:

GeoRef Thesaurus and Guide to Indexing, First Edition

Copyright (C) 1977 American Geological Institute

GeoRef Thesaurus and Guide to Indexing, Second Edition

Copyright (C) 1978 American Geological Institute

All rights reserved

Library of Congress Catalog Card Number 78-65083

International Standard Book Number 0-913312-07-X

Printed in the United States of America

\author{
American Geological Institute \\ 5205 Leesburg Pike \\ Falls Church, Virginia 22041
}

\footnotetext{
The Thesaurus was photocomposed on a Videocomp from a tape generated by SAMANTHA programs. Eterna bold and light fonts were used for the text.

Cover photograph: San Andreas Fault

This is on the Carrizo Plain, about half way between Los Angeles and San Francisco. (Photo by Robert E. Wallace, U.S. Geological Survey) Reprinted from Geotimes, February 1975
} 


\section{CONTENTS}

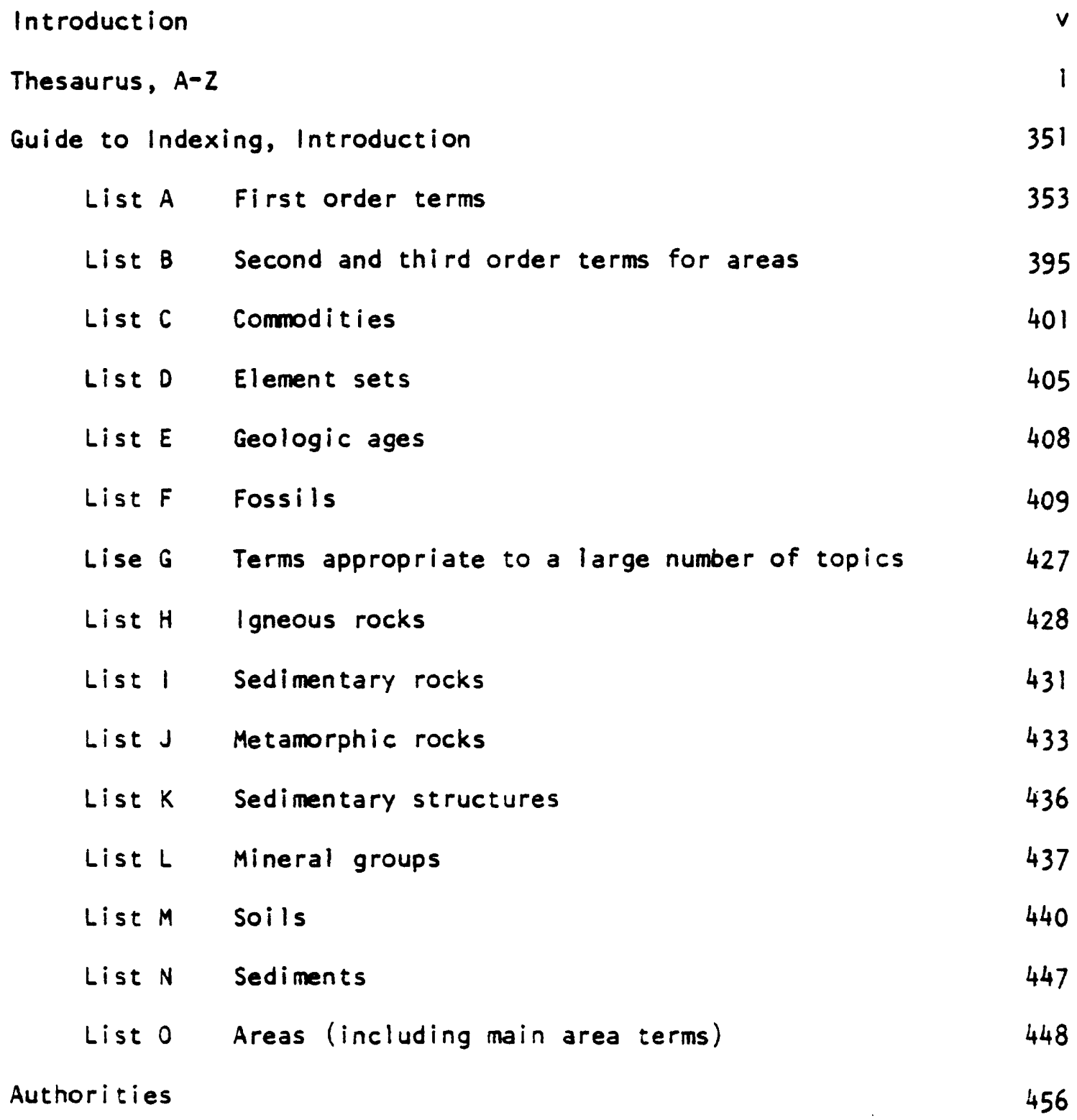


The second edition of the GeoRef Thesaurus and Guide to Indexing contains over 12,500 terms, of which approximately 3000 are new. There are geographic place names, systematic terms (rocks, fossils, minerals, etc.) and non-systematic terms (geologic features, processes, properties, materials, etc.).

The ANSI 239 Standard, Guidelines for Thesaurus Structure, Construction and Use (1974), has been followed herein.

\section{SOURCE OF THE VOCABULARY}

Since May 1978, GeoRef has included five segments, the first three of which are new additions:

(1) Bibliography and Index of North American Geology (1961-1970)

(2) Bibliography of Theses in Geology (1965-1966)

(3) Geophysical Abstracts (1966-1971)

(4) Bibliography and Index of Geology Exclusive of North America (1967-1968)

(5) Bibliography and Index of Geology (1969 to present)

The index terms and sets used in all five segments have much in common. They derive from a common source, the early volumes of the Bibliography and Index of North American Geology. This Thesaurus is based on that indexing vocabulary as it has evolved down the years. It displays, interrelates, and regularizes the vocabulary.

This edition has been derived from terms in GeoRef file Segments 4 and 5 . Most of the terms in Segments 1-3 are also included, but we have been unable as yet to study the indexing in those Segments in detail in order to incorporate notes and cross-references for them. We intend to do so. Meanwhile, help in searching Segments $1-3$ can be found in List A of the Guide.

\section{INDEXING}

Prior to 1977 when the first edition of the Thesaurus appeared, the Guide to Indexing was the only tool available for GeoRef indexers and searchers. The Guide, which consists of structured lists of terms has been revised and is included herein, with its own Introduction.

GeoRef indexing is in three level sets (see the Introduction to the Guide), which follow definite rules which can be found under each first level term in the Thesaurus.

First and second level terms have been tightly controlled in GeoRef, and few changes have been made in terms on these levels. Level three has been

1. Available from the American National Standards Institute, 1430 Broadway, New York, N. Y., 10018. Price $\$ 4.50$. 
more open-ended to accommodate specific locations, minerals, etc. Beginning in 1978, level three has been shortened to a single term. The other terms which had been included in level three became supplemental index terms. This change does not affect searching. Its effect on the printed indexes is evident by a comparison between 1978 and earlier publications. Briefly, the 1978 indexes have a single term plus title on level three instead of a term string. Also in 1978 cross-references were added to the index and selected supplemental terms to the citations.

Over 1500 terms are valid on levels one and two. All are included herein. Also included are all systematic and geographic level three terms used over four times and all non-systematic terms used over 24 times.

\section{AUTOPOSTING}

If a term appears in the indexing of a document, it does not necessarily follow that its broader terms will appear. Certain broader terms will be added because they are called for by the set structures. For example, for most geographic, stratigraphic, and fossil narrower terms, one, but not every broader term is required by the set structures. Other broader terms are added to facilitate computer searching.

As of January 1978, selected broader terms are autoposted (automatically added) by the computer. For example, each time Kansas is entered by an editor/ indexer, the computer adds United States.

Those broader terms which are autoposted are designated as BA or BZ terms. For example:

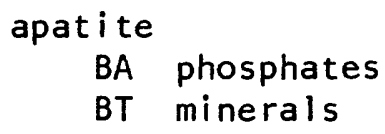

(Each time apatite is indexed, phosphates is autoposted, but minerals is not autoposted.)

Autoposting is used selectively for:

a. Areas (see List 0 in the Guide)

b. Age and stratigraphic terms, excluding formations (see List E)

c. Fossils (see List F)

d. Igneous, sedimentary, and metamorphic rocks (see Lists $H, I, J$ )

f. Sediments (see List N)

g. Minerals (see List L)

h. Soils (see List M)

i. Non-systematic terms (in only a few cases, such as faults)

TERM RELATIONSHIPS

In term entries, relationships are indicated by the tags $C 0$, UF, BT, BA, BX, $B Z, N T, N A, N X, N Z$, and $S A$. 
a. Geographic Coordinates--

In use since September 1977, coordinates are assigned to the principal area(s) studied in a document.

A fix fielded format of thirty characters is used to represent coordinates. For example, the coordinates for Alabama, lat. $\mathrm{N} 30^{\circ}-\mathrm{N} 35^{\circ}$, long. W8 $5^{\circ}-$ W8 $88^{\circ} 30^{\prime}$ are given as:

\section{N 300000 N 350000 \\ W0850000W0883000}

Principal geographic areas and a few others have coordinates herein. Any area is eligible and coordinates will be added for more areas. Coordinates for areas are used as needed, whether or not they appear herein.

Coordinates are used in addition to applicable area terms. For more information see inside front cover.

b. Use/Used For--

The use/used for (UF) relationship indicates synonyms or alternate spellings of a term. For example:

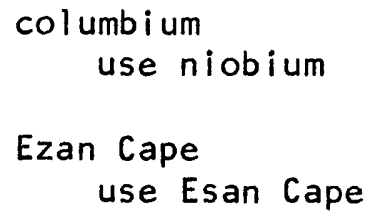

Also, inverted forms of multiword terms have been cross-referenced when appropriate. For example:

$$
\begin{aligned}
& \text { control, erosian } \\
& \text { use erosion control }
\end{aligned}
$$

\section{c. Broader Term/Narrower Term--}

The broader term/narrower term relationship is that of genus to species. The broader term represents a class of which the narrower term is a member. For example:

$$
\begin{gathered}
\text { olivine group } \\
\text { BA orthosilicates } \\
\text { silicates } \\
\text { BT minerals }
\end{gathered}
$$

The narrower term cannot be a part of the broader term, in a part-whole relationship, except in the case of geographic place names and geologic age terms.

Variants of BT-NT introduced in this edition are $B A-N A$. BX-NX, and $B Z-N Z$. 
BA-NA indicates autoposting (see Autoposting above).

BX-NX shows logical broader terms on the same hierarchical level or from different hierarchies. For example:

$$
\begin{gathered}
\text { Chautauqua County } \\
\text { BX Kansas } \\
\text { New York } \\
\text { BT United States }
\end{gathered}
$$

(Both Kansas and New York have a Chatauqua County.)

$B Z-N Z$ is for a combination of $B A-N A$ and $B X-N X$. For example:

Hawa i i

$$
\begin{aligned}
& \text { BZ Pacific Ocean } \\
& \text { United States }
\end{aligned}
$$

(The broader terms are from different hierarchies and both are autoposted by Hawa i i.)

\section{d. See Also--}

The see also (SA) indicates related terms or terms of ten appearing together in GeoRef indexing other than broader terms and narrower terms. Examples are:

$$
\begin{aligned}
& \text { Gallup Sandstone } \\
& \text { BT Upper Cretaceous } \\
& \text { BT Cretaceous } \\
& \text { SA Mesaverde Group } \\
& \text { SA New Mexico }
\end{aligned}
$$

geochronology

SA absolute age

NOTES

A note may occur immediately after a term to indicate the following:

a. Date Term Became Valid--If no date is given, the term is valid for GeoRef Segments 4 and 5 . If a date is given, this is the year in which the term began to be used in GeoRef. ( 1 t is not the year in which the term was added to the Thesaurus.)

b. Set Level--The set level on which the term is currently used may be given. For example:

$$
\begin{aligned}
& \text { boudinage } \\
& \text { includes use on level } 3 \text { under sedimentary } \\
& \text { structures (1) soft sediment deformation (2)... }
\end{aligned}
$$

(Boudinage can be found under soft sediment deformation, which is a second level term under sedimentary structures.) 
All valid index terms can be used on level three. Unless otherwise specified in a note, a term cannot be used on level one or two. List $A$ in the Guide shows the valid first level terms for all segments of GeoRef.

c. Set Structure--For each valid level one term, the Thesaurus shows how the sets are to be structured.

d. Usage--The phrase "includes use", which occurs frequently in the notes, suggests an example of current and significant GeoRef usage, but is not meant as a listing of all possibilities. It means "this is an important use", but not "this is the only use".

e. Reference to the Guide--Notes may refer to the lists in the Guide.

f. Previously Used Term--If a term has had 100 or more postings, but is no longer valid for indexing, a note appears under that term in the Thesaurus and a note to "also search" the term occurs under the preferred term entry.

For invalid terms with a frequency of less than 100 , there are notes to "also search" the term in the entry of the preferred Thesaurus term. There may be a UF also if it is appropriate.

g. Geography and Stratigraphy--Brief notes are given for most terms to assist the user in locating an area. Directions are abbreviated in these notes as $N, E, S$, and $W$.

h. Combined Terms--Usually only single terms occur on any level of a set. However, a few terms can occur together, separated by commas, such as mineral deposits, genesis. Explanatory notes are provided under each of these terms.

MULTILINGUAL THESAURUS

A multilingual thesaurus in geology is being developed by an IUGS/ICSU AB Working Group, of which G. N. Rassam, Chief Editor of GeoRef, is a member. One decision of this Group was not to use adjectives as terms. We have moved to conform to this decision (see Adjectives, below).

\section{ADJECTIVES}

Due to the Multilingual Thesaurus and to the dropping of term strings on level three (see under Indexing), several hundred adjectives have been replaced by nouns. For example:

$\begin{array}{lll}\text { andesitic } & \text { became } & \text { andesitic composition } \\ \text { disseminated } & \text { became } & \text { disseminated deposits } \\ \text { sublittoral } & \text { became } & \text { sublittoral environment }\end{array}$

The only remaining group of adjectives are age terms (see List E).

\section{TERM VALIDATION}

The Thesaurus on computer tape is the source of direct access validation files currently in use to check the spelling, capitalization, and level of 
terms. Index terms which don't validate can be accepted by overriding the validation. These become candidate Thesaurus terms when they have occurred

five or more times.

\section{ALPHABETIZATION}

Terms are sorted word-by-word rather than letter-by-letter. Specifically:

- The sort is on letters, numbers, spaces and hyphens.

- Spaces sort before hyphens; hyphens sort before letters; letters sort before numbers.

-An open parenthesis is sorted as if it were a space.

-All characters, including punctuation marks, other than letters, numbers, hyphens and the open parenthesis, are squeezed out in the sort, i.e., are treated as if they did not exist.

-A few terms are identical except that one begins with a lower case letter, one with an upper case letter, e.g., alpine and Alpine. When this happens, the term with the lower case letter precedes the other term.

\section{FEEDBACK}

The computer file from which the Thesaurus was produced will be regularly updated for future editions. Users are encouraged to send in corrections and comments. Let us hear from you!

\section{ACKNOWLEDGMENTS}

The following petroleum companies provided a large portion of the support for the first edition of the Thesaurus:

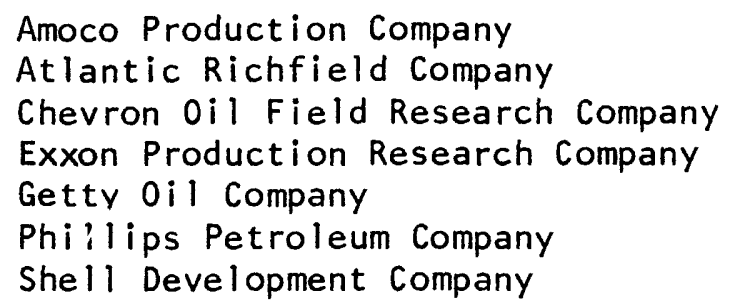

In particular, we are grateful to William Baum (deceased) and Margaret McLean of ARCO.

Editorial work on this edition was done by Carol Heckman with assistance from G. N. Rassam, Chief Editor, and the editors/indexers. Work on the geographical terms for the first edition was done by Ed Moon. Jack Wolfire handled the programming and photocomposition. Lesa Warren and Hazel S. Kirby typed and formatted the Guide, Introduction and front matter.

John Mulvihill

Manager, GeoRef 


\begin{tabular}{|c|c|}
\hline \multicolumn{2}{|l|}{$\mathbf{a a}$} \\
\hline use & aa lava \\
\hline $\begin{array}{l}\text { aa lav } \\
\text { Term } \\
197 \\
\text { UF } \\
\text { BT } \\
\text { SA }\end{array}$ & $\begin{array}{l}n \text { introduced in } 1978 \text {. Before } \\
8 \text {, also search aa AND lava. } \\
\text { aa } \\
\text { lava } \\
\text { pahoehoe } \\
\text { volcanism }\end{array}$ \\
\hline $\begin{array}{l}\text { Aache } \\
\text { City } \\
\text { gium } \\
\text { BT }\end{array}$ & $\begin{array}{l}\text { en } \\
\text { near the intersection of the Bel- } \\
n \text { and Netherland borders. } \\
\text { North Rhine-Westphalia } \\
\text { Germany }\end{array}$ \\
\hline \multicolumn{2}{|c|}{$\begin{array}{l}\text { Aalend } \\
\text { use Aland }\end{array}$} \\
\hline $\begin{array}{l}\text { Aaleni } \\
\text { Euro } \\
\text { perm } \\
\text { use } \\
\text { See } \\
\text { BA } \\
\text { BT } \\
\text { SA }\end{array}$ & $\begin{array}{l}\text { ian } \\
\text { ope. Lowermost Middle or up- } \\
\text { most Lower Jurassic. Includes } \\
\text { on level } 3 \text { under age terms(1). } \\
\text { list } \mathrm{E} \text {. } \\
\text { Jurassic } \\
\text { Mesozoic } \\
\text { Dogger } \\
\text { Lower Jurassic } \\
\text { Middle Jurassic }\end{array}$ \\
\hline $\begin{array}{c}\text { Aar } M \\
\text { BT }\end{array}$ & $\begin{array}{l}\text { Massif } \\
\text { Switzerland }\end{array}$ \\
\hline
\end{tabular}

River valley in central and N Switzerland. Also search Aare Valley.

UF Aare Valley

BT Switzerland

Aare Valley

use Aar Valley

Aargau

Canton in N.

BT Switzerland

Abakan

Town on Yenisei River SW of Krasnoyarsk in Khakass Autonomous Oblast.

BT Russian Republic USSR

Abashiri

City in NE Hokkaido.

UF Abasiri

BT Hokkaido Japan

Abasiri

use Abashiri

Abee

Village in central.

BT Alberta

Canada

Aberdeen

City on North Sea.

CO N565000N574500

W0014500W0041000

BT Scotland

Great Britain

United Kingdom

Aberdeenshire

County in NE.

BT Scotland

Great Britain

United Kingdom

Aberystwyth

Town on Saint Georges Channel.

BT Wales

Great Britain

United Kingdom

Aberystwyth Grits

Upper Llandoverian. Form part of the Ystwyth Stage. $N$ and central

Wales and NW England.

BT Silurian

SA England

United Kingdom

Wales

Abilene

Arch in central Kansas.

UF Abilene Arch

BT Kansas

United States

Abilene Arch

use Abilene

Abitibi

County on James Bay.

BT Quebec

Canada

Abkhasia

use Abkhazia

Abkhazia

Abkhaz Autonomous Soviet Socialist Republic. Also search Abkhasia.

CO N42200ON432000 E0421500E0400000

UF Abkhasia

BT Georgian Republic USSR

ablation

Includes use on level 3 under sedimentation(1).

SA glaciers

mass balance

sedimentation

wind erosion

wind transport

Abo

use Turku

abrasion

UF mechanical erosion

SA detritus

erosion

glaciation

grinding

planation

abrasives

General. Includes use as level 3 commodity term under industrial minerals(1). See list C.

SA corundum

diamonds

diatomite

garnet

industrial minerals

pumice

silica

Abruzzi

Autonomous region on the Adriatic

Sea.

BT Italy

NT Chieti

Marsica

Absaroka Mountains

use Absaroka Range

Absaroka Range

Range of the Rocky Mountains. Index states as applicable. Also search

Absaroka Range.

CO N433000N450000 W1090000W1101500

UF Absaroka Mountains

BT United States

SA Beartooth Mountains

Montana

Rocky Mountains

Wyoming

\section{abserokite}

Includes use on level 3 under igneous rocks(1) basalt family(2). See list $\mathrm{H}$.

BA basalt family

BT igneous rocks

\section{absolute age}

For radiometric or radiogenic (isotopic) dating methods; for other methods (non-isotopic) see geochronology. Includes use on level 1 : on level 2 under orogeny(1). If 1 term set options are:

dates

material [rock group, rock type mineral name (e.g. charcoal granite, metamorphic rocks shells, sediments)]

methods

name of method [Ar/Ar, C-14 $\mathrm{H}-3, \mathrm{He}-4 / \mathrm{He}-3, \mathrm{lo} / \mathrm{Th}, \mathrm{K} / \mathrm{Ar}$ $\mathrm{Pb}$-alpha, $\mathrm{Pb} / \mathrm{Pb}, \mathrm{Pb} / \mathrm{Th}, \mathrm{Pb}$ 210. $\mathrm{Re} / \mathrm{Os}$. $\mathrm{Sr} / \mathrm{Rb}$. Th/Th, Th/ $\mathrm{U}, \mathrm{U} / \mathrm{He}, \mathrm{U} / \mathrm{Pb}, \mathrm{U}-238 / \mathrm{Pb}$ 206, U-235/Pb-207, U/Pd $\mathrm{U} / \mathrm{Th} / \mathrm{Pb}$, uranium disequilibrium]

techniques

subtopic [e.g. instruments, models, sample preparation, sampling]

topic [applications, bibliography, catalogs, interpretation, philosophy] subtopic

UF actual age (absolute age)

SA age

$\mathrm{Ar} / \mathrm{Ar}$

C-14

changes of leve

charcoal

dates

diffusion

geochemistry

geochronology

$\mathrm{He}-4 / \mathrm{He}-3$

lo/ $/ \mathrm{Th}$

lo/U

isochrons

isotopes

$\mathrm{K} / \mathrm{Ar}$

new methods

orogeny

$\mathrm{Pb}-210$

$\mathrm{Pb} / \mathrm{Pb}$

$\mathrm{Pb} / \mathrm{Th}$

radioactive decay

radiometric properties

relative age

$\mathrm{Sr} / \mathrm{Rb}$

Th/Th

Th/U

time

$\mathrm{U}-238 / \mathrm{Pb}-206$

$\mathrm{U} / \mathrm{He}$

$\mathrm{U} / \mathrm{Pb}$

$\mathrm{U} / \mathrm{Th} / \mathrm{Pb}$

uranium disequilibrium whole rock

absorption

Includes use on level 2 under aurora(1); on level 3 under spectro scopy(1) methods(2): on level 3 under geochemistry(1) processes(2).

SA absorption and scattering

adsorption

atomic absorption

aurora

emission spectroscopy

geochemistry

sorption

spectroscopy

absorption and scattering

Includes use on level 2 under

aeronomy(1)

SA absorption

aeronomy

aurora

scattering

absorption spectroscopy

Not a valid index term. Use absorption under spectroscopy $(1)$.

Abu Dhab

Sheikdom. One of federation of 7 states at $S$ end of Persian Gulf. Includes use on level 3 as an area term (list O).

BT United Arab Emirates Arabian Peninsula

Abukuma Mountains

NE of Utsunomiya in E central Honshu. Also search Abukuma Plateau.

UF Abukuma Plateau

BT Honshu Japan

Abukuma Plateau use Abukuma Mountains

\section{abundance}

Includes use on level 2 under commodity terms (list $\mathrm{C}$ ) and under chemical elements (list D); on level 2 under isotopes(1).

SA organic materials

\section{abyssal cones}

use submarine fans

abyssal environment

Term introduced in 1978. Before

1978. search environment

SA deep-sea environment

environment

marine environment oceanography

abyssal fans

use submarine fans

abyssal plains

Includes use on level 3 under oceanography(1).

SA continental rise

ocean basins

ocean floors

oceanography plains

Abyssinian Rift valley

use Ethiopian Rift

abyssolith

use batholiths

Ac

use actinium

Acadian

Provincial series, Canada. Includes use on level 3 under age terms(1). See list $E$.

BA Middle Cambrian Cambrian

BT Paleozoic

NT Lancara Formation

SA Acadian Phase

Canada

Acadian Orogeny use Acadian Phase

Acadian Phase

Use Acadian for the age. Before 1978. also search Acadian Orogeny. Also search orogeny AND Acadi-

an.

UF Acadian Orogeny

BT Devonian

SA Acadian Antler Orogeny orogeny

Acantharins

Suborder. Includes use on level 2 under Radiolaria(1). See list F.

BA Porulosida Radiolaria

BT Invertebrata 


\section{BA Osteichthyes \\ Pisces \\ BT Vertebrata \\ acanthodians \\ use Acanthodii \\ Acanthodii \\ Subclass. Includes use on level 3 un- der Pisces(1) Placodermi(2). Also search acanthodians. \\ UF acanthodians \\ BA Placoderm! \\ Pisces \\ BT Vertebrata \\ acanthopores \\ SA Bryozoa \\ Acceglio \\ Village in S \\ BT Italy \\ SA Piedmont \\ accelerograms \\ Includes use on level 3 under seis- mology (1). Also search acceleration: accelerographs: accelerometers. \\ SA engineering geology seismology seismometers}

\section{accessory minerals}

Includes use on level 3 under petrology(1). Before 1978, search minerals AND accessory.

BT minerals

SA heavy minerals

Accomac County

use Accomack County

Accomack County

On the Delmarva Peninsula. Also search Accomac County.

UF Accomac County

BT Virginia

United States

Accra

City on the Gulf of Guinea.

BT Ghana

\section{accretion}

Term used for sedimentation through 1977. After 1977, term includes use under planetology(1) as genetic concept for the Moon and planets.

SA deposition

Moon

planetology

sedimentation

accumulation

Used as a general term.

SA deposition

glaciers

ice

precipitation

snow

accuracy

Used as a general term.

SA calibration

corrections

efficiency

errors

reliability

Acer

Genus. Includes use on level 3 un der angiosperms(1) Dicotyledoneae(2).

BA Dicotyledoneae angiosperms

BT Plantae

Acheulean

use Acheulian

Acheulian

Archaeologic classification.

UF Acheulean Acheullian

BA Paleolithic
BT Cenozoic

Acheullian

use Acheulian

achondrites

Includes use on level 3 under mete orites(1).

$\mathrm{BA}$ meteorites

SA chondrites

howardites

stony irons

acid mine drainage

Includes use on level 3 under engi-
neering geology(1) or geophysica

Before 1978, also search drainage

AND mines.

SA drainage

environmental geology

mines

pollution

sulfuric acid

acidic

A valid level 2 index term through

1977. After 1977. use acidic com

position on level 2 under igneous rocks (1).

\section{acidic composition}

Term introduced in 1978. Includes use on level 2 under igneous rocks(1). Before 1978, also search acidic

SA acids

composition

igneous rocks $\mathrm{pH}$

acidity

use $\mathrm{pH}$

acids

SA acidic composition

amino acids

compounds

fatty acids

fulvic acids

humic acids

$\mathrm{pH}$

sulfuric acid

acmite

BA pyroxene group

chain silicates

silicates

BT minerals

SA aegirine

Aconcagua Province

Central Chile. Also search Acon-

cagua.

BT Chile

NT La Ligua

acoustic logging

use acoustical logging

acoustic methods

use acoustical methods

acoustic surveys

use acoustical surveys

acoustic waves

use acoustical waves

acoustical

A valid level 2 index term through 1977. After 1977. use acoustical logging on level 2 under well-logging(1).

\section{acoustical logging}

Not a valid index term from 1975 to

1977. After 1977, includes use on

level 2 under well-logging(1). Before

1978. also search well-logging AND

acoustic; acoustic logging.

UF acoustic logging logging. acoustical

$B A$ well-logging

SA acoustical methods acoustical surveys

acoustical methods

Includes use on level 2 under geo physical methods(1). Also search acoustic methods: acoustic.

UF acoustic methods

BA geophysical methods

SA acoustical logging

acoustical surveys

deep-tow methods

echo sounding

methods

sonar methods

coustical properties

surveys(1).

SA engineering geology geophysical surveys physical properties properties

\section{acoustical surveys}

Includes use on level 2 under geophysical surveys(1). Also search acoustic surveys: acoustic.

UF acoustic surveys

BA geophysical surveys

BT surveys

SA acoustical logging acoustical methods sonar methods

\section{acoustical waves}

Also search acoustic AND waves: acoustical AND waves; sonic waves: sound waves.

UF acoustic waves sonic waves sound waves

SA waves

Acqui

Town in
BT Italy

SA Piedmont

acquisition, data

use data acquisition

acritarchs

Hystrichosphaerids are included

here and under Dinoflagellata. In

cludes use on level 2 under palyno-

morphs(1). See list $F$.

BA palynomorphs

NA Baltisphaeridium

NZ Hystrichosphaeridae

SA Dinoflagellata

actinium

Includes use on level 1 and 2 as a

chemical element (list D).

UF $A C$

SA elements

actinolite

BA amphibole group chain silicates silicates

BT minerals

SA actinolite facies asbestos

actinolite facies

Term introduced in 1978

BT facies

SA actinolite metamorphic rocks

\section{Actinopterygi}

Includes use on level 3 under Pisces(1) Osteichthyes(2). See list F.

BA Osteichthyes Pisces

BT Vertebrata

NA Amiidae

SA Cyprinidae fish

action, frost

use frost action

activation analysis

Including field applications and instruments. Includes use on level 3 under chemical analysis(1) methods(2). Also search activation.

UF radioactivation analysis

SA analysis

chemical analysis

isotopes

neutron activation analysis

activation energy

SA energy particles

active faults

BA faults

active layer

As of 1978, term is used on level 2

under permafrost(1).

UF annually thawed layer layer, active mollisol

SA permafrost soils

activity

Includes use on level 3 under geo chemistry(1).

SA geochemistry

activity, igneous

use igneous activity

actual age (absolute age) use absolute age

Acungui Group

BT Precambrian

SA Brazil

Parana

Ada County

SW Idaho.

BT Idaho

United States

Adak isiand

In central part of Aleutian Islands SW of Alaska Peninsula.

BT Alaska 

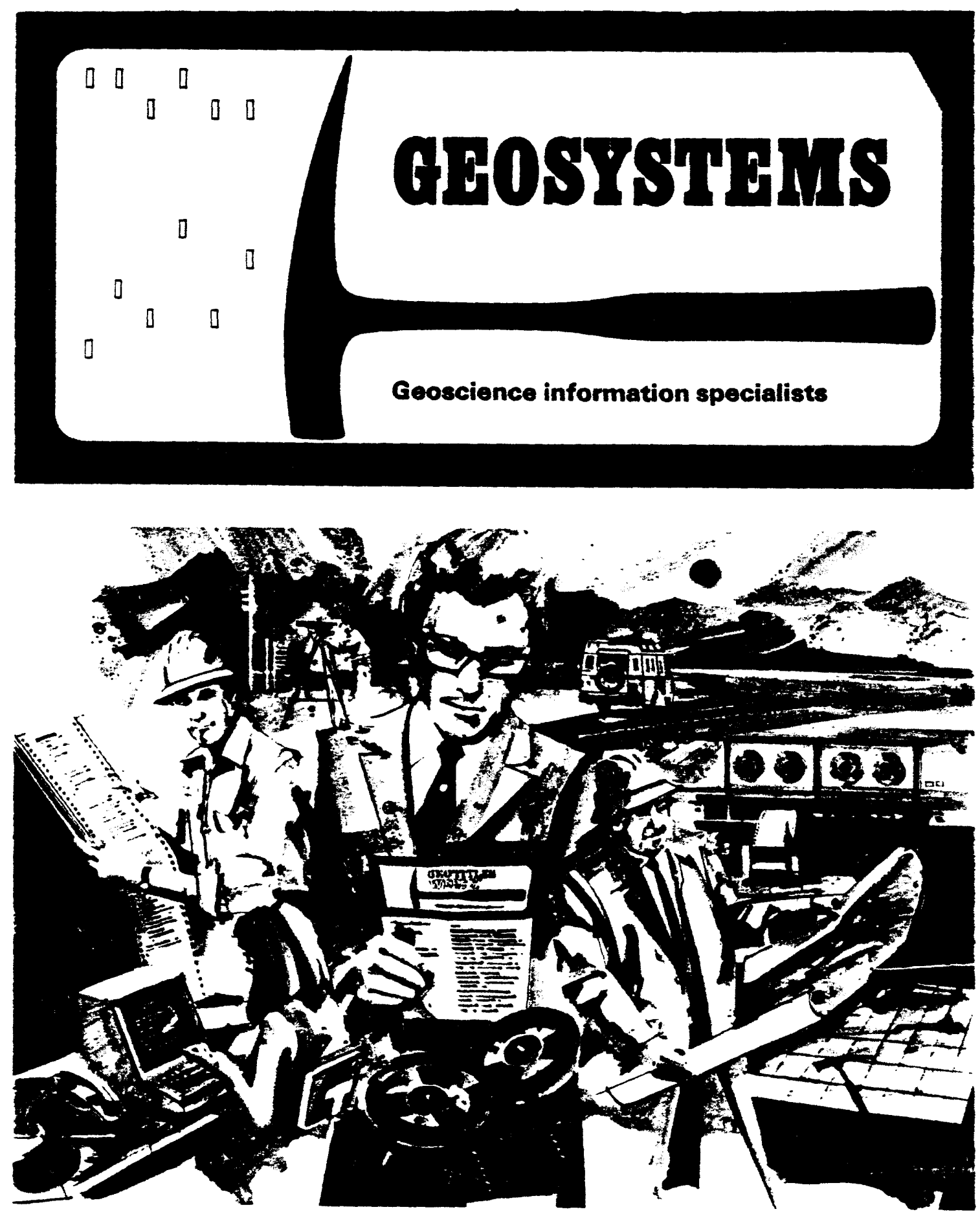


\section{WHAT GEOSYSTEMS DO}

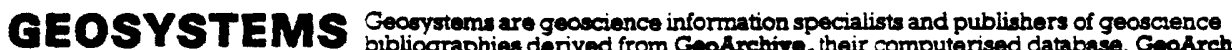
bibliographies derived from GeoArchive, their computerised databese. GeaArehive has been under development since 1968 and with over 500,000 references is now the world's most comprehensive and best-indexed geoscrence database. The iniormation in Geafrehive can be accessed through publicanons, by online retrieval, by means of current or retrospective profiles, or from leased magnetic tapes. INFOENATIOA Geosystems inclex more than 100,000 references each year. Apart from current the seventeenth century. A lead-in to this earier literature is being provided by a current project to index 10,000 geoscience bubliographres : in addition, the more important journals are being indexed from the îrst issues.

Geosystem's critena for inclusion of matenal in GeoArchive are that the source should be in the public domain and should have information content, even if the reference is to a small news item in a magazine. More than 10,000 geoscience serials have been identified by Geosysterns and included in a computensed file called Geoerials; about 5,000 of these are currently being published and are indexed for GeoArchive. Booiks from more than a thousand publishers are also uncluded. Geosystems are the oniy organisation to process geoscience conference matenal systematically severa bundred conferences are covered each year. About 100,000 geological maps from the Institute of Geological Sciences libranes are being indexed and added to GeoArchive. Doctoral diesertations are also included.

To achieve such comprehensive coverage of the literature, Geosystems use the resources of many large specralised libranes, ensunng unbiased internatona coverage. The budgetary constraints on acquistion expenenced by a single ibrary are also avoided.

11D EXIV Geosystems have developed Gecanura, a sophusticated modern thesauroclassification of geoscience which has subject, geographical and stratugraphic thesauri arranged hierarchically, with an alphabetcal index of over 5,000 terms. Followng more arranged hierarchically, with an alphabetcal index of over 5.000 rems. Following more for geoscrence, with many advantages over other systems which lack proper or geoscience, with many adva

\section{$\lim _{0 \rightarrow 3}$}

$\sin$

$\cos$

(1)

$\rightarrow \times$ atisurost

Qudieradinger

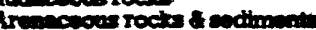

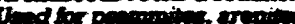

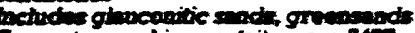

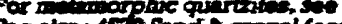

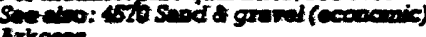

Arkanes

Gropuche

belodes turtiditio

Arythoov rocic

\begin{tabular}{|c|c|}
\hline (7000) & 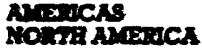 \\
\hline$\omega_{3}$ & anins \\
\hline 80 & Intrioe Plain \\
\hline $\begin{array}{l}(44) \\
7447 \\
7447 \\
74.0\end{array}$ & 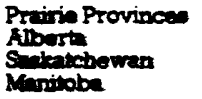 \\
\hline
\end{tabular}

(seo) masozoic

$(+\infty)$ Junssuc

(670) Upper Juraseric

(615) Oxiordian

(6:0) Kimmeridgian

(6e5) Tithomian

Extracts from subject. goographicel and strutigraphic thesauri.

Gecenure provides the facility for carrying out general or highly specific retnevais. From the extract above. ior example, a retreval on sandstones and arkoses could be achieved using $5533 / 5534$ to grve very specific references, or 5532/5534 to include papers on arenaceous rocks in general, or broadened still further to $5530-3532 / 5534$. Terms included in the scope notes are autornancally included in the search so that a retrieval on 5535 Greywackes would aiso retrieve references on turbidites. A search may be further refined by introducing geographical and stratigraphic constraunts ; the may be furher renned by introducing geographical and strangraphic constralnts; the geographical and stratgraphic thesaun may also be used independently to carry our retrievals on specific areas or geological perods. Thus a bighly specinc search tor reierences on a precuseiy defined toptc - for example, Upper Jurassic sandstones of Sasikatchewan - may be accomplished quejely and aceuratel
codes in logral combination : 5333 and (7447) and (670/885).

Geosystem's ectitonal team is composed of geologists who have been specailly trained in indexing. They scan the original publicanons and asngn approprate terms from Gecemres so that relevant retreval is assured in response to a request. Certain ategories of data are extracted and tagged for subsequent special retrieval ; it has been found that such specific undexing is more useful than inclusion of a free-format been found that such specific indexing is more userul than inclusion of a free-format abstract, and so the tagging system is being expanded. At present, Lo exaraple, he perrinent bibliographical data from geological maps.

COMEA C Citations relating to all aspects of the geosciences are indexed by Geosystems, including, but not limited to, the followng subjects :
Regronil geologr
zatianes
Economic geology
Mining \& potroieum proctuctor
Environmental geology
Gecomechanio
Ocmology
Enorgy sources
Minoral depont
Aydrology \& hydrogeology Mineralogy
Petrology
Palecontology
Geopbyiacs
Physacal geology
Tectonicas
Structural geology
Geomorpbology
Geochronology
Stratigraphy
Paieogeology
Mothodology 


\section{PRODUCTS AND SERVICES}

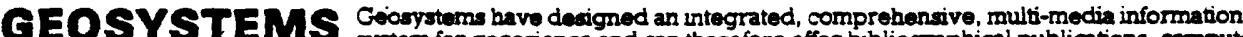
syatem for geoecience and can therefore offer bibliographical publications. computer output on microfim or microfiche (COM) cumulations, computer retrieval, leased magnetic tapes, and several special services. All work by Geosystems is performed in confidence, and no disclosure is made to third parties.

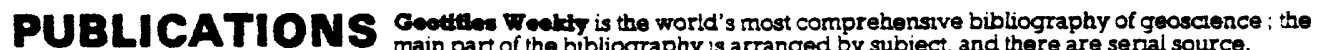
main part of the bibliography is arranged by subject, and there are sernal source. author, geographical and stratgraphic indexes in each issue. It is sent by air.

Cececom Danth is a bimonthly bibliography of economic geology, with special emphasis on mathematical methods and computer applications. It covers the whole field of applied geology, uncluding minung, petroleum, enguneering geology, geophysics and geochemistry.

Ceesedemce Decumentation is a bumonthly joumal for geology librarans, information specialists and research workers. It is the only journal in this field and contains papers, news items and Geodoc index. which gives information on new literature in the field and lists new geoscrence seriais.

DH Hegraphy of Vextebrate Peloentology is a quarterly joumal published in association with the Society of Vertebrate Paleontology, and continues their Bibliography of Vertebrate Paleontology and Related Subjects. The new senes started in September 1973.

Cecundale is a computer listing of more than 10,000 geoscience serial publications identified by Geosystems, arranged by ttle abbreviation.

Geosarus is Geosystems' thesaurus for geoscience and ts the basts of the indexing system used for GeoArehive and the derved publicanons. It is avavlable as a separate publication, but is sent free to all Geotites Weekly subscribers.

Ceotiter Repertorim is a computer output on merofilm (COM) cumulated index to Geotive Wealdy from 1969 . Further information is avaliable on request.

CEOARCMIVIE GeoArchive, the computerised database, may be accessed three ways: 1. Geedrohivo Omlthe is made avarlable by Geosystern through the Lockheed DULOG Information Retrieval Service. Further informanon on DLILOG can be obtaned from Lockheed Information Systerns, Coce 5020/201, 325i Hanover Street. Palo Alto. Califormia 94034, USA. or local DLALCG representative in New York, Washington, Los Angeles, and London.

2. Coan rehutve treales are available from Geosysterns in London. Users submit search questions and their profile is run against GeoArchive (retrospectuve profiles), or against new additions to the database (current proflies). Profiles can be modified as required.

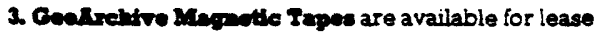

SPECLA 1. Inxd Cepr Sarviee: Geosystems recognuse that supplyng relevant references to the literanure may not always be sufficient. Where a reference is required urgently and SERV/CES is not avalable locally, Geosystems will usually be able to help obtain it

2. Geabatn Savdea: Geosystems staff see more current geoscience literature than any other organiation; special monitorng of a defined topic or geographucal area can thorefore be arranged, with information forwarded daily, or less frequently, as required.

3. Iherature Inodew surdee: Geosystems can-provide revews of the avalable iterature on a topic, following clients' instructions.

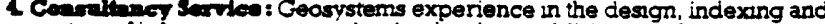
operation of information systems has lead to the establisinment of a consultancy service. Expenenced senior staff are avalabie for asengnments, such as information systems dengn, library automation, indexang, eaing, and training geologists, libranans and information scientists at all leveis in geoscience information work.

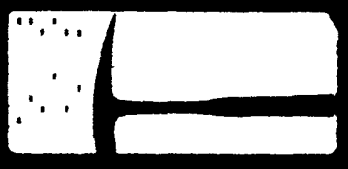




\section{ANNUAL SUBSCRIPTIONS AND FEES}

1. Publications

1. Geontles Weekly (uncludes Geosaurus)
2. Geocom Bulletn
3. Geoscience Documentaton
4. Gibliography of Vertebrate Paleontology
5. Geosenals
ALL GEOSYSTEMS PERIODICALS
6. Geosaurus

Geoarchive

.. Online sernce va the Lockheed DLALOG Informanon Rerneval Service (telecommuncauon charges are extra) Offine prunang of references va DLALCG. each

2. Pronles service

Retrospectuve search

Current proñle. per year

Each reierence printed

3. Magnenc tape leasing

3. Special Services
¿. Hard coov service
2. Geodata service
3. Literature seview service
4. Consultancy service

USS

5450 by aur

590

$\$ 60$

$\$ 36$
$\$ 25$

$\$ 600$

?lease enqure

s70/hour

s 0.15

$\$ 50$

$5 \mathrm{i} 00$
$30: 5$

Please enqure

From 55

From $\$ 50 /$ month

From $\$ 100$

Please encure

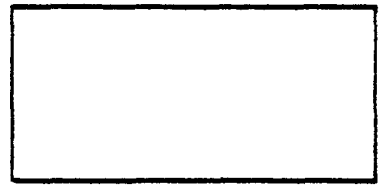




\title{
APPENDIX 3 \\ Reference Manual for machine-readable bibliographic descriptions
}

\author{
Prepared by
}

the UNISIST/ICSU-AB Working Group on Bibliographic Descriptions with the assistance of ICSU and ICSU-AB member services

Compiled by M.D. Martin

\section{Unesco, Paris 1974}




\section{Acknowledgements}

The preparation of the UNISIST Reference Mamual has involved the participation of a large number of individuals and organizations, whose assistance is gratefully acknowledged. They include all those individuals who served as members or observers of the UNISIST/ICSU-AB Working Group on Bibliographic Descriptions; the member services of ICSU.AB, and other organizations represented on the
Working Group; the University of Sheffield Postgraduate School of Librarianship and Information Science, which was responsible for testing the first draft of the Manual; and all organizations which contributed time and effort in carrying out the test.

The preparation of the Manual was undertaken with the financial support of Unesco and ICSU. 


\section{Introduction}

This Reference Manual, prepared by the UNISIST/ICSU.AB Working Group on Bibliographic Descriptions, represents the results of some four years' work by an international group brought together within the framework of UNISIST, the ICSU-UNESCO joint project to study the feasibility of a world science and technology information network.

The Working Group (referred to hereafter as 'WGBD') has been a special concern of the ICSU Abstracting Board in co-operation with Unesco. It has included direct or indirect representation of all the ICSU-AB member services, together with other experts serving in an individual capacity or as representatives of organizations with special interests in mechanized information processing, including ISO, FID, IFLA, LATUL, INIS and OECD.

The scope and purpose of the WGBD's work has been to define, for most types of scientific and technical literature commonly covered by secondary information services, a set of data elements which will constitute an adequate bibliographic citation. For each type of literature, an essential minimum set is identified, together with additional supplementary elements. It cannot be emphasized too strongly, however, that the sets of data elements de. fined in the Manual are not to be regarded as exclusive. The WGBD has been well aware that for many applications the bibliographic description must be supplemented with additional information. The group's purpose has been to define a minimum set of-data elements which could be agreed upon by abstracting and indexing services, to facilitate the exchange of information between services, and to emable them to present their computer-based products to the user in a more compatible and therefore more easily usable form. It is hoped, nevertheless, that this Manual will find other applications in the wider field of information procesaing and exchange.

The scope of the WGBD's recommendations is further limited to defining the representation of these data elements as they should appear in a machine record for exchange purposes between two or more computer-based systems. Nothing in the Reference Mamual should be interpreted as attempting to lay down standards for input or display formats. A local system may choose any input format which is convertible by computer programme to the exchange format; and the exchange format has been designed with the aim of retaining the highest degree of flexibility for deriving different types and arrangements of output, whether in the form of computer printout or printed publications such as abstracts journals and indexes.

It has been the policy of WGBD to work as closely as possible within the framework of ISO recommendations wherever they exist. Some aspects of the group's work have been or will be submitted to ISO for consideration as international recommendations; and reference is made to current and forthcoming ISO recommendations and standards, wherever possible.

In particular, the bibliographic exchange format des- cribed in the Manual is an implementation of an international standard ISO 2709: 'Documentation - Format for bibliographic information interchange on magnetic tape' [1].

A first draft of the Reference Manual was completed early in 1972, and was the subject of a test conducted by an independent expert organization (University of Sheffield, Postgraduate School of Librarianship and In. formation Science), with the co-operation of an international group of libraries and secondary information services. A report was submitted to a Working Group meeting in November 1972, and the results of the test and subsequent discussions have been incorporated in an extensive revision of the Manual.

It must be emphasized that the Manual does not set out to be a training manual for staff who are unfamiliar with bibliographic problems or computer applications in this field; nor is it intended as a cataloguing manual to be placed in the hands of library or information staff engaged in the actual preparation of bibliographic descriptions on a day-to-day basis.

It is to be regarded as a specification manual for technical management and systems design staff in information centres, abstracting and indexing services, and libraries, to assist them in designing local systems in such a way that they can exchange files in either direction with other centres which have adopted the Reference Manual format. The reader of the Mamual is therefore expected to be already familiar with the fundamentals of bibliographic data handling in mechanized and manual systems.

It also needs to be emphasized that the Reference Mamual does not represent a single monolithic standard which must be applied unvaryingly to all situations. There are various degrees of freedom in the application of the conventions which it describes: and it is expected that individual users or other groups will select a level of implementation which is appropriate to their functional requirements. Areas of implementation choice are identified as they arise in Parts 1 and 2 of the Manual.

The Reference Monual is presented in four parts.

Part 1 defines in broad outline the format and content of bibliographic records, the notions of literature type and bibliographic level, and the sets of data ele. ments regarded as essential for each type of literature.

Part 2 gives detailed definitions of each individual data eiement and, where necessary, guidance on how the data element content is to be selected and entered.

Part 3 provides more detailed specifications of the record format, iharacter coding and other aspects which are primarily of concern to computer system designers.

Part 4 consists of a set of examples showing complete bibliographic descriptions prepared in accordance with the conventions described in the Manual.

Additional background information is given in a series of appendices. 


\section{Chapter 1.1}

\section{BIBLIOGRAPHIC RECORDS}

For the purposes of the Reference Manual, a bibliogruphic record is defined as a collection of information which pertains to a single document, and which is stored in machine-readable form as a self-contained and unique logical structure. A bibliographic record is likely to inchude a bibliographic description of the document in question; some form of classification and/or indexing applied to the subject content of the document; an abstract or summary; and other information. The Reference Manual is concemed only with that part of the record which constitutes the bibliographic description. Additional user-defined data fields will be required in order to carry such other information as may be needed for a particular application.

From the computer system point of view, it should be noted that the Reference Manual definition of a bibliographic record constitutes a logical record, with no special assumptions regarding the breakdown into physical records or blocks on a recording medium.

\section{Documents}

A document is any published item which is to be described in a bibliographic record. Since the Reference Marual is primarily designed for secondary information services which provide access to current and pent literature, a document need not be a single physical piece. It may be an article, chapter or other contribution; it may be a volume or monograph; or it my be a (non-serial) collection which is to be treatod as a single item for purposes of recording.

Specific classes of document ('iterature types') which are covered in the present Manual are:

Serials (including serial contributions)

Books (including book chapters, and collective works)

Conference publications (including individual conference papess)

Reports (inctuding report chapters)

Theses and dimertations

Patent documents

\section{Bibliographic description}

The bibliographic description of a document is a collection of information which is intended to piovide a usique and unambiguous reference, such as will enable a libraian to identify and retrieve the document, or an intending purchaser to order it from the publisher or other source. It must be borne in mind that the prime function of secondary information services is to inform their users of the existence of relevant documents, and to provide this information in such a form as to enable the user (a) to retrieve relevant references (b) to assess the iikely value of the documents referred to and (c) to obtain original documents on the basis of the references given.

The most important function of the bibliographic description is to meet objective (c), although some data elements (title, author name, author affiliation, etc.) may be considered equally important for retrieval or relevance asessment. It is important to draw a clear distinction between 'bibliographic description' and 'bibliographic record'. The term 'bibliographic description' refers to the information which is required in order to describe a given document. A bibliographic description is made up of a number of 'data elements. The term 'bibliographic record', property speaking, refers to the structure within which the bibliographic description is stored in machine-readable form. A bibliographic record is made up of a number of 'data fields'

\section{Data elements}

A data element is a piece of information forming part of the bibliographic description and having a specific functional relationship with the content of the document to which the record refers. Examples of data elements are: title, author name, patent number.

Data elements are separately identified within the machine record so that each element can, if desired, be independently accessed and manipulated by computer programme. This is achieved by dividing the bibliographic record into a series of data fields, identified by field numbers or tags. Data fields are further subdivided into subfieids, introduced by subfield identifiers. Esch data element nomally occupies a given subfield of a tagged data field.

\section{Data fields}

More details of the format and structure of the machine record are given in Part 3. For the purposes of Parts 1 and 2 of the Manual, however, it is important to have a basic understanding of the layout of data fields.

The machine record has three distinct parts: a fixedlength leader (the content of which is described in Part 3); a variable-tength directory; and variable-tength data fields. The directory may be regarded as a list of field numbers or tags identifying the data fields which are present in the record, and providing pointers to the location of the fields. within the variable-tength data part of the record. Thus the field number or tag which identifies the data field is not contiguous with the data field itself.

Each data field begins with two or more indicator characters, followed by one o: more subfietds, followed by a field separator.

The number of indicator characters at the beginning of each field is predetermined for a given implementation of the Reference Manual: the Manual requires a minimum of two, but additional indicators may be included at the user's discretion. Each subfield consists of a subfield 
also be a finite collection of such items (i.e. a moiti-volume work); published simultaneously of during a predetermined period of time.

A book may contain individual chapters or parts by separate authors and/or covering separate topics, so that in secondary information services it may be appropriate to treat such chapters or parts as 'documents' in their own right.

\section{Reports}

'Reports' are also particularly difficult to define: again, the following are suggested as guidelines.

A report is a published item, usually not available to be purchased through normal commercial channels, but obtainable from the organization resporisible for its issue or from a clearingthouse such as the United States Govemment NTIS. It is usually : but not always - identifled by a report number; and may exhibit some of the characteristics of a serial, in that the mumbering scheme often has a component for 'report series', and there may sometimes be a series title.

A report may contain individual chapters or parts by separate authors and/or covering separate topics, so that in secondary information services it may be appropriate to treat such chapters or parts as 'documents' in their own right.

\section{Theses and disertations}

Theses and dissertations may be defined as treatises which have been submitted to a university or other educational institution in fulfilment of the requirements for a higher degree course. Most frequently they are not 'published' in a conventional sense, but they may be available through the university concerned or through a clearinghouse system. Some theses are subsequently published in book form, and it would be recommended that these should be treated as 'books', with the option of including data elements appropriate to a thesis as part of the bibliographic description.

\section{Patent documents}

Pated documents ase documents publistied or bid apen for public inspection by a patent office, andsfaling imo one of the following categories: patents, inventors? certificates, utility models or certificaten, and applications therefor Since the legal definitions of thee differutt types depend on differing national prectices, and since. they will generally be well understood by those services which cover patent documents, no fuller definition will be attempted in the Mainual. $A$ list of patent documents arranged by type of document is given in Appendix $D$.

\section{Conference publications}

Conference publications are a special category, in that they do not in themselves constitute a separate literature type. Papers presented at a conference may be published in any of a number of forms: as books, as contributions to or issues oi a serial, or as reports.

For the purposes of the Reference Mamual, individual papers which happen to have been presented at a conference are not necessarily to be regarded as conference publications, although some users may consider it worthwhile to include a reference to the conference in such cases. Reference to the conference is regarded as essential if and only if the document(s) are explicitly described as constituting the official publication of the conference proceedings. This may, again; apply to a book, a serial issue, or a report.
Consequently, 'conference publication' is never a complete description of the literature type: the document(s) concerned must also be identified as belonging to one of the:other categories named in the last paragraph.

For any document identified as belonging to a conference publication, a small set of additional data elementa: is defined, to be added to the set of essential elements required for whatever main literature type is invoked.

\section{Literature type codes}

In the bibliographie record; the literature type or types to which the document is considered to belong are represented by codes in the leader position of the record (see Part 3 for details).

The following literature type codes may be used either in isolation, or in combination if the document has characteristics of more than one type:

Serial, Book, Report, Thesis or Dissertation, Patent.

The following literature type code may be used onty in combination with another code:

Conference publication.

Note, however, that it is not obligatory to use more than one literature type code if the document has characteristics of more than one type. It is equally permissible, as an implementation option, to assign a document to a single main type, while including in the bibliographic description some data elements which describe aspects of a different type. For example, if a report belongs to a report series, it is permissible to include an ISSN and a series title in the record without formally identifying the. document as being of type 'serial'.

The selection of essential data elements for the bibliographic description is dependent first on the assignment of the document to a given literature type or types; and secondly, on a decision as to the bibliographic level at which the document is to be treated. The notion of bibliographic level is defined in the next chapter.

\section{Chapter 1.3}

\section{BIBLIOGRAPHIC LEVEL}

The notion of 'bibliographic level' may be novel to some users, but it is increasingly widely employed in mechanized information systems such as INIS and MARC.

Its purpose is to define unambiguously the different types of record which are required when the document to be recorded is:

(a) a part of a larger physical piece: tor example, an article in an issue of a journal; a chapter in a book; a section in a report.

(b)a single piece in its own right: for example, an issue or part of a serial; a book in one volume; a report; a patent document.

(c) a collection of physical pieces: for example, a multivolume work issued at one time, or over a predeter. mined and finite period of time.

When the document selected for recording in the machine system is a part of a larger physical piece, the record is said to be at the analytic level.

When the document is a single piece in its own right, the record is said to be at the monographic level.

When the document is a collection of physical pieces, the record is said to be at the collective level. 


\begin{tabular}{|c|c|c|c|c|c|c|c|c|c|c|}
\hline \multirow[t]{2}{*}{ Tae } & \multirow{2}{*}{$\begin{array}{c}\text { Field nane } \\
-\end{array}$} & \multicolumn{2}{|c|}{ Sertel } & \multicolumn{3}{|c|}{ Book } & \multicolumn{2}{|c|}{ Report } & \multirow{2}{*}{$\frac{\text { Inee1e }}{M}$} & \multirow{2}{*}{$\frac{\text { Petent }}{A / M}$} \\
\hline & & $\boldsymbol{A}$ & $\boldsymbol{H}$ & $\mathbf{A}$ & $\mathbf{M}$ & c & $\mathbf{A}$ & $\mathbf{M}$ & & \\
\hline $1 \phi 1$ & $\begin{array}{l}\text { Intermational standard Serial } \\
\text { Nuber (ISSN) }\end{array}$ & $\mathbf{E}$ & $\mathbf{E}$ & & & & & & & \\
\hline 42 & coDen (interil alternative to ISSN) & * & * & & & & & & & \\
\hline Ads & 'Short title' of serial & $\mathbf{z}$ & $\mathbf{E}$ & & & & & & & \\
\hline Ap/4* & Seriee deeigmetion & & & & & & & & & \\
\hline Ads & Volume unimer & $\mathbf{s}$ & $\mathbf{E}$ & $\mathbf{E}^{\prime}$ & $\mathrm{E}^{1}$ & & & & & \\
\hline 196 & Isene or part number & $\mathbf{z}$ & $\mathbf{E}$ & $\mathrm{E}^{1}$ & $\mathbf{E}^{1}$ & & & & & \\
\hline Adn & $\begin{array}{l}\text { Other identification of losue or } \\
\text { part }\end{array}$ & $\mathbf{E}$ & $\mathbf{z}$ & & & & & & & \\
\hline 108 & Title of contribution $(\operatorname{ann} 1 y+1 c)$ & $\mathbf{E}$ & & $\mathbf{E}$ & & & $\mathbf{E}$ & & & \\
\hline $1 \phi 9$ & $\begin{array}{l}\text { Ttlo of volue, monogreph or } \\
\text { patent docuent }\end{array}$ & & $\mathbf{s}$ & $\mathbf{E}$ & $\mathbf{E}$ & & $\mathbf{E}$ & $\boldsymbol{E}$ & $\mathbf{E}$ & $\mathbf{E}$ \\
\hline A1ф & Title of collection & & & $\mathbf{E}^{1}$ & $\mathbf{E}^{1}$ & $\mathbf{E}$ & & & & \\
\hline 411 & $\begin{array}{l}\text { Person associated with a } \\
\text { contribution }\end{array}$ & $\mathbf{E}$ & & $\mathbf{z}$ & & & $\mathbf{E}$ & & & \\
\hline$A 12$ & Person assoclated with a wonograph & & $\mathbf{E}$ & $\mathbf{E}$ & $\mathbf{E}$ & & & $\mathbf{E}$ & $\mathbf{E}$ & \\
\hline$\$ 13$ & Person aseoclated with a collection & & & & & $\mathbf{E}$ & & & & \\
\hline
\end{tabular}

1. For books (at analytic and monographic levels) fields $A \emptyset 5, A \varphi 6$ and $A 1 \emptyset$ are essential only if the item is part of a collection having numbered parts.

- Tags marked with an aterisk indicate data elements which are never designated as essential.

\begin{tabular}{|c|c|c|c|c|c|c|c|c|c|c|}
\hline \multirow[t]{2}{*}{ The } & \multirow[t]{2}{*}{ " Morde nane- } & \multicolumn{2}{|c|}{ Serial } & \multicolumn{3}{|c|}{ Book } & \multicolumn{2}{|c|}{ Report } & \multirow{2}{*}{$\frac{\text { Thesis }}{M}$} & \multirow{2}{*}{$\frac{\text { Petent }}{\mathcal{A M}}$} \\
\hline & & $\Lambda$ & $\mathbf{M}$ & $\Delta$ & $\mathbf{M}$ & c & $\Lambda$ & $\mathbf{M}$ & & \\
\hline 114 & Affiliation - contribution & $\mathbf{E}$ & & $\mathbf{z}$ & & & $\mathbf{E}$ & & ${ }^{\circ}$ & \\
\hline 115 & Affiliation - monocraph & & $\mathbf{z}$ & & & & & & & \\
\hline $116 *$ & Affillation - collection & & & & & & & & & \\
\hline$\triangle 17$ & Corporete author - contribation & $\mathbf{E}$ & & $\mathbf{E}$ & & & $\mathbf{E}$ & & & \\
\hline A18 & Corporete author - monorraph & & $\mathbf{E}$ & & $\mathbf{E}$ & & & $\mathbf{E}$ & & \\
\hline A19 & Corporete author - collection & & & & & $\mathbf{E}$ & & & & \\
\hline 12 & Pace anbers & $\mathbf{E}$ & $\mathbf{E}$ & $\mathbf{E}$ & & & $\mathbf{c}$ & & & \\
\hline 121 & Date of tesue or ingrint & $\mathbf{E}$ & $\mathbf{s}$ & $\mathbf{E}$ & $\mathbf{E}$ & $\mathbf{E}$ & $\mathbf{z}$ & $\mathbf{E}$ & $\mathbf{z}$ & \\
\hline 122 & Date of publication ${ }^{2}$ & & & & & & & & & $\mathbf{z}$ \\
\hline 123 & Lanounes (a) of text & $\mathbf{E}$ & $\mathbf{E}$ & $\mathbf{z}$ & $\mathbf{E}$ & $\mathbf{z}$ & $\mathbf{E}$ & $\mathbf{E}$ & $\mathbf{E}$ & \\
\hline$\Delta \mathbf{2 4}=$ & Lanouare (s) of sumartes & & & & & & & & & \\
\hline$\Delta 25$ & $\begin{array}{l}\text { Pabliehor, mane and location } \\
\text { (monoraph or colloction) }\end{array}$ & & & $\mathbf{E}$ & $\mathbf{z}$ & $\mathbf{E}$ & & & & \\
\hline 126 & $\begin{array}{l}\text { Intermational Stendard Book Number } 3 \\
\text { (ISBN) }\end{array}$ & & & $\mathbf{E}$ & $\mathbf{E}$ & $\mathbf{E}$ & & & & \\
\hline$\Delta \mathbf{2 7}$ & Dettion & & & $\mathbf{z}$ & $\mathbf{E}$ & E & & & & \\
\hline
\end{tabular}

2. Field A22 may be used for any literature type where the actual date of publication is known to differ from the nominal date of issee.

3. Field A26 (ISBN) may be used for any type of literature if the publisher has chosen to assign an ISBN to the piece being recorded.

- Tags marked with an asterisk indicate data elements which are never designated as essential. 
The category 'essential' is defined as meaning that any data element so described must be included in the bibliographic description if it is either present on or derivable from the original piece (in some instances, with the assistance of an external authority: for example, a serial title code - either ISSN or CODBN - is an escential element for serials, although it will usually be necessary to refer to ISDS or CODEN services in order to obtain the codel.

In this context, the designation 'eseential' must not be taken to mean that it is necesenrily valid in computer systems design to incorporate checks which require the inclusion of 'essential' data elements in all records for a particular literature type. In many ceases, valid circumstances may arise in which an 'eseential' data element is absent (e.g. authomhip may be unidentified; a report may be unnumbered). The category 'supplementary' is defined as meaning that:

(a) Any data element so describod is regarded as being relevant to the literature type in question, and likely to provide useful information, worthy of inclusion in the bibliographic record.

(b) The data element is not, however, an absolute requirement for complete, unambiruous bibliographic description, and its inclusion is therefore optional, at the discretion of the individual user or system designer. The fact that $a$ data element is not designated as either 'eseential' or 'supplementary' for a given literature type does not mean that it cannot or should not be included in bibliographic secords of this type, provided that it is present on or derivable from the piece. This again is an area where users of the Mermal are preseated with a free choice. The designation 'supplementary' is primarify intended to draw attention to data elements whose inclusion is recommended, but not regarded as obligatory.

Thus, the fact that a blank ('-') appears against a particular data element in the tables in this chapter does not neceasarily mean that the element in question is 'illogl' in the given context.

In particular, where an individuat piece has the chance. teriatics of more than one literature type, some users may wish to include whatever additiond dats elements are necessary for a full description. Others may prefer to limit the bibliographic record to the essential datz elements for one particular literature trpe, depending on the functional requirements of their data base. Either approach is an equally valid implementation of the Reference Manual

\section{Section 1.5.1: SERIALS}

\section{Bibliographic level}

The scope of the Reference Marual does not extend to the cataloguing of serials at the collective level (for which see, for example, International Standand Bibliographic Description for Serials [ 3] and Guidelines for ISDS [ 21). Since the main concern of the Reference Mamual is with the bibliographic description of individual scientific and technical documents, as covered in secondary information services, provision is made only for the description of serial contributions, at the analytic level, and serial issues or parts, at the monographic level, in the event that the issue or part is to be treated as a single document.

\section{Data element matrix for serials}

This matrix is a subset of the full data element matrix given in Chapter 1.4, showing those items which are considered to be essential data elements for serials, and those which are considered to be supplementary data elements. Detailed definitions of each element are given in Part 2 of the Manual, which can be referenced by the tag code shown in the matrix. Status code ' $E$ ' means that the data element must be included if present on or derivable from the original document (thus, for example, a serial title code - either ISSN or CODEN - is an essential data element even though it may not appear on the piece). Status code ' $S$ ' means that the data element is not a re. quired bibliographic data element, and that its inclusion is at the discretion of the individual user.

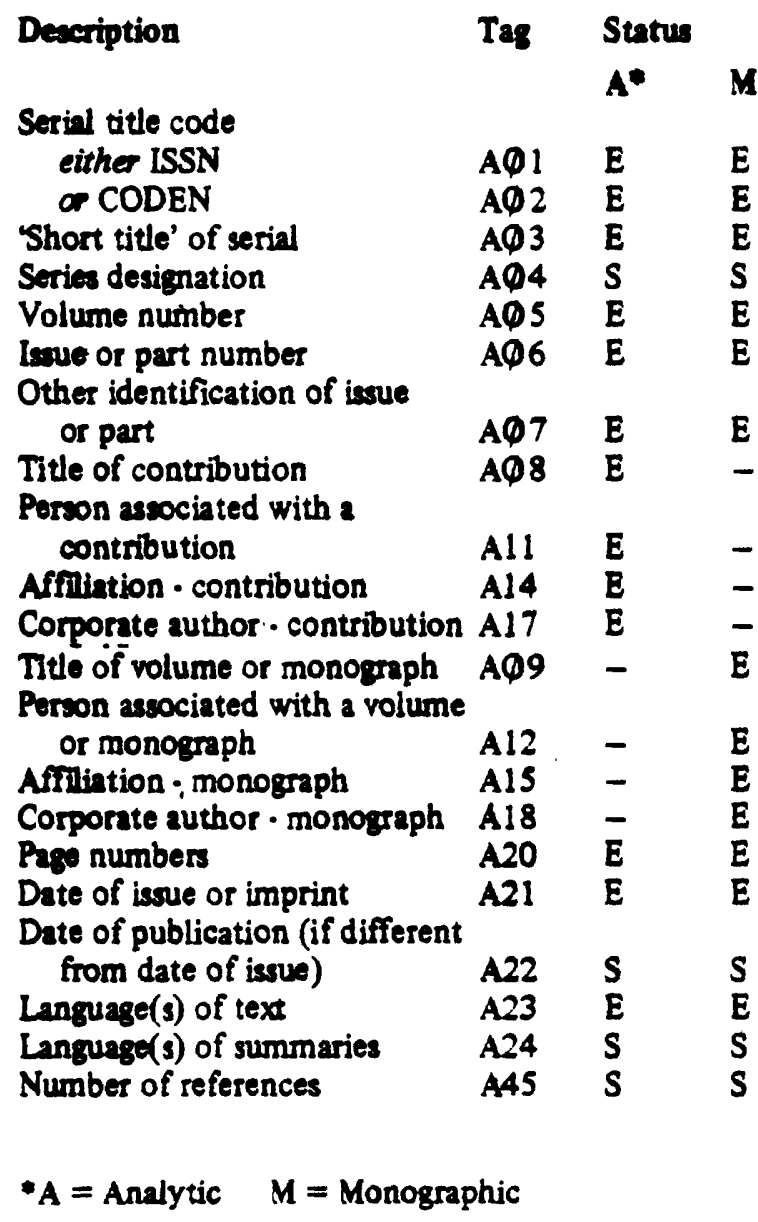

Bibliographic level

In this section, the notion of bibliographic level is used to distinguish between bibliographic records which refer to:

(a) A collection of books, treated as a single entity (collective)

(b) A monograph or single volume from a collection (monographic)

(c) A chapter in, or contribution to, a volume or monograph (analytic) 
Section 1.5.4: THESES AND DISSERTATIONS

\section{Bibliographic level}

Theses and dissertations are regarded as exclusively monographic publications; the analytic and collective levels are not used.

\section{Data element matrix for theses or dissertations}

This matrix is a subset of the full data element matrix given in Chapter 1.4, showing those items which are considered to be essential data elements for theses and disertations, and those which are considered to be supplomentary dats elements. Detailed definitions of each element are given in Part 2 of the Momual, which can be referenced by the tag code shown in the matrix.

Status code ' $E$ ' means that the data element must be included if present on or derivable from the original document. Status code ' $S$ ' means that the data element is not a required data element, and that its inclusion is at the discretion of the individual user.

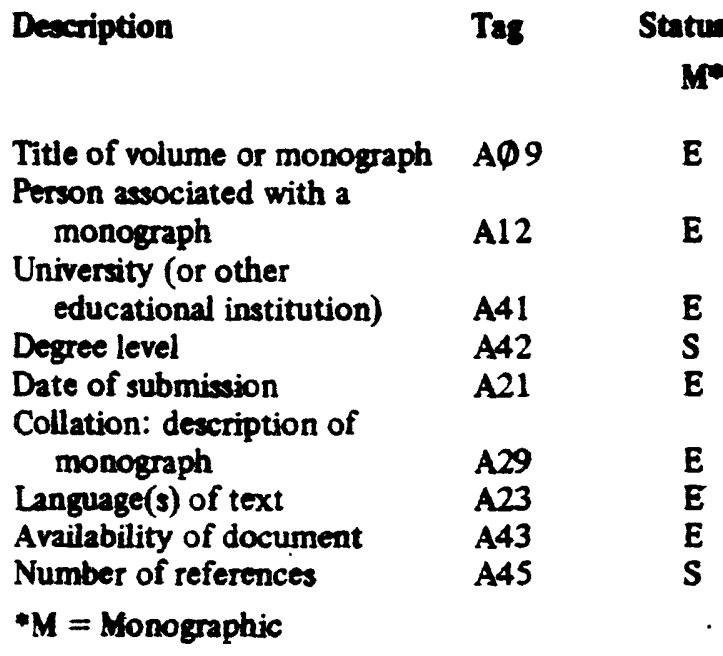

\section{Section 1.5.5: PATENT DOCUMENTS}

\section{Definition}

'Patent documents' include patents, inventors' certificates, utility models or certificates, and applications therefor. $A$ list of patent documents arranged by type of document is given in Appendix D. Throughout this section, the term 'patents' is to be read including all types of patent document as here defined.

\section{Coverage of patents by abstracting and indexing services}

Those abstracting and indexing services which cover patent documents may do so from either or both of two points of view: either in order to provide a comprehensive coverage of patents in a particular subject field, is suf Esient detail to satisfy legal as well as scientific interests; or more selectively, from the point of view of scientific and technical information content.

The minimum set of essential bibliographic data elements defined in the Reference Manual is designed to satisfy the requirements of this second approach. Some supplementary data elements are also included, but services which aim at a comprehensive coverage of patents as legal documents may need to add further data elements to this
Relationship between the Reference Manual and ISO proposals

In preparing this section of the Reference Manual, due account has been taken of ISO/TC 46 (Secr.611) 1072E (Fifth Draft ISO Proposal: Patents and like documents: bibliographic references: essential and complementary elements) [4]. All elements defined in the ISO Proposal as essential for 'short' bibliographic references to patent documents have been incorporated into the recommendations of the Reference Mamual.

\section{Relationship between the Reference Manual and ICIREPAT recommendations}

This section of the Reference Marual has been prepared after full consultation with representatives of the World Intellectual Property Organization (WIPO), and every effort has been made to retain a strict correspondence with the relevant recommendations of ICIREPAT * for the identification and presentation of bibliographic data elements appearing on patent documents.

\section{INID codes}

An ICIREPAT recommendation [5] provides for a numeric encoding scheme whereby the various data elements appearing on the first page of a patent document can be identified without knowledge of the languages used for the laws of the country in question. The scheme is already successfully applied by a number of Patent Offices.

This encoding scheme has been given the acronym 'INID' (ICIREPAT Numbers for Identification of Data).

INID codes are printed against relevant data items on the first page of a patent document. They are frequently enclosed in a small circle (see example below); or they may be printed in parentheses or brackets.

\begin{tabular}{|l} 
(54) $\begin{array}{l}\text { Methode et appareil pour faire des } \\
\text { plaques optiques en fibres conduc- } \\
\text { trices d'image fusionnées ensemble. }\end{array}$ \\
(72) Invention de : Frederik Harwood \\
Norton.
\end{tabular}

\section{Example}

As far as possible, a close correspondence has been maintained between UNISIST recommended data elements and ICIREPAT recommendations. The IND codes are included in the matrix of data elements for patent documents. It should be noted, however, that the conversion is not always on an exact one-to-one basis: see data element definitions in Part 2 for full details.

A complete list of $\mathrm{NDD}$ codes is given in Appendix E.

* Paris Union Committee for International Co-operation in Information Retrieval among Patent Offices. 


\section{DATA ELEMENT DEFINITIONS}

Purt 2 of the Reference Manual provides detailed definitions of data elements, arranged in alphanumeric order of data field codes.

Each data olement is defined in terms of:

(a) A brief nummary of the escential features (Field definition)

(b) A detailed deacription of the dats content / Date deacription)

(c) Examples, wherever neceasary and appropriate.

However, where a group of fields shares an identical structure, the field definition is given in fall for each one, but the date description is given only under the first, and an additional section defining the use of the individual fields is provided.

\section{General conrentions}

The following conventions are spplicable to all fields:

(a) Indicusions

Indicator potitions 1 and 2 are rewrved for the uses indicated in the Mrunat Whese thay are not so uned, they are entered ar zerom. If either or both of the indicator positions is used, the vive zero is nover actioned a spectic meaning; but, in goneral, the user systen he the option of entering a 2000 indicator with the meantes tot specified' (ceo, for example, field $A 98$ ):

In the exampiser, only two indiestor pocitions are sown. In a speciffe ineplenentution, on or moro extra indicator positions would bo inmerted, if to quired, after indicatos position 2 and before the first subeteld idientifies.

(b) Subfield identifies

As defined in Purt 3, a subfiedd idoutifier consints of the ISO charecter $I_{1}$ and one other symbol (wanlly

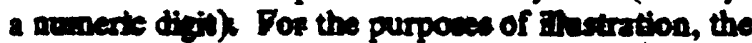
ISF code is reprenented by the symbol $C$. Bipses sion of tho form "soufield $\varphi^{\prime}$, sabind $1^{\prime \prime}$ are unod to decignite the subbeld introctuced by the identifier Q4. the sobficicintroduced by thi identifier on and so on.

(c) Field separators

The field separator character $\mathbf{S S}_{2}$ is omitted in $\mathbf{a l}$ examples, but should be understood as beins present in the bibliographic record as the chanacter immediately following the end of the data string shown in any example.

(d) Craracter coding

No attempt is made in the examples to reproduce the code structures which would be used in the machine record: all data strings are shown as phin text. (o) Representation of 'zero' and 'spece'

To avoid ambiguity, the symbol ' $\emptyset$ ' is used for the number zero'. 'Space' or 'blank' is represented by $\checkmark$.

(f) Implementation options

Where a number of user options exist, it has not always been possible to show all alternatives in the set of examples chosen for a particular data field. In such cases, the selection of a particular option does not imply that this is a preferred' implementation.

(g) 'Notes' subfield

The 'notes' subfield (identifier @N) is an optional subfield which may be included in any data field to incorporate additional free-form information which the user wishes to associate specifically with the content of the field. For this reason, it is shown as a permitted subfield in all data fields, although it will be obvious that its use in connexion with some fields which are themselves free-form is rather improbuble. It may, however, have some application in a situation where the user system needs to enter additional information which must be suppressed for the purposes of a particular output, such as a printed publication.

\section{AФ1: ISSN}

\section{Field definition}

Tag: $\quad A \emptyset 1$

Indicatoss: Not used: entered as zeros

Subfolds: 0: ISSN: fixed length, eight charecters. Chrncter set restricted to numerals only, except for the last character which may be a numeral or letter ' $\mathrm{X}$ '.

Repeatable:No N: Notes

\section{Date description}

Field $A Q 1$ is used to onter the Intermational Standard Serinl Number (ISSN) as a unique identification of a secuil title.

The ascignment and dissemination of ISSN are the responsibility of the International Serials Data System. besed on an Intermational Centre in Paris (Centre International pour l'Enregistrement des Publications en Série: CIEPS) and National or Regional Centres.

The format and basic requirements for the assignment of ISSN are defined in an ISO Standard [6] fuller details of ISSN assignment and the operation of ISDS are given in Guidelines for ISDS [2]

The ISSN is an 8-digit number, the last figure being a check character. (Because of the method of checkdigit calculation, the last character may be either 
2 'Short title' not derived from ISDS.

NB: ovea though a locally constructed short title may have been prepared in accordance with the relevant ISO Standard, indicator I should not be used unless the title has been checked against ISDS lints.

\section{Examples}

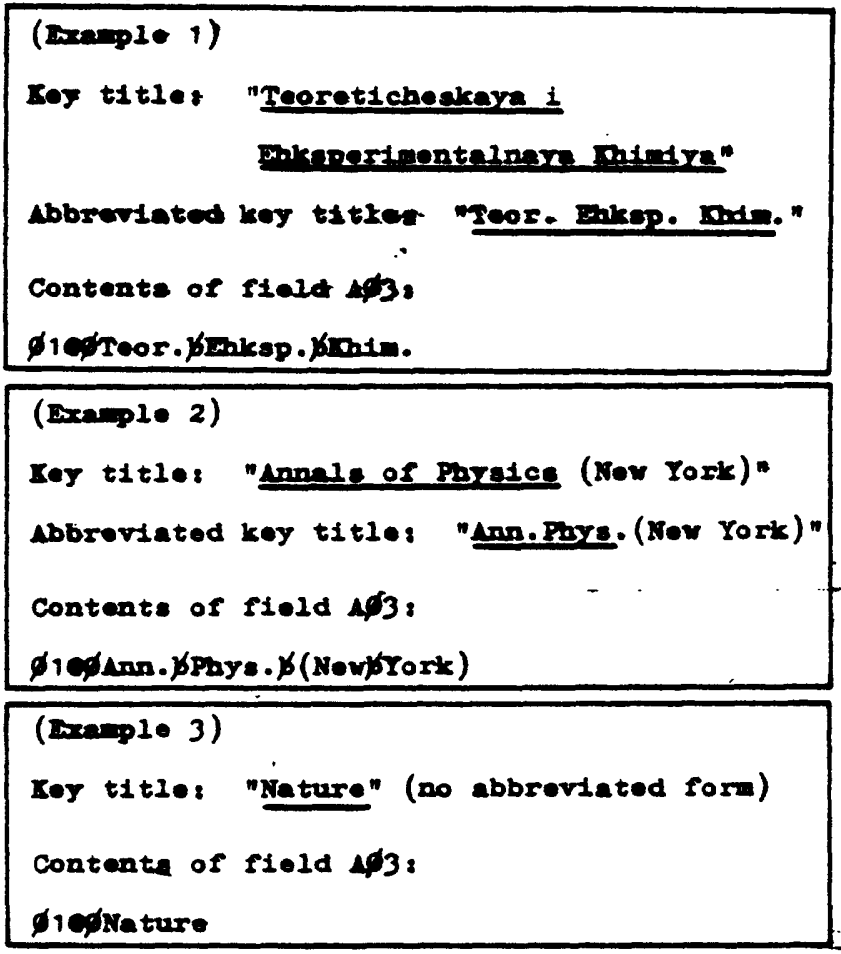

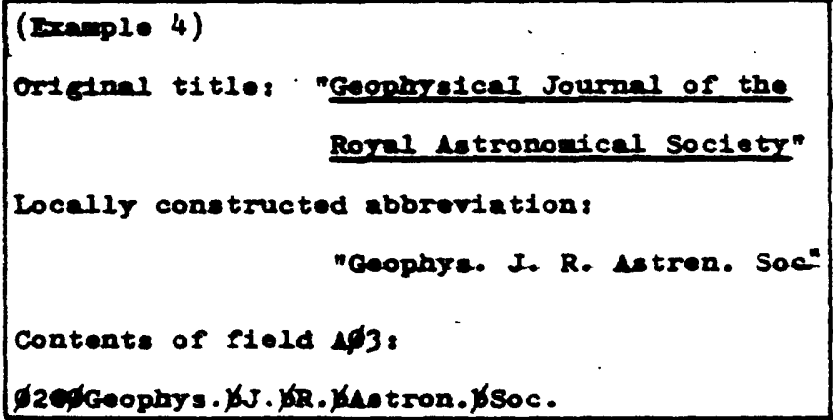

\section{AQ4: SERIES DESIGNATION}

\section{Field definition}

Tag: AQ4

Indientors: Not used: entered as zeros

Subfields: Q: Series designation N: Notes

Repeatable:No

\section{Date description}

Field AQ4 is used to recond a series designation which distinguishes beiween succesive isues of the sume serial title: i.e. a chronological series desigantion. It should not be confused with a series designation which differentintes between two or more parts published concurrently (e.g. Speciel Series"; 'Series A: Physics'); in the latter case the two parts will be dirtinguished by separate and unique serial codes and the series designation will be regarded as an integral part of the title, in accordence with ISDS prectice.

A series designation may be alphabetic or mixed -1- h- -umetic (e.g. 'New Series', Third Series', 'Series 2'). it should be entered as subfield $Q$ in the original language and precise wording shown on the piece, if neceseary transliterated in accordance with UNISIST recommendations.

A chronological series designation is seldom, if ever, an element which is absolutely required in order to distinguish between issues of a serial. This field is therefore regarded as optional.

\section{3.: Exomple}

Serles designation: "New Series"

Contents of field Aф4:

$\phi \phi e \phi N e w \not S e r i e s$

\section{AФ5: VOLUME NUMBER}

\section{Field definition}

Tag: AQS

Indicators: Not used: entered as zeros

Subfields: 1: 'Caption'

2: Volume number

3: Year: fixed length, four-digit number

4: Subdivision of volume

N: Notes

Repeatable:No

\section{Date description}

Field AQ5 is used to record a volume number, and any other information relating to the numbering of volumes or parts of volumes other than individual issues.

The field is divided into four subfields:

1 This subfield may be used if it is desired to enter a 'caption' (e.g. 'Vol', Tom', etc.). Captions should be entered exactly as given on the original, transliterated if necescary. Captions are regarded as an optional element.

2 This subfield is used to enter only the volume number itself, without 'captions' (e.z. 'Vol', v', 'Tom', 'Band'). If the volume number is numeric (whether arabic or roman, cardinal or ordinal) it should be entered as an arabic number without suffixes such as 'th', 'tme'. If the volume number is non-numeric, it should be entered exactly as given on the original, transliterated if neceseary. If the volume number is a multiple number (e.g. 1.2), the two numbers should be entered in subfield 2 , separated by a hyphen.

3 This subfield may be used to enter a "year used as volume number". The year is entered in full as a four-digit numeric. The year should also be inchuded in Feld A21, as part of the date of issue.

4 This subfield is used to identify any part or subdivision of, or supplement to, a volume, other than an individual issue. Any entry made in the subfield should be in the original language and precise wording of the primary joumal, transliterated if necesinry.

Some journals carry a continuous volume number in spite of title changes, as well as a volume number referring to the present title, e.g. Tom XV (XIVI)'. In such cases, use only the number which refers to the present title. 


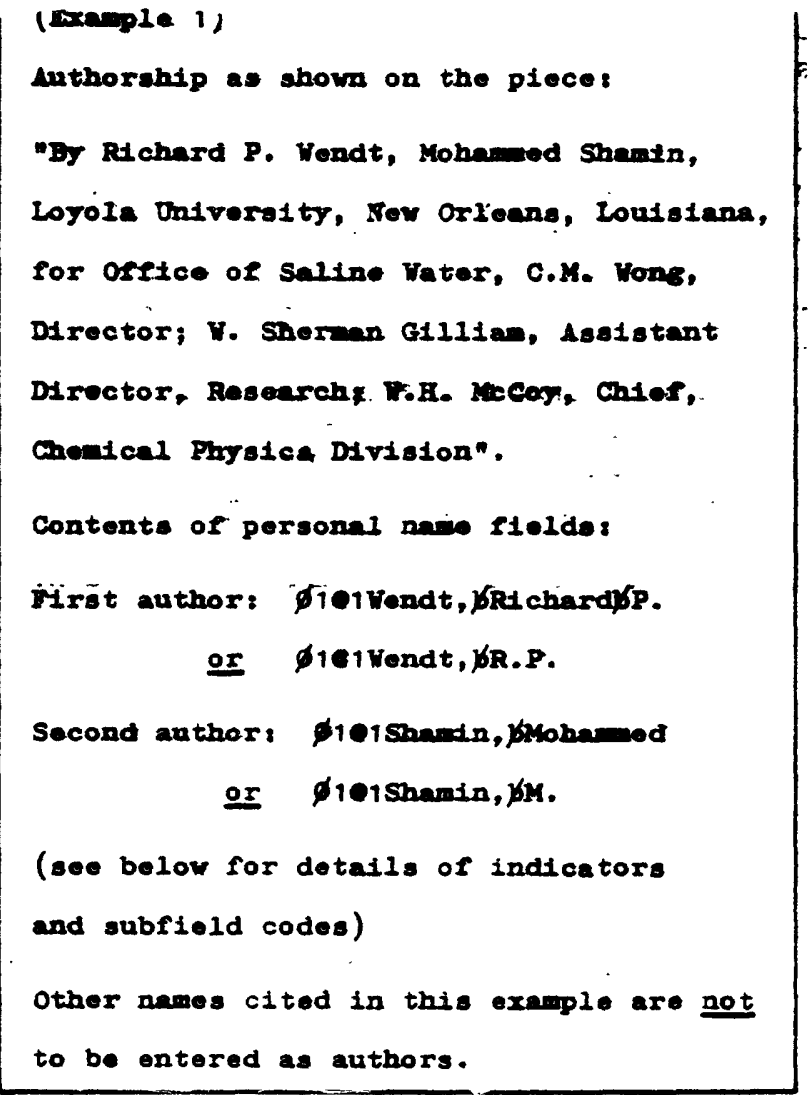

\section{Date description (all 'personal name "flelas)}

This section is applicable to fields A11, A12, A13 and A34, except where otherwise noted.

\section{Indicators}

Indicator position 2 is used to define the relationship between the person whose name has been entered in the bibliographic record, and the item to which the record refers. Most commonly, this relationship will be that of author. or editor, but provision is made for other possibilities, in accordance with the table* below:
Relationship not specified (may be any of thow listed below)

1 Author

2 Editor

3 Compiler

4 Translator

5 Illustrator

6 Preface or introduction by

$X$ Other (specifically not one of those listed above)

\section{Subfields}

The field structure for personal names provides a number of subfields ( 1 to 6 ) for entering alternative forms of an author name. Any of the following forms may be inchuded (but only subfield 1 is an cuential etement): 1. Namee derived from the piece, unittered except for tranaliteration if neceseary. It is also permisable to erter here a name in which an iritial has been expanded to a full forename (by seference to an authority file), or forenames replaced by initials, provided the mame has not otherwise been altered.

- This table of indicator ralues appties to fields A11, A12 and A13, but not to field $A 34$ (q.v.) authority file, where this differs from the form given in the primary publication by something more than the substitution of a forename for an initial, or vice-versa. An example would be where a non-Russian name has been transliterated into Cyrillic, and when retransliterated in accordance with UNISIST recommendations, it emerges in an incorrect form (e.g. 'Courtois' - 'Xurto'). It is important to retain under subfield 1 the form derived directly from the primary publication, since users may not know the original form of the name.

3. 'Real name', where the name given on the piece (and recorded under subfield 1) is a pseudonym.

4. 'Pseudonym', where the individual whose real name is given on the piece (and recorded under subfield 1) is known to have published under another name.

5. 'Former name' where a change of name is known to have occurred, e.g. maiden name for a married woman author, or former name if the person cited actually changed the name by which he was known, for example on moving to take up residence in another country.

6. 'Subsequent name' where a change of name is known to have occurred, e.g. married name for a woman author writing under her maiden name, or subsequent name if the author later changed the name by which he was known at the time of writing the item in question.

Subfield 9 is used as follows:

9. 'Role': in the event that the relationship between the person cited and the bibliographic item cannot be adequately defined by any of the specific indicators listed above, this subfield may be used to enter a free-form description of the relationship.

\section{Elements in a personal name}

The conventions described under this and subsequent sections apply equally to any of subfields 1 to 6 , except as otherwise noted.

The elements in an individual name may be defined as follows:

$\begin{array}{lc}\text { Tey' name or names } & \text { 'K' } \\ \text { Forename and/or initials } & \text { 'F' } \\ \text { Suffix } & \text { 'S' } \\ \text { Title } & \text { 'T' }\end{array}$

All names are to be entered in the following form:

\section{R,WF,WSW(T)}

Commas are used to separate the 'key' names (sumames) from the forename and/or initials, and to separate the forenames from any suffix (such as ' $\mathrm{r} r$ ', 'III'). A title, if required, is entered in parentheses at the end of the name. For example:

'Rutherford (Lord)'

'Rutherford, James D., JF.'

'Rutherford, J.D.'

\section{'Key' names}

The 'key name' element $(K)$ corresponds to the surname in a Western name. The term 'key name' is used rather than 'surname', however, since there may be occasions when it is not clear that the content of this element really represents a surname in the Western sense. (Also, it is envisaged that there may be an exact 


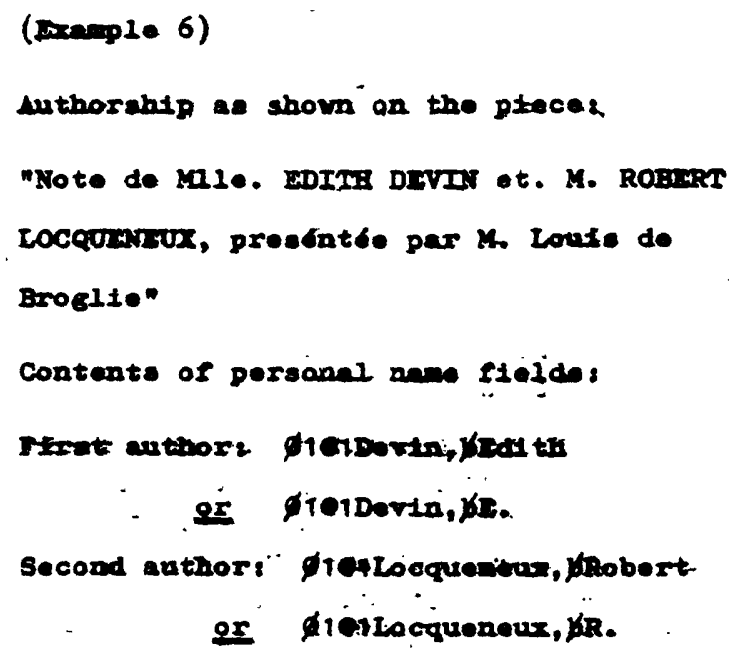

Terms which indicate affiliation with religious orders (e.e. Sirter, Brother) are not retained unlews only the forename(s) are given:

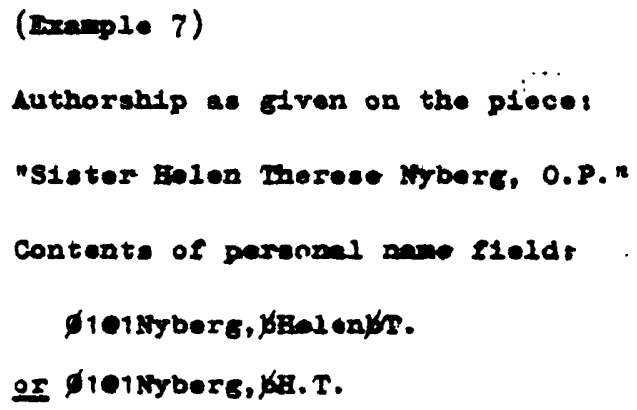

Honorific titles are normally_omitted, but may be retained if they constitute an indispenable part of the neme:

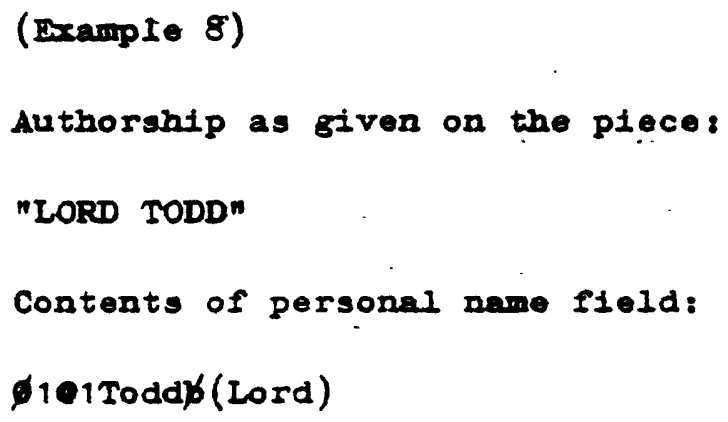

\section{Spellitis}

Individual author sames are to be sntered in the vernacular, as they appear on the original piece, except:

(a) If transliteration from a non-roman alphabet to roman alphabet is required, UNISIST recommended transliteration schedules are to be used.

(b) If an 'established form' of the name is known to the originator of the bibliographic description, and if this form differs from what has been derived from the original, then the 'established form' may be entered in subfield 2.
This is particularly likely to arise where a nonRussian name is transliterated into Cyrillic for publication in a Russian joumal, and is subsequently retransliterated to the roman alphabet.

In all cases, the name as given on the piece (transliterated if necessary) should be regarded as the primary form for entry in a bibliographic description, since the use of the 'established form' depends on prior knowledge which may not be accessible to all users of a bibliographic data base. Subfield 1 should always carry the name as derived from the piece.

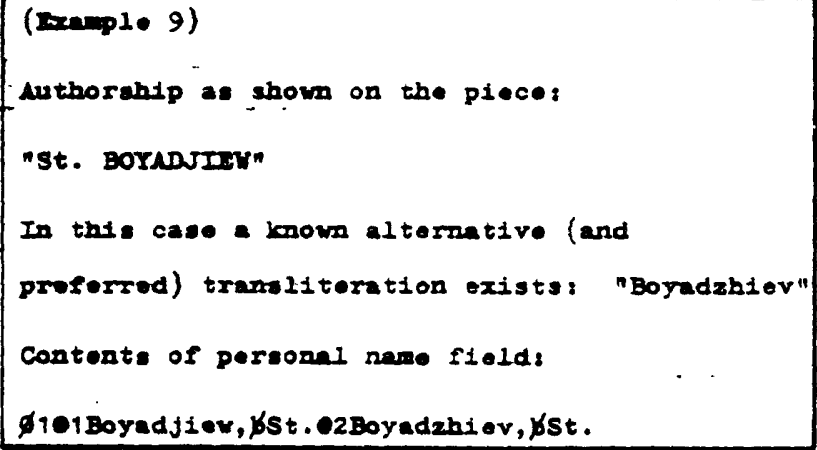

\section{Surname prefixes}

All surname prefixes are retained in personal author names. A prefix and the name to which it is affixed are together regarded as forming a single 'key' name. Exmples of frequently used prefixes are:

$\begin{array}{llll}\text { ran la } & \text { lo } & \text { van der } \\ \text { roa della de } & \text { vander } \\ \text { do lo dea } & \\ \text { da del . de la } & \end{array}$

Soe note below on "Special symbols used in author nemes", and examples given in that section.

\section{Compound somames}

Compound sumames are the rule for most Spanish and Portuguese authors, and are occasionally found among almost all nationalities.

If the surname is a compound containing a hyphen (e.e. 'Litvak-Gorskaya, L.B.'), the whole compound name should be entered as a singie 'key' name.

If it is apparent that the surname is a compound which is not bxphenated, both aames should bo entered an key' names, (e.8. 'J. Hunter Dunn'). If in doubt, enter only the final element as a 'key' name and treat the first element as a forename.

\section{Nomes that indicate marital status}

In certain languages a married woman author's name is the same as her husband's with the addition of one or more letters, or a different wordending. For example, in Hungarian the suffix '-ne' may be applied to either a forename or a surname. Names of this kind should be entered exactly as they appear on the contribution without modification, and in accordance with the rules previously defined: 
(d) Words may be abbreviated in accordance with UNISIST recommendations.

2 Address of orgunization. The address or location of the organization should be entered in subfield 2. The address should be entered in the fullest available form, ignoring any redundancy which may arise where the place name forms part of the name of the organization (e.g. 'Cambridge University, Cambridge, Engiand'). However, an incomplete addres may be entered where no fuller information is available.

3 Country code. The country of the affiliation may optionally be entered in subfield 3, using an ISO Standard country code (

(It will be noted that the option is deliberately left open for country names to be entered 'informally" as part of the address, or to be encoded in a specific subfield if there is a requirement that a file be search. able automatically by country. It is expected that any individual service, or parties to an exchange, would adopt a consistent policy across the data base concerned.)

\section{Selection of the affiliation}

The minimum requirement for a bibliographic citation is considered to be the inclusion of a single organizational affiliation, selected wherever possible as giving the location where the work described in the piece was done. The rules on following pages are interded to aid selection of a single affilintion in cases where this criterion cannot readily be applied by reference to the information given on the pioce.

(a) One author: only one address given. This address is to be entered:

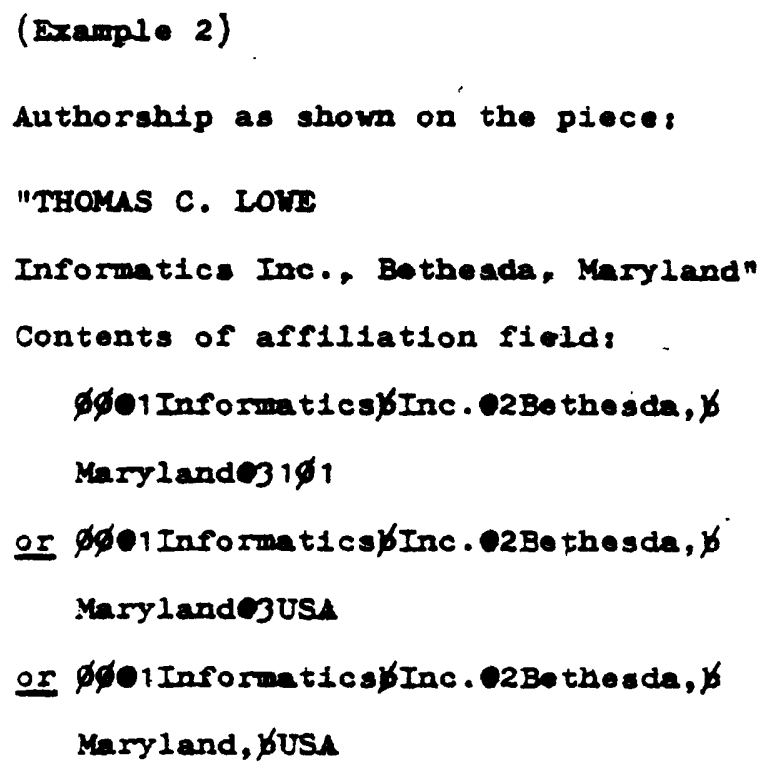

(b) One author: several addresees given. One address only is to be selected, in accordance with the fotlowing descending sequence of preferences: location where the work was done; author's affiliation at the time of the work; first organization cited:

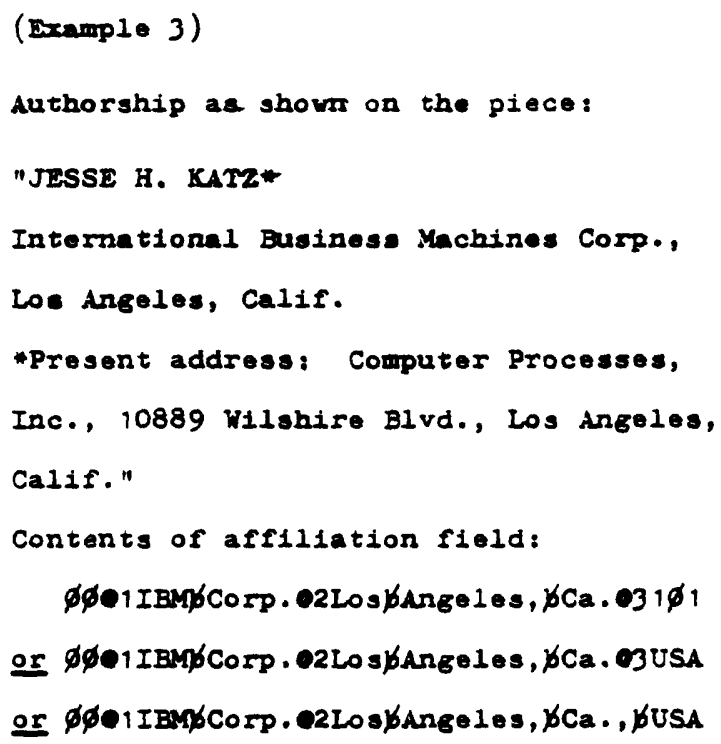

(c) More than one author: only one address given. This addreas is to be entered:

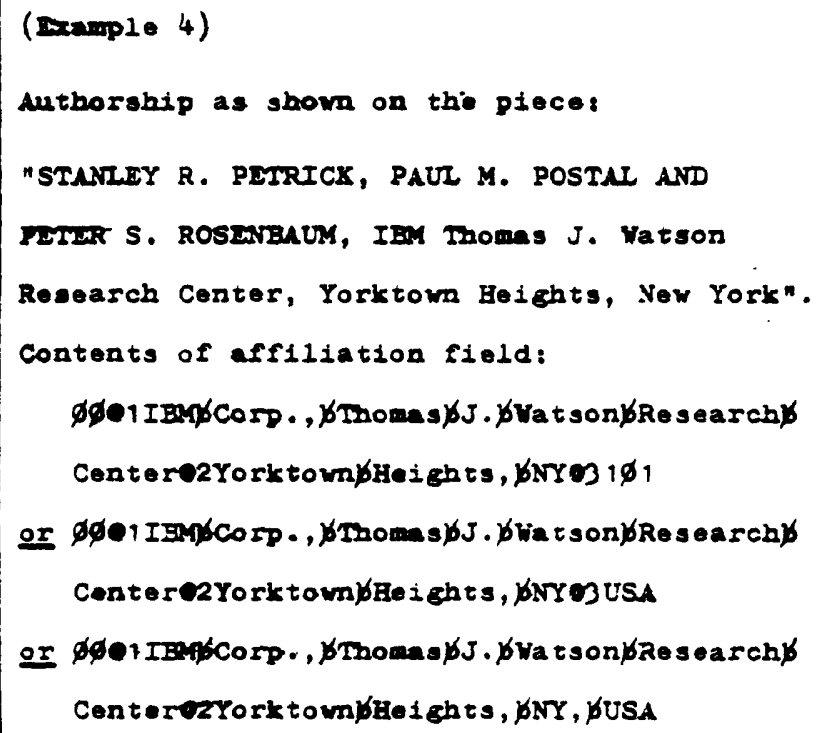


(a) Fields A14, A15 and A16 should not be used for this purpose.

(b) Locally-ascigned, repeatable field tags should be allocated to differentiate between 'address at the time of the work', 'present address', etc.

(c) Indicator position 1 should be used to link personal names and the related affiliations.

(d) Field A14, A15 and A16 shourd be reserved for the preferred' affilintion as defined in this section. Where neceseary, the preferred' affilintion would be derivable by algorithm from the entries made in locally-axigned fields.

See also the note on multiple authors and affiliations at the end of the section on field All.

\section{A15: AFFILLATION - MONOGRAPH}

\section{Field definition}

Tag: A15

Indicators: Not used: entered as zeros

Subfields: 1: Name of orgunization

2: Address or location

3: Country code (optional element): fixed length, two or throe characters (alpha-

. betic or numeric, depending on the code adopted)

Repeatable:No

N: Notes

\section{Use of field A1S.}

Field A15 is used to enter the nume and address of a single organization to which one or more of the individuals cited as authors (or editors, ete.) of a manograph are affilinted. Monosraphic items inctude:

(a) Book publishod as a single piece;

(b) Volum forming part of a series or collection of books;

(c) Reports

(d) Thesis or dissertation.

Field A15 is not used for the affilintion of individuals anocinted with a patent document.

Although field A15 akways refers to a morogopphic item, it may occur in a record entered at the analytic level, for example when the record refers to a chaptor in a book.

\section{Date description}

See field A14.

\section{A16: AFFILIATION - COLLECTION}

\section{Field definition}

Tag: $\quad$ A16

Indicators: Not used: entered as zeroe

Subfields: 1: Name of organization

2: Address or location

3: Country code (optional element): fixed length, two or three characters (alpha betic or numeric, depending on the code adopted)

Repeatable:No

\section{Use of field A16}

Field A16 is used to enter the name and address of a single organization to which one or more of the individuals cited as authors (or editors, etc.) of a nonseriat collection are affiliated.

Although field A16 always refers to persons associated with the authorship of a collective item, it may occur in a record at the monographic or analytic levels, for example when the record refers to a single volume forming part of a collection, of to a chapter in a book which is itself part of a collection.

\section{Dete description}

See field A14.

\section{A17: CORPORATE AUTHOR (CONTRIBUTION)}

\section{Field definition}

Tag: $\quad$ A17

Indicators: Not used: entered as zeros

Subfields: 1: Name of corporate author

2: Address of corporate author (optional element)

3: Country code (optional element): fixed length, two or three characters depending on the code adopted

$\mathrm{N}$ : Notes

Repeatable:Yes: if there is more than one corporate author associated with a contribution, each one cited in the bibliographic record requires a separate repetition of field Al7.

Note that the definition of field $A 17$ applies also to fields A18 (CORPORATE AUTHOR - MONOGRAPH), A19 (CORPORATE AUTHOR - COLLECTION) and A35 (CORPORATE BODY ASSOCLATED WITH A PATENT DOCUMENT).

\section{Use of field $A 17$}

Field A17 is used to enter the name and, optionally, the address and country of a corporate author of a contribution (paper, article, letter, book chapter, etc.)

Field A17 is used only for records at the analytic level. Where more than one corporate author is cited in connexion with a contribution, field Al7 may be repeated as many times as required.

\section{Data description (all 'corporate outhor' fields)}

\section{Subfields}

1 Name of a rporate author. Where several levels of the organization are cited (e.g. laboratory, faculty, university), they should be entered in descending order of scale, from the larger unit to the smaller. Por large and complex organizations, such as some university or government depertments, discretion may be exercised in omitting intermediate levels, the inclusion of which does not add significant information to the entry, provided always that the most specific unit is cited and that the entry provides an unambiguous identification of the organization: 
3: Country code (optional element): fixed length, two or three characters (alphabetic or numeric, depending on the codeadopted)

$\mathrm{N}$ : Notes

Repeatable:Yes: if these is more than one corporate author asocisted with 2 collection; each one cited in the bibliographir record requires a sepante repetition of field A19.

\section{Use of field A19}

Fiold A19 is used to entes the nameind, optionally, the addreas and country of a corporats anthos associnted with a nomserinl coliection.

Nthough field A19 atwys refers to a colloction of items, it may occur in a recond at the monographic a antytic lovela, for cormple whes the recond refers to a single vohume formins part of acollection, or to a chapter in a book which is itsere pant of a collection.

Whese more thas one corparate author is cited in connexion with a non-serial collection, field A19 may be repeated as many times as requited.

\section{Datu descutption}

Soe field A17.

\section{A20: PAGE NUMBERS}

\section{Field defution}

Tag: $\quad$ A20

Indicators: Not used: entered as zeroe

1: Papo number

2: Pags frament: mumeric only

3: Additional information

Repeatable:No

\section{Dute deccription}

Field 120 is used to enter the pere rivinowe of an individual contribution (es. a jotimn articlo es a paper in a conference proceeding). Pupo thimbers' my be reprosented by a single member if the contribution is contained extively withich oncepage; or by first and lest page numbers if the contribution occupies a continuous 'run' of papes; or by s string of singte sumbers and/or pairs of numbers in the case of dincontimuous pagination.

Fiold 120 oecurs only' in recond at the andytic level.

\section{Subfields}

1 Puge numbers Subfield 1 is used to enter the page numbers ai described above. The nurthers should be entered exacthy as given on the piece, transliterated if necesary where letters are used as part of the page number. If roman numerals are used, they should not be converted into arbic numerals, since the distinction may aften be significant within a single publication.

All numbers (including first and last numbers of a sequence such as 12341235) should be entered in fill. A hyphen is used to separate the first and last page numbers of a contimuous sequence. Commas are used to separate individual page numbers or

pairs of numbers where pagination is discontiniuous; as $27-40,44,46-57,53,55^{\prime}$. Note that ambiguity could occur if the pege numbering on the piece included hyphens (if pages were numbered within chapters or issues as 123-41,123-42,123-43, etc.). In such a case it is recommended that these hyphens be changed to full points (as 123.41, 123.42; etc.).

2 'Page fragment number'. Subfield 2 is used to define a 'page fragment' if several short contributions are contained within a single page, or several contributions begin on a single page. The contents of subfield 2 will always be taken as modifying the first page number cited in subfield 1. When several contributions begin on a single page, they are to be ascigned page fragment numbers' $1,2,3$, etc., in a sequence based on scanning the page strictly column by column, from top to bottom within each column and from left to right across the page. This 'page fragment number' and nothing else, should be entered in subfield 2.

3 Additionat information. Subfield 3 is used to enter additional or alternative page numbers, or pagina. tion which cannot be expreseed in the manner dofined for subfield 1. Examples are:

(a) Serials which carry page numbering both within isuse and within volume. In such cases the page numbering within the larger unit (usually volume or year) is to be regarded as the preferred numbering, and will be entered in subfield 1 . The inse page numbering may be entered in subfield 3 , but is not regarded as an escential element.

(b) Ftems whose only page numbering is within the individual contribution. In such cases subfield 3 may be used in free form to describe the pegination.

\section{Examples}

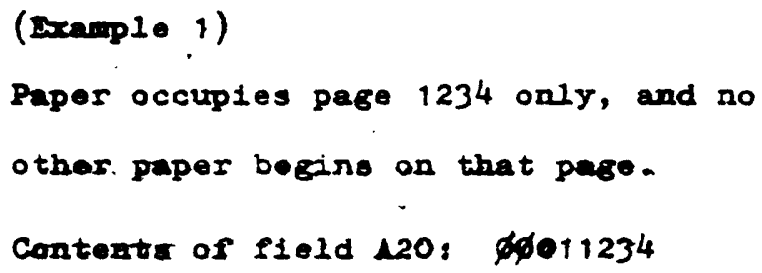

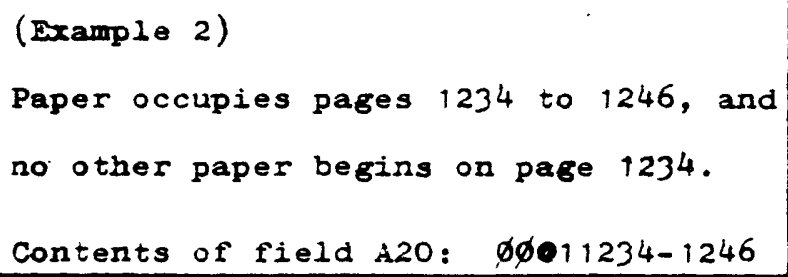




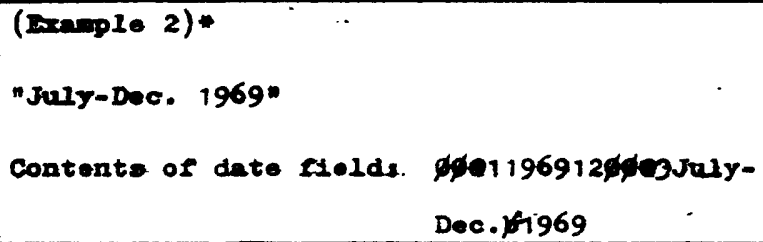

\section{A22: DATE OF PUBLICATION}

\section{Field definition}

Tag: A22

Indicators: Pocition 1 not used: eatered as zera. Poaition 2 may take any of the values $\varphi, 1,2,3,4,5,6$ (for patent documents oaly: otherwive entered as zero)

Subfields: 1: , Narmalized date', entered in ISO Standard format: fixed length, eightdigit numeric.

2: 'Deta part'

3: Date in fullynon-Gregorian date $\mathrm{N}$ : Notes

Repeatable:No

\section{Use of field $A 22$}

Fietd A22 is used to record

(a) The actual date of publication uf a serial isaue, report, or other item, if this is different from the nominal date of issue, and the information is available on the piece.

(b) The date of publication of a patent document. When used under (a) above, field A22 is in all respects identical to field $\mathbf{A} 21$.

\section{Date of publication of a patent document}

When field $\mathrm{A} 22$ refers to a patent document, indicator position 2 may optionally be used to distinguish between different circumstances and methods of publication, in accordance with the following table:

$\checkmark$ Mode of publication not specified.

1 Date of making available to the public by viewing, or copying on request, an unexamined document, on which no grant has taken place on or before the said date.

2 Date of making availablo to the public by viewing or copying on request, an examined document on which no grant has taken place on or before the said date.

3 Date of publication by printing or similar process of an unexamined document, on which no grant has taken place on or before the said date.

4 Date of publication by printing or similar process of an examined document, on which no grant has taken place on or before the said date.

5 Date of publication by printing or similar process of a document, on which grant has taken place on or before the said date.

6 Date of making available to the public by viewing, or copying on request, a document on which grant has taken place on or before the said date.

The following table shows the relationship between these indicators and ICIREPAT INID Codes for publication dates.

$\begin{array}{cc}\text { Indicator } & \text { INID Code } \\ 0 & \text { any of } 41-45,47 \\ 1 & 41 \\ 2 & 42 \\ 3 & 43 \\ 4 & 44 \\ 5 & 45 \\ 6 & 47\end{array}$

For patent documents, only subfieid 1 (date in ISO Standard format) will normally be used.

\section{Data description}

For all other aspects of field A22 format and contents, see field A21.

\section{A23: LANGUAGE(S) OF TEXT}

\section{Field definition}

Tag: $\quad$ A23

Indicators: Not used: entered as zeros

Subfields: 0 : Language code or codes

Repeatable: No

$$
\mathrm{N} \text { : Notes }
$$

\section{Date description}

Field $\mathrm{A} 23$ is used to enter one or more fixed-length codes indicating the language or languages in which the text of the item appears. The codes used should be in accordance with the relevant ISO Standard (in preparation); see Appendix B.

Pending the availability of an ISO Standard, an interim coding scheme may be adopted as agreed by the parties to an exchange of bibliographic information.

If the original text appears in more than one lan.

- Vot applicable to field A32: see examples under field A32. 
(c) Title identifier

(d) Check character

Components (a), (b) and (c) are of variable length (within the overall fixed length of the number), and are made up of arabic digits $\varphi$ to 9 . Component (d) is a single character, which may be the letter $X$ or any of the digits $\varphi$ to 9 .

In written or primted form, the four components are corventionalify separated by spes or hypiens. In the machine record, the number should be stored in packed form, without separators.

\section{Calculation of check churecter}

The check character is calculated on modulus 11, as described in the following example:

(a) Write the digits of the number without check character: $\quad 5.7198989$

(b) Write the constant weights. aseocinted with ach position of the number:

(c) Multiply each digit by its amociated weight:

(d) Add the product of these multiplication:

Q45 567446362418

$0+45+56+7+4+46+36+$

$2 a+18=226$

(c) Divide the sum by modulue $226 \div 11=20$, phus 2 11 to find the reminder: remaindes of 6

(f) Subtract the remaindes from. modulus 11 . to find the required chock digit:

$$
116=5
$$

If the result of this subtraction is 10, use check. charactor $X$ If thare is na reparinder, thercheck digit is 0.

(8) Append the check digit to make the foll ten-digit ISBN: 6571639895 .

\section{Example}

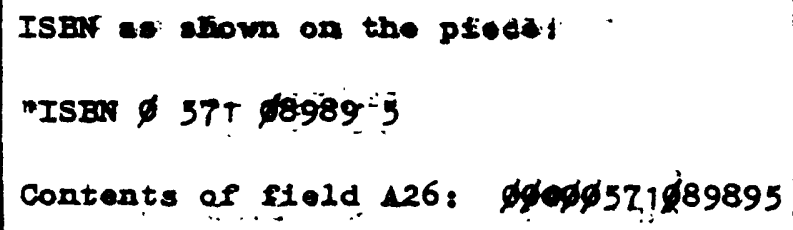

\section{A27: EDIMON}

\section{Field definition}

Tag: $\quad$ A27

Indicators: Not usedi_entered as zeros

- 6: Edition number. vigiable-Jength mumeric only

Repeatable:No

$$
\text { N: Notes }
$$

\section{Data description}

Field A27 is used to enter the edition number of a monograph or collection. Subfield $\emptyset$ should contain one or more numeric digits, and nothing else. Roman numerals should be converted to arabic, and ordinals should be entered as pure numbers, without suffixes such as "th". Any other information concerning the edition or editions should be entered in free form in subfield $\mathbf{N}$.
Field A27 is applicable only to an item at either the monographic or collective level, but it may also appear in a record at the analytic level, for example when the record describes a chapter in a book.

\section{Example}

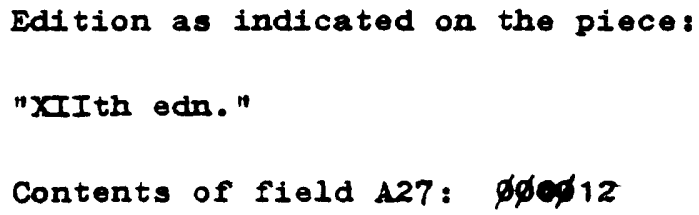

\section{A28: COLLATION: DESCRIPTION OF NON-SERIAL COLLECTION}

\section{Fleld definition}

Tag: $\quad$ A28

Indicators: Not used: entered as zeros

= 1: Number of pieces: rariable-tength, numeric only

2: Other descriptive information (optional element)

\section{Repeatable:No}

$$
\mathrm{N} \text { : Notes }
$$

\section{Data description}

Field A28 is uned to describe the physical pieces which togethes constitute 2 non-serivl collection to which the bibliographic record refers.

Athough field A28 ahways refers to a collective item, it may be included in a record at the monographic or analytic levels, for example when the recend describes a single volume belonging to a collection, or a chapter in a book which is itself pert of 2 collection.

\section{Subfields}

1 Number of pieces: in the simplest case, the or description required may be the number of pieces or volumes which together constitute the collection. This number, and nothing else, is entered in subfield 1, as one or more numeric digits.

2 Other descriptive information: any other descriptive information regarding the physical composition of the collection (e.z. format, collation of individual volumes, plates, maps, inserts) may optionally be entered in subfield 2 , in free form.

\section{3- Example}

\section{Twenty-fous rols"}

Contents of field A28: $\varnothing \varnothing 0124$ 


\section{A31: LOCATION OF MEETING}

\section{Fleld definition}

Tag: A31

Indicators: Not used: entered as zeros

1: Loeation of meeting

2: Country code (optional element): fixed length, two or three characters dependins on the code adopted

N: Notes

Ropectable:No.

\section{Data desertprion}

Field A31 is used to enter the location of a meeting the name of which has been entered in fietd $A 3 \varphi$.

\section{Subfields.}

1 Location of meetings entered in free form. The amount of detail required will be dictated partly by the nature of the location, and partly by the information available on the piece. If the country is given in the form of a code in subfield 2, it should not be inchuded in subfield 1.

2 Country code. The country in which the meeting was beld may optionally be entered in subfield 2, using an ISO Standard country code (see Appendix A). Field A31 may be used in records at all bibliographic levels.

\section{Example}

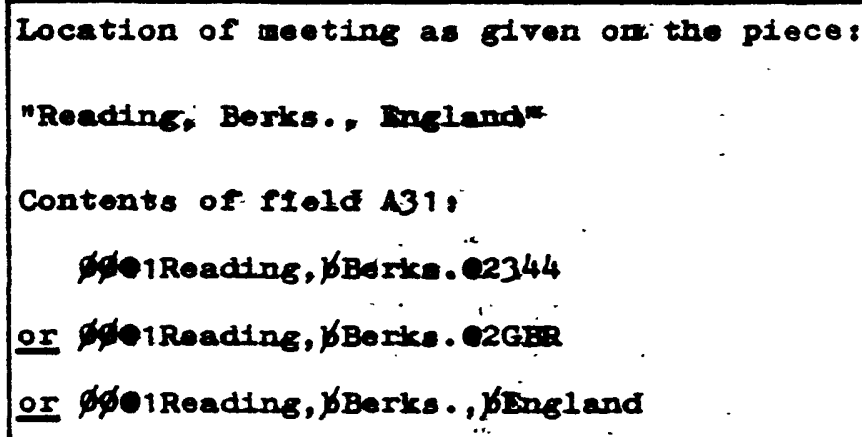

\section{A32: DATE OF MEETING}

\section{Field definition}

Tag: A32

Indicators: Not used: entered as zeros

Subfields: 1: Normalized date': fixed length, eightdigit nurieric

2: Date part'

3: 'Date in full'

Repeatable:No

\section{Data description}

Field $\mathrm{A} 32$ is used to enter tho date (or inclusive dates) of a meeting, the name of which has been entered in field $\mathbf{A} \mathbf{3 0}$.

The format and method of use for field $A 32$ is as described for field A21 (DATE OF ISSUE OR IMPRNNT), except that whore isclusive dates are cited for a meeting, the hormalized date' in subfield 1 should be derived fon- the tarting date of the moeting not the ead date (see Examples).

Field A32 may be used in records at all bibliographic levels.

\section{Examples}

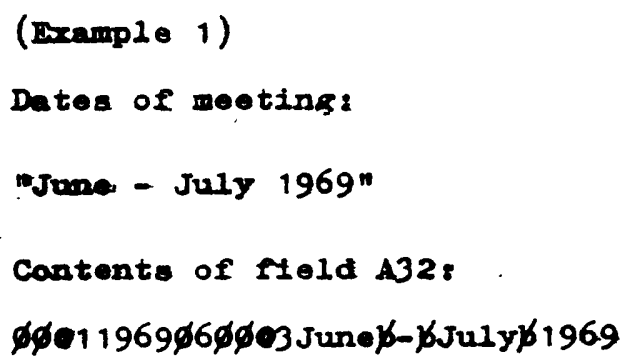

(Bramp1e 2)

Date of meeting:

"27th June - 3rd July 1971"

Contents of field 132 :

\$01 $1971 \not 62703276 J u n e \not-\not 3 \not J u 1$ yb 1971

\section{A33: IDENTIFICATION OF PATENT DOCUMENT}

\section{Field definition}

Tag: $\quad$ A33

Indicators: Not used: entered as zeros

1: Country code: fixed length, two or three characters depending on the code adopted

2: Type of patent document (ICIREPAT code): fixed length, two charecters

3: Type of patent document (CODEN): fixed length, six characters (this subfield is an altemative to subfield 2)

4: Type of patent document, as a free text description (optional element)

5: Document number

$\mathrm{N}:$ Notes

- Repeatable:No

\section{Duta description}

Field A33 is used to enter the full identification of a patent docurnent.

The preferred form of identification consists of the following subfields:

1 Country code

2 ICIREPAT code (see Appendix D)

5 Document number

Alternative forms of identification may consist of either 1 Country code or 1 Country code 3 CODEN

5 Document number

4 Type of document, as a free text description

5 Document number 


\section{Dote description}

Field A37 is used to enter detrils of a priority application which is cited on the patent document to which the bibliographic record refers. It is regarded as an optional element in the bibliographic description of a patent document.

The field is divided into three subfields, to record respectively the country of the priority apptication, the application number, and the date, all of which must be entered.

A patent documont may cite more than one priocity application, in which case field A37 may be repeated as many times as required.

Field A37 may appear in a record at either the monographic or analytic level; depending on whether the bibliographic record is derived from the patent document itself or from an entry in an official gazette, treated as a serial 'contribution':

\section{Subfields}

1 Country where the priority application was made. The country should be entered using one of the ISO Standard country codes (see Appendix A).

Subfield 1 corresponds to ICIREPAT INID 33.

2 Number actioned to the priority application. The number must be recorded in full, including any prefixes or suffixes. It should be entered without commas or spaces, but punctustion marks which link a prefix or suffix to the number should be ro tained. Note that the application number to be entered in this subfield should not be confused with:

(a) the application number associnted with the patent document to which the record refers: this number is entered in field A36.

(b) the document number (if known) amigned to a patent document arising from the priority application: this number is not a required data element in the bibliographic description.. Subfield 2 corresponds to INID 31.

3 Date of fitting of priority application: to be entered in ISO Standard format, as an eight-digit number of the form YYYYMMDD, where

YYYY represents the year in full

MM $"$ the month expresied as a two-digit number with leading zero where required

DD $n$ the dry of the month expreseed as a two-digit number with leading zero where required.

Subfield 3 corresponds to INID 32.

\section{Example}

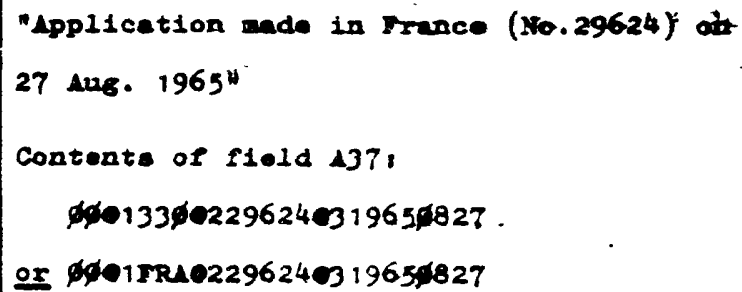

\section{A38: REFERENCE TO A LEGALLY RELATED DOMESTIC DOCUMENT}

\section{Field definition}

Tag: $\quad$ A38

Indicators: Position 1 not used: entered as zero Position 2 may take any of the values $\emptyset, 1,2,3,4$

Subfields: 1: Country code: fixed length, two or three characters depending on the code adopted (optional element)

2: Type of patent document (ICIREPAT code: fixed length, two characters

3: Type of patent document (CODEN): fixed length, six characters (this subfield is an alternative to subfield 2)

4: Type of patent document, as a free text description (optional element)

5: Document number

6: Application number (this subfield is an alternative to subfield 5 , when the document number is not known) $\mathrm{N}:$ Notes

Repeatable:Yes: if more than one legally-related domestic document is cited. Field A38 may be repated as many times as required

\section{Data description}

Field A38 may be used to record details of a patent document (a) legally related to the document to which the bibliographic record refers, and (b) published in the same country.

Field A38 is regarded as an optional element in the bibliographic description of a patent document.

The preferred form of reference to a legally related domestic document consists of the following subfields: 1 Country code (optional, since by definition it must be the same as the country code in field A33)

2 ICIREPAT code (see Appendix D)

5 Document number (or subfield 6: application number may be used when the document number is not known).

The definitions and form of entry for subfields 1 to 5 are identical to those given under field A33: other forms of reference than the preferred' form may be used as in field $\mathrm{A} 33$. Conventions for recording an application number in subfield 6 are as described under field $A 36$, subfield 1.

Field A38 may be repeated if more than one legally. related domestic document is cited.

\section{Indicators}

Indicator position 2 may be used to distinguish between different types of legal relationship between the document cited and the document to which the bibliograph- . ic record refers, in accordance with the following table of values:

$\emptyset$ Relationship not specified: may be any of those given below

1 Relation due to addition(s)

$2 "$ " "division(s)

3 " " continuation(s) - including

$4 " \quad "$ " reissue(s) 
1: Name of orgrization

2: Addrea or location (optional element)

3: Country code: fixed length, two or three characters, depending on the code adopted (optional ejement)

$\mathrm{N}:$ Notea

Repratables Yes: if mose than one orpanization is cited, field A49 may be repeated as many times. as required

\section{Date description}

Field A4C is used to enter the name of an organizititon responsible for performing the whole $a$ part of the work which is the subject of a report, if and only if this or ganization is different from the corporate author or author affilintion.

The formet of field $A 4$ is identical to the defined for field At7 (CORPORATE AUTHOR). Only subfiad. 1 (name of orenization) is an cuontial element: others are optional.

Field A46 may be repeated as required, if more than one organization is cited as responsible for the work.

Field A46 occurs only in records describing report literature, and may be used at either the monographic or analytic lovel.

\section{A41: UNIVERSITY (OR OTHER EDUCATIONAL INSTITUTION)}

\section{Fleld defunition.}

Tag: A41

Indicators: Not used: entered as zeros

1: Name of univerity, of other institution

2: Address or location (optional element)

3: Country code: fixed lendts twa or three characters, depending on the code adoptod (optional element)

Repertable:No

$$
\mathrm{N}: \text { Notes }
$$

\section{Date description}

Field A41 is used to enter the nome of thruniversity university depertment, or other degree-granting institytion, to which a thesii or disertation was submitted.

The format of field A4I is identical to that definied. for field A17 (CORPORATE AUTHOR), Only subfield 1. (ame of university, ar other institivion) in an exential elament: others are optionel.

Field A4l occurs only in records decicribinge thetis or discertation, and therefore can be used only at the monographic level.

\section{Example}

\begin{tabular}{|c|}
\hline 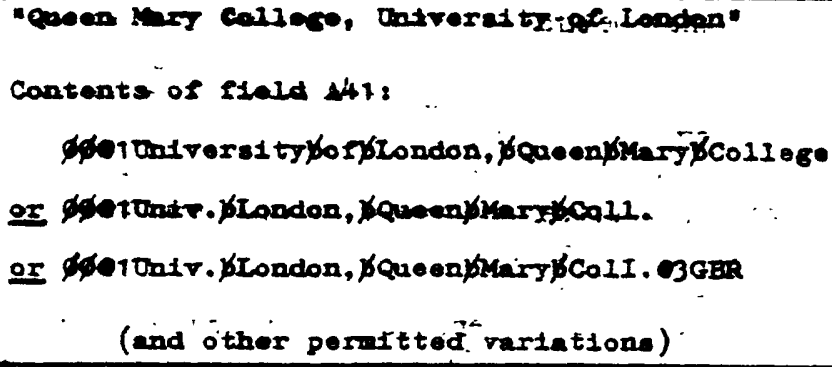 \\
\hline
\end{tabular}

\section{A42: DEGREE EEVEL}

\section{Field definition}

Tag: $\quad$ A42

Indicators: Not used: entered as zeros

Subfields: Ф: Degree levet'

N: Notes

Repeatable:No

\section{Data description}

Field $A 42$ is used, in a record. which refers to a thexis: or erertation, to enters 2 noto of the level of the do. gres for which the thesis or discertation was presented. This information may be entered in free form.

Field A42 is an optional data element. It is used onty at the monograptic level.

\section{Example}

$$
\begin{aligned}
& \text { "Ph.D." } \\
& \text { Contents of field A42: } \\
& \text { фøo } \phi \text { Ph.D. }
\end{aligned}
$$

\section{A43: AVAILABILITY OF DOCUMENT}

\section{Field definition.}

Tag: - $\quad$ A43

Indicators: Not used: entered as zeros

Subfieldas : Aveilability note

Repeatable:No

\section{Data description}

Field A43 is used to enter the source of availability of the document to which the bibliographic record refers, together with any other notes relevant to the procese of obtaining the original document (e.g. restrictions on availability, prico, order number).

An entry in field A43 may be made in free form, but should include the name (and, optionally, the address) of the organization from which the document is avilable. Abbreviations, if used, should be in accord. ance with UNISIST recommendations.

Field A43 may be used in records at all bibliographic levels. It is particularty relevant for seports and any other items which are not available through normal commercial channels.

\section{Example}




\section{Chapter 3.1}

\section{RECORD FORMAT.}

\section{ISO Standard}

UNISIST proposais for a standardized bibliographic description in machine-readable form are to be regarded as a specific implementation of the International Standard ISO 2709 [1] for a communication format for bibliographic records. This Standard is a generalized derivative of the MARC II record structure, but independent of the data element definitions and tagsing scheme used for Libray of Congreas MARC data baser.

\section{Record format: general}

The UNISIST/ICSU-AB Working Group on Bibliographic Descriptions has recommended the adoption of the record format defined by ISO 2709. The WGBD's objective has been to define an implementation of this standard which

\begin{tabular}{|c|c|c|}
\hline $\begin{array}{l}\text { Characters } \\
\text { (or bytes) }\end{array}$ & ISO Standard & UNISIST implementation \\
\hline 0 to 4 & Recond length & $*$ \\
\hline 5 & $\begin{array}{l}\text { Recond status chrractes } \\
\text { (e.8. new; amended) }\end{array}$ & $\begin{array}{l}\text { Record status character (to be defined by agreement between parties } \\
\text { to an exchange: if not used, enter as zero) }\end{array}$ \\
\hline 6 to 9 & $\begin{array}{c}\text { Implementatioa codes } \\
\qquad:\end{array}$ & $\begin{array}{l}\text { Character positions 6-8: literature type codes (see notes below) } \\
\text { Character position 9: bibliographic level code (see notes below) }\end{array}$ \\
\hline 10 & $\begin{array}{r}\text { Indicator length } \\
\qquad \therefore-\end{array}$ & $\begin{array}{l}\text { Indicator length: minimum } 2 \text { for UNISIST exchange records; but } \\
\text { additional indicator positions may be defined by agreement between } \\
\text { parties to an exchange; see below. }\end{array}$ \\
\hline 11 & Identifier length & '2": see below \\
\hline 12 to $16^{\circ}$ & Base addreaciof data. & $*$ \\
\hline 17 to 19 & For unstems & 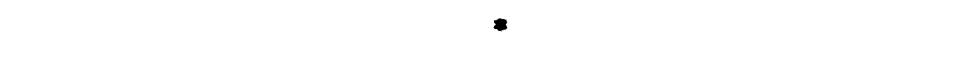 \\
\hline 20,21 & Directory mp & - \\
\hline 22,23 & For future use & $\bullet$ \\
\hline
\end{tabular}

would be suited to the needs of abstracting and indexing services, information centres and others.

The record structure defined by ISO $2709 \mathrm{will}$ be referred to hereafter as the "ISO bibliographic record".

The ISO bibliographic record is divided into three sec. tions: a fixed length leader occupying this first 24 characters or bytes; a variable length directory; and data fields of fixed or variable length. Some aspects of the record structure are described below, but for full details the reader should consult ISO 2709. A diagrammatic repre. sentation of the record format is attached at the end of Part 3.

\section{Record format: leader}

The table below shows the contents of the fixed leader at the beginning of each record, as specified by ISO and as applied in the proposed UNISIST implementation (an asterisk in the right-hand column indicates exact correspondence with the ISO Standard): 
moximum flexibility of assignment, and effectiveness of table-oriented programme design. An intellectual structuring of groups of tags assigned to related' data elements may be useful for some purposes, but this structuring should be reflected in the contents of the tables used to interpret the tags, not in the tag representations themselves. The usefulness of such intellectual groupings is solely for input or output, not for exchange between machine systems.

The alphanumeric format with base $A Q \emptyset$ was chosen. to avoid confusion with the widely-known MARC systems which use tag in the nnge 100-999.

\section{Nesting of sub-records}

Certain situations may arise in which it is desirable, for bibliographic reasons, to treat a record as including one or more sub-records. For example, if a paper is a translation of an item which has been published eisewhere, it may be necessary to include a citation of the original source as a sub-record within the main record referring to the transiation. In general, this situation will normally arise whenever reference must be made in a bibliographic record to one or more related documents, or whese it is necessary to treat a collective work at more than one bibliographic level.

A number of techniques may be suitable in different circumstances for dealing with this type of problem:

(a) Use of a 'notes' field. Where the information regarding related items is required solely for display, and need not be procensod in a structured way, it may be inchelet ie five formen part of a notes field, but this approsch renders it useles for computer procousing.

(b) Cros-referenging between records. In some circumstances the rehated items may be entered as separate. bibliogiaphic recoses, with pointers in cach direction and ar indication of the nature of the relationship betweon them.

(c) Nesting of sub-records one ormore sub-records using the same data elements as the main record, may be nerted within the bibliographic record, to form a hierarchical structure.

A procedure for structuring a record in to a number of sub-records is refered to in ISO 2709, but is not fully dofined. It to based on the use of tas 902 as a "sul-record directory", containing pointers to the main directory. This procedure hes been adopted in some systems, including for exmote, DIS. It is videly regarded by exirting usors as being foes than wholly satinfactory. At the present time, therefore, the Reference Manual does not embody any recommendations on the technique to be employed: for this purpose.

\section{Physicattapestandards}

It should be noted that the asumption is made throughout Part 3 of the Refoence Naraial thit the basie medium for exchange will be nine-track, halfinch magnetic tape recorded at 800 bpi in NRZI mode in an industry= compatible form, complying where applicable with relevant. ISO Recommendation Extension of the ENISIST. exchange formaf tö ninē-track tape recorded in othes modes or at other packing densities is trivial; extension to physical formats or media which differ in other respects may require more work to define a suitable representation of the exchange record.

\section{Standard separators}

The followinestandard separators or delimiters are used in the ISO bibliographic record format, and therefore in the UNISIST exchange format:

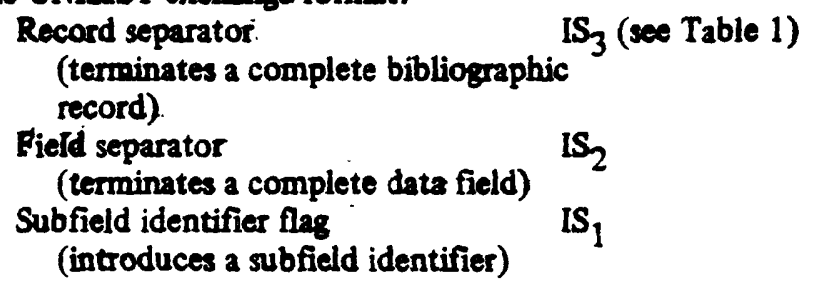

\section{Chapter 3.2}

\section{REPRESENTATION OF EXTENDED CHARACTER SETS}

\section{ISO Standard}

At the time of writing, a Working Group of ISO/TC46 is developing a comprehensive draft standard for character sots to be used in bibliographic information exchange. When the results of its work become available in the form of an ISO Standard, it is expected that users of the Referance Manual will be advised to adopt them, and this chapter will be amended accordingty.

\section{Interim Recommendations}

The UNISIST/ICSU-AB Working Group on Bibliographic Dercriptions developed its own detailed proposals for the representation of extended character sets. These were based on an existing ISO Recommendation, R646 [12], shown in Table 1 at the end of this chapter, and an existing USSR Standard, GOST 13052-67 [13] (Table 2). The WGBD proposals have been taken into account in the work now being undertaken within ISO/TC46; and in the interim it is recommended that character coding should be based on the ISO and USSR standards referred to above. In the light of the ISO/TC46 derelopments it is considered inappropriate to lay down any separate guidelines for the representation of exteonded character sets. 
TABLE 1: ISO set

\begin{tabular}{|c|c|c|c|c|c|c|c|c|}
\hline & $0^{-}$ & 1 & 2 & 3 & 4 & 5 & 6 & 7 \\
\hline 0 & NUL & $\mathrm{TC}_{2}$ & SP & 0 & 0 & $\mathbf{P}$ & • & $p$ \\
\hline 1 & $\mathrm{TC}_{1}$ & $\mathrm{DC}_{1}$ & $l$ & 1 & $\mathbf{A}$ & $\mathbf{Q}$ & a & $q$ \\
\hline 2 & $\mathrm{TC}_{2}$ & $\mathrm{DC}_{2}$ & $n$ & 2 & B & $\mathbf{R}$ & $\mathrm{b}$ & $r$ \\
\hline 3 & $\mathrm{TC}_{3}$ & $\mathrm{DC}_{3}$ & $\boldsymbol{E}$ & 3 & C & $\mathbf{s}$ & c & $\mathbf{s}$ \\
\hline $4^{\cdots}$ & $\mathrm{TC}_{4}$ & $\mathrm{DC}_{4}$ & $\phi$ & 4 & D & $\mathbf{T}$ & d & $t$ \\
\hline 5 & $\mathrm{TC}_{5}$ & $\mathrm{TC}_{8}$ & $\%$ & 5 & $\mathbf{E}$ & $\mathbf{U}$ & $e$ & $\mathbf{u}$ \\
\hline 6 & $\mathrm{TC}_{6}$ & $\mathrm{TC}_{9}$ & $\&$ & 6 & $F$ & $v$ & $f$ & $\boldsymbol{V}$ \\
\hline 7 & BEL & $\mathrm{TC}_{10}$ & - & 7 & $\mathbf{G}$ & $W$ & $g$ & $w$ \\
\hline 8 & $\mathrm{FE}_{\mathrm{O}}$ & CAN & ( & 8 & H & $\mathbf{X}$ & $\mathbf{h}$ & $x$ \\
\hline 9 & $\mathrm{PE}_{1}$ & $\mathbf{E M}$ & ) & 9 & $I$ & $\mathbf{Y}$ & $i$ & $y$ \\
\hline 10 & $\mathrm{PE}_{2}$ & SUB & * & $:$ & $\mathbf{J}$ & z & $\mathbf{j}$ & z \\
\hline $11 \ldots$ & $\mathrm{FE}_{3}$ & ESC & + & ; & $\mathbf{K}$ & {[} & $\mathbf{k}$ & \\
\hline 12 & $\mathrm{FE}_{4}$ & $\mathrm{IS}_{4}$ & 1 & $<$ & L & & 1 & \\
\hline 13 & $\mathbf{F E}_{5}$ & IS $_{3}$ & - & $=$ & $\mathbf{M}$ & ] & $\mathbf{m}$ & \\
\hline 14 & so & Is $_{2}$ & - & $>$ & $\mathbf{N}$ & A & $\mathbf{n}$ & - \\
\hline 15 & SI & IS $_{1}$ & $/$ & $?$ & 0 & & 0 & DEL \\
\hline
\end{tabular}




\section{EXAMPLES OF COMPLETE BIBLIOGRAPHIC RECORDS:}

This section embodies examples of each type of itterature treated by the Reference Mamual.

Bech example is in three perts:

- the original that derived from the pioce;

- implementation codes entered in the leader part of the record to identify literature type and bibllographic level;

- data fiolds required for the bioliogrephic deacription. Except where otherwise noted, the data fields in these examples have been limited to those identified in Part 1 of the. Momual as essential for the given literature type.

The conventions for representing data fields are identical to those used dsewhere in the Manual, and defined in Chapter 1.1 and at the boginning of Part 2:

Where the Reference Manual allows certain degrees of freedom, the selection of a particular option in the examples does not imply that it is a 'preferred' form.

\section{Example 1: SERLAL CONTRIBUTTON}

Communications of the ACM, Volume 8, Number 5; Mny 1965, prges 300-305. 'BLNSYS - A 1401 Opereting System with Braille Capabilities'. J.B. LANDWEHR, C. MCLAUGHIN, H. MUELLER, M. LUCHSTEIN AND S.V. POLLACK. University of Cincinnati, Medical Computing Center, Cincinnati, Ohio.

Implementation codes in leader, character positions 6 to 9:

Character position 6: bit position 7 $=1$, other bits $=$ zero $-7,8:$ all zero

" 9: bit position $7=1$, other bits $=$ zero

These codes indicate literature type $=$ serial, bibliographic level $=$ analytic.

\section{Data fields}

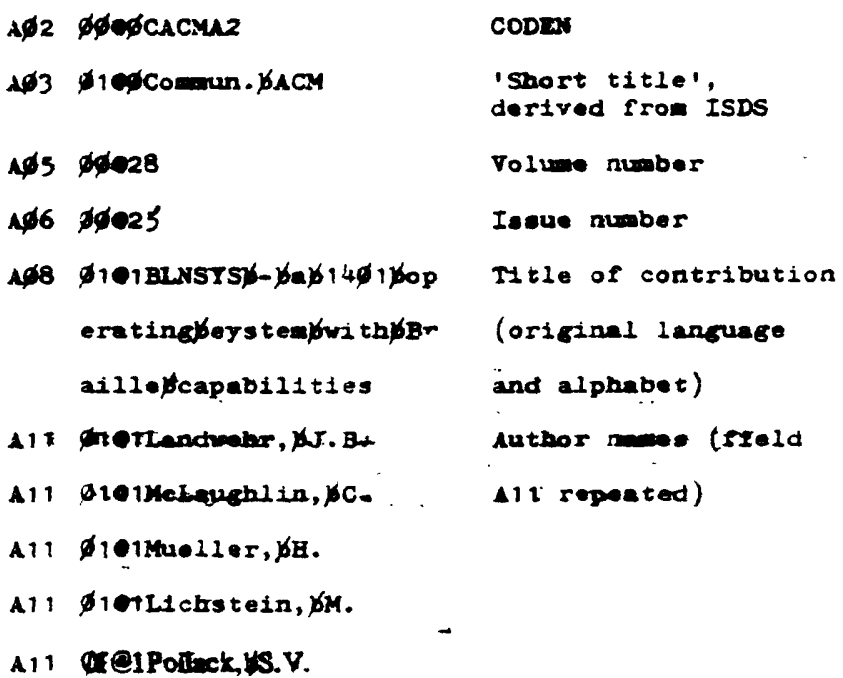

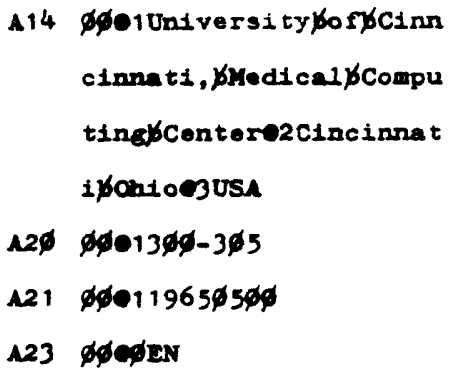

\section{Example 2: 'BOOK' (MONOGRAPH)}

'An Insight into Management Accounting'. John Sizer. Penguin Books, Harmondsworth, Middlesex, England. 1969. 341 pp. ISBN 0140210873.

Implementation codes in leader, character positions 6 to 9:

Character position 6: bit position $6=1$, other bits $=$ zero - $"$ 7,8: all zero

" "9: bit position $6=1$, other bits $=$ zero

These codes indicate literature type $=$ 'book', bibliographic level = monographic.

Date fields $\wedge \phi 9$

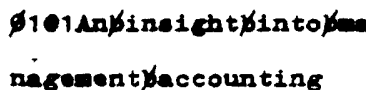

A12 101sizer,pu.

$121 \% 11969 \%$

$\triangle 23$ WEN

125 penguintBooks 1 Periar mondeworth, fringland

126 14\%14\$21ф873

$129 \$ 01341$

\author{
Tit10 of sonograph \\ (original languace \\ and alphabet) \\ Author name \\ Date of ioprint \\ Language of text* \\ Publisher namo \\ and location \\ ISEN \\ Collation
}

\section{Example 3: REPORT (MONOGRAPHIC)}

'Erosionskorrosion i vattenledningar av kopparör'. Lage Knutsson, Einar Mattsson \& Bengt.Eric Ramberg. Statens institut for by R23:1971, 29 pp.

English title also given: 'Erosion corrosion in copper water tubing'.

Implementation codes in leader, character positions 6 to 9

Character position $6:$ bit position $5=1$, other bits $=$ zero

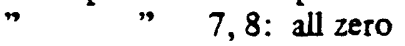

-. 9: bit position $6=1$, other bits $=$ zero

These codes indicate literature type $=$ report, bibliographic level $=$ monographic.

- The code 'EN' is employed here to represent 'English' by way of example only, pending the availability of 2 standard codine scheme. 


\section{Example 6: CONFERENCE PAPER}

(This example refers to an individual paper from a conference proceedings published as a monograph).

W.D. Kingery, Editor: 'Ice and Snow: Properties, Procesces and Applications'. Proceedings of a Conference held at The Maxachusetts Institute of Technology, Fobruary 12-16, 1962. The M.I.T. Press, Cambridge, Masachusetts, 1963. (xv+684pp.) On the Metamorphism of Snow', M.R. de Quervain, pp. 377.390, 11 references.

Implementation codes in character pasitions 6 to 9:

Chaneter position 6: bit position $6=1$, bit position $2=1$, other bits $=$ zero
"
7, 8: all zoro
" 9: bit pocition $7=1$, other bits $=$ zero

These codes indicate literature type $=$ conference proceedings published in 'book' form, bibliographic level $=$ analytic (since the record refers to a single paper).

\section{Date fields}

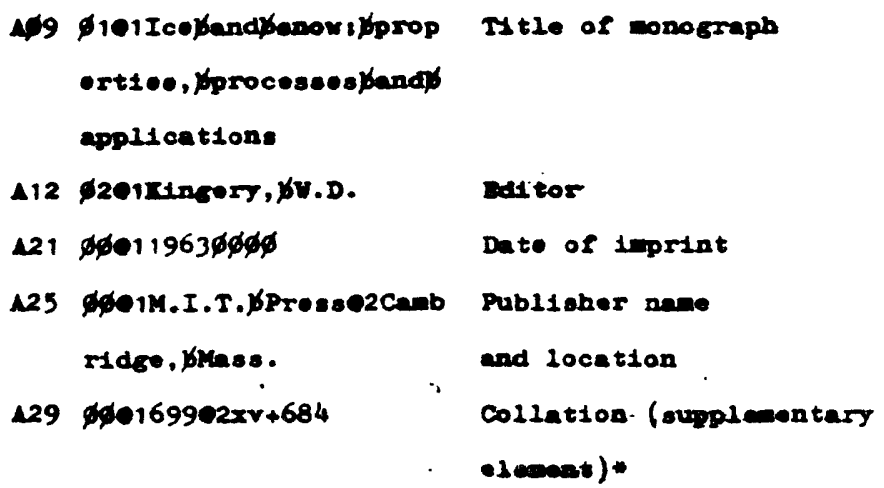

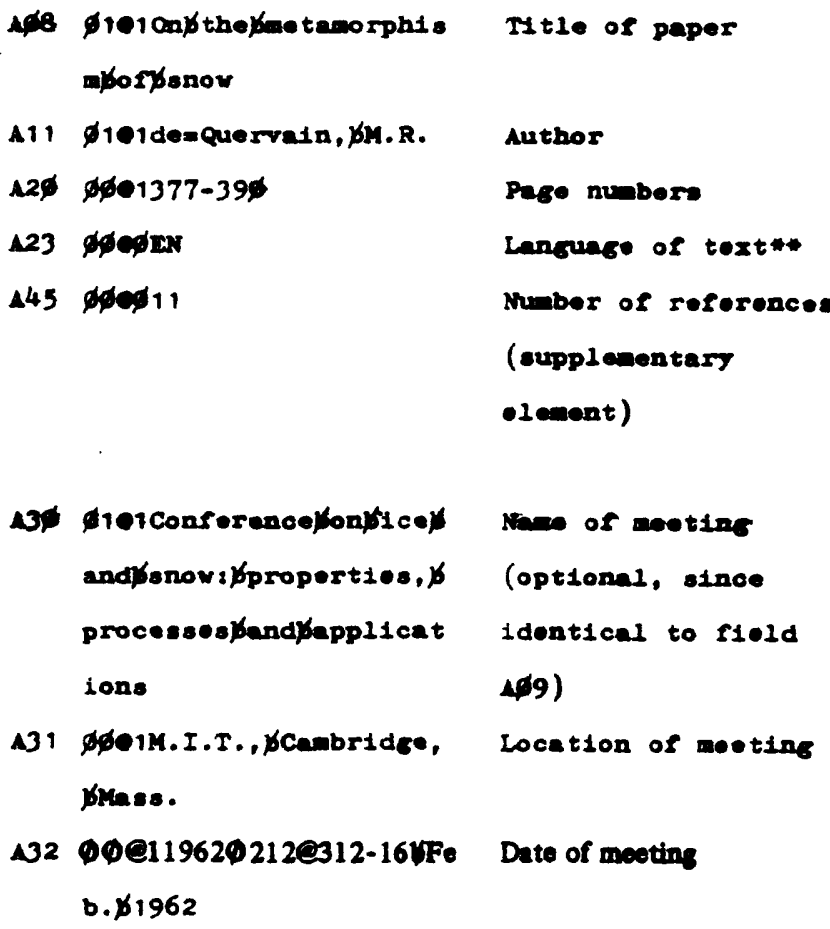

131 \$6e1M.I.T., bcambridce, prass.

132 DQ1196202120312-16VFo Date of meeting b. $\$ 1962$

- The use of subfield 2 in field $A 29$ is by way of example, and not necessarily a recommended practice.

- The code 'EN' is employed here to represent 'Earilin' by way of example only, pending the availability of a standard codins scheme. 


\begin{tabular}{|c|c|c|c|c|c|c|c|c|c|c|c|}
\hline \multirow{2}{*}{$\begin{array}{l}\text { Letter } \\
\text { number }\end{array}$} & \multicolumn{4}{|c|}{ Gyrille char. } & \multicolumn{6}{|c|}{ Hacd in } & \multirow{2}{*}{ 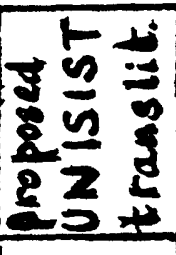 } \\
\hline & prin & ed & mano & $=$ & $\frac{5}{2}$ & 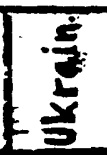 & $\frac{\bar{c}}{\frac{3}{5}}$ & 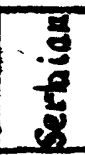 & $\frac{3}{3}$ & 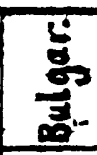 & \\
\hline 7 & - & -6 & 7 & 2 & - & & .. & $x$ & & & $d \mathbf{j}$ \\
\hline 8 & 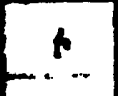 & $t$ & $i$ & $\dot{\mathcal{X}}$ & -. & .. & $\ldots .$. & & $x$ & & 8 \\
\hline-9 & 0.8 & 8 (B) & $e(\ddot{e})$ & $\varepsilon(\varepsilon)$ & $f x$ & $x$ & $x$ & $x$ & $x$ & $x$ & - \\
\hline 20 & $\epsilon$ & $\epsilon$. & $\varepsilon$ & $\varepsilon$ & _- & $x$ & & - & & & je \\
\hline. .11 & * & $x$ & $2 k$ & $|x|$ & $8 x$ & $x$ & $x$ & $x$ & $x$ & $x$ & $2 h$ \\
\hline-12 & $\therefore$ & 3 & 3,3 & 3 & $x$ & $x$ & $x$ & $x$ & $x$ & $x$ & 2 \\
\hline 13 & 3 & 3 & 1 & $S$ & & & $\ldots$ & & $x$ & & $d z$ \\
\hline 4 & ? & $n$ & $u$ & $u$ & $x$ & $x$ & $\ldots$ & $x$ & $x$ & $x$ & $i$ \\
\hline $25 \ldots$ & 1 & $I$ & $i$ & $I$ & $x$ & $x$ & $x$ & & & & $y^{i}$ \\
\hline 16 & 1 & $y$ & $f i$ & $\ddot{z}$ & $E$ & $x$ & $-\therefore$ & & $E$ & & yi_ \\
\hline 17 & 1 & 3 & $i$ & 2 & 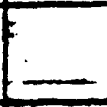 & - & - & $x$ & $x$ & & $-j$ \\
\hline 18 & 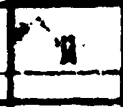 & A & $\bar{u}$ & $u$ & $x$ & $x$ & $x$ & & & $x$ & $j$ \\
\hline-39 & 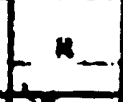 & x & $K$ & 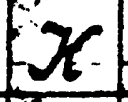 & $x$ & $x$ & $x$ & $x$ & $x$ & $x$ & $k$ \\
\hline & $x$ & 1 & $\alpha$ & $\because \Omega$ & $x$ & $x$ & $x$ & $x$ & $x$ & $x$ & 1 \\
\hline 21 & $x$ & $b$ & 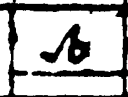 & $E 1$ & & $\therefore$ & & $x$ & $x$ & $\ldots$ & $-1 \pm$ \\
\hline$\ldots 22$ & $\approx$ & $n$ & $\alpha$ & $\mathscr{M}$ & $x$ & $E x$ & $x$ & $x$ & $x$ & $x$ & $m$ \\
\hline 23... & 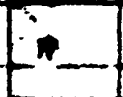 & . & -4 & 72 & $8 x$ & $-x$ & $x$ & $x$ & $x$ & $x$ & $n$ \\
\hline 24 & 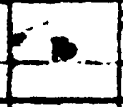 & se & . & -76 & 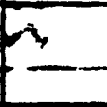 & $\ldots$ & - & $x$ & $x$ & & $n \dot{j}-$ \\
\hline-25 & $\therefore$ & - & - & \begin{tabular}{|l|}
6 \\
\end{tabular} & $x$ & $-x$ & $x$ & $x$ & $x$ & $x$ & ० \\
\hline 26 & $n$ & $\pi$ & $n$ & $\pi$ & $x$ & $x$ & $x$ & $x$ & $x$ & $x$ & $\rho$ \\
\hline 27 & $p$ & $P$ & $n$ & $\infty$ & $x$ & $x$ & $x$ & $x$ & $x$ & $x$ & $r$ \\
\hline 28 & - & 6 & $c$ & $e$ & $x$ & $x$ & $x$ & $x$ & $x$ & $x$ & $s$ \\
\hline 29 & I & & $m, \bar{m}, z$ & $\pi$ & $x$ & $x$ & $x$ & $x$ & $x$ & $x$ & $t$ \\
\hline
\end{tabular}




\section{Appendix D}

\section{ICIREPAT CODES FOR PATENT DOCUMENTS}

In fields A33 and A38, reference is made to the ICIREPAT code 8 the preferred meam of identifying type of patent document'. This Appendix embodies an ICIREPAT paper which defines a 'standard code for identification of dif. ferent kinds of patent document', and lints a subotantiak number of known types of document.
It will be noted that in fields $\mathrm{A} 33$ and $\mathrm{A} 38$ the ICIREPAT code is specified as a two-character fixedlength code. This Appendix defines only the first character, which is always a letter of the Roman alphabet. The second character, which is numeric, will be defined by mational patent offices. If only the first character is known, it is recommended that the second character position be entered as "Y' (blank or space).

\section{WIPA}
Alf: shared systeme-sI.8
(E)
IIIf: $4.3 .8 .1(E)$

\section{SMANARD CODE FOR IDEÍTTFICATION OF DIFEERENT RINDS OF PATENT DOCUMENTS}

\section{Introduction}

1. The recomendation provides for groups of letter codes in order to distinguish patent docuents. The letter codes also facilitate the storage and retrieval of such documants.

2. If any office wants to anplify the information contained in the letter code, this letter code may be optionally associated with a numerical code. The meaning of such numerical code should then be defined by each Patent office avalling itself of this option.

3. The code also provides for a letter for non-patent Ilterature documents (N) and for documents to be restricted to the internal use of patent offlces (X) (e.g. confidential documents, not to be disclosed outside the office). See in this respect also SI.I (ICIRzPAT Manual pages 4.3 .1 .1 to 4.3 .1 .4 ).

\section{Definitions}

4. For the purposes of this recomendation, the expression "patent docurents" includes patents for inventions, Inventors' certificates, utility certificates, utility models, patents or certificates of addition, inventors' certificates of addition, utility certiflcates of addition and published applications thercfor.

5. For the purposes of this recomendation, the ters "entry in an official gazette" means at least one comprehensive announcement in an official gazette regarding the making avallable to the public of the complete text, elaims (1f any) and drawings (if any) of a patent document.

6. For the purposes of this recomendation, the terms "publication" and "published" are used in the sense of

$$
\text { aaking avat Iable to the public for inspection or copying on request }
$$

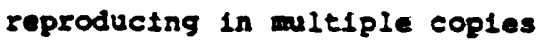

(111)

printing

of patent document.

Explanation: If, at a particular procedural stage, a copy of the document 1s first ande avaliable to the public for inspection or copying and is then, at the sam procedural stage, printed or reproduced in multipie copies. only a single publication is. considered to have occurred. If, on the other hand, printing or multiple reproduction results from a new procadurel stage. this printing is considered to be a further publicat1on of the document, even if the texts at the two stages are Identical.

7. According to certain dational patent laws or regulations, the same patent application may be published at various procedural stages. Por the purpcsis of this recomendation, a publication level is defined as the lerel corresponding to a procedural stage at which normally a document is published under a glven sational patent law.

\section{Becommendation}

8. It is recommended that the code:

(a) be used for the recording of the "kind of document" in machine-readable data carriers, such as 30-column punched cards, magnetic tapes, aperture cards, etc.;

(b) be used on the first page of patent documents, preferably near the document number, if these have been published in the sense of paragraph 6 ; 


\section{Append 1X I}

Ilst of Patent Documnents, Past and Currently Published, and Intended to be Published in the puture, Divided in Accordinan with this code

\section{Code: $A$ Patent_Documents_Numbered_In_Primary_or_Major_Ser1es_E_E1 rgt_Publigeation_Level}

Exanples: Austria

Belgium

Belgium

Bulgaria

Canada

Cuba

Crechos lovak1a

Crechoslorakta

Densark

Egypt

Europat

Finland

Trance

Prance

Prance

Trance-

France

Prance

rrance

France

Prance

German Democratic Republic

German Democratic Republ1c

Germany, Pederal

Republic of:

Bubgary

Ind1a

Ireland

Itaily

Japan

Luxembourg

Luxembourg

Netherlands

Norway
Patent foplicaelon published in the sense of paragraph 6(1)

Brevet d'invention/Oitvindingsoctrooi

Brevet de perfectionnement/Verbeteringsoctrool

Oplsan1e na lzobreten1e po patent

Patent

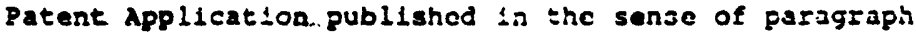
$6(1)$

Patent Application published in the sense of paragraph 6 (i)

Inventors' Certificate Application published in the sense of paragraph $6(i)$

Petent Application published in the sense of paragraph 6(1)

Patent specification

Document published after 18 months

Patent Application pablished in the sense of paragraph $6(1)$

Brevet d'invention (old law)

Brevet dinvention, premiere et unique publication

Certificat d'addition a un brevet d'invention, première et unigue publication

Certificat diutilite, premiere et unique publication certificat d'addstion a un certiflcat d'utilite, premiere et unigue publication

Demande de brevet d'invention, premiare publication Demande. de certifleat d'addition a un brevet d'invention, premidre publication

Demande de certificat d'utilité, premiare publication

Demande de certificat d'addition a un certificat d'utilite, preatare publication

Patentschrift (Ausschliessungspatent)

Patentschrift (Whtschaftspatent)

Offeniegungsschrfst

Patent Application published in the sense of paragraph 6 (i)

Patent specification

Patent speciflcation

Brevetto per Invenzlone industriale

Xoka1 tokkyo koho

Brevet d'invention

Cert:sicat d'addteion $a$ un brevet $d$ 'invention

Ter inzage gelegde sctroolaanvrage

patent Apelleztion published is the scasc of paragrash 6 (1)

Patent soecistcatton 
Code: C (continued)

Examplas: Norway

Patent

sweden

Patentskrift

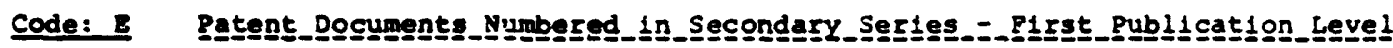

Examples: France

Certiflcat d'addition a brevet d'invention (old law)

Un1ted States Re1ssue

Code: H or I Petent_Documents_Numbered_In_Furthex_Series

Example: United States Defensive publication

Code: M Mad1cagant_Patent_ugguments

Examples: France Brevet special de medicament

France Mddition a un brevet special de medicament

Code: $u$ ut11_tyy_mode1_Doguments_Numbered_1n_Series_other_than_the_Doguments_of_Group_I_E

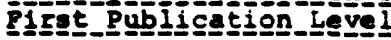

Examples: Germany, Pederal Gebrauchsmoster Republic of

Japan

Kokal j1tsuyo shinan koho

Spain Utility Model Application published in the sense of paragraph $6(1)$

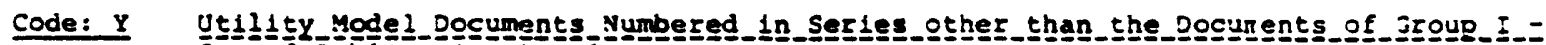
second_pub1 1cateion_Leve!

Examples: Japan

Spain

Jitsuyo shinan koho

modelo de utilidad

[Āppendix II follows 
Appendix $E$

\section{INID NUMBERS FOR IDENTIFICATION OF PATENT DATA ELEMENTS}

This Appendix embodies an ICIREPAT paper which dofines a set of codes for identification of bibliographic dats on the first page of a patent document and in entries in an official garette. These codes, known as INID numbers, have been referred to in Chapter 1.5 and in the descriptions of individual patent data etements in Part 2.
INID numbers are organized into decimal groups $(10,26$, etc.), each of which is subdivided into a number of specific items $(12,13,14,21,22,23$, etc.).

The individual codes are used only with the precise meanings defined on subsequent pages. If none of the specific item definitions is applicable, the generic code for the group (ending in ()) may be used.

This Appendix is included for reference purposes only, to ascist in creating bibliographic records for patent documents which use the INID system. INID numbers are aot themselves used in UNISIST exchange records.

\section{ICIRUPAT}

\section{Recempendatica comoersing Biblingrephie Dew}

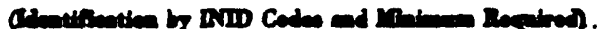

c to Fin Page of a Puent Dacinoat and in

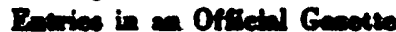

Introdwetion

1. The recommendation STAC III No. 62d of September 1967 providee for means whereby the rarions data appearing on the firvt pase of a patent doenmest can be idestified without boviledse of the laniguage ased and the law appliod. This recommondation is already weecenfully applied by varion Patent Offices.

2. The recommendation STAC III Ne. 77 \& of September 1967 likewies provides for moens whereby tho various dete apparing in entrice in official gasettes and like pablientions can be ideatified.

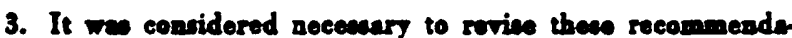
tions in eertain reapects in the light of experionce with their oce

4. It was slop conoidered neceseary to inclede in the roeomandation an indieaties of the minimum bibliographis data to be provided or the fint pase of meh a document, and in an entry is weh a gasette, in order to give the information

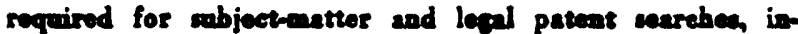
abding findins patant families, and for documantation par-

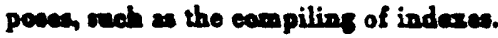

Definidions

5. "Patent docusents" iscludes prenth inventors" certificaten atility modolo or cartificaten and appliention thorefor.

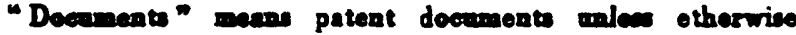
ant.

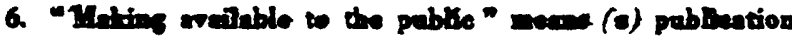

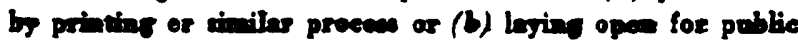

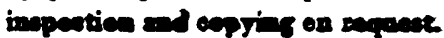

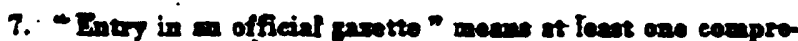

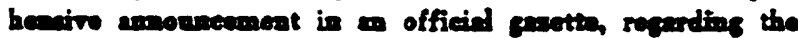

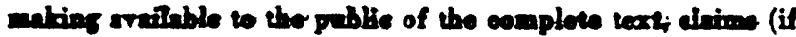

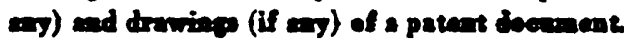

8. "INID" in an acromym for "ICIRBPAT Number for the Ideatifieation of Data"

\section{Genared}

9. The lint of definition of bibliographic data doments with their correpponding INID codes in given below. The INID codes which are preeeded by a single asterisk (") rolate to thoee data elomente whieh are considared to be the minimam elemente whieh should sppear on the first pase of a docerwent and is a extry is an official rasetta Tho INID coden which an preceded by a double enterisk (**) relate to those data denem which are conidered to be minimum elemonta in eireunstances opecified in the accompaning noten.
10. The INID codes should be amociated with the corro oponding data elements in 10 far at these eloments normally appear on the firat page of the document or in the entry is the official rasette. The INID codes should preforably be indicated uine Arabie anmeral within omall circlos of - if this is not foavible - is parenthoses, immodiately before the corresponding data element. Provided the presentation of biblio craphic data olomente in ontries in an official sasette is uniform INID codes mas be applied to the data elemente in a representutive opecimen entry in each sasotto icouod, instead of being incladed in each entry.

11. If data elemonts to which INID codes aro anipoed in eceordance with thin recommendation do not appear on the first pere of a doeument or in an entry in an official gasette - beeanes thos are not applicable (0.8. when no priority is claimed) or for tome other reason - it is not noceust to call attention to the nop-axistance of orch elements (o. f. by loaring a pace or by providing the relovant INID code fol lowed by a dabh).

12. Two or more INID codes may be asigmed to a single date element when necesany.

13. The list of date elomente has been organised into catogories $(10,20 \ldots 70)$ to facilitate grouping of related elomente. Eech categery hes two or more subdivisions to each of which an INID code has been anigned. If none of the specific codea can be anigned to a date eloment which clearly falle within the category definition, the relevant category code, eadins in 0 , should be need.

14. In order that the wers of patent documents and official casertes may be exabled to mate maximum ase of these INID codee it is recommended that a list of the codes be publinhed in Pateas Office or other official pablicationes e. 8 . official gasettee, at repular intervale.

\section{Implemenseation}

15. It is of conres open to each Patest Office to implosecat this rocommendntios oither in its ontirety or to some lesear extert, whicherver it finds more convenient.

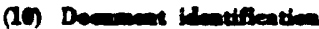

(11) Naniber of the docomente

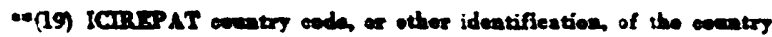

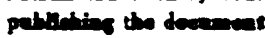

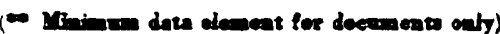

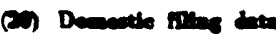

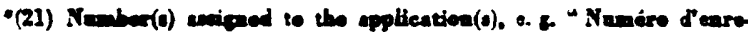

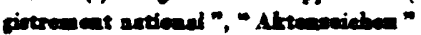

-(22) Deto(o) of ringes apliantion(o)

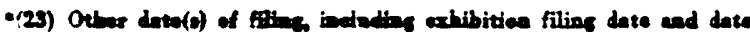

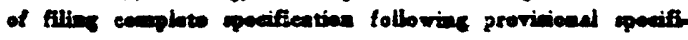
antion 


\begin{tabular}{|c|c|c|c|c|c|}
\hline Character & Pos 1 & Pos 2 & Pos 3 & Pos 4 & Pos 5 \\
\hline $\mathbf{A}$ & 11 & 7 & 5 & 3 & 1 \\
\hline $\mathbf{B}$ & 22 & 14 & $1 \varnothing$ & 6 & 2 \\
\hline C & 33 & 21 & 15 & 9 & 3 \\
\hline D & $1 \varnothing$ & 28 & $2 \varnothing$ & 12 & 4 \\
\hline $\mathbf{E}$ & 21 & 1 & 25 & 15 & 5 \\
\hline $\mathbf{F}$ & 32 & 8 & $3 \phi$ & 18 & 6 \\
\hline $\mathbf{G}$ & 9 & 15 & 1 & 21 & 7 \\
\hline $\mathbf{H}$ & $2 \phi$ & 22 & 6 & 24 & 8 \\
\hline$I$ & 31 & 29 & 11 & 27 & 9 \\
\hline $\mathbf{J}$ & 8 & 2 & 16 & $3 \varnothing$ & $1 \phi$ \\
\hline $\mathbf{K}$ & 19 & 9 & 21 & 33 & 11 \\
\hline L & $3 \varnothing$ & 16 & 26 & 2 & 12 \\
\hline $\mathbf{M}$ & 7 & 23 & 31 & 5 & 13 \\
\hline $\mathbf{N}$ & 18 & $3 \varnothing$ & 2 & 8 & 14 \\
\hline 0 & 29 & 3 & 7 & 11 & 15 \\
\hline $\mathbf{P}$ & 6 & $1 \varnothing$ & 12 & 14 & 16 \\
\hline $\mathbf{Q}$ & 17 & 17 & 17 & 17 & 17 \\
\hline $\mathbf{R}$ & 28 & 24 & 22 & $2 \varnothing$ & 18 \\
\hline $\mathbf{S}$ & 5 & 31 & 27 & 23 & 19 \\
\hline $\mathbf{T}$ & 16 & 4 & 32 & 26 & $2 \phi$ \\
\hline $\boldsymbol{U}$ & 27 & 11 & 3 & 29 & 21 \\
\hline $\mathbf{v}$ & 4 & 18 & 8 & 32 & 22 \\
\hline$W$ & 15 & 25 & 13 & 1 & 23 \\
\hline $\mathbf{x}$ & 26 & 32 & 18 & 4 & 24 \\
\hline $\mathbf{Y}$ & 3 & 5 & 23 & 7 & 25 \\
\hline $\mathbf{Z}$ & 14 & 12 & 28 & 16 & 26 \\
\hline
\end{tabular}




\begin{tabular}{|c|c|c|c|c|c|c|c|}
\hline Total & $\begin{array}{l}\text { Check } \\
\text { Character }\end{array}$ & Total & $\begin{array}{l}\text { Check } \\
\text { Character }\end{array}$ & Total & $\begin{array}{l}\text { Check } \\
\text { Character }\end{array}$ & Total & $\begin{array}{l}\text { Check } \\
\text { Character }\end{array}$ \\
\hline$\phi$ & 9 & 24 & $\mathbf{x}$ & 48 & $\mathbf{N}$ & 72 & $\mathrm{D}$ \\
\hline 1 & A & 25 & $\mathbf{Y}$ & 49 & 0 & 73 & $\mathbf{E}$ \\
\hline 2 & B & 26 & $\mathbf{Z}$ & $5 \varnothing$ & $\mathbf{P}$ & 74 & $\mathbf{F}$ \\
\hline 3 & C & 27 & 2 & 51 & $\mathbf{Q}$ & 75 & $\mathrm{G}$ \\
\hline 4 & D & 28 & 3 & 52 & $\mathbf{R}$ & 76 & $\mathrm{H}$ \\
\hline 5 & $\mathbf{E}$ & 29 & 4 & 53 & $\mathbf{S}$ & 77 & $I$ \\
\hline 6 & $F$ & $3 \varnothing$ & 5 & 54 & $\mathbf{T}$ & 78 & $\mathrm{~J}$ \\
\hline 7 & G & 31 & 6 & 55 & $U$ & 79 & $\mathbf{K}$ \\
\hline 8 & $\mathbf{H}$ & 32 & 7 & 56 & $\mathbf{V}$ & $8 \phi$ & L \\
\hline 9 & $I$ & 33 & 8 & 57 & $W$ & 81 & $\mathbf{M}$ \\
\hline $1 \varnothing$ & $\mathbf{J}$ & 34 & 9 & 58 & $\mathbf{x}$ & 82 & $\mathbf{N}$ \\
\hline 11 & $\mathbf{K}$ & 35 & A & 59 & $\mathbf{Y}$ & 83 & 0 \\
\hline 12 & L & 36 & B & $6 \phi$ & $\mathbf{z}$ & 84 & $\mathbf{P}$ \\
\hline 13 & $\mathbf{M}$ & 37 & C & 61 & 2 & 85 & $\mathbf{Q}$ \\
\hline 14 & $\mathbf{N}$ & 38 & D & 62 & 3 & 86 & $\mathbf{R}$ \\
\hline 15 & 0 & 39 & $\mathbf{E}$ & 63 & 4 & 87 & $\mathbf{s}$ \\
\hline 16 & $\mathbf{P}$ & $4 \varnothing$ & $\boldsymbol{F}$ & 64 & 5 & 88 & $T$ \\
\hline 17 & $\mathbf{Q}$ & 41 & $\mathbf{G}$ & 65 & 6 & 89 & $U$ \\
\hline 18 & $\mathbf{R}$ & 42 & $\mathbf{H}$ & 66 & 7 & $9 \varnothing$ & $\mathrm{V}$ \\
\hline 19 & $\mathbf{s}$ & 43 & $I$ & 67 & 8 & 91 & $W$ \\
\hline $2 \phi$ & $\mathbf{T}$ & 44 & $\mathbf{J}$ & 68 & 9 & 92 & $\mathrm{x}$ \\
\hline 21 & $\mathrm{U}$ & 45 & $\mathbf{K}$ & 69 & $A$ & 93 & $Y$ \\
\hline 22 & $\mathbf{v}$ & 46 & L & $7 \varnothing$ & B & 94 & $\mathrm{Z}$ \\
\hline 23 & $W$ & 47 & $\mathbf{M}$ & 71 & $\mathrm{C}$ & 95 & 2 \\
\hline
\end{tabular}


Items marked with an asterisik (*) are considered essential for users of the Reference Mamual

-1 ISO 2709 - 1973: Documentation - Format for bibliographic information interchange on magnetic tape.

2 UNISIST International Serials Data System: Guideines for ISDS, Unesco: Paris 1973.

3 IFLA: International Standard Bibliographic Description for Serials (in preparation).

4 ISO/TC46 fifth draft proposal: Patents. Bibliographical references, Essential and complementary elements.

5 ICIREPAT Recommendations concerning biblio graphic data on the first page of a patent document and in entries in an official gazette. (Incorporated in Appendix E).
*6 ISO DIS 3297 - 1973: International Standard Serial Numbering.

7 CODEN for Periodical Titles, ASTM Data Series DS23B, American Society for Testing and Materials: Philadelphia 1970 (2 vols).

-8 ISO/R4 - 1972: Documentation - International code . for the abbrevintion of titles of periodicals.

49 ISO 833 - 1973: Documentation - International list of periodical title-word abbreviations.

10 ISO/R2014 - 1971: Writing of calendar dates in allnumeric form.

- 11 ISO 2108 - 1972: International Standard Book Numbering.

12 ISO/R646 - 1973: 7-bit coded character sets for information processing interchange.

13 GOST 13052-67 (USSR standard for 7-bit coded character sets). 

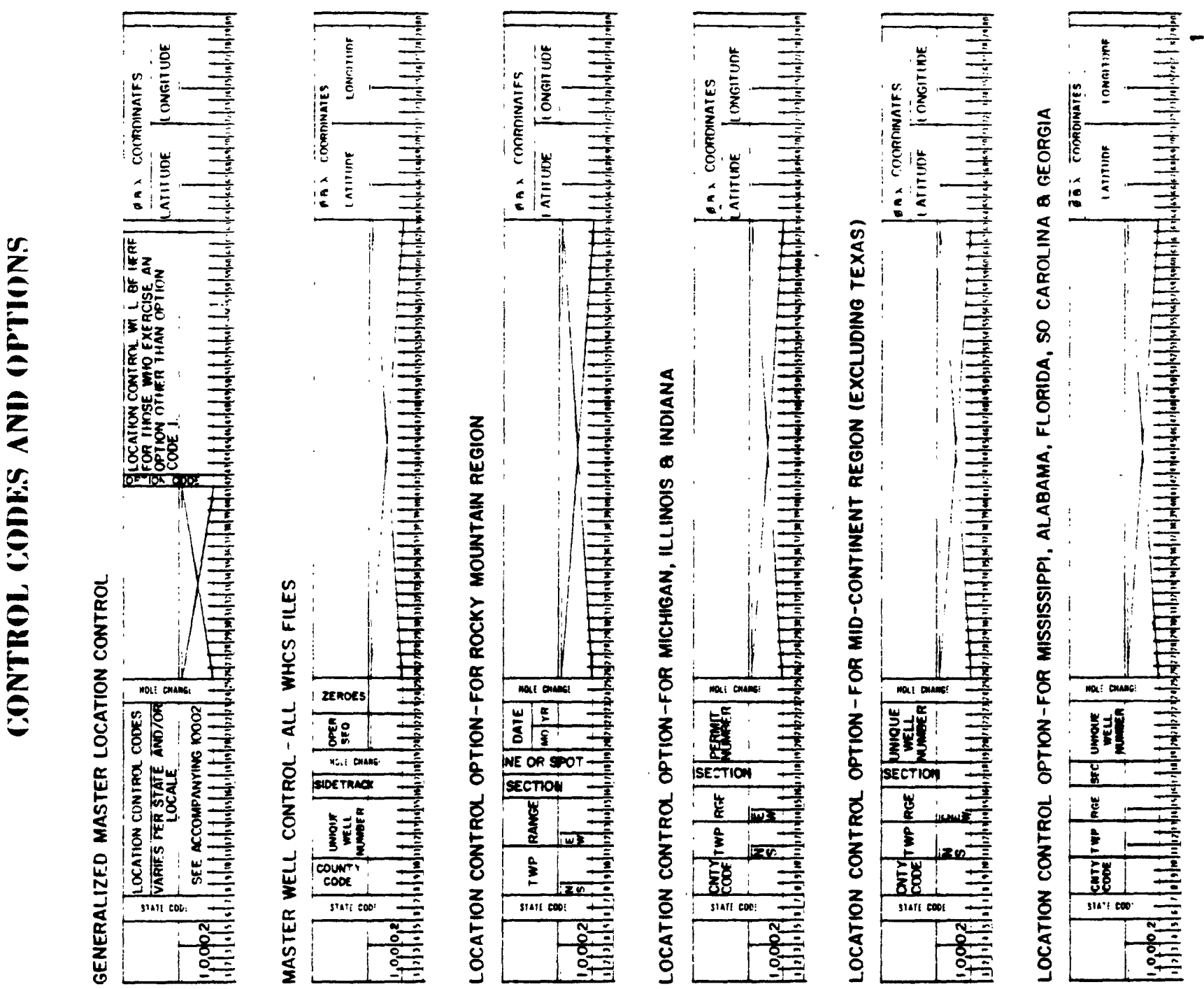

$\stackrel{2}{2}$

它

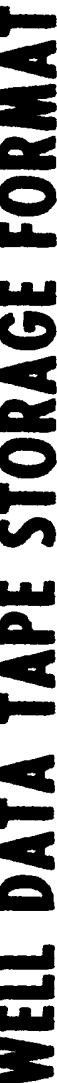

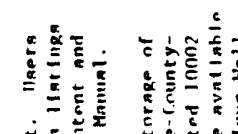

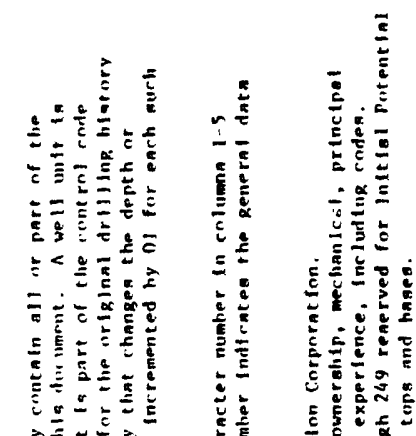

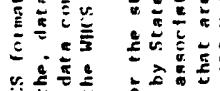

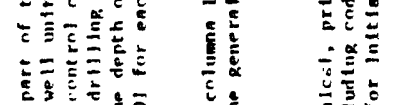

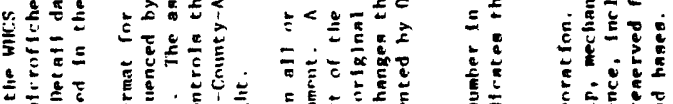

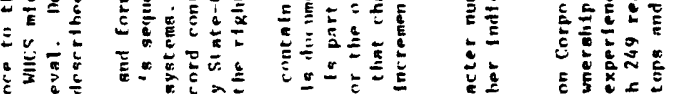

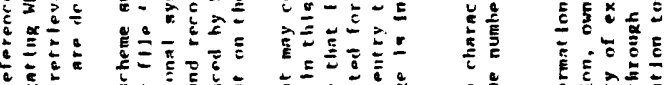

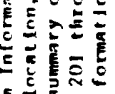

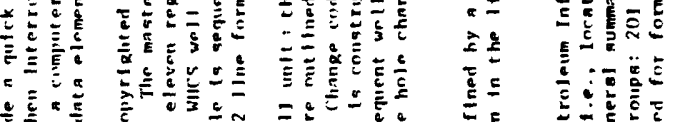

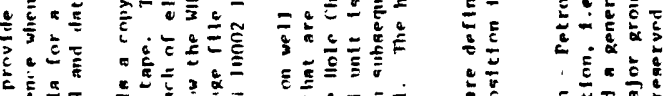

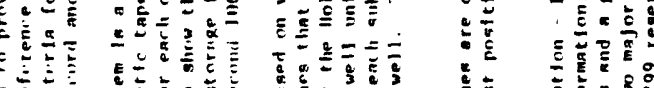

20

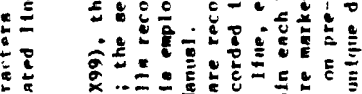

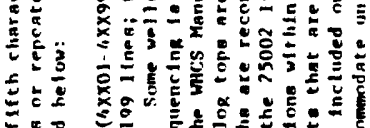

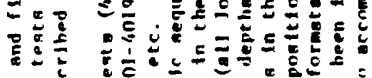

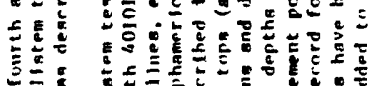

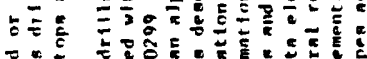

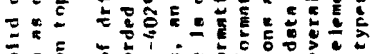

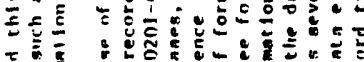

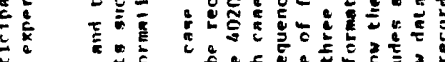

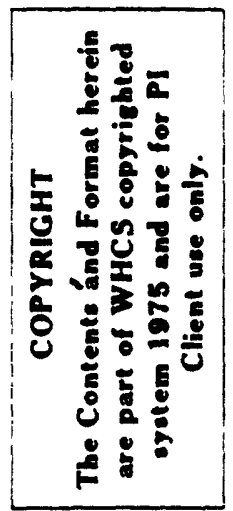

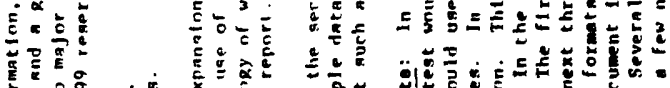

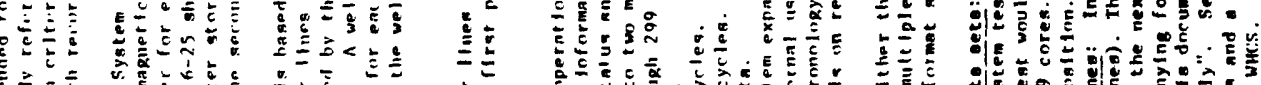

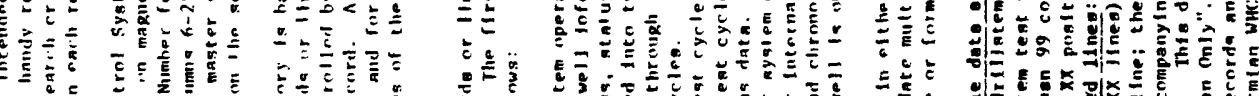

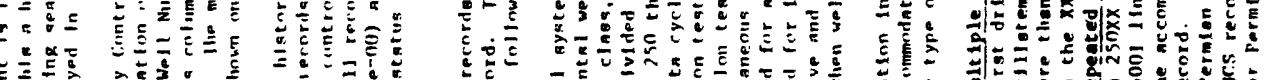

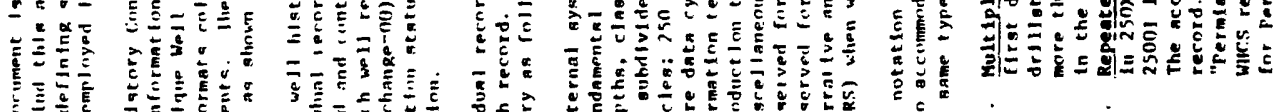

$x_{x}^{2}=-i$

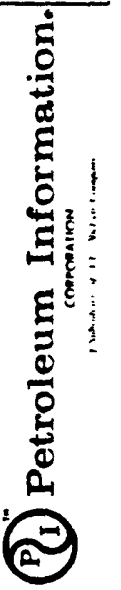



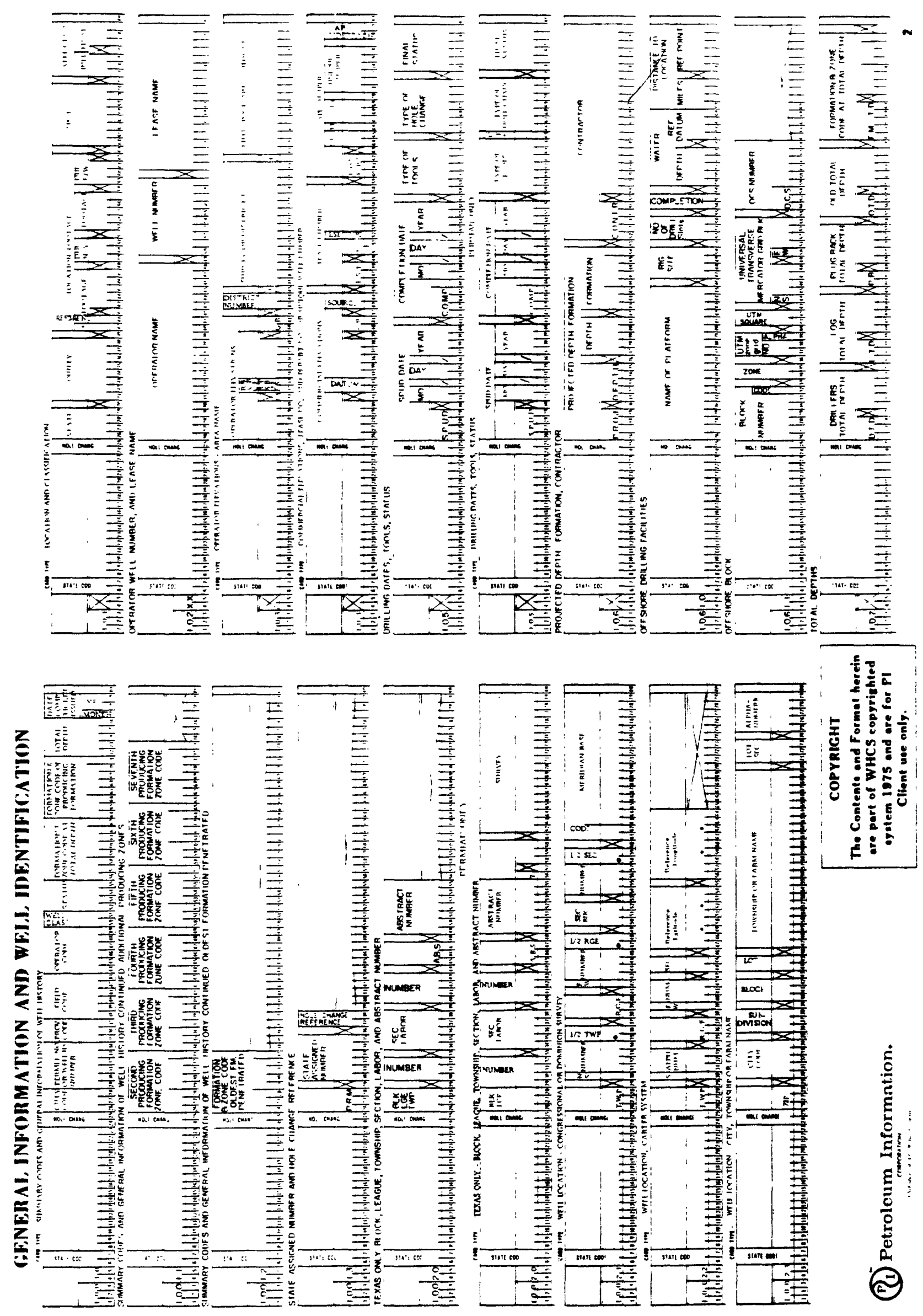

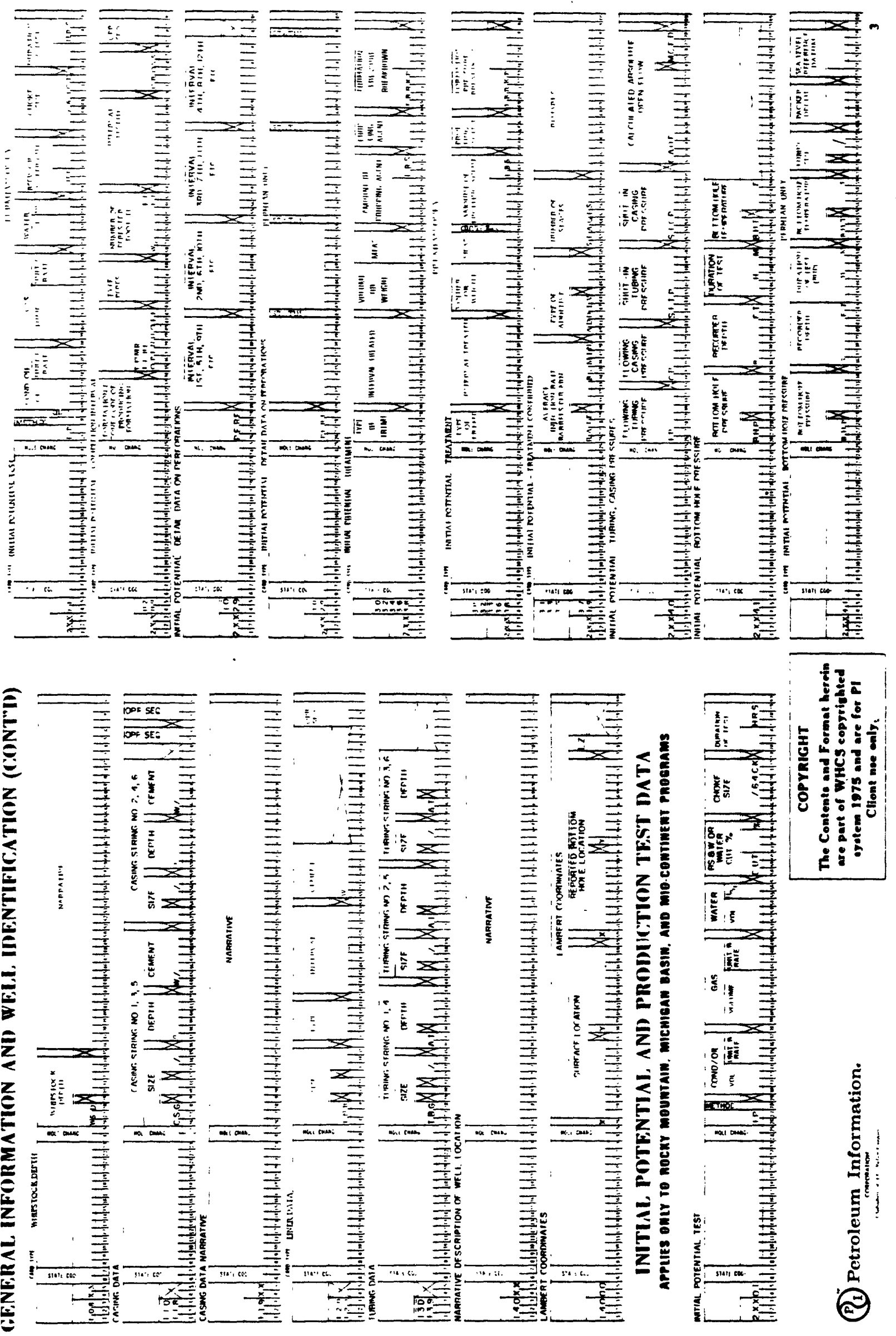


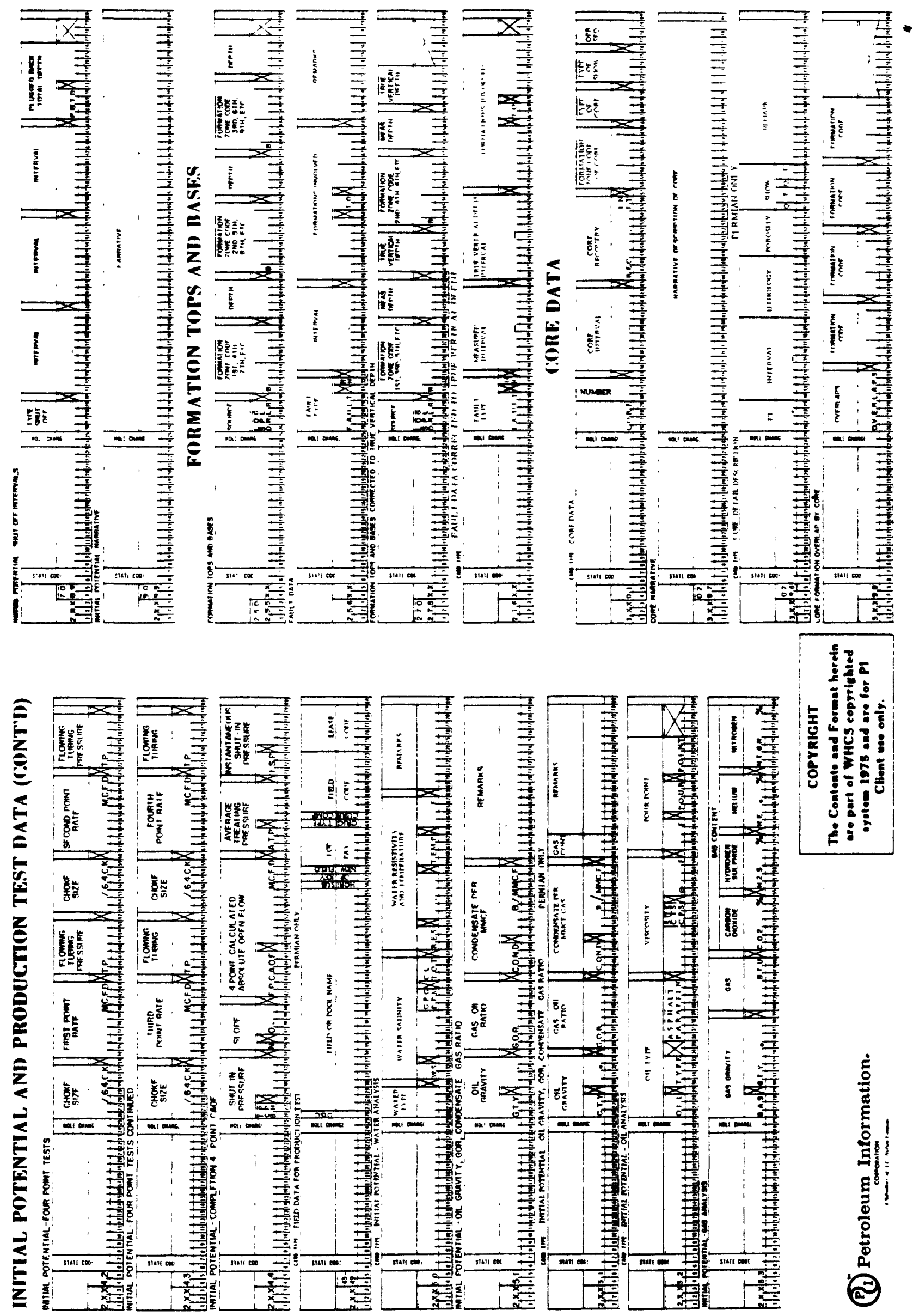



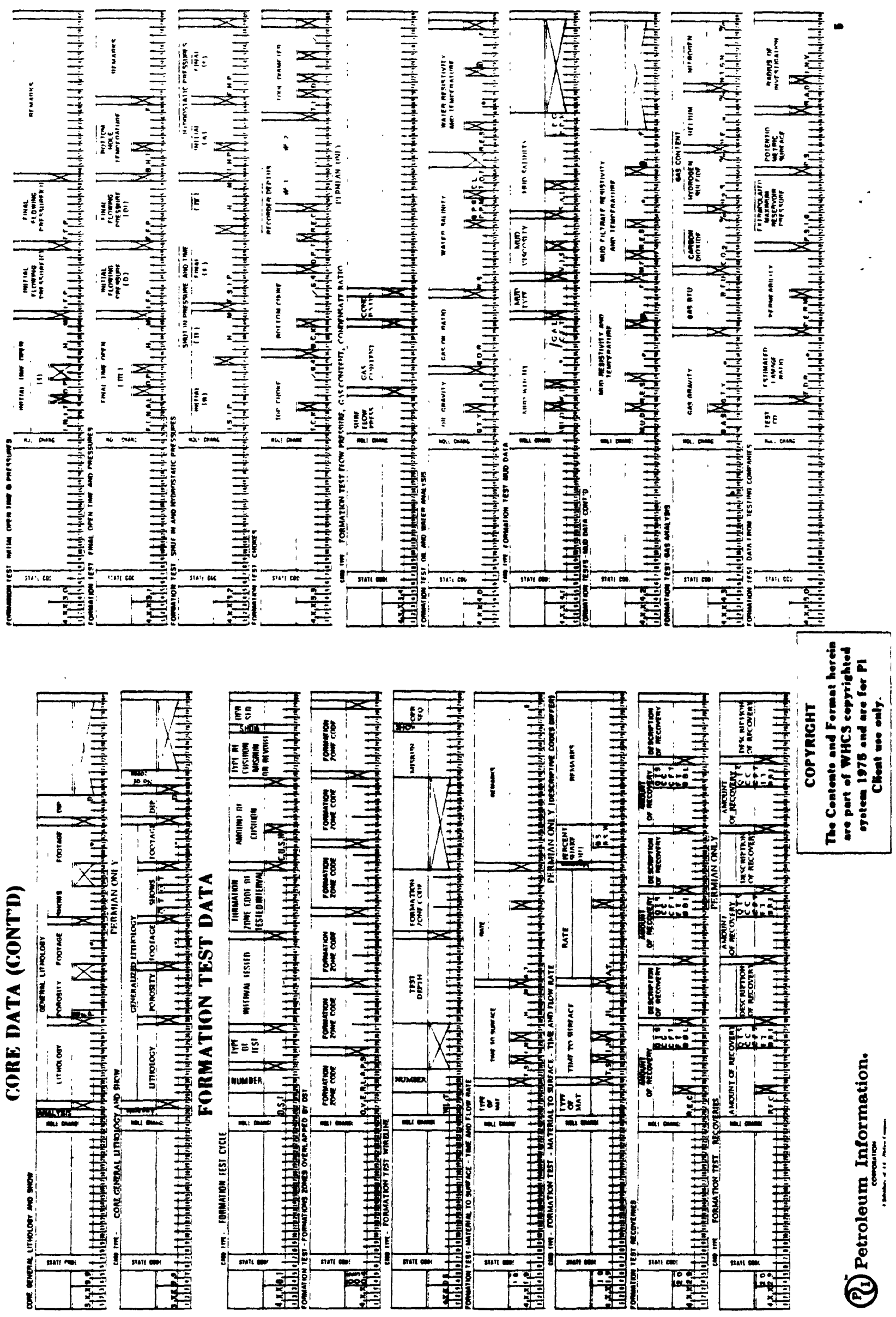


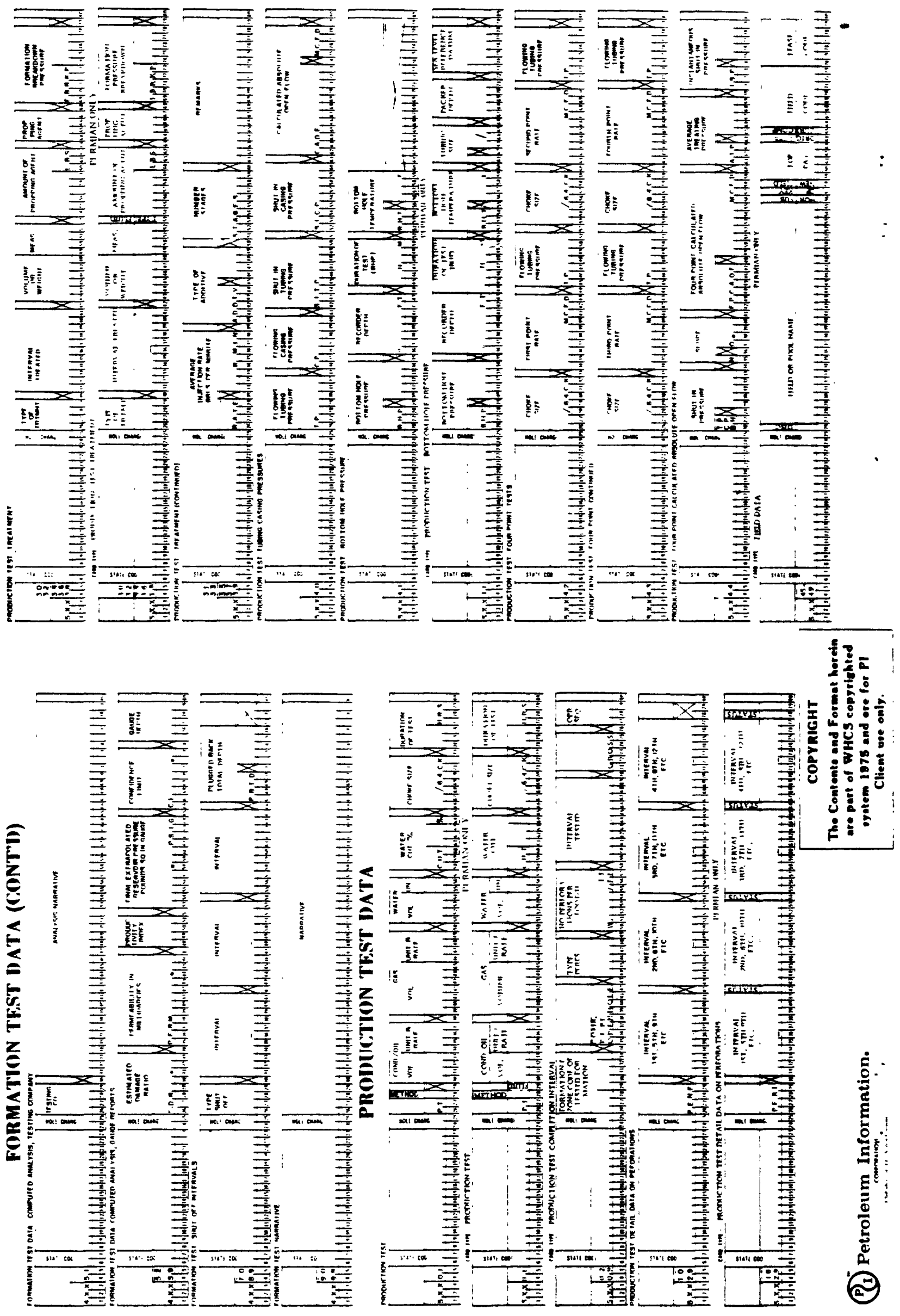



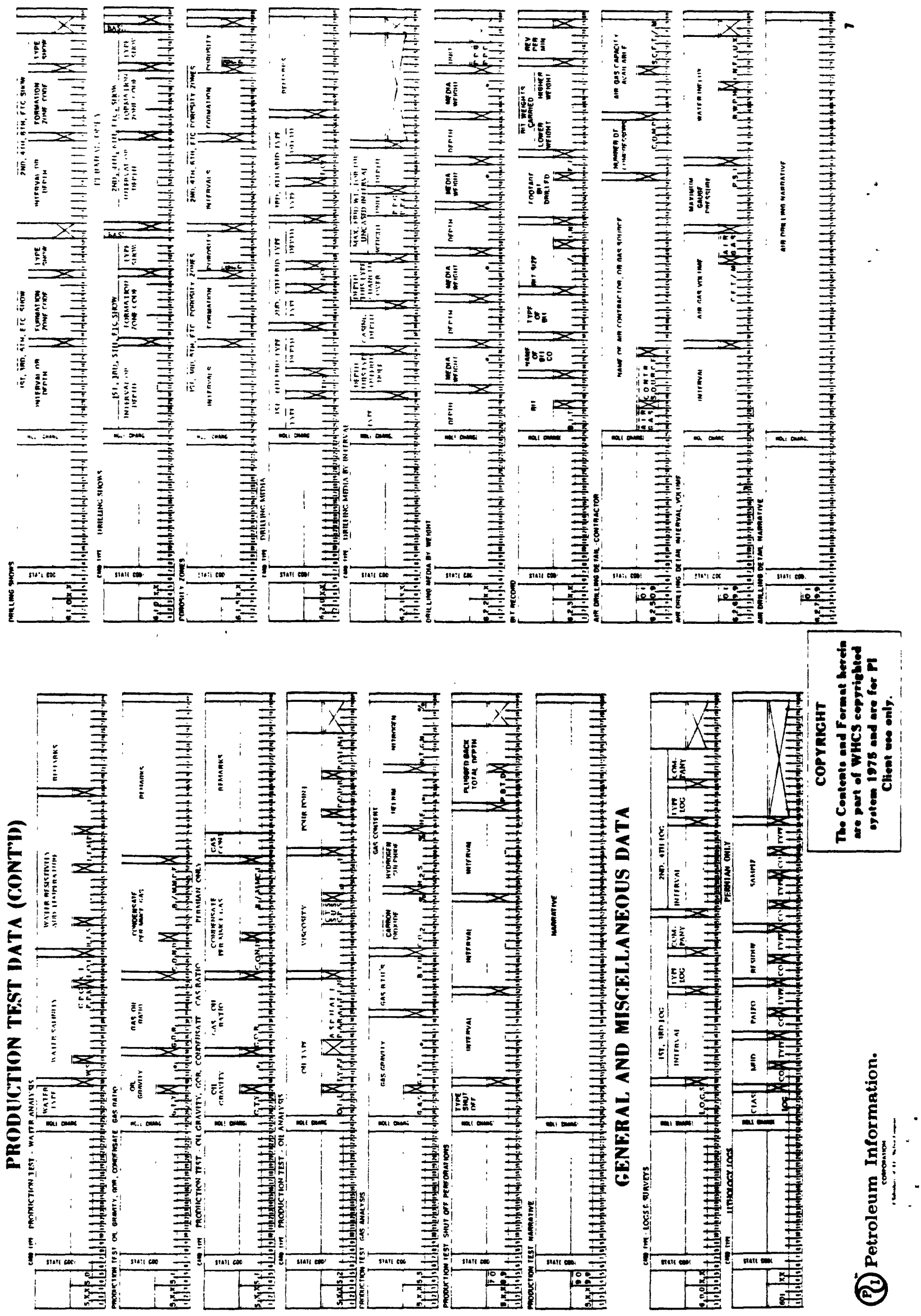

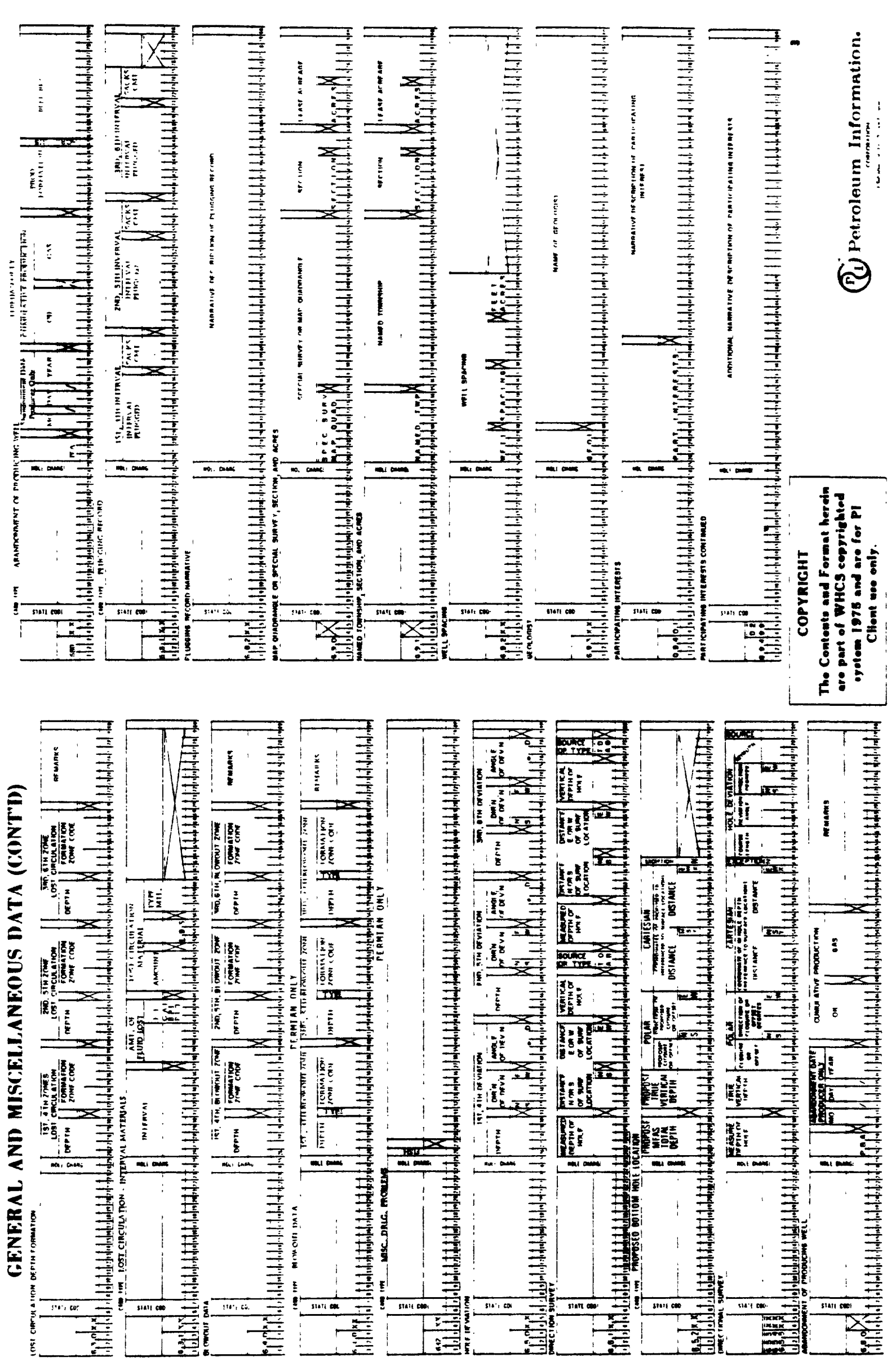


\section{A IDENTIFICATION}
AI CONTINENT<
$>$ A2 COUNTRY

A3 STATE

A3A STATE CODE $<$

A4 COUNTY

A4A COUNTY CODE $<$

A5 FIELO

A5A FIELD CODE NO. (FROM FPC CODE BOOKX

A5B UNIQUE ID NUMBER

A6 POOL

A6A STATE OR FEDERAL, IDENTIFICATION NO.

A7 SOURCE DOCUMENT (OTHER THAN STATE REPORTS OR OIL SCOUTS REVIEW)

A7A STATE REPORTS

A7B OIL SCOUTS REVIEWK

ATC FPC EXHIBIT H DATAK

B FIELD/POOL DATA

BI REGULATORY DISTRICT OR AREA

B2 PRODUCING FORMATION NAME

B2A STRATIGRAPHIC CODE

GEOLOGIC AGE OF PRODUCING FORMATION (FROM DICTIONARY OF STRATIGRAPHIC NAMES) B3

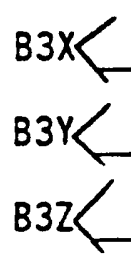

(Revised 4/78) 
B4 DESIGNATION OF FIELD \& POOL BY STATE REGULATORY AGENCY (CIRCLE APPROPRIATE CODES)

B4A OIL

B4B CONDENSATE

BAC GAS

B4D
B4E NON-ALLOCATED OR NON-EXEMPT

B4F GAS STORAGE

$\because \quad B 4 G$ HELIUM

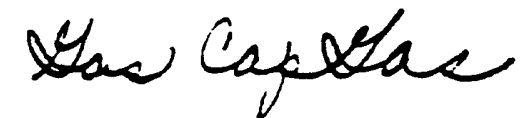

B5 OFFSHORE

B6 LOCATION

- BGA SECTION

B6B TOWNSHIP

B6C RANGE

B6D MERIDIAN

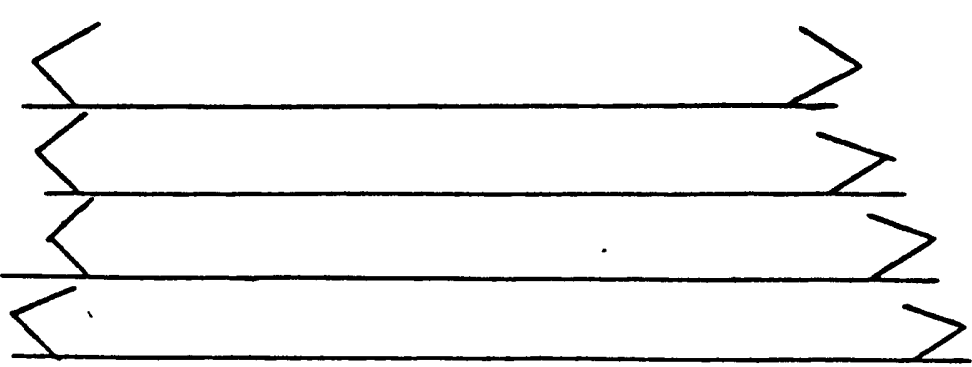

B7 FIELD CENTERPOINT

B7A LATITUDE

B7B LONGITUDE

B7C FIELD ELEVATION (AVERAGE FT.)

B8 TYPE OF RECORD

B8A FIELD RECORD -

- B8B POOL RECORD

C FIELD/POOL DATA CONTINUED

CI NO. OF POOLS IN FIELD

C2 YEAR DISCOVERED

C3 YEAR ABANDONED
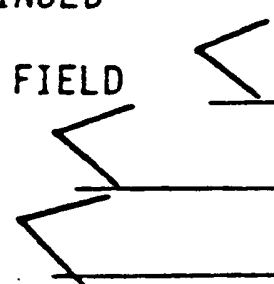
C4 FIELD DISCOVERY METHOD (CIRCLE APPROPRIATE CODE)

$\begin{array}{llll}\text { C4A } & \text { SEISMIC } & \text { C4G } & \text { PHOTOGEOLOGY } \\ \text { C4B } & \text { SUBSURFACE } & \text { C4H } & \text { RANDOM DRILLING } \\ \text { C4C } & \text { SEISMIC PLUS SUBSURFACE } & \text { C4J } & \text { OLD WELL REENTERED } \\ \text { C4D } & \text { SURFACE } & \text { C4K } & \text { GEOCHEMICAL } \\ \text { C4E } & \text { GROUND MAGNETICS } & \text { C4L } & \text { GRAVITY } \\ \text { C4F } & \text { AIRBORNE MAGNETOMETER } & \text { C4M } & \text { TREND } \\ & & C 4 Z & \text { OTHER }\end{array}$

C5 TRAP TYPE (GENERAL)

C5A STRUCTURAL

C5B STRATIGRAPHIC .

C5C STRUCTURAL PLUS STRATIGRAPHIC

C5D HYDRODYNAMIC

C5E OTHER

C6 TRAP TYPE (SPECIFIC)

C6A ANTICLINE

C6B SALT DOME .

C6C FAULT

CED NOSE

CGE SYNCLINE

C6F TERRACE

CGG FRACTURE

C6H HOMOCLINE

C6J DOME

CGK DIAPIR FOLD
CGL BURIED HILL

CGM REGIONAL FACIES CHANGE

CEN UNCONFORMITY

CGP LATERAL CHANGE IN POROSITY AND PERMEABILITY

C6Q IGNEOUS INTRUSIVE

C6R ASPHALT DEAL

C6S BIOHERM (REEF)

CET BIOSTROME

CGU SECONDARY CHEMICAL ALTERATION

CEW MONOCLINE

C6X LENSE

C6Z OTHER 
D PRESENT STATUS OF POOL (MUST BE ANSWERED ON EVERY FORM)

DI ABANDONED

DIA OIL

DIB GAS

DIC CONSOLIDATED OR DIVIDED POOLS

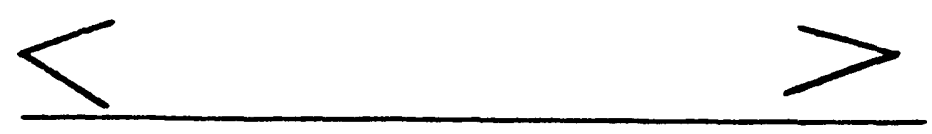

D2 TEMPORARILY ABANDONED

D2A OIL

D2B GAS

D3 PRODUCING

D3A OIL

D3B GAS

D4 SHUT-IN

D4A OIL

DAB GAS

D5 GAS STORAGE (DEVELOPED OR UNDEVELOPED)

DQL ENHANCED RECOVERY it

D7 UNITIZED POOL

DTA YES

D7B NO

D8 DEEPEST WELL

FIELD

POOL

D8A DEPTH (FT.)
D8B FORMATION NAME
D8C GEOLOGIC AGE (FROH DICTIONARY) D8D OPERATOR - LEASE - WELL NUMBER 
DIO GEOLOGIC BASIN (NAME)

DI1 GEOLOGIC BASIN CODE NUMBER

\section{DISCOVERY WELL}

E DISCOVERY WEIL OF $\langle F I E ! D\rangle$ OR $\langle$ POOL $\rangle$

EIA OPERATOR NAME

EIAI CODE

$J$ (FROM CODE BOOK ONLY)

EIA2 WELL'NO.

EIA3 LEASE NAME

EIB LEASE TYPE (MUST BE ANSWERED WHEN LEASE NAME IS AVAILABLE)

EIBI FEDERAL

E1B4 UNIT

E1B2 STATE

E1B5 INDIAN LAND

E1B3 FEE

E1B6 OTHER

EID ELEVATION (KB, DF, GRD, OTHER) FEET

EIE WATER DEPTH (FOR OFFSHORE WELLS ONLY)

EIH DEEPEST FORMATION PENETRATED

EIHI FORMATION NAME

EIH2 GEOLOGIC AGE FROM DICTIONARY ONLK

EIH3 DEPTH

EIK PERFORATION (FEET)

EIKI TOP

EIK2 BOTTOM

EIS DISCOVERY WELL SECTION

EIT DISCOVERY WELL TOWNSHIP 
EIR DISCOVERY WELL RANGE

$F$ NUMBER AND TYPES OF WELLS

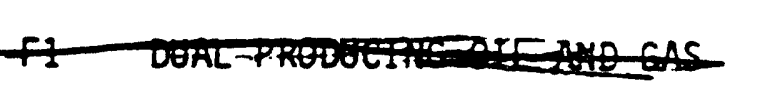

FIAI FLOWING

FIA2 GAS LIFT OR AIR LIFT

FIA3 PUMPING OR ARTIFICIAL LIFT

FIA4 OTHER

FIA5 TOTAL PRODUCING

FIA6 CAPABLE OF PRODUCING

FIA7 duel Producino $O \mathrm{il}$ \& $\mathrm{Eac}<$

FIC SHUT-IN OR TEMPORARILY ABANDONED

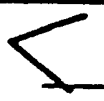

F1D SERVICE

FIDI INJECTION

FID2 DISPOSAL

F2 PROVED ACREAGE (DEVELOPED ACREAGE)

F2A FIELD AREA (TOTAL APPROVED BY STATE)

F3 SPACING (ACRES PER WELL)

F4 WELL DENSITY (ACRES PER WELL)

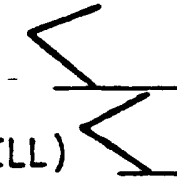

F7 PRODUCING INTERVAL (POOL)

F7A AVERAGE THICKNESS (FT.)

FTA1 AVERAGE FEET PERFORATED

F7B DEPTH TO TOP (FT.)

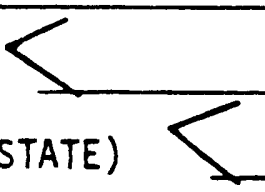

F7C DEPTH RANGE

F7CI SHALLOWEST

F7C2 DEEPEST 
F7D CONTACT (OIL, WATER \& GAS) SUBSEA FT.

F7DI ORIGINAL WATER CONTACT (SUBSEA FT.)

F7D2 ORIGINAL GAS/OIL CONTACT (SUBSEA FT.)

FTD3 CURRENT WATER CONTACT (SUBSEA FT.) F7D3A YEAR

F7D4 CURRENT GAS/OIL CONTACT (SUBSEA FT.) F7D4A YEAR

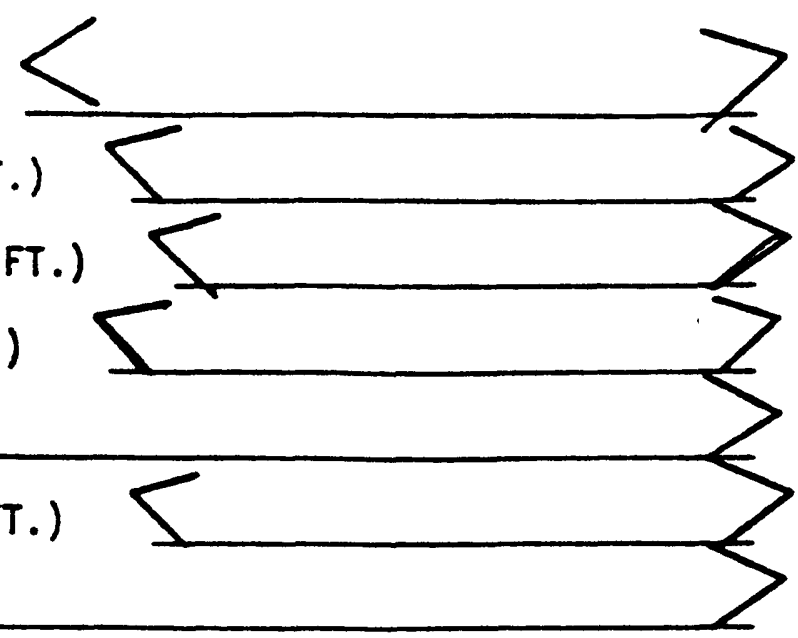

$G$ RESERVOIR DATA - GENERAL

G1 LITHOLOGY (SPECIFIC)

GIA SILTSTONE

GIB SHALE

GID CHERT

GIE ANHYDRITE

GIF INTRUSIVE IGNEOUS (SERPENTINE)

OR EXTRUSIVE IGNEOUS

GIK METAMORPHICS, DETRITAL, SANDSTONE, - CONGLOMERATE, ARKOSE, GRANITE WASH, BEACH SANDSTONE, BAR SANDSTONE, NEARSHORE MARINE SANDSTONE, OR CHANNEL SANDSTONE

G1T LIMESTONE (CHAT), OOLITIC LIMESTONE; MICRITIC LIMESTONE, LIMESTONE REEF, OR - MARLSTONE

GIU DOLOMITE OR DOLOMITE REEF

GIV CARBONATE

GIZ OTHER

- G2 PRIMARY DRIVE TYPE (CIRCLE ONE OR MORE)

G2A DISSOLVED (SOLUTION) GAS OR DEPLETION

G2B GAS CAP GAS

G2C GAS EXPANSION OR VOLUMETRIC (DRY GAS POOLS ONLY)

G2D WATER DRIVE

G2E GRAVITY 
G3 POROSITY (PERCENT)

G3A RANGE

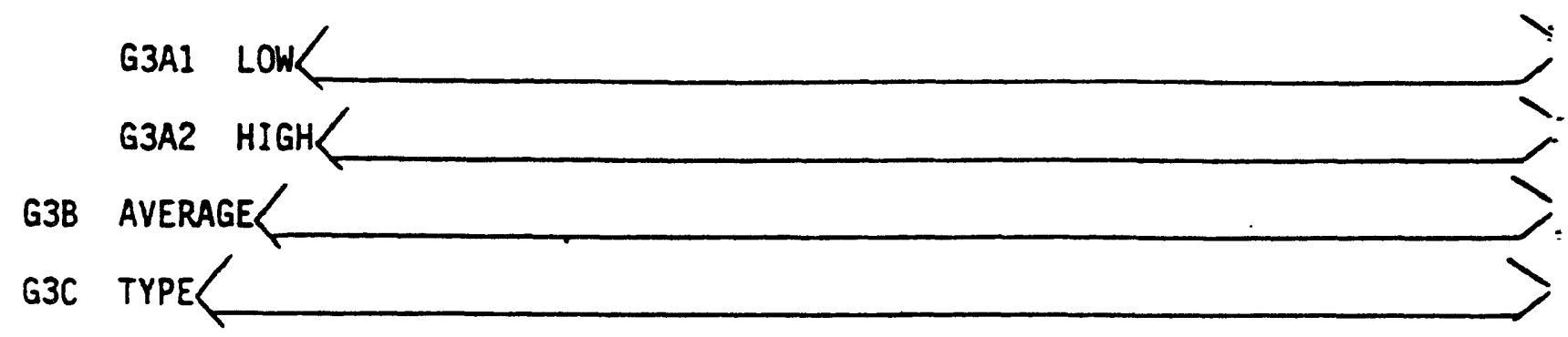

G3CI INTERGRANULAR (PINPOINT)

G3C2 INTERCRYSTALLINE

G3C3 VUGGY

G3C4 FRACTURE

G4 PERMEABILITY (MILLIDARCIES)

G4A RANGE

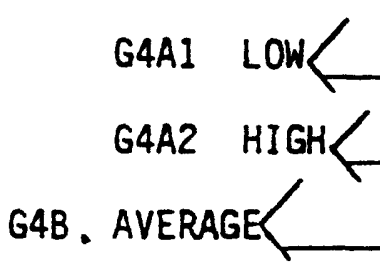

G5 ORIGINAL FORMATION VOLUME FACTOR

G5B CURRENT FORMATION VOLUME FACTOR

G5B1 YEAR

G6 RECOVERY FACTOR- (PERCENT)

G6A PRIMARY

GGB SECONDARY

G7 WATER SATURATION (PERCENT)

G7A RANGE (PERCENT)

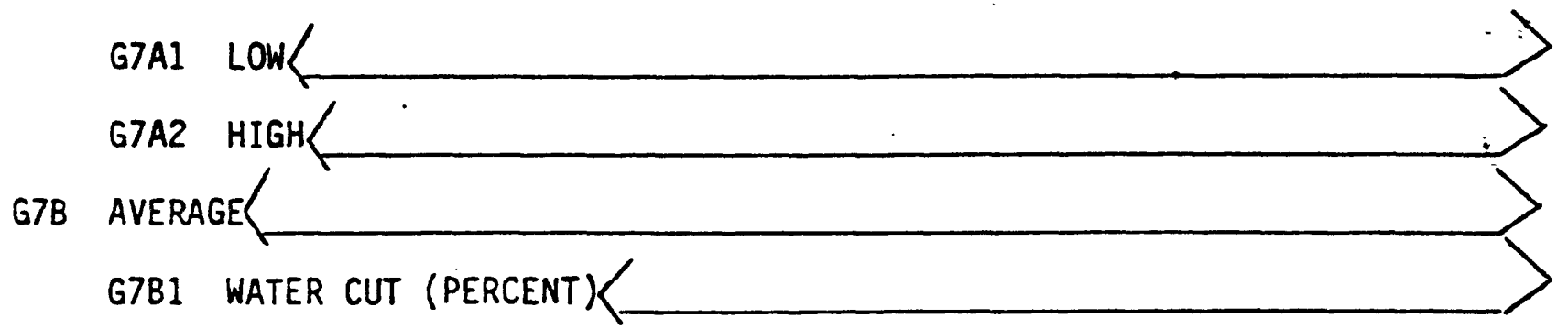


G7C OIL SATURATION (PERCENT)

GTC1 RANGE (PERCENT)

GTC1A LOWK

GTCIB HIGH

G7C2 AVERAGE

G7D GAS SATURATION (PERCENT)

G7D1 RANGE (PERCENT)

G7D2 LOW (PERCENT)

G7D3 HIGH (PERCENT)

G7D4 AVERAGE (PERCENT)

G8 BULK VOLUME

G8A ACRE-FEET

G9 TEMPERATURE DEGREES (FAHRENHEIT)

G9C RESERVOIR OR BOTTOM HOLE

G9Z SATURATION PRESSURE

G921 PSIA

G9Z2 AT (OF)

G10 SALINITY (PPM)

GII VISCOSITY (CENTIPOISEK

gila PSIA

GIIB AT (OF)

H RESERVOIR DATA - CONTINUED

HI GAS MEASUREMENT BASE

HIA PRESSURE BASE (PSIAX

HAA TEMPERATURE BASE (OF)

HIS ASSOCIATED GAS GRAVITY

HIC

HZA3 NON-ASSOCIATED GAS GRAVITY 
H2 SHUT-IN BOTTOM HOLE PRESSURE (PSIA)

H2A INITIAL OR ORIGINAL RESERVOIR PRESSURE

H2B_ CURRENT (REPLACE XX WITH APPROPRIATE YEAR)

H2C DATUM (SUBSEA FT.)

H4 PRESSURE AT ABANDONED CONDITIONS (PSIA)

H5 AVERAGE RATE OF PRESSURE DECLINE (PSI/BBL PRODUCED)

H6 GAS-CONDENSATE RATIO (BBL/MMCF)

H7 INSTANTANEOUS PRODUCING GAS-OIL RATIO (CF/BBL)

H7A INITIAL
H7B CURRENT

H7B1 YEAR

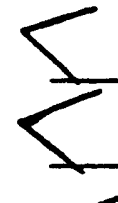

H8 Z FACTOR

H8A INITIAL

H8B ABANDONED CONDITIONS

H8C CURRENT H8CI YEAR

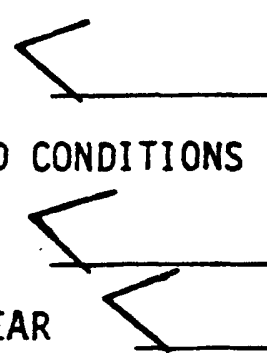

K PRODUCTION

KI ANNUAL (REPLACE XX WITH APPROPRIATE YEAR)

KIB CRUDE OIL

KID CONDENSATE

KIF WATER

KIG JASSOCIATED GAS

KIH HELIUM S

KIJ CARBON DIOXIDE

KIK HYDROGEN SULFIDE

KIT TOTAL GAS

im Alucioied Ha.

KIN Xa Mactis 
K2 CUMULATIVE

K2B CRUDE OIL

K2C NATURAL GAS

K2D CONDENSATE

K2F WATER /

K2G ASSOCIATED GAS

K2H HELIUMK

K2J CARBON DIOXIDE

K2K HYDROGEN SULFIDE

K2T TOTAL GAS

K2BYR YEAR

KZDYR YEAR

K2GYR YEAR 
FORV - OOG \%

$L$ ANOUNTS OF HYDROCARBONS REPORTED

I. ORIGINALLY IN PLACE

LIA CRUDE OIL (EBL)

LIB CONDENSATE (BBL)

LIC NATURAL GAS (MCF)

L2 TOTAL ORIGINAL PHYSICALLY RECOVEPABLE

L2A YEAR

L2B CRUDE OIL (BBL)

L2B 1 (BBL/ACRE)

L2B2 (BBL/ACRE-FT.)

L2C CONDENSATE (BBL)

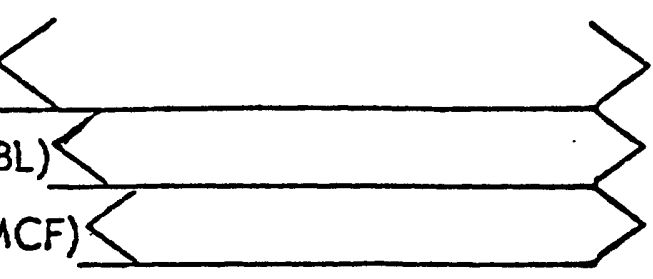

L2Cl (BBL/ACRE)

L2C2 (BBL/ACRE-FT.) $\leq$

L2C3 (BBL/MCF)

L2D NATURAL GAS (MCF)

L2D1 (MCF/ACRE)

L2D2 (MCF/ACREFT.)

L2E ASSOCIATED GAS (MCF)

L2EI - - (MCF/ACRE)

L2E2 (MCF/ACRE-FT.)

L4 ORIGINAL PHYSICALLY RECOVERABLE (SECONDARY)

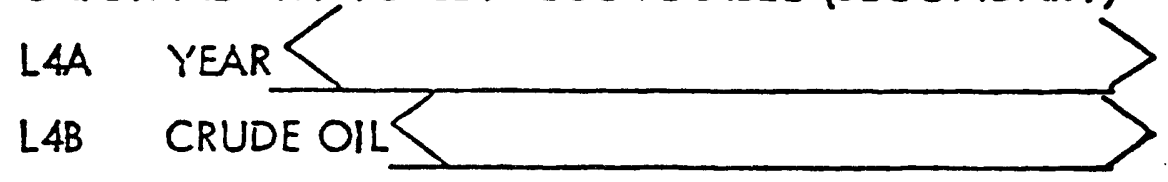

L5 PRODUCING CAPACITY ANNUAL OR BBLS/DAY L5A CRUDE OILS

L5AI ANNUAL

L5A2 BBLS/DAY 
L5B CONDENSATE

\section{L5BI ANNUAL}

L5B2 BBLS/DAY

L5C NATURAL GAS

L5CI NON-ASSOCIATED

L5C2 OTHER

L7 AAPG RESERVE CATEGORY
LIA OIL
L7B GAS

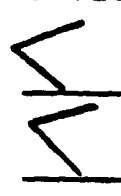

L8 API/AGA RESERVES EST. DEC. 31, 1974

L8A REMAINING PROVED . CRUDE OIL RESERVES (FIELD BBLS)

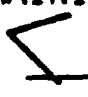

L8B DAILY CRUDE OIL PRODUCTIVE CAPACITY 90 DAYS (FIELD BBLS)

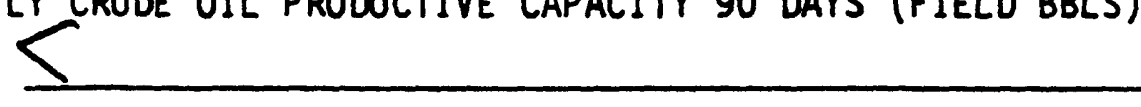

M SECONDARY RECOVERY

M1 FIRST CYCLE OF INJECTION

MIA - - YEAR INITIATED

MIB TYPE

MIC . YEAR ABANDONED

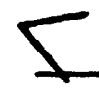

M2 SECOND CYCLE

M2A YEAR INITIATED

M2B TYPE

M2C YEAR ABANDONED

M3 THIRD CYCLE

M3A YEAR INITIATED

MBB TYPE $\leq$

MBC YEAR ABANDONED

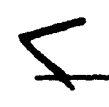


M6 WATER FLOOD ACREAGE

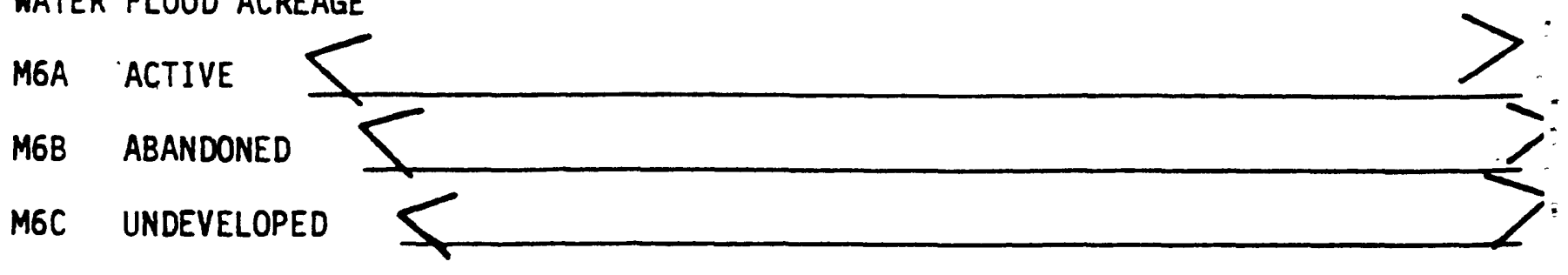


$\therefore-000.31$

CRUU:E OIL ANNRLYSIS: TOTAL SAMPLE

NIA ANALYSIS (AGENCY) $\leq$

NIB SAMPLE ID NUMBER (AGENCY)

NIC SPECIFIC GRAVITY

NID API GRAVITY

NIDI PANGE

NID2

NID3

LOW

NID4

HIGH

AVERAGE

NIE SULFUR (WEIGHT PERCENT)

NIF NITROGEN (WEIGHT PERCENT)

NIG ASPHALT (WEIGHT PERCENT)

NIH ISOTOPE RATIO $\mathrm{c}^{13} / \mathrm{C}^{12}$

NIJ ISOTOPE RATIO $\mathrm{S}^{32} / \mathrm{s}^{34}$

NIK POUR POINT $\left.{ }^{\circ} F\right)$

NIL CARBON RESIDUE (\% OF CRUDE)

NIM RESIDUIM

NIMI PERCENT OF CRUDE <

NIM2 SPECIFIC GRAVITY

NIM3 VOLUME PERCENT<

NIN VISCOSITY (SAYBOLT UNIVERSAL SECONDS)

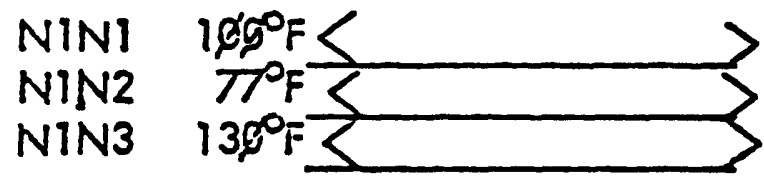

NIP APPROXIMATE SUMMARY (VOLUME PERCENT)

NIPI LIGHT GASOLINE <

NIP2 GASOLINE \& NAPTHAS

NIP3 KEROSENE <

NIP4 GAS-OIL

NIP5 NON-VISCOUS

NIP6

NIP7

NIP8

LUBE MEDIUIM

VISCOUS <

RES!DUE <

NIPQ DISTILLATIONLOSSL

NIPSA

$$
\text { OTHER } \leq
$$

N2N VISCOSITY (CENTIPO::

N2NI

N2N2

N2N3

N2N4

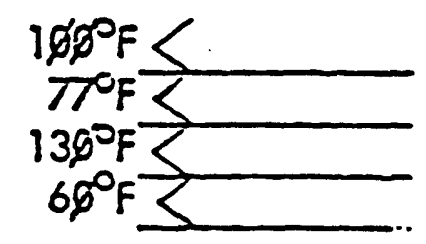


N1Q METALS PRESENT<smiles>CCC1CC1</smiles>

NIR OTHER NON-METALS PRESENT

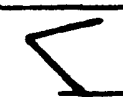

$P$ CRUDE OIL ANALYSIS: FRACTIONS

PI VOLUME PERCENT

P2 FRACTIONS 2-15, EACH

P2A SPECIFIC GRAVITY

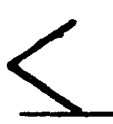

P3 FRACTIONS 11-15, EACH

P3A VISCOSITY (SAYBOLT UNIVERSAL SECONDS, 1000F)

P3B CLOUD POINT $\left({ }^{\circ} F\right)$ 


\section{Q WATER ANALYSIS}

Q1 AMALYST (AGENCY) $<$

Q2 SAMPLE NO. (AGENCY) $\leq$

Q3 $\mathrm{PH}<$

Q4

QS RESISTIVITY

Q5A OHM - METERS S > > >

QSB TEMP. (OF) $\leq$

Q6 CHEMICAI CONSTITUENTS (PPM OR M. PER LITER)

Q6A TOTAL SOLIDS (MG/L)

Q6AI TOTAI SOLIDS (PPM)

Q6B Lit (MG/L)

Q6B1 Lit (PPM)

Q6C Nat (ME/L)S

Q6C1 Nat (PPM)

Q6D $\mathrm{X}+(\mathrm{NG} / \mathrm{L})$

Q6D1 $\quad X+(P P M)<$

Q6E Nat PLUS R+ (MG/L)

Q6E1 Nat PLUS $K+$ (PPM)

Q6F Rot $^{\circ}$ (MG/L)S

Q6F1 $\mathrm{Bb}+($ PPM)

Q6G Cst (MG/L)

Q6G1 Cst (PPM)

Q6H Cat+ (MG/L)

Q6HI Catt (PPM)

Q6J $\mathrm{NgH}(\mathrm{MG} / \mathrm{L})<$

Q6ת MBH (PPM)

Q6R ST+t (MG/L)

Q6RI SIt (PPM)

Q6L Bat+ (MG/L)

Q6L1 Batt (PPM)

Q6M Srt+ PLUS Batt (MG/L)

Q6m Sitt PLUS Batt (PPM) $\leq$

Q6N B+H (MG/L) $\leq$

Q6N1 B+t+ (PPM)

Q6P Fet+ (MG/L)

Q6P1 Fett (PPM)

Q6Q Mntt (MG/L)

Q6Q1

Q6R $\mathrm{Cl}^{-}(\mathrm{MG} / \mathrm{L}) \leq$

Q6RI $\mathrm{Cl}^{-}$(PPM)

Q6S Br- (MG/L)<

Q651 BI- (PPM)

Q6T $\mathrm{HCO}^{-}$( $\left.\mathrm{MG} / \mathrm{L}\right)<$

Q6T1 $\mathrm{HCO3}^{-}$(PPM) $\leq$

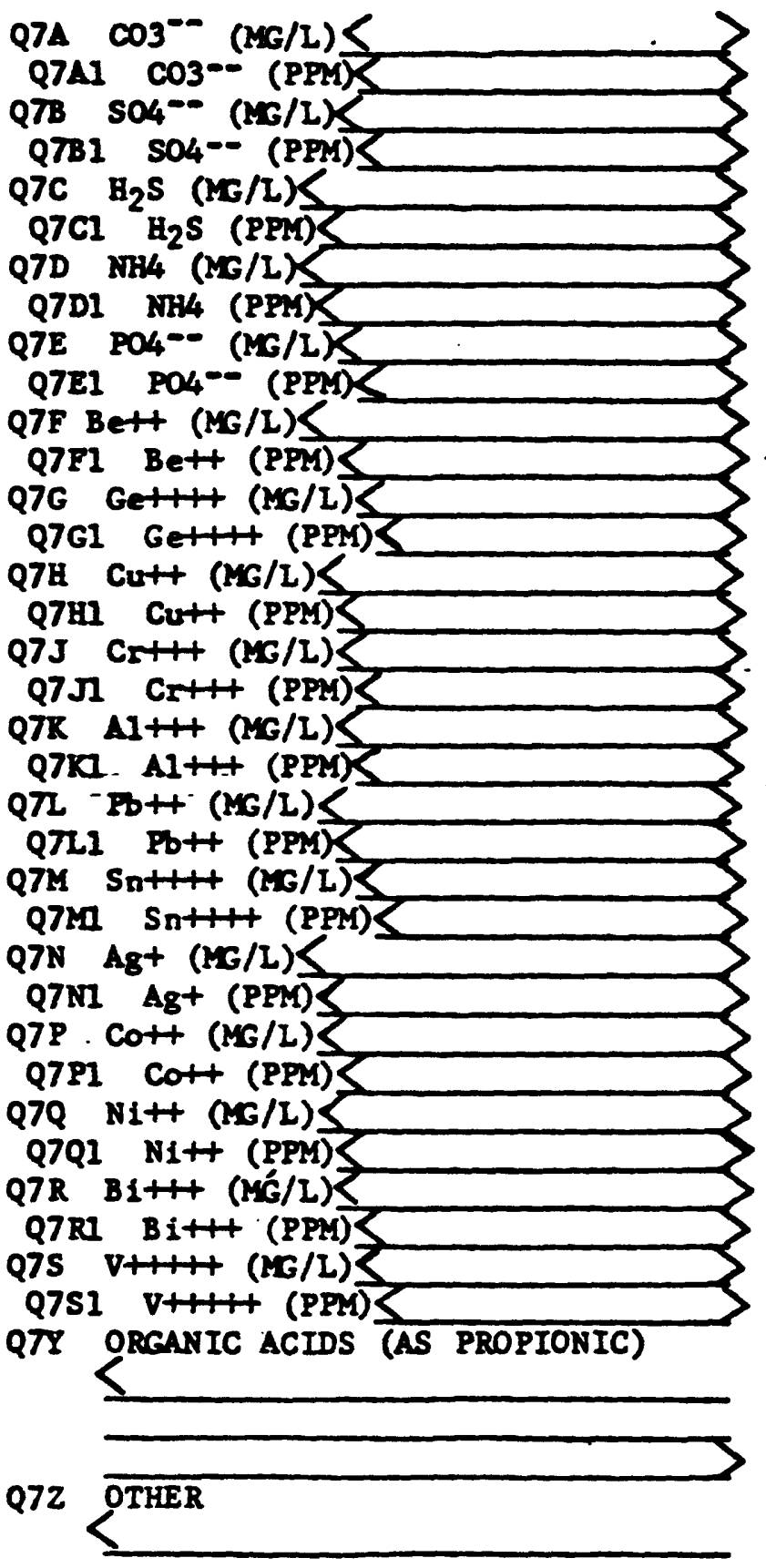

Q4A SPECIFIC GRAVITY $\left(68^{\circ} \mathrm{F}\right)$

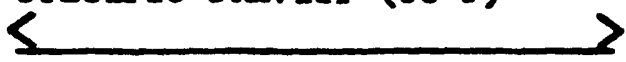


FORY - 006001

R miturar gas amiysis

21 NUIYST (AGENCY)

R2 SAMPLE NO. (AGENCT)

23 VILLEAD PRESSURE (PSIG)

oh heating vauUe (BTU/CO. FT.)

25 SFECIFIC GRAVIII

36 CONSTITUENTS (ROL PERCENT),

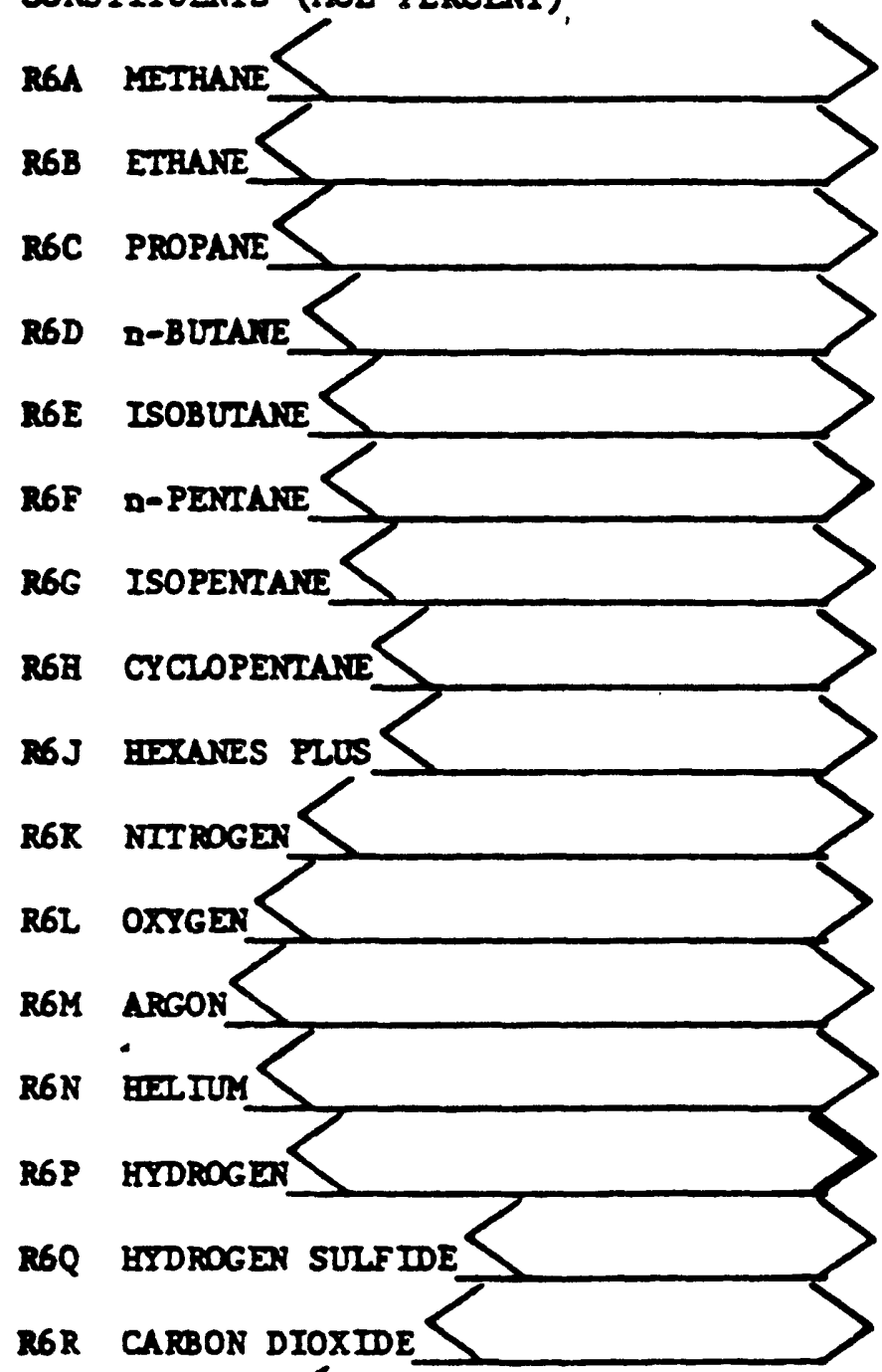

R62 RDMRTES

2 COMARTS 